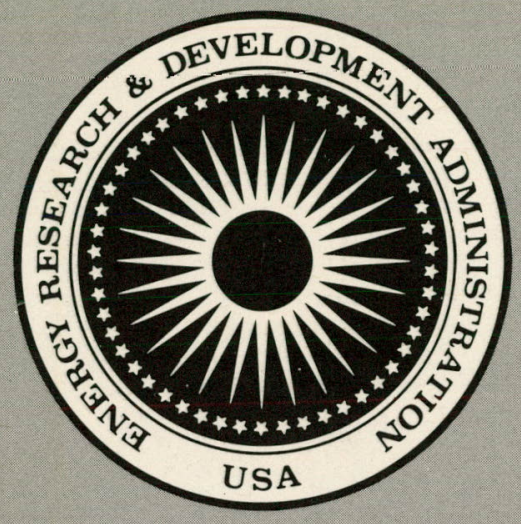

COO-2552-6

ASSESSMENT AND STUDY OF EXISTING CONCEPTS AND METHODS OF CRYOGENIC REFRIGERATION FOR SUPERCONDUCTING TRANSMISSION CABLES

Final Report

By

F. J. Kadi

R. C. Longsworth

Date Published-February 1976 PORTIONS OF THIS REPORT ARE THLEGTBLE. It has been reproduced from the best availablo copy to permit the broadest possible avallability.

Advanced Products Department

Air Products and Chemicals, Incorporated

Allentown, Pennsylvania 


\section{DISCLAIMER}

This report was prepared as an account of work sponsored by an agency of the United States Government. Neither the United States Government nor any agency Thereof, nor any of their employees, makes any warranty, express or implied, or assumes any legal liability or responsibility for the accuracy, completeness, or usefulness of any information, apparatus, product, or process disclosed, or represents that its use would not infringe privately owned rights. Reference herein to any specific commercial product, process, or service by trade name, trademark, manufacturer, or otherwise does not necessarily constitute or imply its endorsement, recommendation, or favoring by the United States Government or any agency thereof. The views and opinions of authors expressed herein do not necessarily state or reflect those of the United States Government or any agency thereof. 


\section{DISCLAIMER}

Portions of this document may be illegible in electronic image products. Images are produced from the best available original document. 


\section{NOTICE}

This report was prepared as an account of work sponsored by the United States Government. Neither the United States nor the United States Energy Research and Development Administration, nor any of their employees, nor any of their contractors, subcontractors, or their employees, makes any warranty, express or implied, or assumes any legal liability or responsibility for the accuracy, completeness or usefulness of any information, apparatus, product or process disclosed, or represents that its use would not infringe privately owned rights.

This report has been reproduced directly from the best available copy.

Available from the National Technical Information Service, U. S. Department of Commerce, Springfield, Virginia 22161

Price: Paper Copy $\$ 7.75$ (domestic)

$\$ 10.25$ (foreign)

Microfiche $\$ 2.25$ (domestic)

$\$ 3.75$ (foreign) 


\section{AN ASSESSMENT AND STUDY OF EXISTING CONCEPTS AND METHODS OF CRYOGENIC REFRIGERATION FOR SUPERCONDUCTING TRANSMISSION CABLES}

\section{Final Report}

F.J. Kadi and R.C. Longsworth

February 1976

Prepared For

THE U.S. ENERGY RESEARCH AND DEVELOPMENT ADMINISTRATION UNDER CONTRACT NO. E(11-1)-2552

\section{ADVANCED PRODUCTS DEPARTMENT}

AIR PRODUCTS AND CHEMICALS, INC.

$$
\text { P.0. BOX } 538
$$

ALLENTOWN, PENNSYLVANIA 18105

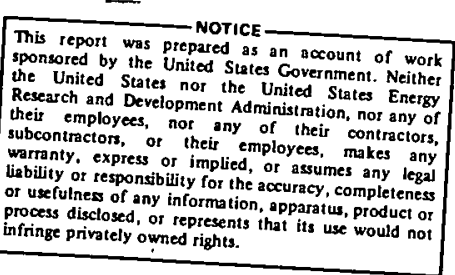

sponsored by the Urepared as an account of work the United States nor the Unined States. Neither theis employees 
SECTION IITLE

PAGE

ABSTRACT

1.0 INTRODUCTION

2.0 SUPERCONDUCTING POWER TRANSMISSION PROGRAM REVIEW

2.1 U.S. PROGRAMS

2.2 CONSIDERATIONS IN SELECTING OPERATING CONDITIONS

2.2.1 Electrical Considerations

2.2.2 Thermodynamic Considerations

SPACING BETWEEN STATIONS

Refrigerator cost Relative to Total cost

2.4 .2

Heat Shield

$2.12^{-1}$

2.4 .3

Reliability

2.12

Hel ium Inventory and Storage

2.12

Far End Expander

2.15

2.4 .5

2.4 .6

2.4 .7

2.4 .8

2.4 .9

2.4 .10

Efficiency, Cost and Size

2.15

"Potheads"

2.17

Unequal and Variable Refrigeration Loads

2.17

Higher Temperature Superconductors

2.18

Summary

2.18

2.18

3.0 SURVEY OF EXISTING LARGE HELIUM REFRIGERATORS

3.1 METHODS OF GATHERING AND PRESENTING INFORMATION

3.2.1 Turbo-Expander Experience 


\section{TABLE OF CONTENTS}

SECTION TITLE

PAGE

4.0 REFRIGERATION SYSTEM COMPONENT CHARACTERISTICS

4.1

4.1 HELIUM REFRIGERATOR MANUFACTURER SURVEY

4.1

4.2 COMPRESSORS

4.5

4.2 .1

Compressor Questionnaire

4.5

4.2 .2

Reciprocating Compressors

4.10

4.2 .3

Screw Compressors

4.10

4.2 .4

Centrifugal Compressors

4.14

4.2 .5

Summary of Compressor Characteristics

4.14

4.3 TURBINE EXPANDERS

4.15

4.3.1 Introduction

4.3.2 Turbine Expander Performance and Design Range

4.15

4.18

4.21

4.3 .3

Refrigeration and/or Liquefaction Capacity of

Commercially Available Systems

4.3.4 Cost Estimates of Turbines in Size Range of

Interest in BNL Plan $3 \mathrm{~A}$ Study

$4.4 \quad$ HEAT EXCHANGERS 4.23

4.4.1 - General Discussion 4.23

4.4.2 Fast Cooldown 4.26

4.4.3 Aluminum Plate Fin Exchanger Core Costs 4.26

4.5 INSTRUMENTATION AND CONTROLS 4.26

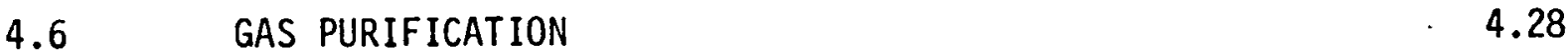

4.6.1 General Problem 4.28

4.6.2 Source of Contaminants 4.29

4.6.3 Method of Removal 4.31

4.6.4 Contaminant Detection 4.34

$\begin{array}{lll}4.7 & 4.35\end{array}$

$\begin{array}{lll}4.8 & \text { VACUUM SYSTEM } & 4.36\end{array}$

4.8.1 Insulation $\quad 4.36$

4.8.2 Vacuum Equipment 4.38

$4.9 \quad$ STORAGE DEWARS 4.38 
SECTION - TITLE

PAGE

5.0 REFRIGERATOR COLD BOX

5.1

5.1 SYSTEM CLEANUP

5.1

5.2

STARTUP

5.1

5.3

STEADY STATE

5.3

5.4

TRANSIENTS

5.3

5.5

OFF DESIGN OPERATION

5.3

5.6

WARMUP

5.3

5.7

CONTROLS AND INSTRUMENTATION

5.4

5.8

GAS PURITY

5.4

5.9

CONSTRUCTION

5.5

5.10

MAINTENANCE

5.6

5.11

BACKUP REFRIGERATION

5.6

5.12

COST

5.6

6.0 APCI EXPERIENCE WITH STANDARD NITROGEN PLANTS

6.1

6.1 STANDARD PLANT DESIGN AND OPERATIONS

6.3

6.2

HISTORICAL EXPERIENCE

6.6

6.3

FAILURE AND MAINTENANCE EXPERIENCE FOR STANDARD

6.6 NITROGEN PLANTS

6.4

OUTAGE DURATION VS. FREQUENCY

6.14

6.5

MAINTENANCE

6.14

6.6

RELATION OF NITROGEN PLANT TO HELIUM PLANT

6.17

6.7 EXTRACTION OF HELIUM PLANT RELIABILIITY PARAMETERS
FROM STANDARD NITROGEN PLANT DATA

6.22 
6.7.1 APCI Nitrogen Plant Turbo-Expander MTBF

7.0 OPTIMIZATION CRITERIA AND ALTERNATE REFRIGERATION SYSTEMS

7.1 CRITERIA USED FOR OPTIMIZATION

7.3 COMPRESSOR OPTIMIZATION

Reliability of Cold Box Case CB/H I 


\section{TABLE OF CONTENTS}

SECTION TITLE

PAGE

8.2.3 Labor Cost

8.24

8.2 .4

Demand Cost

8.25

8.2 .5

Power Cost

8.25

8.2 .6

Maintenance Cost

8.25

8.2 .7

Capital Cost of Equipment

8.25

8.2 .8

Life of Equipment and Return on Investment

8.29

8.3

RESULTS OF RELIABILITY AND ECONOMIC STUDY

8.29

8.3.1

Compressor Optimization

8.29

8.3.2

Cold Box Optimization

8.32

8.3.3

Refrigeration Station Optimization

8.35

9.0 SENSITIVITY OF COST AND RELIABILITY TO

9.1 IMPROVEMENTS IN KEY AREAS

9.1 EFFECT OF REDUCTIONS IN $t^{\prime}$ and $t^{\prime \prime}$

9.1

9.2

EFFECT OF REDUCING COMPRESSOR AND COLD BOX FAILURE RATES

9.1

9.2 .1

Effect of Reducing Helium Storage Dewar/Heat

9.4

9.2 .2

Exchanger Backup System Failure Rate

9.2 .3

Effect of Turbine Reliability and Efficiency

9.4

Effect of Compressor Reliability and Efficiency

9.6

9.3

EFFECT OF SWITCH OVER RELIABILITY

9.6

9.4

SUMMARY

9.7

10.0

BUSINESS FACTORS

10.1

10.1 EQUIPMENT SPECIFICATION, OWNERSHIP AND OPERATION

10.1

10.2 DEVELOPMENT INVESTMENTS

10.3

11.0 RECOMMENDATIONS

11.1

11.1 FURTHER SYSTEM STUDIES

11.1

11.2 BEST CURRENT SYSTEM

11.2 
SECTION TITLE

PAGE

11.3 DEVELOPMENT WORK

11.2

11.4 DEVELOPMENT PROGRAM

11.4

ACKNOWLEDGEMENTS

APPENDIX

A.1

APPENDIX B

B. 1

APPENDIX C

C. 1

BIBLIOGRAPHIES 


\section{LIST OF TABLES}

TABLE $\quad$ TITLE

PAGE

2.1 ANTICIPATED REFRIGERATION REQUIREMENTS FOR MAJOR U.S. SUPERCONDUCTING POWER TRANSMISSION STUDIES

2.2 BNL PLAN 3A COST ESTIMATE TWO SUPERCONDUCTING CABLES $68 \mathrm{Km}$ LONG

2.3 BNL HEAT LOAD PER LINE, PLAN 3A

3.1 HELIUM AND HYDROGEN REFRIGERATOR/LIQUEF IER OPERATING EXPERIENCE

3.2 MEAN TURBO-EXPANDER OPERATING HOURS PER FAILURE

3.3 DRY-LUBRICATED RECIPROCATING COMPRESSOR FAILURE AND MAINTENANCE SUMMARY SHEET

3.4 LABYRINTH SEAL RECIPROCATING COMPRESSOR FAILURE AND MAINTENANCE SUMMARY SHEET

4.5 TURBO-EXPANDER SIZE RANGE SUMMARY FOR PRESENT STATE-OF-THE-ART EQUIPMENT

4.6 COMPARISON OF CORE AND COIL TYPE HEAT EXCHANGERS

4.7 IMPURITIES, REMOVAL METHODS 


\section{LIST OF TABLES}

TABLE $\quad$ TITLE

PAGE

6.2 OUTAGE RECORD FOR STANDARD NITROGEN PLANT

6.9

6.3 OUTAGE TIME INTERVAL BREAKDOWN FOR - SIX STANDARD

6.15 NITROGEN PLANTS

6.4 SUMMARY OF OUTAGES LONGER THAN 24 HOURS SIX APCI

6.16 STANDARD NITROGEN PLANTS, UNATTENDED

6.18 PLANTS WITH HELIUM PLANTS

6.6 EVOLUTION OF HELIUM (THREE TURBINE) COLD BOX REL IABILITY PARAMETERS FROM STANDARD NITROGEN PLANT DATA

6.7 EVOLUTION OF HELIUM (THREE DUAL TURBINE SETS) COLD BOX RELIABILITY PARAMETERS

7.1 REFRIGERATION REQUIREMENTS FOR BNL DUAL 4800 MVA, 345KV SUPERCONDUCTING POWER TRANSMISSION LINE (PLAN 3A)

8.1 EXPRESSIONS FOR PROBABILITY OF FAILURE IN ONE YEAR

FOR COMPRESSOR AND COLD BOX CASES LISTED

8.2 TABULATION OF RELIABILITY ANALYSIS INPUT PARAMETERS 8.9

8.3 YEARLY LABOR COSTS

8.26

8.4 COST OF MAINTENANCE RELATED PARTS AND MATERIALS 8.27

8.5 CAPITAL COST OF MAJOR COMPONENTS AND SUBSYSTEMS

8.6 COMPRESSOR RELIABILITY AND COST ANALYSIS 8.30

8.7 COLD BOX RELIABILITY AND COST ANALYSIS

(ASSUMES GAS SUPPLIED BY OIL LUBRICATED SCREW COMPRESSOR) 8.33 


\section{LIST OF FIGURES}

FIGURE

TITLE

PAGE

1.1

CONCEPTUAL VIEW OF TWO ADJACENT REFRIGERATION STATIONS

1.4

ALONG SUPERCONDUCTING POWER TRANSMISSION LINE

2.1

BROOKHAVEN NATIONAL LABORATORY REFRIGERATOR

FLOW SCHEMATIC, PLAN 3A

2.2

UNION CARBIDE, LINDE DIVISION, REFRIGERATOR

FLOW SCHEMATIC

2.3 LOS ALAMOS SCIENTIFIC LABORATORY REFRIGERATOR

2.5

FLOW SCHEMATIC

2.4 HELIUM PRESSURE-ENTHALPY DIAGRAM WITH BNL, UC, AND LASL CABLE CONDITIONS

2.5 REFRIGERATOR FLOW SCHEMATIC UNDERSTUDY OF BNL USING FAR END EXPANDER AND NO HEAT SHIELD

4.1

COMPRESSOR VS. FLOW

4.2

BALJE DIAGRAM FOR SINGLE STAGE RADIAL TURBINE

4.19

4.3

APPROXIMATE DESIGN RANGE FOR CURRENT HELIUM

4.20 EXPANSION TURBINES

4.4

TURBINE EXPANDER COSTS

4.24

$4: 5$

ALUMINUM PLATE FIN HEAT EXCHANGER CORE COSTS

4.27

4.6

COST OF VAPOR SHIELDED HELIUM STORAGE DEWARS

4.40

5.1 FLOW SHEET OF RECOMMENDED LASL COLD BOX

5.2

COLD BOX COST

5.7

6.1

APCI STANDARD NITROGEN PLANT, SIMPLIFIED FLOW

6.4 SHEET $(38,000 \mathrm{SCFH})$

6.2 


\section{LIST OF FIGURES}

FIGURE TITLE

PAGE

6.3 PERCENTAGE BREAKDOWN OF SOURCES OF PLANT OUTAGE

6.12 FOR A STANDARD NITROGEN PLANT

6.4 AVERAGE PERCENTAGE BREAKDOWN OF SOURCES OF PLANT OUTAGE FOR SIX STANDARD NITROGEN PLANTS

7.1

COMPRESSOR CASE STUDIES

7.2 COLD BOX CASE STUDIES, FULL CAPACITY TWO HALF CAPACITY TURBINE SETS

7.3 COLD BOX CASE STUDIES, FULL CAPACITY, ONE TURBINE SET

7.4 CONCEPTUAL DESIGN FOR A CENTRIFUGAL PUMP-LOOP/ HELIUM STORAGE DEWAR BACK-UP SYSTEM FOR ONE CABLE OF BNL PLAN $3 A$

7.5 CONCEPTUAL DESIGN FOR A WARM COMPRESSOR CIRCULATING LOOP/HELIUM STORAGE DEWAR BACK-UP SYSTEM FOR ONE (1) CABLE OF BNL PLAN 3A

8.3 RELIABILITIES OF SUBSYSTEMS WHICH CONTRIBUTE TO THE TOTAL RELIABILITY OF A SINGLE REFRIGERATION STATION AND ITS ASSOCIATED $12 \mathrm{~km}$ CABLE LENGTH FOR BNL PLAN 3A WITH. FAR END EXPANDER

INFLUENCE OF THE NUMBER OF REFRIGERATION STATIONS, N, ALONG TRANSMISSION LINE ON THE ALLOWABLE LIMITS OF $Q_{C}^{\prime}$ and $Q_{C B}^{\prime}$ 
LIST OF FIGURES

FIGURE TITLE

8.6 COMPRESSOR PROBABILITY OF FAILURE VERSUS

CAPITAL PLUS TOTAL OPERATING COST IN ONE YEAR

8.7. COLD BOX PROBABILITY OF FAILURE VERSUS CAPITAL PLUS TOTAL OPERATING COST IN ONE YEAR

9.1 SENSITIVITY OF FAILURE PROBABILITY TO REDUCTIONS IN DOWNTIME

9.2

9.3
SENSITIVITY OF FAILURE PROBABILITY TO REDUCTIONS IN FAILURE RATE

SENSITIVITY OF CASE BC/H IV AND TOTAL AYSTEM PROBABILITY. OF FAILURE TO REDUCTIONS IN DEWAR/HEAT EXCHANGER FAILURE RATE, $\lambda_{D}^{\prime}$
PAGE

8.31

8.34

9.2

9.3

9.5 


\title{
AN ASSESSMENT AND STUDY OF EXISTING CONCEPTS AND METHODS OF CRYOGENIC REFRIGERATION FOR SUPERCONDUCTING TRANSMISSION CABLES
}

\author{
F.J. Kadi and R.C. Longsworth
}

\section{ABSTRACT}

A review of current programs to develop superconducting power transmission shows that current plans require helium refrigerators operating at 5 to $13 \mathrm{~K}$ and 3 to $15 \mathrm{~atm}$ pressure with compressor power input in the range of 1,300 to 3,500 HP. Future requirements will probably trend towards slightly higher temperatures and larger refrigerators. Present large helium refrigerators and APCI standard nitrogen plants were studied and an average outage frequency of about 18 per year is found to be typical for both. Cost and reliability studies of alternate refrigeration systems based on studies of components shows that the best current system which would have a failure rate of once in 20 years would consist of two full size oil flooded screw compressors in parallel, manifolded to two full size cold boxes and a liquid helium back up dewar. The principal area of development needed to implement this system is in the switch over mechanisms. These include switching to an auxillary power source in the event of power interruption, switching to the standby compressor, and switching to the back up liquid helium dewar. Costs are projected as being only slightly greater than preliminary estimates.

\subsection{INTRODUCTION}

The objectives of the present program are; to assess the state-of-the-art of helium cryogenic refrigeration systems for future ac and dc superconducting transmission cables; assess the criteria for optimization; and define the necessary steps to insure that optimized refrigeration systems will be available when needed.

This report summarizes the work that was done to carry out the assessment and concludes with recommendations for future work resulting from the assessment. The report contains the following sections:

* Section 2 - Superconducting Power Transmission Program Review. Reports from the centers working on superconducting power transmission were read and centers in the U.S. were visited. Refrigeration requirements for present systems have been determined and trends in future requirements are projected. 
* Section 3 - Survey of Existing Large Helium Refrigerators. Reports of most of the major helium refrigerators were studied and many of the plants in the U.S., Canada, and Europe visited. A comprehensive collection of design and operating experience is presented along with some component reliability data.

* Section 4 - Refrigeration System Component Characteristics. Manufacturers of essential components including helium refrigerators, helium turbo-expanders, and compressors were surveyed to ascertain the performance, size, cost and reliability of present equipment and trends in future equipment. This is reported along with internal studies of heat exchangers, controls, gas purification, piping, vacuum sys tems, and storage dewars.

* Section 5 - Refrigerator Cold Box Design. This section outlines a specification for future cold boxes designed for high reliability along with an example of the proposed concepts.

* Section 6 - APCI Experience with Standard Nitrogen Plants. Unattended standard nitrogen plants owned and operated by APCI were studied to determine causes of failure, failure rates, outage duration, and maintenance time. Comparisons to helium plants are made. The experience presented in this section provides the best known basis for guiding work in developing large helium refrigeration systems with high reliability.

* Section 7 - Optimization Criteria and Alternate Refrigeration Systems. The optimium refrigerator is defined as that which meets the specified level of reliability at the lowest capital plus operating cost. Different possible combinations of compressors and cold boxes are described. Two alternate concepts of using liquid helium as a back up are analyzed.

* Section 8 - Reliability and Cost of Alternate Refrigerator Sys tems Using Current Technologies. Methods of analyzing system reliability and cost are presented followed by analysis of the systems described in section 7 .

* Section 9 - Sensitivity of Cost and Reliability to Improvements in Key Areas. Assumptions are made regarding improvements in maintenance time, and compressor, expander, and dewar reliability, and their effect on cost and system reliability evaluated.

* Section 10 - Business Factors. Consideration of whether it would be best for the utilities or cryogenic companies to own and operate the refrigeration system are discussed. The question of who is going to be responsible for developing the needed equipment is also discussed. 
* Section 11 - Recommendations. It is recommended that the next step in the development process be further optimization studies of the entire transmission line using the information contained in this report to improve the definition of the refrigerator that will be needed.

Figure 1.1 shows the refrigerator concept that emerged from this study as being the best using current technology. Redundant compressors and cold boxes with liquid helium back up are shown. The primary area of uncertainty at the present time is in the area of switch over reliability from one unit to the other.

Recommendations for specific development work are made and a program for carrying out development work is presented.

The results of this study indicate that refrigerator systems which are reliable enough for superconducting power transmission lines are feasible and their cost is not much greater than the preliminary estimates that have been made. 


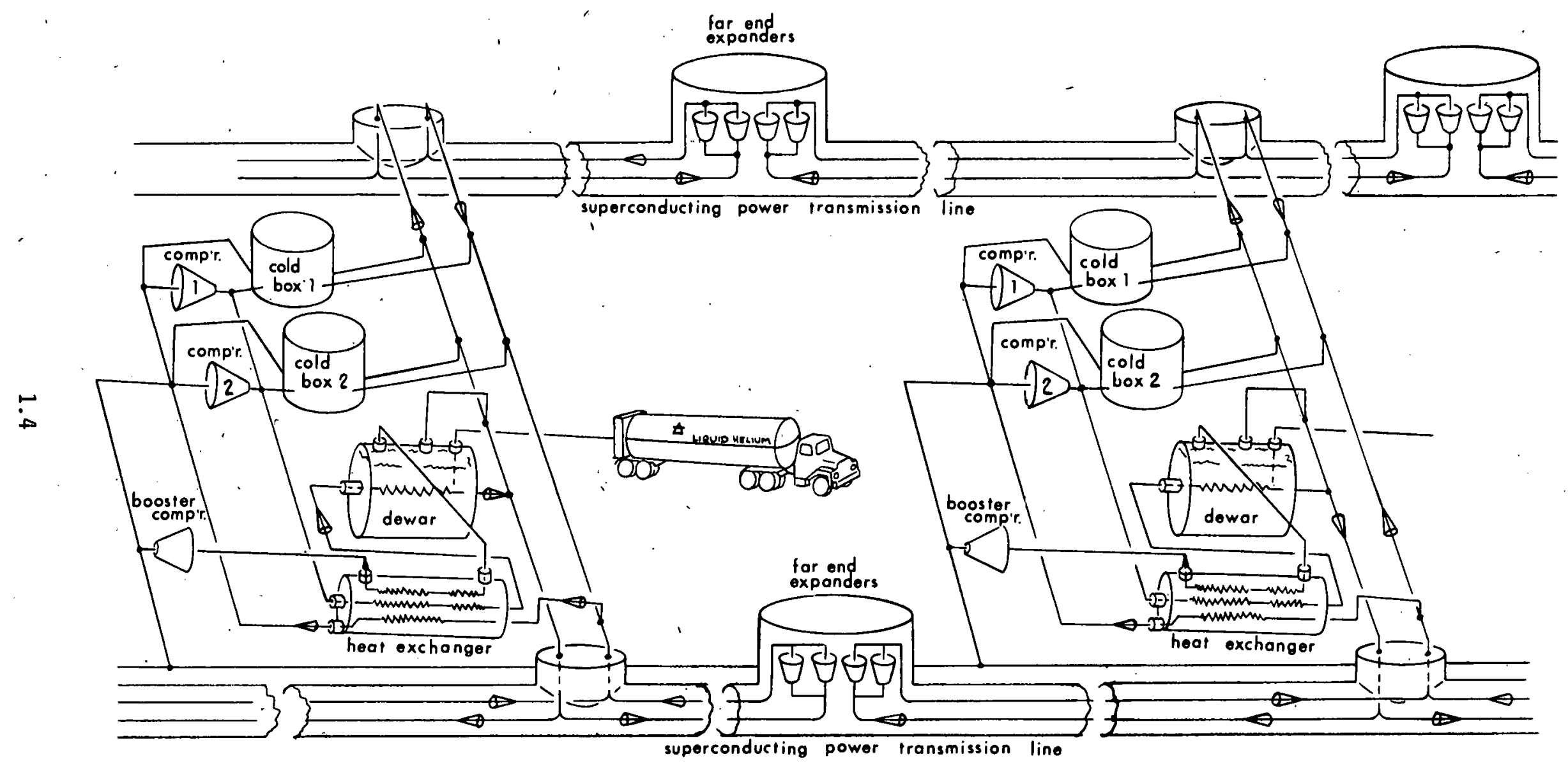

FIGURE 1.1 CONCEPTUAL VIEW OF TWO ADJACENT REFRIGERATION STATIONS ALONG SUPERCONDUCTING POWER TRANSMISSION LINE 


\subsection{SUPERCONDUCTING POWER TRANSMISSION PROGRAM REVIEW}

\subsection{U.S. PROGRAMS}

Work on superconducting power transmission in the United States is being carried out at Brookhaven National Laboratory (BNL), Los Alamos Scientific Laboratory (LASL), Stanford University (SU), Union Carbide Technical Center (UC), and the National Bureau of Standards at Boulder Colorado (NBS). The work at these centers was reviewed primarily from the standpoint of understanding the refrigeration requirements. Reports on work being done in Europe and Japan were reviewed for an understanding of alternatives and trends.

The work at BNL and UC represent very comprehensive studies of complete systems for transmission of ac power using the two prime candidate superconducting materials. LASL is in an early phase of a comprehensive study of dc power transmission. The work at SU is limited to studies concentrating on superconducting materials and dielectric losses. At NBS the work is concentrated on studying the thermal and flow stability characteristics of helium. BNL's Cryenco enclosure [A.11] and UC's enclosure [A.14] both contain radiation shields and both consist of factory evacuated rigid sections welded together in the field. The BNL three phase superconducting cable is drawn through the central tube using conventional cable drawing techniques. Helium cooling the cable flows out through the central tube and returns through a small tube in the vacuum space thermally isolated from the cable tube. In the BNL enclosure the shield is cooled by helium in a tube bonded to it and returns through a separate isolated tube. The UC heat shield is cooled by bleeding hel ium from the cable tube to cool the shields before it leaves the vacuum jacket. The bleed streams feed into an external warm return tube.

In their work on the dc transmission line, LASL has considered a number of possible cryogenic cable designs: One of their early concepts centered upon a bipolar cable design in which the positive dc cable was in one cryogenic envelope and the negative dc cable was in another separate envelope [A.43]. The helium would flow out through one envelope and back through the other. One advantage of this design is that the dielectric material would be essentially at room temperature. Another cable concept revolves around the use of a coaxial cable design in which the supercritical helium would leave through a central conductor of circular cross section and return in the annular space between the inner conductor and the cylindrical outer conductor. This design would appreciably reduce the cryogenic envelope cost over the bipolar design and it lends itself readily to utilization of the far-end expander concept conceived by Dean \& Staff while at BNL and discussed more fully at the end of this section. The dc mode of operation under study at LASL results in a higher permissible operating temperature 
than the two ac lines under study; thus, the cost of refrigeration is less and an intermediate heat shield in the enclosure is not economically justified. This simplifies the enclosure design so that no piping connections need to be made in the field and conventional bayonet joints can be used.

Table 2.1 summarizes the anticipated refrigeration requirements for the major U.S. superconducting power transmission studies based on the enclosure concepts described above. The BNL data is taken from a study report on a $68 \mathrm{~km}$ line for the Long Island Lighting Company to bring power from the eastern end of Long Island toward New York City. The data presented is for plan $3 A$ which assumes two separate lines each capable of carrying the full load of 4,800 MVA. If it is assumed that there is only one refrigerator at each station serving both lines then the total refrigeration and power per station is double the values listed. Figure 2.1 is a flow schematic for the refrigerator.

The data for UC is based on their design of a standard line. Decisions regarding the total length of a line and whether or not a redundant 1 ine would be used would be based on a specific system study. Figure 2.2 is a flow schematic for their refrigerators.

The LASL data was obtained from the people at LASL who are still in the early stages of their program looking at alternate cable materials, enclosure configurations, and refrigeration systems. As such this data is tentative but it is adequate to compare the refrigeration system characteristics for a dc line with an ac line. Figure 2.3 is a flow schematic for the refrigerator being studied. This is similar to the refrigerator on the BNL cold neutron moderator $[B .20]$.

In looking at table 2.1 one sees that the operating temperatures for the three lines are quite different. It is approximately true that the cost of refrigerators and more importantiy their power per watt of refrigeration is proportional to the reciprocal of the operating temperature. operating temperature is determined by the cable material and the margin required to maintain it in the superconducting state. Superconducting materials have dielectric heating effects and in ac lines there is a hysteretic heating effect. These losses account for about half of the refrigeration power input while heat leak in the enclosure accounts for the other. Choice of cable material thus includes consideration of heat generation, material cost, fabrication cost, and availability, as well as operating temperature.

The refrigeration requirements of each line are best compared by computing the power input required of a Carnot cycle refrigerator for cooling both the cable and the shield. The actual power of the refrigerator has been estimated in these studies from the Strobridge survey that gives an average value of efficiency vs. refrigeration [B.25]. 


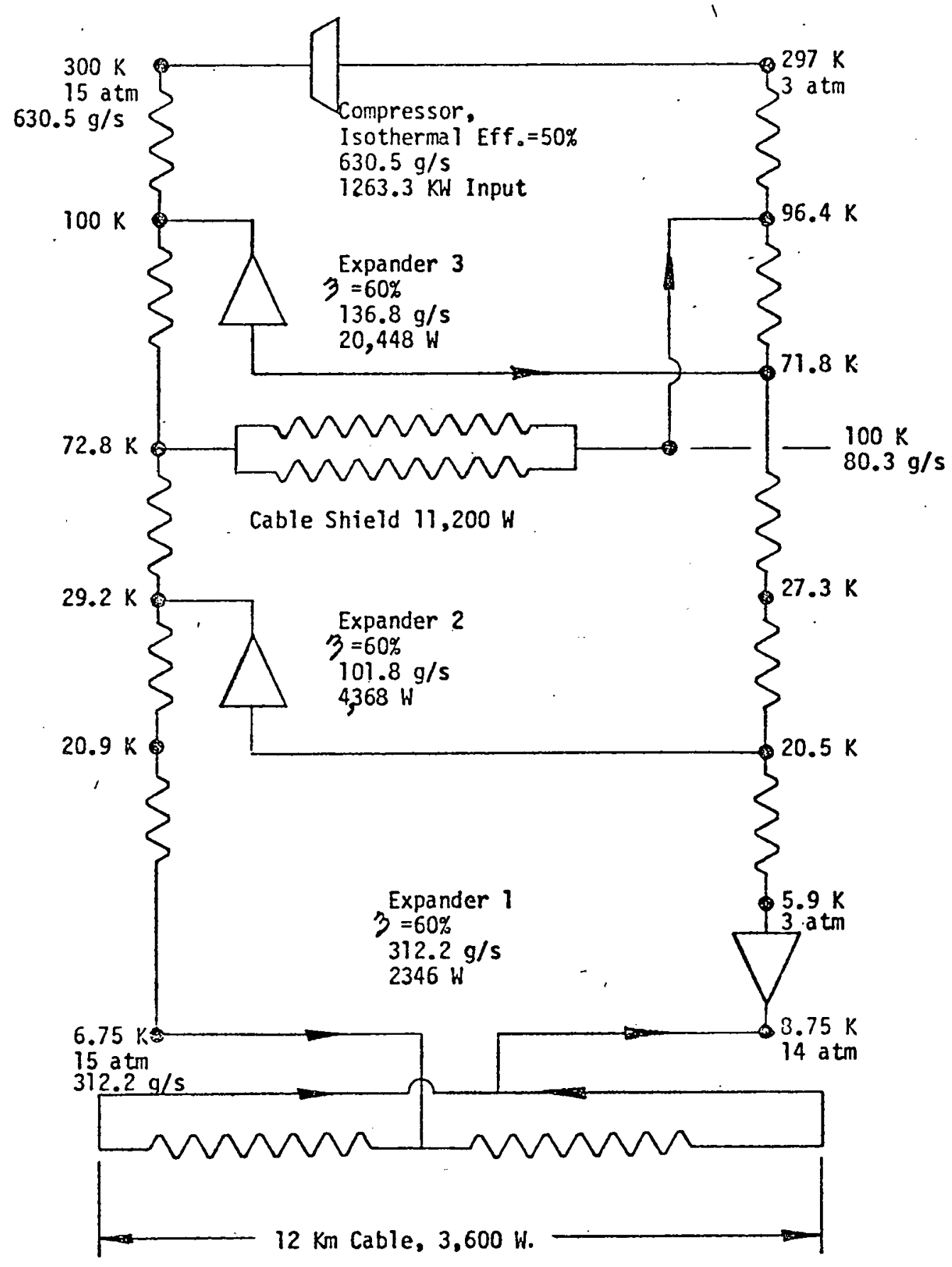

FIGIRE 2.1 BROOKHAVEN INATIONAL LABORATORY REFRIGERATOR FLOW SCHEMATIC, PLAII $3 A$, 


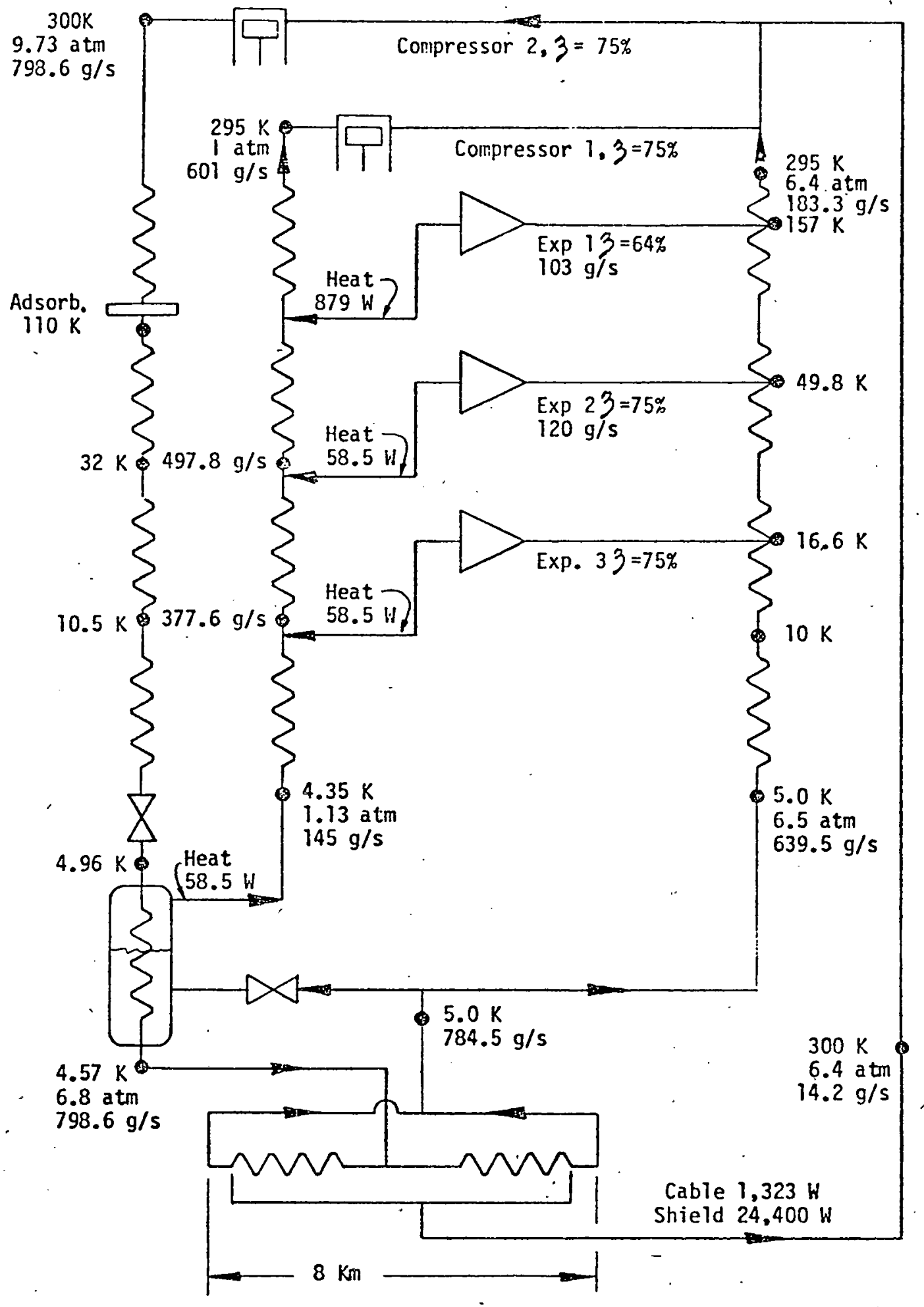

FIGURE 2.2 UNION CARBIDE, LINDE DIVISION, REFRIGERATOR FLOW SCHEMATIC 


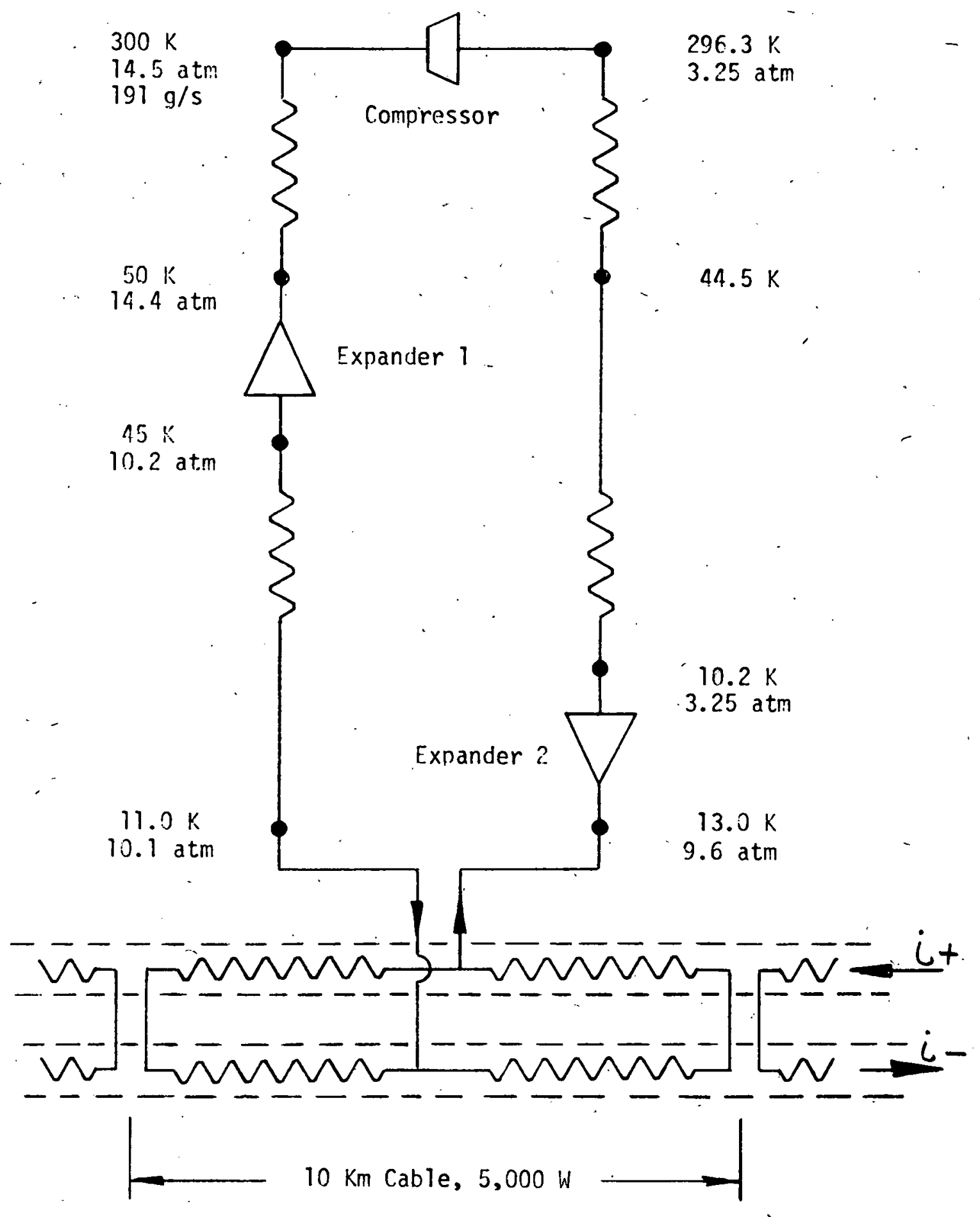

FIGURE 2.3: LOS ALAMOS SCIENTIFIC LABORATORY REFRIGERATOR FLOW SCHEMATIC 
TABLE 2.1

ANTICIPATED REFRIGERATION REQUIREMENTS FOR

MAJOR U.S. SUPERCONDUCTING POWER TRANSMISSION STUDIES

\begin{tabular}{|c|c|c|c|}
\hline DEVELOPMENT GROUP & BNL & $\underline{U C}$ & LASL \\
\hline $\begin{array}{l}\text { Power Rating, MVA } \\
\text { Voltage, KV } \\
\text { Current, KA } \\
\text { AD/DC } \\
\text { Conductor }\end{array}$ & $\begin{array}{l}4,800 \\
345 \\
8 \\
A C \\
\mathrm{Nb}_{3} \mathrm{Sn}\end{array}$ & $\begin{array}{l}3,400 \\
130 \\
14 \\
\mathrm{AC} \\
\mathrm{Nb}\end{array}$ & $\begin{array}{l}2,000-10,000 \\
+100 \\
T 0-50 \\
D C \\
\mathrm{Nb}_{3} \mathrm{Sn} \mathrm{or} \mathrm{Nb}_{3} \mathrm{Ge}\end{array}$ \\
\hline $\begin{array}{l}\text { No. of Vacuum Enclosures } \\
\text { ivo. of Conductors/Enclosures } \\
\text { Cable Tube ID - cm } \\
\text { Distance Between Stations - Km }\end{array}$ & $\begin{array}{l}1(1) \\
3 \\
28.5 \\
12\end{array}$ & $\begin{array}{l}1 \\
3 \\
50.8 \\
8\end{array}$ & $\begin{array}{l}2(2) \\
1 \\
10 \text { est. } \\
10\end{array}$ \\
\hline $\begin{array}{l}\text { Temperature of Cable }-{ }^{\circ} \mathrm{K} \\
\text { Pressure in Cable - atm } \\
\text { Flow Rate in Cable Tube - g/s } \\
\text { Refrigeration/Km (ea. encl.) - W } \\
\text { Total Cable Flow/Station - g/s } \\
\text { Total Refrig./Station - w }\end{array}$ & $\begin{array}{l}6.75 / 8.75 \\
15 / 14 \\
156 \\
300 \\
312 \\
3,600\end{array}$ & $\begin{array}{l}4.57 / 5.00 \\
6.8 / 6.5 \\
400 \\
166 \\
800 \\
1,324\end{array}$ & $\begin{array}{l}11 / 13 \\
10.1 / 9.6 \\
190 \\
250 \\
332 \\
5,000\end{array}$ \\
\hline $\begin{array}{l}\text { Temperature of Shield }-{ }^{\circ} \mathrm{K} \\
\text { Total Shield Flow/Station - g/s } \\
\text { Total Refrig.Station - W }\end{array}$ & $\begin{array}{l}75 / 100 \\
30 \\
11,200\end{array}$ & $\begin{array}{l}4.57 / 300 \\
14.2 \\
24,440\end{array}$ & $\begin{array}{l}\text { none } \\
\text { none } \\
\text { none }\end{array}$ \\
\hline $\begin{array}{ll}\text { Carnot Power } & -\mathrm{KW} / \mathrm{Km} \\
\text { Actual Power/Station } & -\mathrm{KW}\end{array}$ & $\begin{array}{l}13.6 \\
1,263\end{array}$ & $\begin{array}{l}23.2 \\
1,392\end{array}$ & $\begin{array}{l}6.0 \\
964\end{array}$ \\
\hline $\begin{array}{l}\text { Mass of Helium in Cable Tube (3) } \mathrm{Kg} / \mathrm{Km} \\
\text { Transit Time in Cable Tube }-\mathrm{Hrs} \\
\text { Warming Rate (3) - Hrs } /{ }^{\circ} \mathrm{K}\end{array}$ & $\begin{array}{l}4,350 \\
46.4 \\
23.2\end{array}$ & $\begin{array}{l}26,300 \\
73.2 \\
170.2\end{array}$ & $\begin{array}{l}360 \\
5.2 \\
2.6\end{array}$ \\
\hline
\end{tabular}

(1) Data is for 1 of 2 identical cables.

(2) Assumes bipolar cable design configuration.

(3) Authors estimate. 
The information obtained for present programs as presented in table 2.1 has been supplemented with some calculations of the mass of helium in the cable tube, transit time of the helium in the tube, and the rate at which the helium is warming. The mass of helium is computed to permit later discussion of filling and storage equipment. Present enclosure designs have return tubes that are small relative to the cable tube, so the time required for a given element of helium to complete a circuit is somewhat greater than the "go" transit time. Implications of the relatively long transit times will be discussed in connection with required instrumentation.

The parameter that is potentially most significant in terms of system reliability is the warming rate of the helium. If the helium can be allowed to warm $1^{\circ} \mathrm{K}$ while the refrigerator is off, then the system has an ideal built in reserve of refrigeration which can enhance its reliability. At this time, however, it appears doubtful that this effect can be utilized because of heat transfer and flow stability problems associated with stopping the flow of helium. The assumption is made throughout the balance of this study that the flow of helium cannot be interrupted and the refrigerator must, therefore, be designed to provide a continuous flow of helium.

\subsection{CONSIDERATIONS IN SELECTING OPERATING CONDITIONS}

In order to understand why the temperatures and pressures of the helium in power transmission lines are the values given in table 2.1, and in order to understand what must be expected of a refrigeration system which must deliver this helium coolant, it would be helpful to summarize some of the many trade-offs which must be considered in selecting the temperatures and pressures as well as the allowable temperature rise and pressure drops. A good discussion of some of these tradeoffs is given in [A.32]. Most of the paramaters which help to establish the operating pressures and temperatures fall into the category of electrical or thermodynamic considerations.

\subsubsection{Electrical Considerations}

The operating temperature for any superconductor must be less than the transition temperature of the material. Among the current superconductors being tested, niobium has a transition temperature of about $9.3 \mathrm{~K}$ and niobium tin has a transition temperature of about 18.3K. At these temperatures, the superconductor may revert to its normal state through the application of an external magnetic field or through a self-induced magnetic field generated by current flowing in the superconductor. If this magnetic field strength exceeds a certain limiting value called the threshold field, the superconductor will switch back to its normal state. Allowing for the expected 
self induced magnetic field which will appear around a superconductor, and also, taking into account the possibility of carrying fault or overload current, the design limit for temperature of the hel ium coolant in contact with the superconductor is about $5 \mathrm{~K}$ for the niobium line and about $8.75 \mathrm{~K}$ for the niobium tin line if both are used in ac power transmission. For transmission of dc power, the upper limit of the temperature of the niobium tin $l$ ine is about $13 \mathrm{~K}$.

From an electrical standpoint, the pressure of the helium cooling the line should be as high as possible. The reason for this is that in many cases the helium coolant also doubles as the dielectric insulation. The dielectric properties of helium are such that the dielectric strength increases with pressure. Another advantage of high pressure, related to dielectric strength, is that for pressure above the critical pressure of helium $(2.24 \mathrm{~atm})$ low density vapor bubbles cannot form.

In the coaxial type cable design a central superconducting element is separated from an outer conductor which surrounds it by a dielectric material (either a solid dielectric or helium). The central helium flow channels are fairly well fixed by optimizing the electrical properties of the superconductor and dielectric. This optimization will generally give a fixed geometry and size. It generally follows that this type of electrical optimization will more than likely not be optimum from a cooling standpoint.

\subsubsection{Thermodynamic Considerations}

The minimum work, Wc, required to pump heat, $Q$, from a low temperature, $T$, to ambient temperature, To, is given by the Carnot relation as

$$
W c / Q=\left(T_{0}-T\right) / T
$$

This relation is illustrated by considering the two extreme designs. For the UC cable with a maximum allowable temperature of $5.0 \mathrm{~K} \mathrm{Wc} / Q$ has a value of 59, while the LASL cable which can operate at $13 \mathrm{~K}$ has a Wc/Q ratio of 22.1 assuming To of $300 \mathrm{~K}$. The power and capital cost of refrigeration for $5 K$ refrigeration is about 2.6 times that of $13 K$ refrigeration.

Since the cable is cooled by dense gas the heat input causes a temperature rise in the gas, thus there is a temperature difference from the inlet to the exit. If the gas enters at $T_{L}$ and leaves at $T_{H}$ the minimum work required is

$$
W c / Q=\frac{T_{0}}{\left(T_{H}-T_{L}\right) / \ln \left(T_{H} / T_{L}\right)}-1
$$


The temperature rise of $.43 \mathrm{~K}$ of the UC design results in a WC/Q of 61.7 or a penalty of $5 \%$.

For the LASL design allowing a $2 \mathrm{~K}$ temperature rise the $W C / Q$ ratio becomes 24.1 or a penalty of $9 \%$.

Properties of helium from a thermodynamic standpoint that are important design considerations are the specific heat, and the Joule Thomson (J-T) coefficient. In order to understand how these effect the design, a pressure-enthalpy diagram is shown in Figure 2.4 with the $B N L, U C$, and LASL conditions plotted.

From a specific heat standpoint one would like to operate at a thermodynamic state for which the specific heat is large - this would reduce the mass flow rate of helium required for a given heat removal rate and a given allowable temperature rise. This could mean greater distances between refrigerator stations because of reduced pressure drop. Unfortunately, operation near the transposed critical line (maximum specific heat line) is an inherently unstable region to operate in from a thermodynamic and fluid mechanical standpoint; hence, one should try to operate as close to this line as possible without entering into the unstable regions.

In the case of niobium, because the heat capacity of helium in the $4.4^{\circ}$ to $5^{\circ} \mathrm{K}$ range decreases with an increase in pressure, it is advantageous to avoid a high inlet pressure; but the pressure drop should not be so high as to drop the pressure below the critical pressure.

The J-T effect is considered because an increase in temperature due to pressure drop adds to the overall gas temperature rise and thus the refrigeration work. In some temperature and pressure ranges of operation, the J-T coefficient can be negative, in which case any pressure drop in the helium circuit will cause an increase in fluid temperature. If the $J-T$ coefficient is positive, pressure drop causes a temperature drop in the fluid.

The problem of flow stability of helium in the cable tube has been extensively studied at NBS [C.I]. Density wave propagation type of flow instability is especially severe in the immediate vicinity of the helium critical point. The regions on a temperature-entropy chart of hel ium somewhat removed from the critical point and lying in the supercritical fluid region are less apt to cause flow stability problems; unfortunately, not all of the regions around the supercritical zone of the helium vapor dome have been investigated for the $L / D$ ratios being contemplated in the design of the major transmission lines. The L/D ratio used here refers to the flow channel length divided by the fluid hydraulic diameter. One 


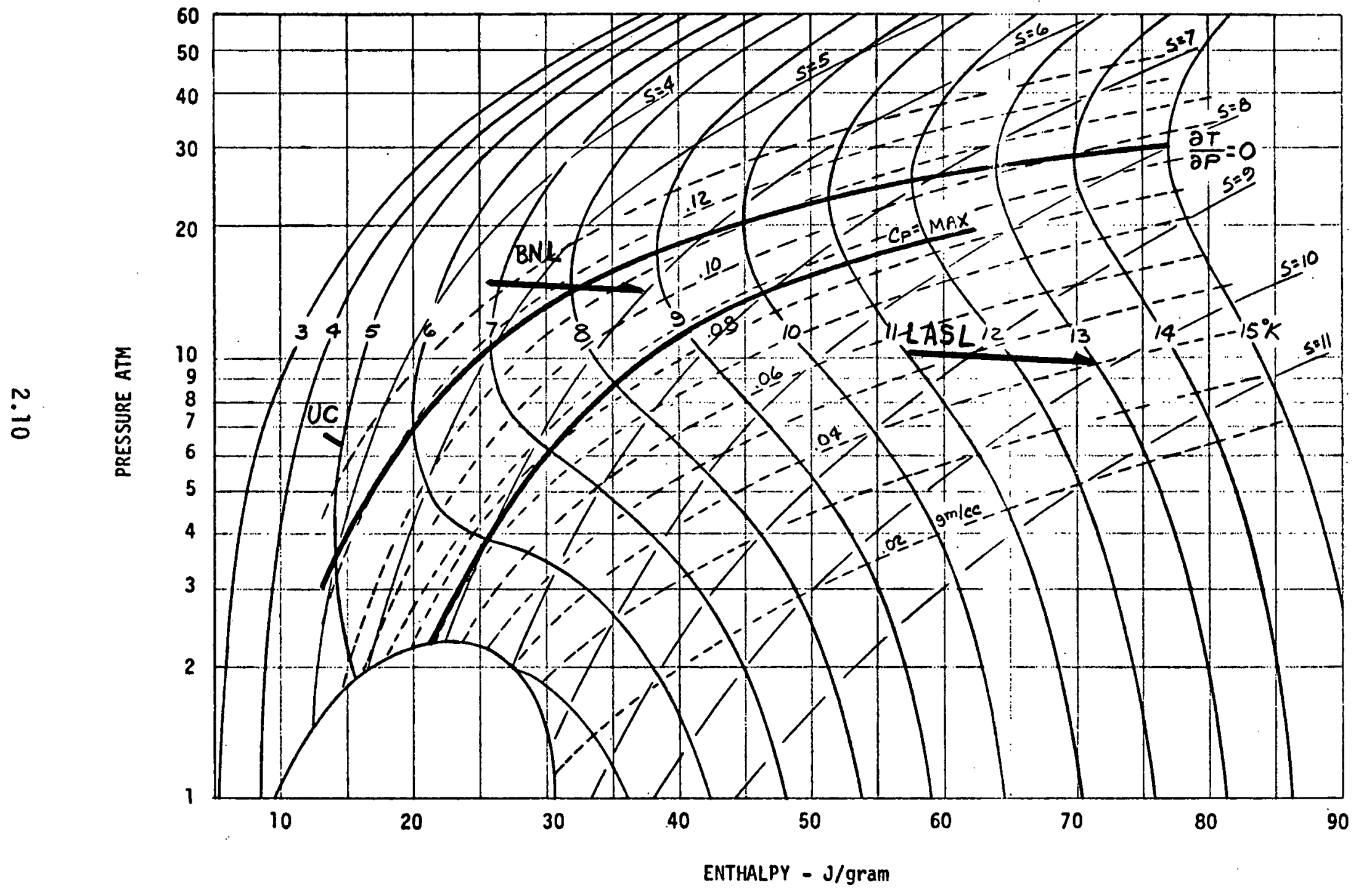

:IGURE 2.4 HELIUM PRESSURE-ENTHALPY DIAGRAM WITH BNL, UC, AND LASL CABLE CONDITIONS 
region which has been investigated is that portion of the temperature entropy chart which is below the critical temperature and above the critical pressure. No oscillations have been observed in this region which approximately corresponds to the zone of operation of the Linde niobium transmission line. The region of the T-S chart corresponding to the temperature range 6.75 to $8.75^{\circ} \mathrm{K}$ (niobium-tin) and pressures higher than $10 \mathrm{~atm}$ (probably on the order of $15 \mathrm{~atm}$ ), al though not investigated thoroughly for density wave behavior, should be reasonably free from oscillations. NBS is planning to run stability tests in most of the regions of interest around the critical point to determine zones of oscillatory flow behavior for the $L / D$ ratios being investigated.

Helium aensity enters into consideration in terms of the total inventory and in terms of the pressure change accompanying a change in elevation. BNL is finding that a line across Pennsylvania presently under study has a 3.5 atm pressure change as it rises over the $300 \mathrm{~m}$ mountains in the central part of the state.

\subsection{SPACING BETWEEN STATIONS}

Within the framework of the numerous trade-offs which must be considered in light of the preceding discussion, the allowable distance between refrigeration stations along a superconducting power transmission line may be computed for a given cable geometry. The prime controlling limitation on the distance between stations is the temperature rise of the helium coolant. For a given combination of coolant mass flow rate, transmission line heat load, effective heat transfer coefficient, and flow circuit length, the superconductor should not exceed the upper temperature limit which has been set for it. With the pertinent heat transfer equations and heat transfer coefficients one may calculate the conductor length for which the limiting temperature is reached.

The other primary limiting factor on the distance between refrigeration stations is the pressure drop in the transmission line. The pressure drop should not be such that the refrigerator cycle efficiency drops to too low a value. Also, the pressure drop should not cause the helium coolant to move into a thermodynamic state which would permit density wave oscillations or an appreciable reduction in the dielectric strength of the helium.

Taking all of these factors into account, the major transmission line development laboratories have found that the best choice for the distance between refrigeration stations falls within the range of about 8 to 12 kilometers. 


\subsection{OTHER FACTORS THAT INFLUENICE THE REFRIGERATOR}

\subsubsection{Refrigerator Cost Relative to Total Cost}

It is important in designing the refrigerator to see what part of the overall system cost it represents. Table 2.2 summarizes the cost estimate for BNL plan 3A prepared in 1973. This is the installed cost of two 4800 MVA lines, $68 \mathrm{~km}$ long with terminals at each end. From this it is seen that the refrigerator represents $7.7 \%$ of the total cost, however, it is influenced by the effectiveness of the enclosure and it has an important influence on the power cost. At the time of this study power was evaluated at $1.3 \$ / K w h$, a value that has already increased appreciably.

\subsubsection{Heat Shield}

The enclosure is seen to represent the largest single item of cost in this study. Of the \$85MM cost of the enclosure, \$21 MM is attributed to the radiation shield. Table 2.3 shows a breakdown for the heat load for different operating conditions and includes an estimate from BNL of the heat load without a shield. Without a shield the heat load of 687 W/Km represents a Carnot power input of $26.1 \mathrm{kw} / \mathrm{Km}$, an increase of $92 \%$ over the ideal power for no shield. This represents an increase in refrigerator plus power cost that is appreciably less than the cost of the shield. This indicates that the heat shield may be deleted in future studies thus increasing the size of the refrigerators.

\subsubsection{Reliability}

Reliability has not been included as a factor in studies to date, thus one of the major objectives of this study is to determine if refrigerators can be built that will be reliable enough for transmission lines. In general one can say that system reliability is enhanced by minimizing the number of active components. This means that reliability considerations will favor larger refrigerators spaced farther apart. Larger refrigerators are also more efficient. 
TABLE 2.2

BNL PLAN 3A COST ESTIMATE

TWO SUPERCONDUCTING CABLES $68 \mathrm{~km}$ LONG

MILLIONS \$ \% OF TOTAL

Conductor

Conductor Cover

Insulation

Cable Fabrication to Reels

CABLE SUBTOTAL

Vacuum Enclosure

Other Material

Cable Installation

Helium

Refrigerators, Installed

Capitalized Power and Maintenance

Engineering and Supervision

Interest During Construction

TOTAL
23.3

3.2

8.5

$\underline{17.5}$

52.5

25.9

80.4

39.6

2.5

1.2

14.6

7.2

4.6

2.3

15.7

7.7

13.0

6.4

1.5

0.8

$\underline{19.0}$

8.9 
TABLE 2.3

BNL HEAT LOAD PER LINE, PLAN 3A

CONDITION

LINE OFF NORMAL MAX

MAX LOAD MAX LOAD

IN 1 LINE NO SHIELD

\begin{tabular}{|c|c|c|c|c|c|}
\hline Load & PiVA & 0 & 2,400 & 4,800 & 4,800 \\
\hline Heat Leak & $\mathrm{w} / \mathrm{km}$ & 55 & 55 & 55 & 480 est. \\
\hline Hysteretic Losses & $\mathrm{w} / \mathrm{Km}$ & 0 & 8 & 42 & 42 \\
\hline Dielectric Losses & $\mathrm{w} / \mathrm{Km}$ & 0 & 165 & 165 & 165 \\
\hline TOTAL LOSSES @ $7^{\circ} \mathrm{K}$ & $\mathrm{w} / \mathrm{Km}$ & 55 & 228 & 262 & 687 \\
\hline Warning Rate & $\operatorname{Hrs} /{ }^{\circ} \mathrm{K}$ & 110 & 26.6 & 23.2 & 8.8 \\
\hline
\end{tabular}

TABLE 2.4

HELIUM SUPPLY AND STORAGE

Current U.S. Capacity Shipped as Liquid

BNL Requirement, Plan 3A

Number of Truck Loads, Liquid

Number of Truck Loads, Gas

Number of-Rail Cars

Value of Helium e $\$ 40 / 1000 \mathrm{ft}^{3}$

Cost of Trucks, Gas

Rental of Train from Bureau of Mines

* Assumes 24 Subsections
$50 \times 10^{6} \mathrm{SCF} / \mathrm{mo}$.

$128 \times 10^{6} \mathrm{SCF}$

ENTIRE LINE ONE SECTION*

$128 \quad 5.3$

711

30

510

21

$\$ 5.12 \times 10^{6}$

$\$ 215,000$

-- $\$ 2.7 \times 10^{6}$

$-$

$\$ 77,000 /$ year 


\subsubsection{Helium Inventory and Storage}

Helium inventory is another factor to be considered. Table 2.4 summarizes the helium supply and storage requirements compared with current U.S. production. As can be seen the hel ium inventory represents over 2.5 months of current U.S. capacity. Most helium in the U.S. is transported as liquid in trucks with 1 MM standard cubic feet (SCF) capacity. It can be assumed that the line would be filled initially with helium delivered as liquid, thus the refrigerator should be designed to utilize the refrigeration of the liquid as delivered. In the event a given section of line has to be warmed for repairs it might not be unreasonable to transfer the hel ium to trucks for sale to the local market. Gas storage in trucks or rail cars is probably not economical in view of the equipment cost shown in table 2.4.. Storage in another section of line has limited potential because the gas is very dense and would thus have to be distributed to several sections. It could not be stored in an operating section because it would upset the temperature and flow conditions. A refrigeration system that has excess refrigeration capacity, a capability of producing liquid and liquid storage facilities is probably a better plan.

While the amount of helium required for the BNL. Plan $3 A$ line is large relative to current U.S. out-put it represents only .033\% of the total U.S. helium supply in storage at the Cliffside field. Present projections [A.41] indicate there is adequate helium in reserve to meet the needs of major U.S. requirements through approximately the year 2030, at which time helium will have to be extracted from the air. In the long run there will be incentives to minimize the helium inventory, however, at the present this is not considered to be a major factor.

\subsubsection{Far End Expander}

A recent development that can have significant influence on the refrigeration system design is an idea advanced by John Dean and Staff while at BNL to put an expander at the far end of the line. The far end of the line is the midpoint between stations where the helium flow is turned around. The idea is to have helium remove electrically generated heat on the go leg, and thermal heat leak on the return leg. Figure 2.5 is a refrigerator flow schematic under study at BNL using a far end expander and no heat shield.

Comparing the ratio of refrigeration per unit flow of this plan with the original BNL plan shows that twice as much refrigeration is produced. The implications of this are that the helium inventory can be reduced and/or the distance between stations can be increased. BNL at present is con- 


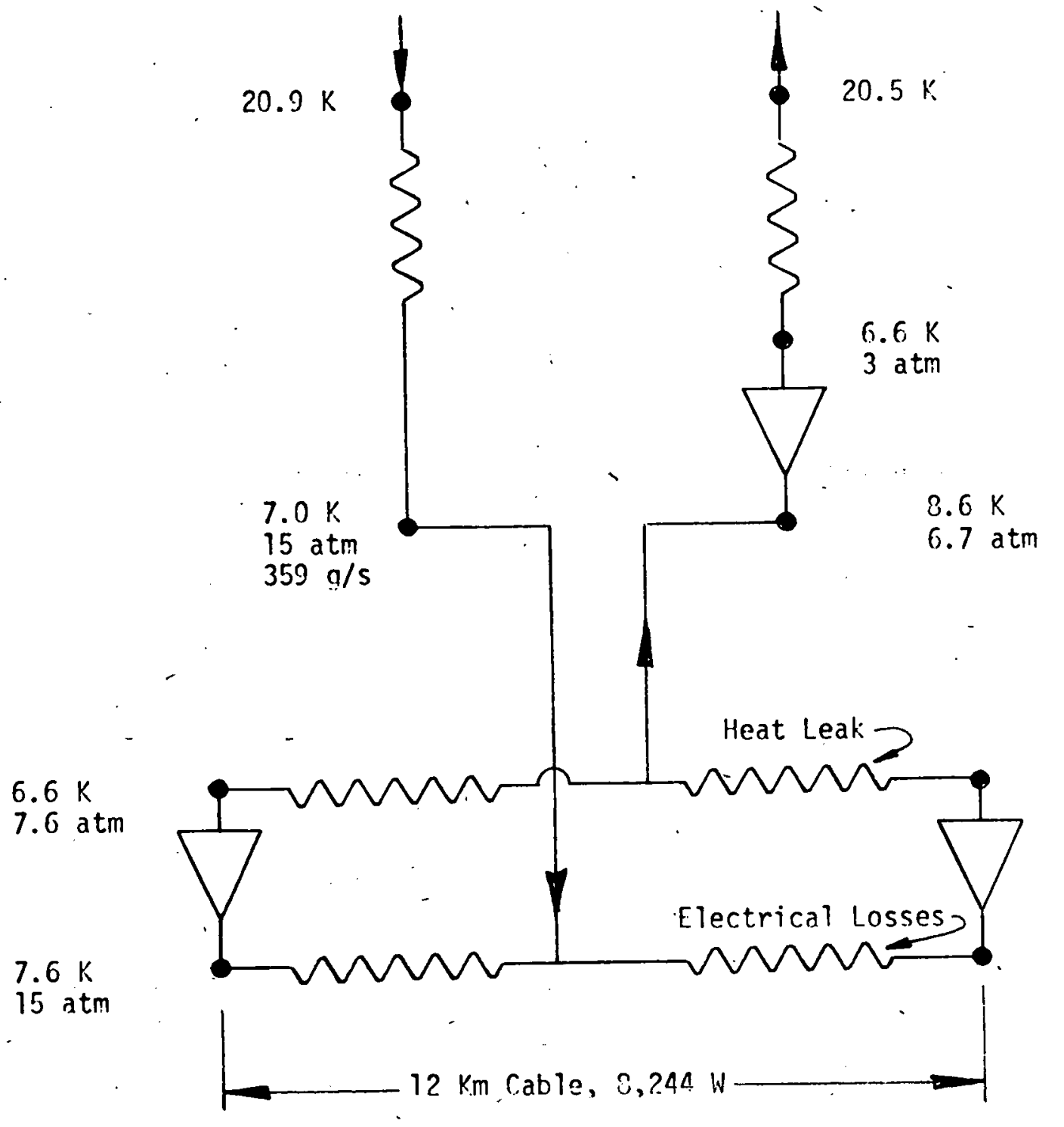

FIGURE 2.5 REFRIGERATOR . FLOW SCHEMATIC UNDER STUDY OF BNL USING FAR END EXPANDER AND NO HEAT SHIELD 
sidering increasing the spacing from $12 \mathrm{~km}$ to $24 \mathrm{~km}$ for this Pennsylvania study. They also feel this concept is more readily adapted to elevation changes.

The primary problem with the far end expander concept that is presently under study is the heat exchange relation between the go and return streams that results in the cable serving as a long heat exchanger. In the present BNL study the maximum temperature of $8.75^{\circ} \mathrm{K}$ occurs $1.5 \mathrm{~km}$ from the refrigerator based on present heat transfer data for the cable. This effect might also present some problems in cooling the line down.

One reason for the high ratio of refrigeration per unit flow is the fact that the return stream is assumed to operate in the region of maximum specific heat, and in fact crosses the transposed critical line. It may be that some flow instability can be tolerated in the heat shield circuit, however, at the present time this is still under investigation.

\subsubsection{Efficiency, Cost and Size}

The data compiled by Strobridge [B.25] shows that there can be significant improvement in efficiency as the size of the helium refrigerator is increased. This same. survey also shows that the cost is proportional to the power input to the 0.7 power. These two factors thus favor having fewer refrigerators that are larger.

\subsection{7 "Potheads"}

A brief comment needs to be made regarding the effect of "potheads" on the refrigerator. It is the opinion of the authors that the helium that is bled out of the cable to cool the electrical cable transitions between the cryogenic temperature and ambient temperature will represent a heat load equivalent to several $\mathrm{Km}$ of cable, but will not significantly alter the design or reliability of the refrigerator. This aspect of the refrigerator design is thus not specifically dealt with in this report.

\subsubsection{Unequal and Variable Refrigeration Loads}

Another consideration that is not included in the present study is the fact that all the refrigerators will not have the same refrigeration load, either because the distance between stations is not the same or because the heat losses in different sections of the line are not the same. An allowance will probably be needed also for deterioration in the enclosure 
insulation requiring an increasing refrigeration rate with time.

From table 2.3 one can see that the refrigeration requirements change somewhat with changes in electrical load. These factors may result in refrigerators at different stations having different capacities and will certainly require that the refrigeration rate be adjustable during operation to conserve power.

\subsubsection{Higher Temperature Superconductors}

There is an on going search for new superconducting materials and means to permit operating with existing materials at higher temperatures. Higher operating temperatures along with possible improvements in insulation will help to reduce the size and power input of the refrigerators. Some idea of the influence of increased operating temperature on reducing the system work requirements can be obtained by referring to the equations in section 2.2.2.

\subsubsection{Summary}

In looking for trends in specifications for future refrigerators one sees there are many factors that will favor having larger refrigerators than are presently contemplated. These factors include probable removal of the heat shield, increased reliability, greater distance between stations due to the far end expander, improved efficiency, and lower cost.

Improvements in superconducting materials and insulation will tend to reduce the refrigerator size, but these factors are deemed to be less significant than the factors favoring larger refrigerators.

Heat transfer considerations and the use of a far end expander will require that the refrigerator run continuously.

Variable refrigeration loads will require that the refrigerator output be adjustable.

These considerations illustrate the point that the enclosure, refrigerator, helium inventory, and power must be optimized as components integrated into the overall system. These studies are still in their early stages, with the present refrigerator study having as a primary objective the compilation of the information relating to the refrigerator needed to advance the total system optimization studies. 


\subsection{SURVEY OF EXISTING LARGE HELIUM REFRIGERATORS}

\subsection{METHODS OF GATHERING AND PRESENTING INFORMATION SURVEY DATA}

In order to develop an optimization criteria for the selection of system components, to be used on the superconducting power transmission line refrigeration system, which will insure a high degree of reliability and low maintenance requirements, it is imperative that one begin the design process by becoming familiar with the many potential problems and failures which can effect the operation of a helium refrigeration plant. The best way of accomplishing this is to talk, first hand, with the people who operate and mainta in large helium refrigeration systems and liquefiers. APCI visited users both in the U.S. and in Europe in order to find out about the problems experienced on refrigeration systems which represent a cross section of the major types of equipment presently available (oil lube turbo-expanders, externally pressurized gas bearing turbines, and self actuated gas bearing turbines). An emphasis was placed on systems using turbo-expanders due primarily to the findings of a recent paper by Dean of LASL [A.40]. Dean did a reliability analysis of a hypothetical refrigeration system which provided cooling for a superconducting power transmission line. His analysis showed that the overall reliability of a refrigerator using reciprocating as opposed to rotating equipment was so poor that the likelihood of using reciprocating expanders and to a lesser extent, reciprocating compressors, on future transmission lines was very remote.

In addition to the APCI visits, information has been utilized from the Strobridge and Sindt report [B,21]. This report covers the operating experience on the turbo-expanders, reciprocating expanders, and compressors used on large helium extraction facility liquefiers. These units represent the largest helium liquefiers in the U.S. This information, together with the APCI visits and APCI $\mathrm{N}_{2}$ plant experience (discussed in section 6.0), provides a good data base from which to proceed with reliability and cost studies.

The installations visited, together with the information obtained by Strobridge and Sindt, are tabulated and summarized in table 3.1. Before proceeding with the discussion, a few words of caution are in order: First, since accurate operating logs were not kept in most of these installations, information which appears in table 3.1 was obtained largely through the operator's attempts to mentally recall past incidents. While most of the failures which appear are probably fairly accurate, there are undoubtedly many failures which occurred but were not reported here. This is espe- 
TABLE 3.1

HELIUM AND HYDROGEN REFRIGERATOR/LIQUEFIER OPERATING EXPERIENCE

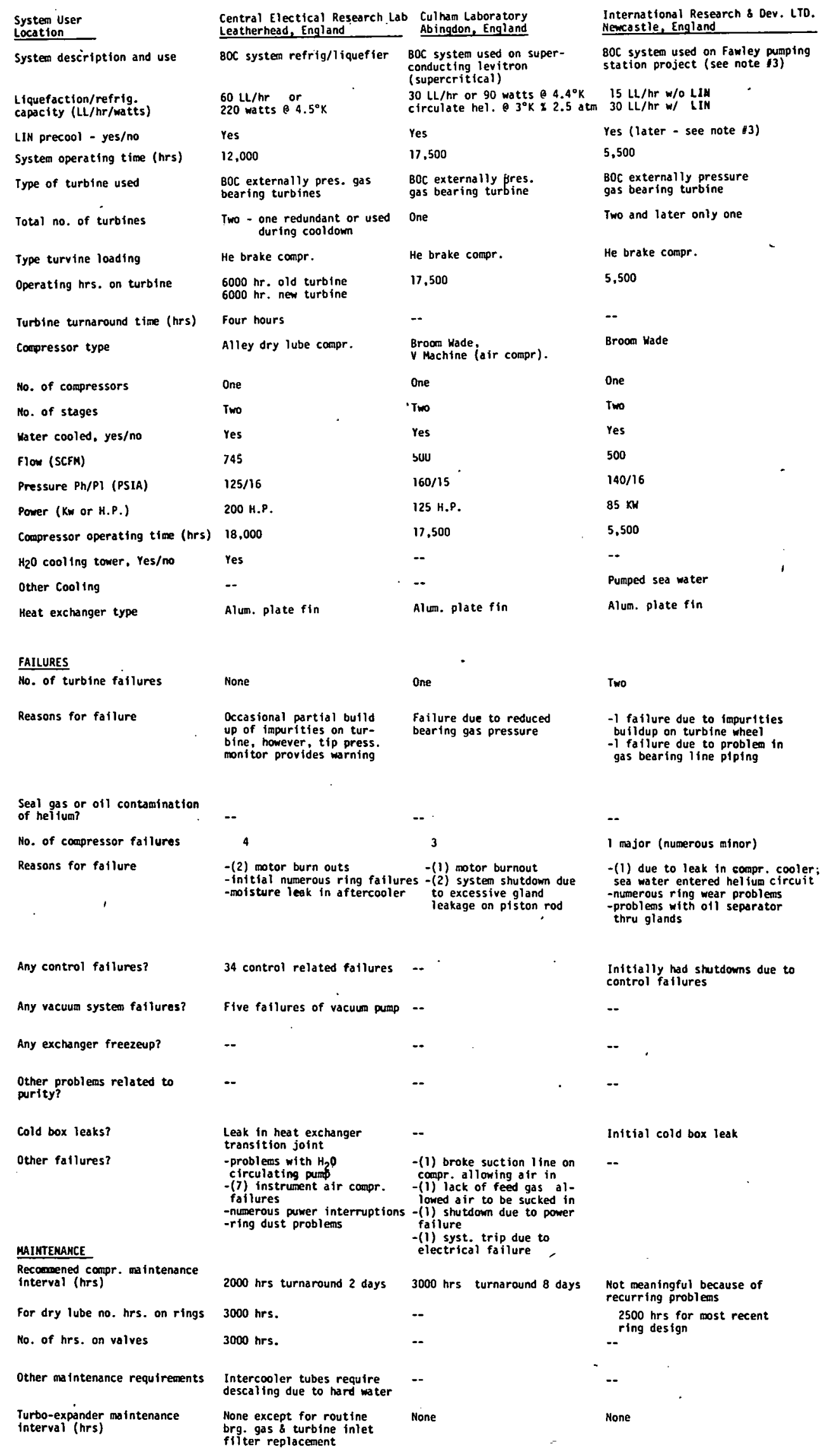


TABLE 3.1

HELIUM AND HYDROGEN REFRIGERATOR/LIQUEFIER OPERATING EXPERIENCE

System User

Location

System descripilion

Liquefaction/refrig.

capacity (LL/hr/watts)

LIM precool - yes/no

System operating time (hrs)

Type of turbine used

Total no. of turbines

Type turbine loading

Operating time on turbines

Turbine turnaround time (hrs)

Compressor type

Mo. of compressors

No. of stages

Water cooled yes/no

Flow (SCFM)

Pressure Ph/PI (PSIA)

Power (Ku or H.P.)

Compr. operating tíme (hrs)

$\mathrm{H}_{2} \mathrm{O}$ cooling tower hrs/no

other cooling

Heaț exchanger type

FAILURES

No. of turbine fallures
Reasons for fallures
Seal gas or ofl contamination
of hel lum?
No. of compressor fallures
Reasons for fallure

Reasons for follure

Any control failures?
Any vacuum system failures?
Any exchanger freezeup?
other problems reloted
to purity?
Cold box leaks?
Other fallures?

MAInTERANCE

Recomended compressor
- antentence interval (hrs)

For dry lube no. hrs. on rings

No. of hrs. on valves

Other wintenance requirements

Turbo expander maintenance

interval (hrs)
CENTER FOR NUCLEAR STUDIES (CENG)

L'Alr Liquide refrigeration sys. L'Alr Liquide liquefier L'Air Liquide refrigerator on.cold neutron source

7. $\mathrm{Km}$ o $18-28^{\circ} \mathrm{K}$ (1 turb.)

No

12,700

$25 \mathrm{LL} / \mathrm{hr}$ (oid turbine) $\quad 100$ watts $4.2^{\circ} \mathrm{K}$

Tro L'Air Liquide externally pressurized gas brg.

Two in parallel

He compressor brake loop

12,700 :

Four

Sulzer labyrinth seal

Two

Two

Yes

(1) $30 /$ compr.

$210 / 40$

$350 \mathrm{Riw} / \mathrm{compr}$.

13,300 hrs 11 compr.

12,700 hrs 12 compr.

Alum. plate fin

Yes Yes.

$19,800 \quad 15,000$

L'Air Liquide externally L'Air Liquide externally pres. pressurized gas brg. surized gas brg. turbo-exp.

turbo-exp.

He compressor brake loop He compressor brake loop

$15,000 \mathrm{hrs}$ old turbine $\quad 15,000$

4,800 hrs. new turbíne

-.

$--$

Sulzer labyrinth seal Sulzer labyrinth sea

One $\quad$ one

Two t ino

Yes - res

-. - -.

220/15 220/15

--

$19,800 \quad 15,000$

$--$

None None

No major failures

Al though actual fallure did not occur. turbine was changed af ter $13,000 \mathrm{hrs}$. due to blade proper regula tor setting proper reguld
on bearing

- Same failure as above, $\alpha$ curred 10 min. after

None

No major failures other than problems with piston rod
gland leakage, valves, etc.

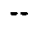

Had to replace cylinder lining after $16.000 \mathrm{hr}$

due to excessive

S1x fallures due to defective or bad settings on control sys.

--

Have had to shut system down 6-7 times due to build-up of impurities on turbine wheel

-.

-one shutdown due to cooling water problem

-pipe broke on compressor due

to vibration

- two air compr. fallures

- seven electrical power failures

8000 hrs. (1 wh turnaround)

$8000 \mathrm{hrs}$.

8000 hrs.

$--$

None

tone

None

$-$

Occasionally clean out water side of helium turbine brake 
TABLE 3.1

HELIUM AND HYDROGEN REFRIGERATOR/LIQUEFIER OPERATING EXPERIENCE

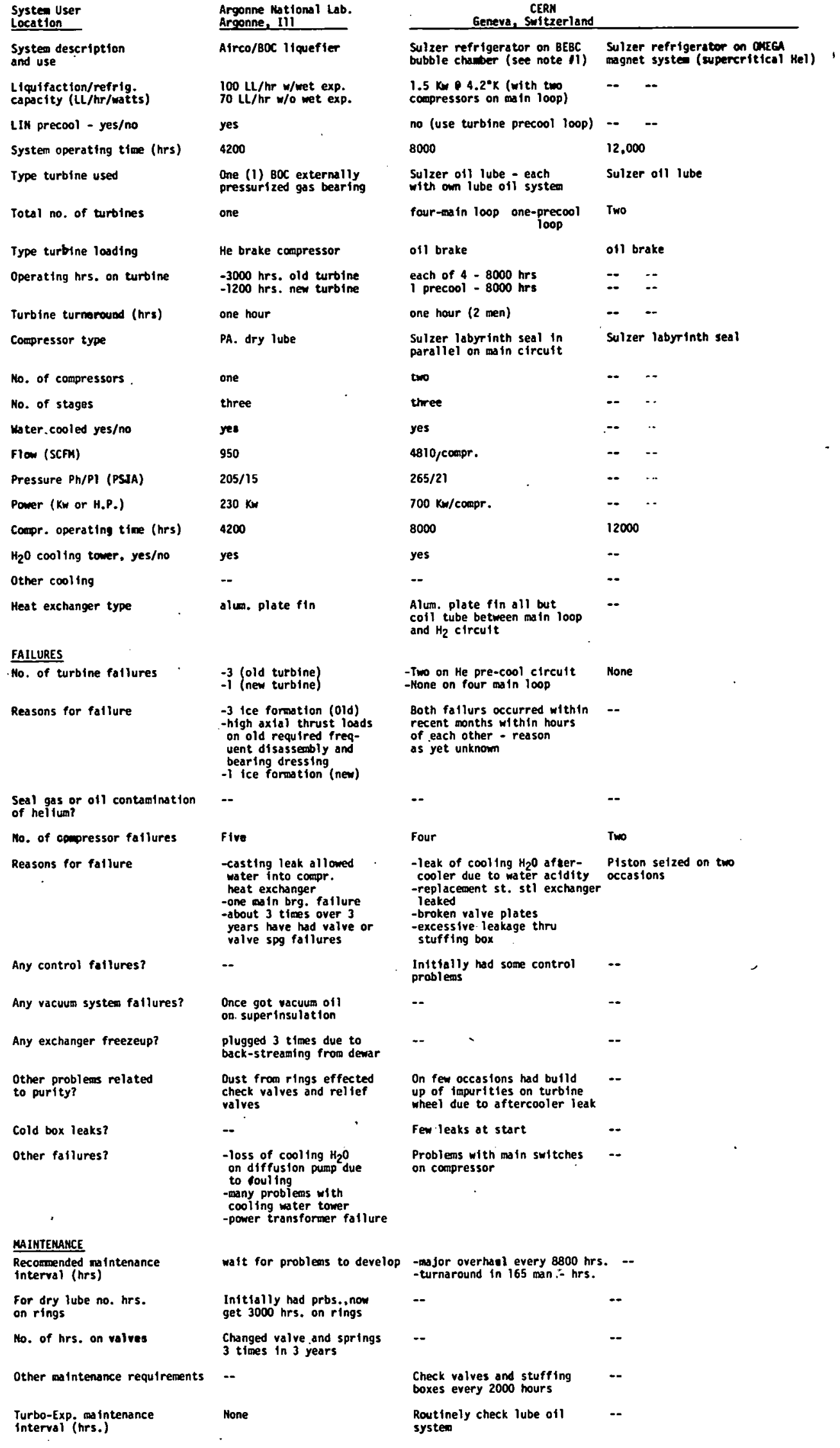


TABLE 3.1

HELIUM AND HYDROGEN REFRIGERATOR/LIQUEFIER OPERATING EXPERIENCE

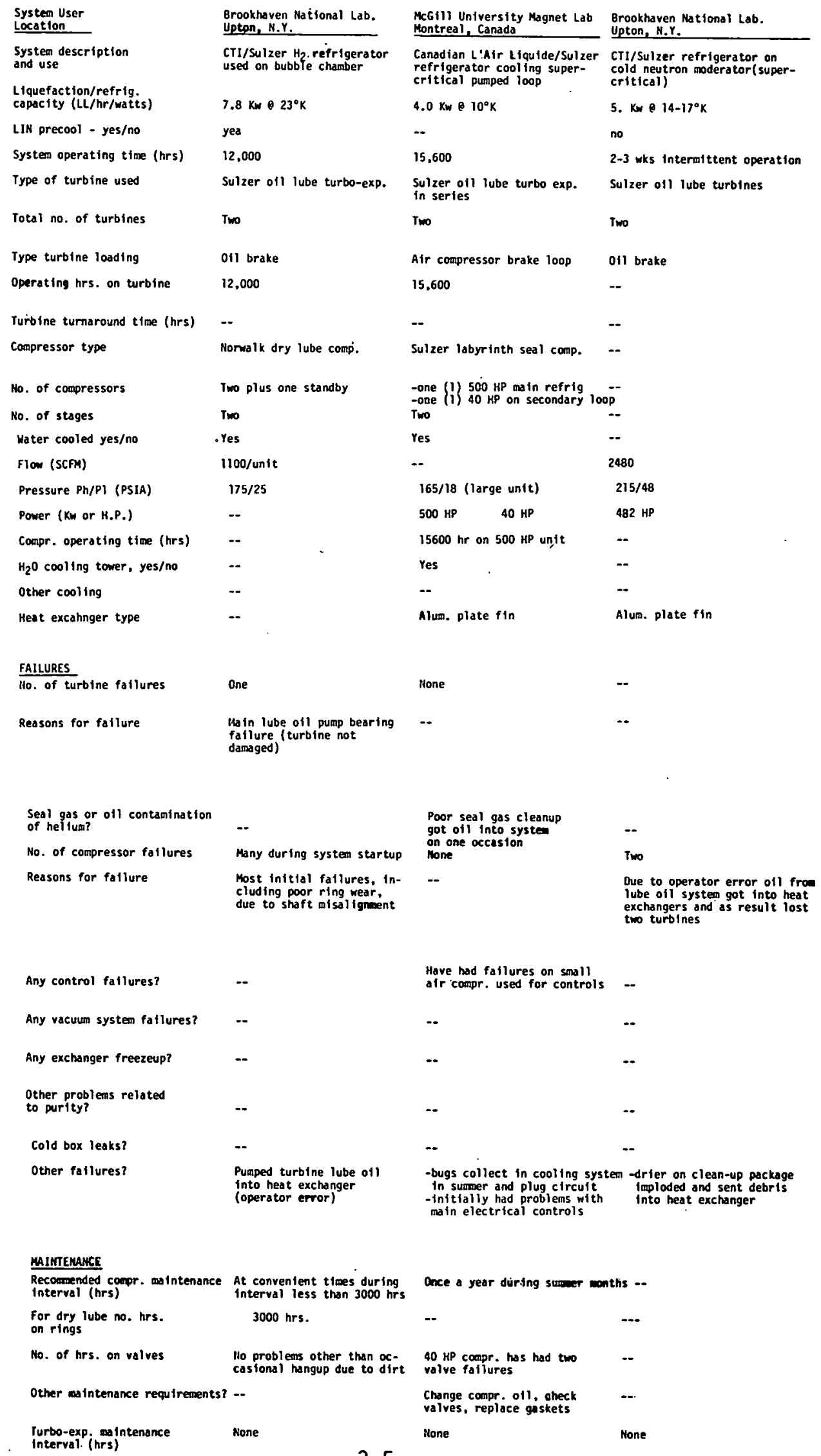


TABLE 3.1

HELIUM AND HYOROGEN REFRIGERATOR/LIQUEFIER OPERATING EXPERIENCE

Systen User

Lacation

Systen description and

use

Liquifaction/refrig.

LIM precool - yes/no

System operating tine (hrs)

Type of turbine used

Total no. of turbines

Type turbine looding

Operating hrs. on turbine

Turbine tumaround time (hrs)

Compressor type

Mo. of compressors

No. of stages

Mater cooled yes/no

Flow (SCFM)

Pressure Ph/PI (PSIA)

Power (Kw or H.P.)

Compressor operating time (hrs)

$\mathrm{H}_{2} \mathrm{O}$ cooling tower, yes/no

Other cooling

Heat exchanger type

FAILURES

No. of turbine fallures

Reasons for failure

Three in the years - Ouring Initial plant stortup due to dirt or solid neon
- Initially had short iffe on tearings and seals

Seal gas or o1l contamination of hell fum?

No. of compressor fatlures

Reasons for failure

\section{$?$} -Initial problems finding
correct ring material

Phillips Greemood Plant (Hote 5)

Hel fum Liquefaction process is a Claude Cycle systew with two turbines in series

Yes

8 years

oil lubricated turbo-expander

Two

011 brake

Dry lube gas Dry lube gas

une

-. -

$-$

$165 / 17$

$165 / 17$

600 H.P.

Pate fin
$-$

Cities Service Jaytark Helium Plant (Mote 5)

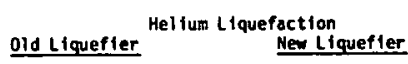

$818 \mathrm{LL} / \mathrm{hr}$ design $\quad 818 \mathrm{LL} / \mathrm{hr}$

$727 \mathrm{LL} / \mathrm{hr}$ nowinal

Yes res

5 years $\quad 1.5$ years

011 lube turbo expander oil lube turbo expander

Two (In series) Imo

011 brake 011 brake

-.

$-\cdot$

Drylube stean turbine Drylube nat. gas motor drive rive compressor

One

Four Five

--

$--$

- $\quad 290 / 15.5$

1200 H.P. $\quad 800$

$-$

$--$

$-$

Plate fin plate fin

One per year Three in 1.5 years

-Frequent bearing fallures - Fallure at startup due to initlally (unit sensitive prlor freezeup

to change in process cond.)- Bearing fallure due to --Diffícultifes starting electrical power loss and stopping - Now about one fatlure/yr.

$-$

-Corrosion of intercooler -Mo major, problems baffles due to poor water quality required

Any control fallures?

Any vacuum system fallures?

Any exchanger freezeup?

Other probiens reloted to purity?

cold box leaks?

Had initial problems

other fatlures?
$-$

$-$

-.

Humerous problems

Initially had problems with flow distribution in heat exchangers
MAIMTERANCE

Recompended compressor

mantenance interval (hrs)

For dry lube no. hrs. on rings

Mo. of hrs, on valves

$--$

other maintenance requirements?

Turbo-expander ma intenance interval (hrs)

lione
Annual overhaul

Rings chenged ot

Pistons rotated $1 / 2$ turn each 6 wonths

Teflon ring replacement

every $2200 \mathrm{hrs}$. (2 day

turnaround)

--

None
Check cospressor rings each

90 days

--

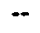

$-$

None 
TABLE 3.1

HELIUM AND HYDROGEN REFRIGERATOR/LIQUEFIER OPERATING EXPERIENCE

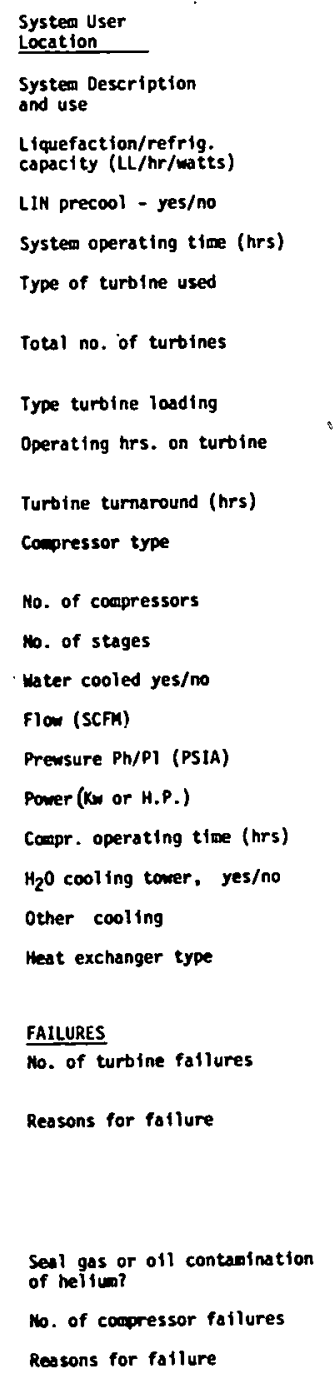

Kansas Refined He Co. This, Kansas

Hel fum I Iquefaction

$-880 \mathrm{LL} / \mathrm{hr}$
$-1090 \mathrm{LL} / \mathrm{hr}$ with wet exp. yes

7.5 yrs

oil lubricated turbo-exp.

Two (in series)

011 brake

--

$\cdots$

Ory lubricated with mat. gas motor drive

Two

Four

--

$\cdots$

225/19

500 H.P.

$-$

$-$

$-$

Plate-fin

10 in 7.5 yrs.

most fallures due to comtaminants in process

comtamin -remaining due to oil pump fallures -most of above problens
corrected

--

$-$

$-$
Lawrence Liverwore Lab. Liversore, Cal.

Airco/boC llquefier

$60 \mathrm{LL} / \mathrm{hr}$

yes

19,000

One (1) BOC externally pressurized gas brg.

One

He brake compr.

19,000

$1 / 2$ hour

Rix dry lube comp.

(rebullt air cospr)

One

Iwo

yes

850

$190 / 16$

250 H.P.

19,000

$-$

$-$

Alum. plate fin
Gesellshaft Fur Kernforschung:(GFK) Karlesruhe, Germany

Linde $A G$ refrigeration system used on multiple experiments (note 2)

380 watts $1.8^{\circ} \mathrm{K}$ or $115 \mathrm{LL} / \mathrm{hr}$

no

15,000

Two Linde AG ofl lube turbo expanders in sertes

Two

011 brake

15.000

Linde AG dry lube, vertical with "Gefangener" piston rings

--

Three.

yes

1950

295/16

$540 \mathrm{~km}$

15,000

Yes

--

Colled tube
No major fatlures during last 13,000 hrs.

- initially got only about 20 stop/start cycles out of bearings - -after initial-problens solved ran ox -examined and found no signs of wear -.

3

-2nd stage bearing due to lack of lubrication - main bearing fallure valve spring breakage

Any control faflures?

Any vacuum system fallures?

Any exchanger freezeup?

Other probleas related to purity?

cold box leaks?

Other follures?

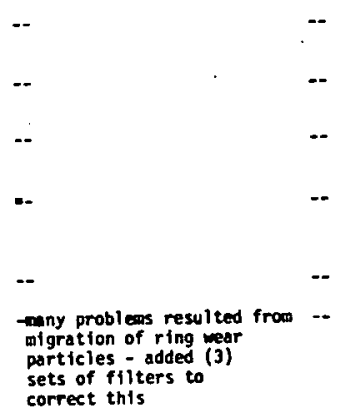

Mintenunce

Reconiended compressor mint. -check campr, p1ston \& rider Interval (hrs) rings - 90 days -change interstage s
filters - 30=60 days fitiers

For dry lube no. hrs. 6600 thes.

Mo. of hrs. on valves

$-$

$-$

$-$

migration of ring mear

partsciles to

2-3000 hours

6000 hrs - rings rotuted every $2000 \mathrm{hrs}$

Valves and valve springs checked every 2000 hrs.

None

3.7
Iwo

- 011 bearing problen due do

overspeed run

-oll bearing problem due

to dirt

2

-number of shutdoums due to excessive stuffing box leakage

Minor control faflures

-2 breakdowns of vacuum pumps used for $1.8^{\circ}$ K operation

--

$-$

$-$

- poor water qual1ty caused problems with cooling liop. exchanger plugging and

corrosion in water line to compr. due to vibration

Check every 8000 hours

Some rings have lasted 15,000 hours

Check overy 8000 hours

Change or check stuffing box every $4000 \mathrm{hrs}$ (some leek
after $1-2 \mathrm{~K} \mathrm{hrs}$ )

None 
TABLE 3.1

HELIUM AND HYOROGEN REFRIGERATOR/LIQUEFIER OPERATING EXPERIENCE

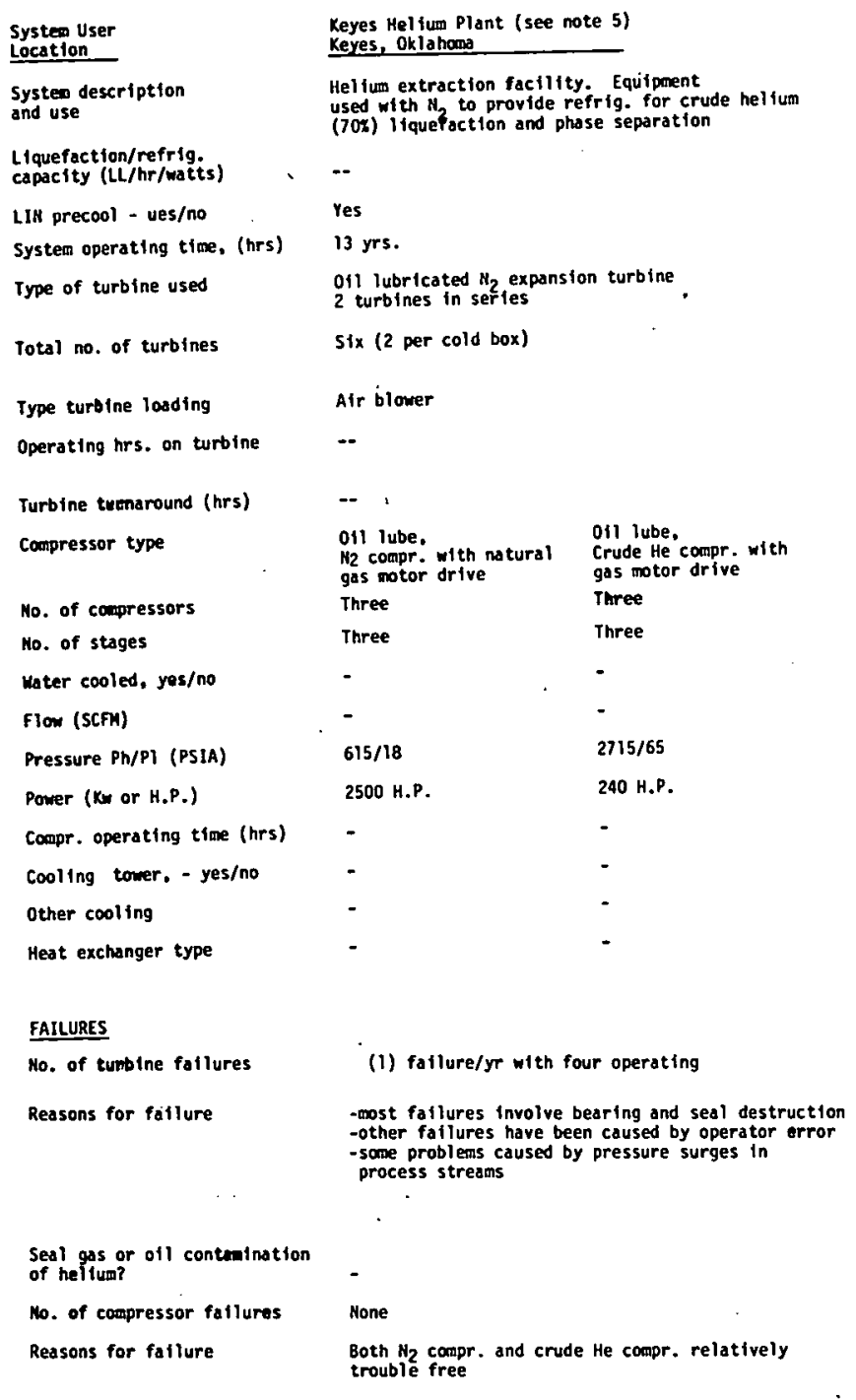

SIM- Swiss Institute of Nuclear Studies vilifigan, Smitzerland

Sulzer refrigeration.jysteo osod! for Muon channel cool Ing

(supercritical)

Total requirenents equivalent to

No

11,000

Sulzer self octuating gas bearing turbines

Two in series

He compr. brake loop

11,000

Three hours

Sulzer labyrinth seal compr.

One

Two

Yes

.780

$150 / 17$

$270 \mathrm{Km}$

11,000

-

Alum, plate fin

One

Bearing fallure due to dirt

Mone

Any control failures?

(1) failure due to a pneumatic

Any vacuum system faflurtes? Insulation is rock wool with $\mathrm{N}_{2}$ purge

Any exchanger freezeup?

Other problems related to purity? -

Cold box leaks?

Other fallures?

MAINTEMULCE

Recomnended coopr. maintenance Annual overhaul of compr/ cylinders when motors serviced

5000 hrs. interval (hrs)

For dry lube no. hrs. on rings

No. of hrs. on valves

Other maintenance requitrenents

Mone 
NOTES

\#1. Total system consists of three (3) refrigeration circuits which are thermally linked through specific common heat exchangers

(a) Main helium circuit produces supercitical helium and consists of two large Sulzer labyrinth seal compressors and a small auxiliary labyrinth seal compressor. Also has oil lubricated turbines (4) which appear as two parallel turbine sets which follow each other in series.

(b) $60^{\circ} \mathrm{K}$ precooling circuit consisting of a Sulzer compressor and single turbine.

(c) $\mathrm{H}_{2}$ circuit, with a Sulzer compressor, linked to main halium circuit through a single heat exchanger. Produces liquid $\mathrm{H}_{2}$ with J-T.

\#2. Experiments served by this refrigerator plus a 300 watt $01.8^{\circ} \mathrm{K}$ MesserGriesheim system include:

(a) He II cooled LINAC Experiment.

(b) Superconducting energy storage experiment.

(c) R.F. Particle Separator.

(d) 2000 liter helium dewar used if liquefying helium.

\#3. System originally designed as two turbine Claude Cycle, later replaced warm turbine with LIN heat exchanger.

\#4. System must simultaneously provide:

- 90 watts at $4.3^{\circ} \mathrm{K}$ and $10 \mathrm{~atm}$

- $0.4 \mathrm{gls}$ gas at $4.3^{\circ} \mathrm{K}$ (lead cooling)

- 1200 watts at $92^{\circ} \mathrm{K}$ and $10 \mathrm{~atm}$ (shield cooling)

- $10 \mathrm{LL} / \mathrm{hr}$ liquid

\#5. Information taken from T. R. Strobridge and C. F. Sindt report "OPERATING EXPERIENCE - HEL IUM EXTRACTION AND LIQUEFACTION EXPANSION DEVICES", prepared for National Accelerator Laboratory, January 1974. Only turbo machinery included here and compressors pertinent to present study. For reciprocating expander experience and other details see this report. 
cially true of the less glamorous types of system shutdowns which were the result of power interruptions, cooling water problems, system leaks, etc. Also, many of these systems reported here were "one of a kind" type installations which inherently would have a higher incidence of failures than well established systems, such as in the case of the APCI standard $\mathrm{N}_{2}$ plants where a larger number of accumulated operating hours have provided a valuable amount of engineering feedback which aids in increasing the reliability of the system.

Of all the refrigerator users visited, the operating experiences on the CENG cold neutron source have been fairly well documented in one of the papers [B.30] given at the recent 5th International Cryogenic Engineering Conference. If one counts the failures on this system; there have been 26 failures on the system in the past 12,700 hours - this works out to about 18 failures per year. It is interesting to compare this to the experience gained from reviewing the APCI $\mathrm{N}_{2}$ plant operating reports. The Alcoa $\mathrm{N}_{2}$ plant, which is to be described in detail in a later section, averaged, over a total operating time of 720,000 hours, about 17.5 outages per year.

\subsection{INTERPRETATION OF DATA}

\subsubsection{Turbo-Expander Experience}

Much interesting information may be gleamed from this summary - but one thing which will be mentioned here is an extension of the Strobridge attempts at coming up with a value representative of the mean turboexpander operating hours per failure. In the summary of the mean turboexpander operating hours per failure found in the user visits and the helium plant facility visits of Strobridge, as given in table 3.2 , the same definition of expander failure has been used here as in the helium extraction plant reports. In this case, a failure refers to any incident in which the turbo-expander either stopped on its own or was stopped at an unscheduled time to perform a repair of replacement. Excluded from the failures given in table 3.2 have been those which occurred during the initial phases of system start-up and run-in.

It is obvious from the tabulation presented in table 3.2 that, by far, the greatest amount of operating experience has been gained by the oil lubricated turbo-expanders; this probably accounts for the higher mean operating hours per failure of the oil bearing turbine compared to either the externally pressurized gas bearing turbine or the self-actuating pressurized gas bearing turbine. It is evident from the user visits that, because of 
TABLE 3.2

MEAN TURBO-EXPANDER OPERATING HOURS PER FAILURE

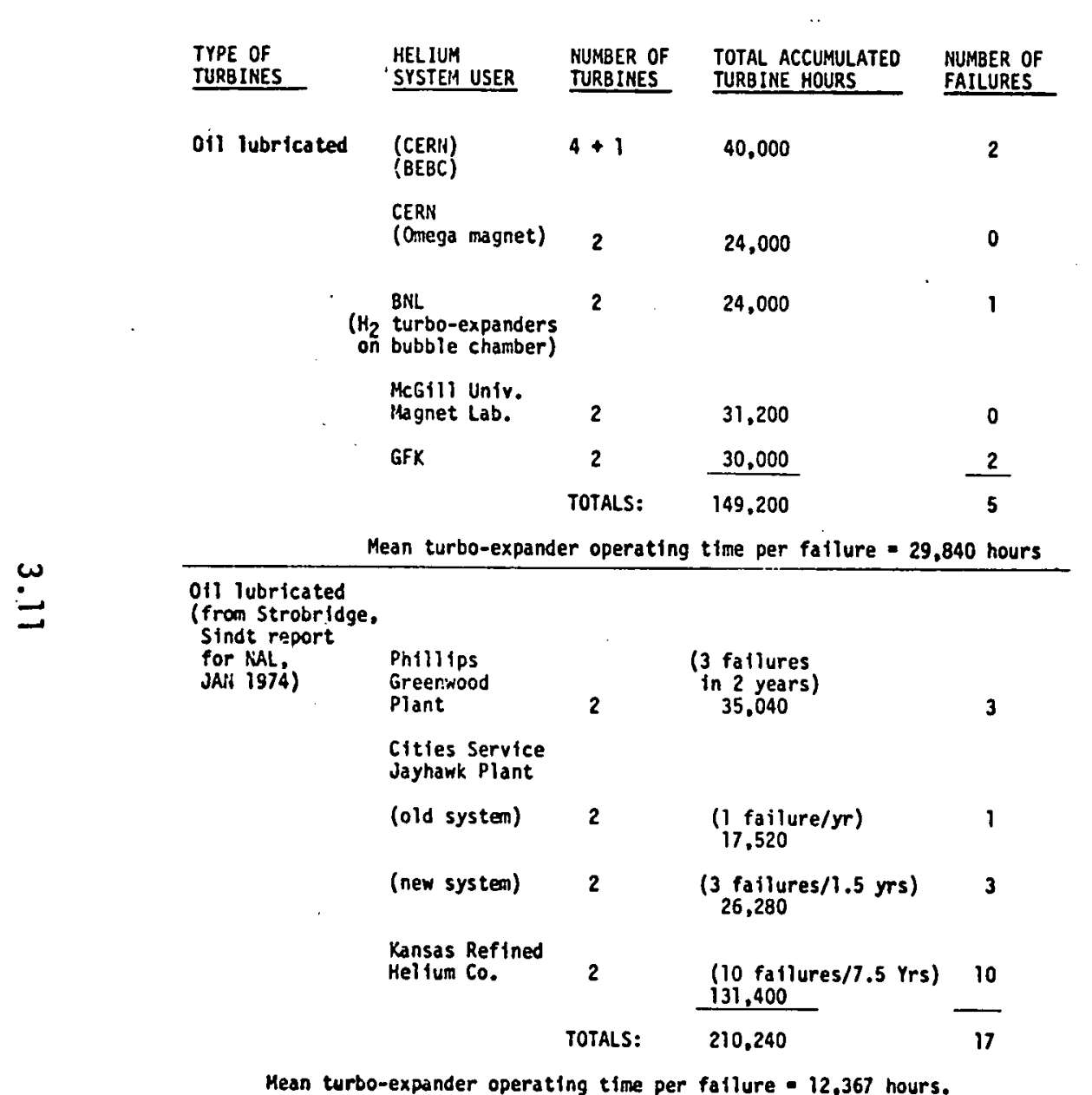

Grand total for all ofl lubr

turbo-expanders:

359,440

22

Mean ofl lube turbo-expander operating hours per fallure $=16.340$

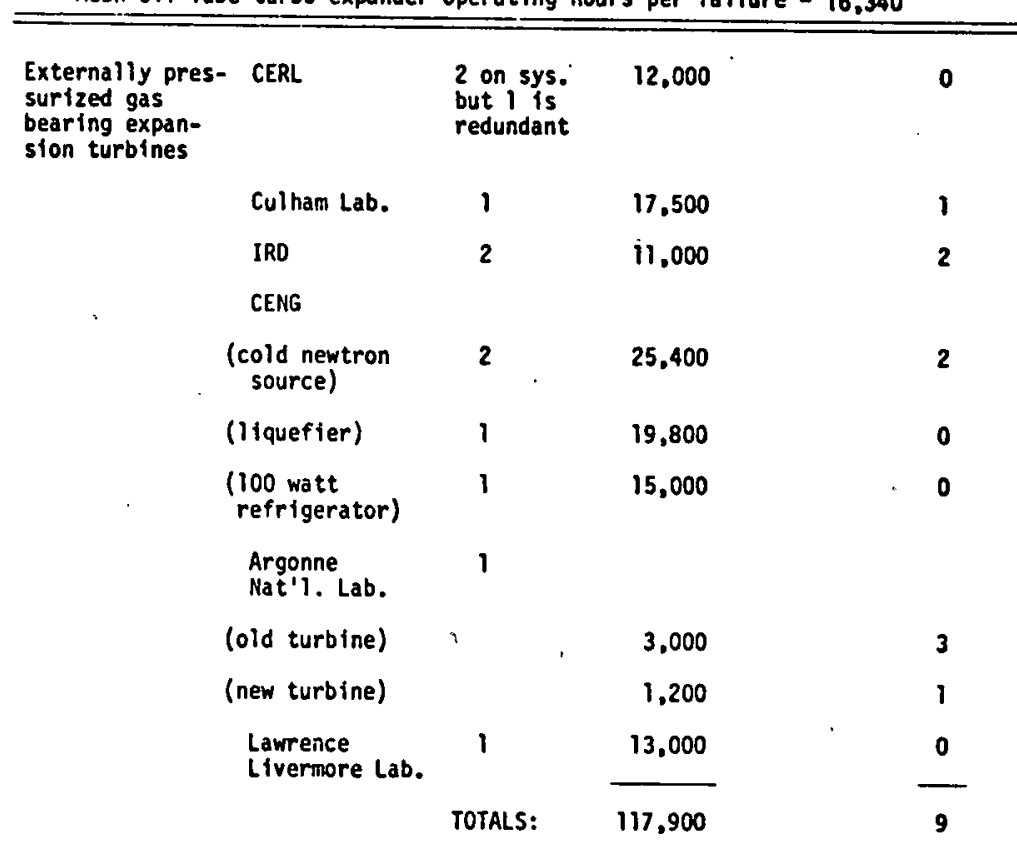

Mean ext. pressure gas bearing turbo-expander operating hours per fallure $=13,100$ hrs.

Self-actu-
ating gas
bearing
turbo-
expander

Mean operating hours per turbine for self actuating gas bearing unit $=22,000$ hours 
a lack of a large amount of operating experience, some of the gas bearing turbine units had extremely long run-in periods; in fact, some of the units may be only now emerging from the run-in or "learning" phases of operation. It obviously would not be fair to assign externally pressurized gas bearing turbines a MTBF of 13,100 hours. Also, a single run of 22,000 hours for the self-actuating turbine is hardly sufficient to judge the merits of this unit.

It is clear from this survey that considerably more data is required before any attempt can be made to select one turbine over another (in overlapping operating ranges) for a particular application. For this reason, no attempt is later made to apply any form of optimization criteria to the individual turbine types; instead, it is assumed that all three types of turbines can attain a MTBF of 25,000 hours (assuming all run-in problems solved). It is this value of MTBF which is used in the system reliability analysis of the present investigation.

\subsubsection{Dry Lube Reciprocating Compressor Experience}

The two primary types of compressors encountered during the helium refrigerator user visits were dry lube reciprocating compressors and labyrinth seal reciprocating compressors.

Table 3.3 lists all the failures and maintenance requirements of the dry lube reciprocating compressors encountered during the APCI helium refrigerator user visits. As indicated by the notes in table 3.1 , many of these machines were air compressors which had been modified for helium service.

The total cumulative operating time logged by these units was 73,700 hours ( 8.4 years) during which time seventeen failures of note occurred; this works out to a mean operating time between failures of 4,335 hours. On the basis of this calculation, the compressor optimization study carried out in section 8.0 , uses a value of 5,000 hours for the dry lube compressor MTBF. This agrees favorably with the MTBF of 4,000 hours supplied by one of the compressor manufacturers 1 isted in table 4.2 .

\subsubsection{Labyrinth Seal Reciprocating Compressor Experience}

Table 3.4 lists all the failures and maintenance requirements of the labyrinth seal reciprocating compressors encountered during user visits. 
TABLE 3.3

DRY LUBRICATED RECIPROCATING COMPRESSOR

FAILURE AND MAINTENANCE SUMMARY SHEET

\begin{tabular}{|c|c|c|c|c|c|c|}
\hline SYSTEM USER & $\begin{array}{l}\text { COMPRESSOR } \\
\text { OPERATING } \\
\text { TIME } \\
\text { (HRS) } \\
\end{array}$ & $\begin{array}{l}\text { NUMBER OF } \\
\text { REPORTED } \\
\text { FAILURES }\end{array}$ & $\begin{array}{l}\text { RECOMMENDED } \\
\text { MAINTENANCE } \\
\text { INTERVAL }\end{array}$ & $\begin{array}{l}\text { TURNAROUND } \\
\text { TIME } \\
\text { (MAN-HRS) }\end{array}$ & $\begin{array}{l}\text { VALVE LIFE } \\
\text { (HRS) }\end{array}$ & $\begin{array}{l}\text { RING LIFE } \\
\text { (HRS) }\end{array}$ \\
\hline $\begin{array}{l}\text { Central Electrical } \\
\text { Research Laboratory }\end{array}$ & 18,000 & 4 & 2,000 & 16 & 3,000 & 3,000 \\
\hline Culham Laboratory & 17,500 & 3 & 3,000 & 64 & - & - \\
\hline $\begin{array}{l}\text { Argonne National } \\
\text { Laboratory }\end{array}$ & 4,200 & 5 & 3,000 & - & 8,000 & - \\
\hline $\begin{array}{l}\text { Brookhaven National } \\
\text { Laboratory }\end{array}$ & - & - & 3,000 & - & - & 3,000 \\
\hline $\begin{array}{l}\text { Cities Service } \\
\text { Jayhawk Helium Plant }\end{array}$ & & & & . & & \\
\hline old liquefier & - & - & - & - & - & 2,200 \\
\hline new liquefier & - & - & - & - & - & 2,200 \\
\hline $\begin{array}{l}\text { Kansas Refined } \\
\text { Helium Co. }\end{array}$ & - & - & - & - & - & $\begin{array}{l}\text { (check) } \\
\text { (co0 } \\
\text { (check }\end{array}$ \\
\hline $\begin{array}{l}\text { Lawrence Livermore } \\
\text { Laboratory }\end{array}$ & 19,000 & 3 & 3,000 & - & $\begin{array}{c}2,000 \\
\text { (check) }\end{array}$ & \multirow{2}{*}{$\begin{array}{c}6,000 \\
-(\text { rotate every } \\
2,000) \\
-\end{array}$} \\
\hline $\begin{array}{l}\text { Gesellshaft Fur } \\
\text { Kernforschung (GFK) }\end{array}$ & 15,000 & 2 & 8,000 & - & $\begin{array}{l}8,000 \\
\text { (check) }\end{array}$ & \\
\hline \multirow[t]{2}{*}{ TOTAL } & 73,700 & 17 & & & & \\
\hline & \multicolumn{6}{|c|}{ MEAN OPERATING TIME BET } \\
\hline
\end{tabular}


TABLE 3.4

LABYRINTH SEAL RECIPROCATING COMPRESSOR FAILURE AND

MAINTENANCE SUMMARY SHEET

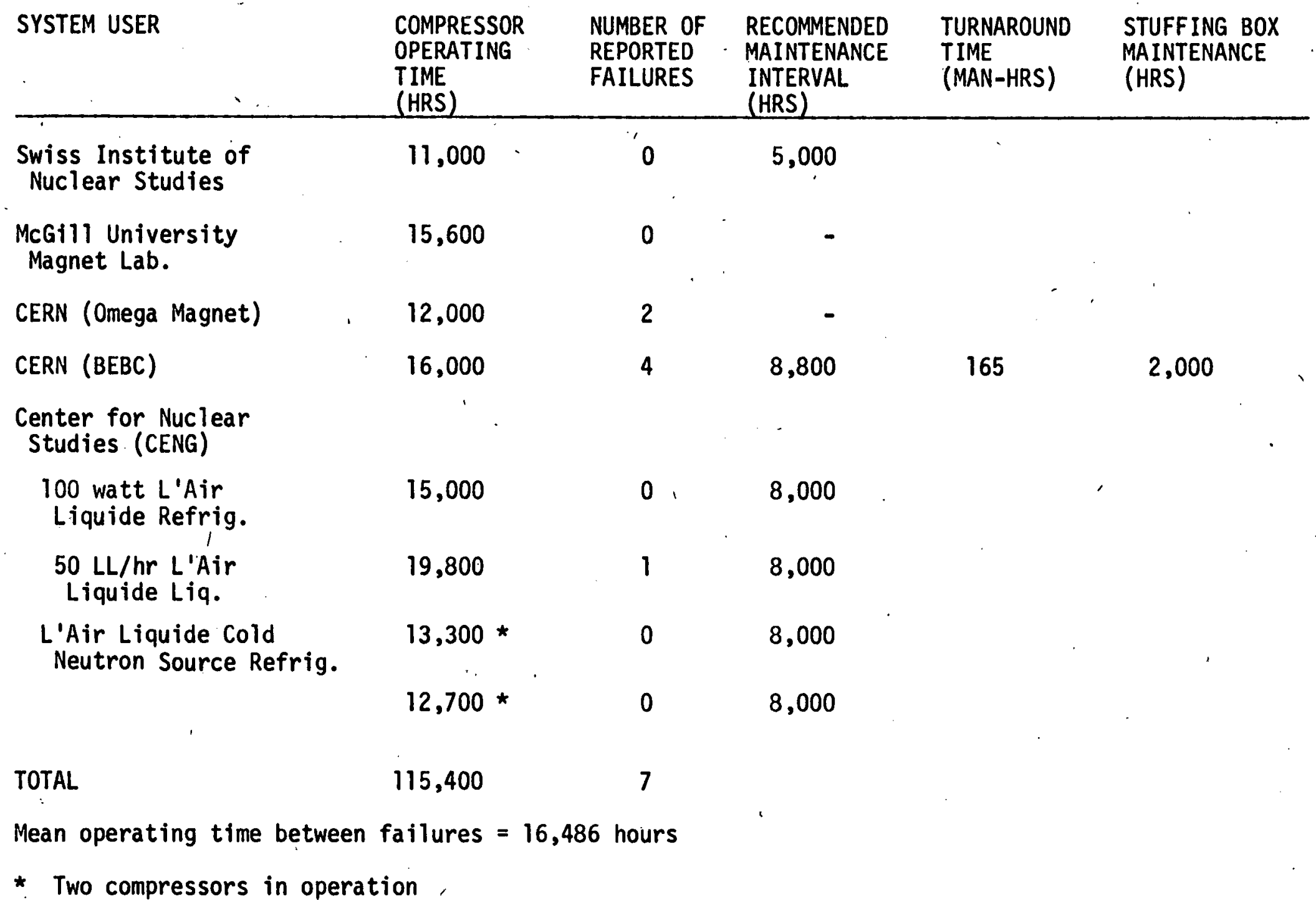


The total cumulative operating hours logged by these units was 115,400 (13.2 years) during which time seven failures of note occurred; this corresponds to a mean operating time between failures of 16,486 hours. On the basis of this calculation, the labyrinth seal compressor MTBF, used in the analysis of section 8.0 , is 17,000 hours. 


\subsection{REFRIGERATION SYSTEM COMPONENT CHARACTERISTICS}

\subsection{HELIUM REFRIGERATOR MANUFACTURER SURVEY}

A questionnaire was sent out to major helium refrigerator manufacturers in order to ascertain their refrigerator recommendations relative to the requirements of a superconducting power transmission line. The questionnaire reproduced in Appendix $A$ encompasses both state-of-the-art refrigeration systems as well as recommendations on development required to bring the reliability and performance of the system components up to the level required by the power transmission lines.

In order to obtain a standard of comparison, the manufacturers were asked to comment on a system which would meet the BNL requirements listed in table 2.1.

- The manufacturers were allowed the freedom of specifying either a refrigerator connected directly to the line or a refrigerator linked only thermally to a closed, pumped, transmission line loop via a heat exchanger.

The manufacturers who responded were:

1. Airesearch Manufacturing Co.

2. British Oxygen Co., Ltd.

3. CTI Cryogenics

4. CVI

5. L'Air Liquide

6. Linde $A G$

7. Sulzer Bros., Ltd.

8. Union Carbide - Linde Div.

A summary of these manufacturers' responses is given in table 4.1. Of particular interest in this survey is the response of manufacturers to the inquiry asking for an assessment of the level of development required in order to bring the critical refrigerator components up to a higher level of reliability. The following summarizes the general trends in the responses for each component.

* Compressor - Two of the manufacturers agreed that the use of centrifugal compressors for helium applications would require a major development effort. They also felt that a modest effort was required to optimize oil lube screw compressors for helium service and to provide adequate means for hydrocarbon detection of oil separator breakthrough. 
TABLE 4.1

HEL IUM REFRIGERATOR STATE-OF-THE-ART AND FUTURE TRENDS

\begin{tabular}{|c|c|c|c|c|c|c|c|c|}
\hline & & & RESPONDENTS & & & & & \\
\hline MANUFACTURING RECOMMENDATIONS & $1 *$ & 2 & 3 & 4 & 5 & 6 & 7 & 8 \\
\hline EXPANDER & $\begin{array}{l}\text { - Major devel. } \\
\text {-minimize ele- } \\
\text { ments, process } \\
\text { gas bearings }\end{array}$ & $\begin{array}{l}\text { - Modest devel. } \\
\text {-cannot eastly } \\
\text { preclude o1l } \\
\text { lube or dyn- } \\
\text { amic gas brgs. } \\
\text { (need study) }\end{array}$ & $\begin{array}{l}\text {-Modest devel. } \\
\text {-expand current } \\
\text { designs into } \\
\text { larger sizes }\end{array}$ & $\begin{array}{l}\text { Present state- } \\
\text { of -art } 0 . x \text {. }\end{array}$ & $\begin{array}{l}\text { Present state- } \\
\text { of-art } 0 . K \text {. }\end{array}$ & $\begin{array}{l}\text { Major devel. } \\
\text {-expander loading }\end{array}$ & $\begin{array}{l}\text { Present state- } \\
\text { of-art } 0 . K_{\text {. }}\end{array}$ & $\begin{array}{l}\text { - Hodest devel. } \\
\text {-bearings }\end{array}$ \\
\hline CIRCULATING PUMP & -Modest devel. & -Modest devel. & $\begin{array}{l}\text { - Major devel. } \\
\text {-centrifugal pump } \\
\text { with } 70 x \text { adfiab. } \\
\text { efficlency }\end{array}$ & Major devel. & Major devel. & -- & -- & $\cdots$ \\
\hline CONTROLS & $\begin{array}{l}\text {-Modest devel. } \\
\text { - Integration } \\
\text { of controls }\end{array}$ & $\begin{array}{l}\text {-Modest devel. } \\
\text {-automattc con- } \\
\text { trol of total } \\
\text { system }\end{array}$ & $\begin{array}{l}\text {-Present state-of } \\
\text { art 0.K. }\end{array}$ & -Modest devel. & -Modest devel. & $\begin{array}{l}\text {-Modest devel. } \\
\text {-rel lability }\end{array}$ & $\begin{array}{l}\text { Present state- } \\
\text { of-art } 0 . K \text {. }\end{array}$ & $\begin{array}{c}\text { Present state- } \\
\text { of -art } 0 . K \text {. } \\
.\end{array}$ \\
\hline HELIÜM PURIFIER & Modest devel. & $\begin{array}{l}\text { - Present state } \\
0 . K \text {. } \\
\text {-address prob. } \\
\text { of inttial } \\
\text { clean-up }\end{array}$ & $\begin{array}{l}\text { - Mosest devel. } \\
\text {-automatic con- } \\
\text { trol of total } \\
\text { system }\end{array}$ & $\begin{array}{l}\text {-Presenit state } \\
0 . K_{\text {. }}\end{array}$ & Modest devel. & $\begin{array}{l}\text {-Present state } \\
0 . x \text {. }\end{array}$ & Modest devel. & $\begin{array}{l}\text {-Present state } \\
\text { O.K. }\end{array}$ \\
\hline $\begin{array}{l}\text { OIL CLEAN-UP PACKAGE } \\
\text { (if ofl lube compr. used) }\end{array}$ & $\begin{array}{l}\text { - Modest devel. } \\
\text {-definition of } \\
\text { allowable levels } \\
\text { of contamination }\end{array}$ & $\begin{array}{l}\text { Present state } \\
0 . \text { K. } \\
\text { - must design for } \\
\text { each specific } \\
\text { application }\end{array}$ & $\begin{array}{l}\text { - Modest devel. } \\
\text { - instrumentation } \\
\text { for oll detection }\end{array}$ & -Modest devel. & $\cdot$ & $\cdots$ & -- & $\begin{array}{l}\text {-Present state } \\
0 . K \text {. }\end{array}$ \\
\hline OPHER POTENTIAL PROBLEMS & $\begin{array}{l}\text { Rellability of } \\
\text { control and } \\
\text { monitoring } \\
\text { equipment }\end{array}$ & $\begin{array}{l}\text {-Problems of re- } \\
\text { sponse of refrig. } \\
\text { to changes in } \\
\text { line conditions } \\
\text {-may require } \\
\text { spectal damping }\end{array}$ & $\therefore$ & $-\cdot$ & $\cdots$ & $\begin{array}{l}\text { Hel fum storage, } \\
\text { nitrogen pumps, } \\
\text { reliablitity of } \\
\text { power supply }\end{array}$ & $\cdots$ & $\cdots$ \\
\hline OTHER COMMENTS - & -- & -- & $\begin{array}{l}\text { Suggest devel. } \\
\text { of centrifugai } \\
\text { compr. with } \\
\text { at least } 70 \% \\
\text { addalb. } \\
\text { efficiency }\end{array}$ & $\begin{array}{l}\text { Room for Improve- } \\
\text { ment in heat } \\
\text { exchanger types }\end{array}$ & $\cdots$ & -- & -- & 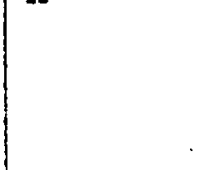 \\
\hline $\begin{aligned} & \text { NOTES * } \text { Respondent answered } \\
& \text { equifment which shou } \\
& \text { with transmission } 1\end{aligned}$ & $\begin{array}{l}\text { ire in terms of pr } \\
\text { stem requirements } \\
\text { ment time frame. }\end{array}$ & $\begin{array}{l}\text { rojected } \\
\text { consistent }\end{array}$ & & & & & & \\
\hline
\end{tabular}


TABLE 4.1

\section{HELIUM REFRIGERATOR STATE-OF-THE-ART AND FUTURE TRENDS}

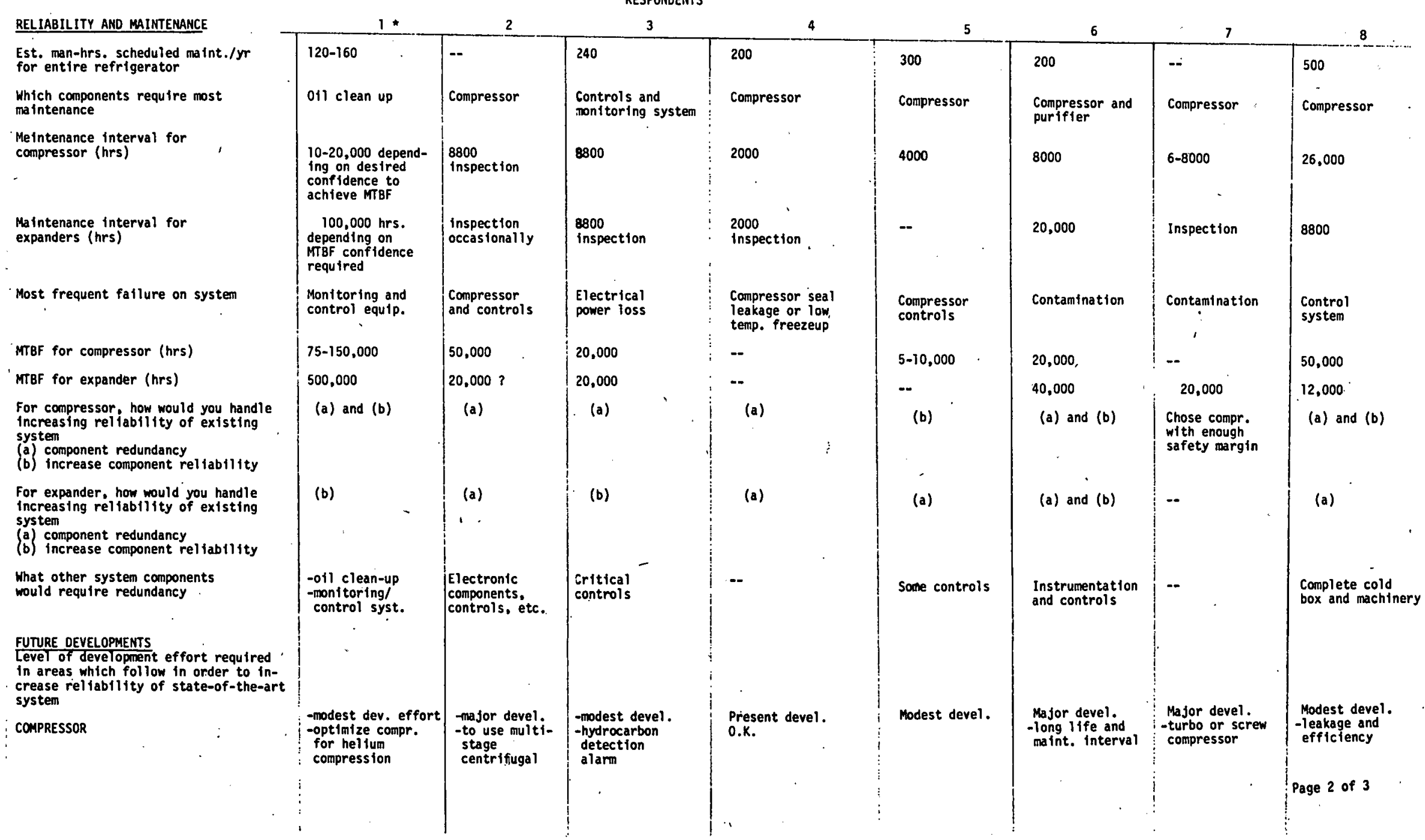


TABLE 4.1

HELIUM REFRIGERATOR STATE-OF-THE-ART AND FUTURE TRENDS




* Expanders - Most of. the manufacturers agree that current gas and oil bearing turbine technology is adequate or that only a modest development effort is warranted.

* Circulating Pumps - Major or modest development required.

* Controls - Modest development effort required or present technology adequate.

* Helium Purifier - Present state adequate or modest effort required.

* 0il Clean-Up Package - Range from modest to no development required. Need to define an allowable limit and to adequately detect any oil carry-over.

* Other Potential Problems - Need to investigage problems related to response of refrigerator to changes in line conditions. Also should look into helium storage and the reliability of the refrigerator power supply.

\subsection{COMPRESSORS}

\subsubsection{Compressor Questionnaire}

At the beginning of the present study, helium compressors were perceived as a major item of initial cost, maintenance cost, unreliability, and as having a significant influence on the power input. For these reasons, the compressor was singled-out for the most extensive investigation. This was done by means of a questionnaire soliciting information from manufacturers followed by interpretation of the responses based on APCI experience with compressors.

Most of the large helium systems in operation today use dry lubricated or labyrinth seal reciprocating compressors. Several recent applications of oil flooded screw compressors for helium has generated a great deal of interest in their use in future helium systems. They have thus been given special attention. It is recognized also that centrigufal compressors are typically preferred in large capacity applications and they are thus included in a generalized way since there are no applications at present for large centrifugal helium compressors.

Compressor manufacturers were solicited to gain information relating to compressor operating characteristics, maintenance, reliability, cost and 
possible trends in future development. For each type of compressor, information was sought regarding the advantages of modifying the compression cycle through the use of oil injection, water injection, or possibly the increase in apparent gas molecular weight through the use of high molecular weight gases such as Freon-12.

In order to obtain some commonality in the size compressor for which information was sought, the manufacturer was asked to comment on two flow ranges for a specific set of operating pressures. The two flow ranges correspond approximately to the sizes required for the Brookhaven and Los Alamos designs assuming one large refrigerator or two half size refrigerators at each station. The conditions specified were:

* Flow range \#1: 2400-4500 SCFM

* Flow range \#2: 5000-10,000 SCFM

* Pressure levels: $15 \mathrm{~atm} / 3 \mathrm{~atm}$ absolute

* Cooling: water-cooling at $85^{\circ} \mathrm{F}$

* Cost: 10 identical units

Appendix $B$ contains a copy of the questionnaire. Most questionnaires were returned with descriptive literature that gave additional information. Some of the responses were in letter form, telephone calls, or visits.

Table 4.2 summarizes the results of the survey with compressors grouped by type. In order to establish a common cost basis, the cost of the additional components that would be included on a compressor as it is shipped from the factory were added as needed. Costs were estimated based on current price experience with similar units. Motor costs are for open $2,300 \mathrm{~V}$, induction-type motors coupled direct to the drive shaft. Controls include the motor starter and protective-type devices. Administration cost of $30 \%$ is added to cover the overhead costs of specifying and purchasing equipment. Other costs that are not included in this cost are shipping, foundations, installation, installed power charge (about $133 \$ / \mathrm{kw}$ on Long Island), a protective building, and start-up and acceptance testing.

Most of the compressor manufacturers quoted the efficiency in the conventional way of adiabatic efficiency per stage or, in the case of turbine compressors, per casing. In order to compare compressors with different numbers of stages on a common bas is the efficiencies were converted to isothermal efficiency. The cases where a gas mixture is assumed are not reduced to a common efficiency because the present processes do not define a use for the second fluid. 
TABLE 4.2

COMPRESSOR SURVEY

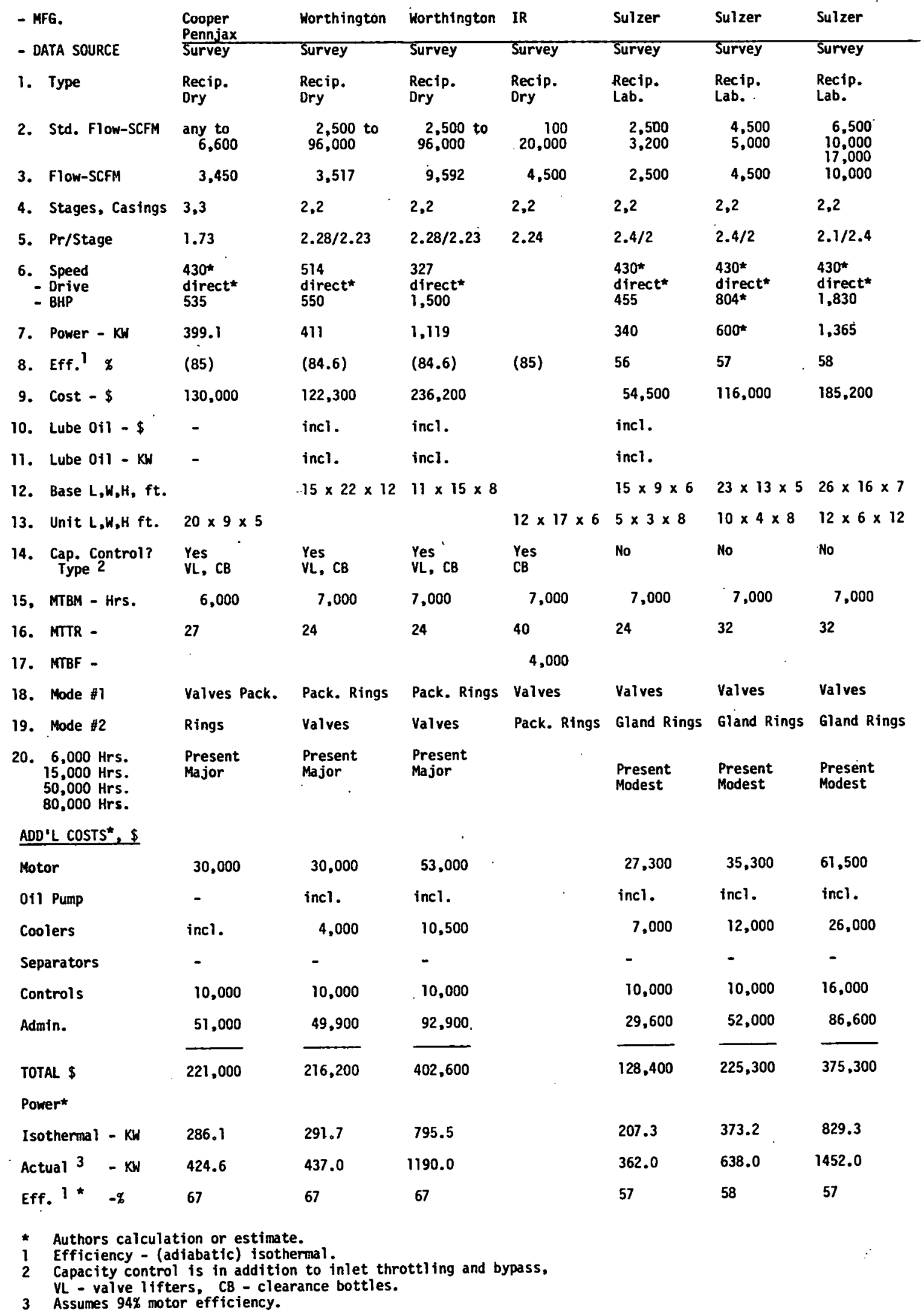


TABLE 4.2

COMPRESSOR SURVEY

\begin{tabular}{|c|c|c|c|c|c|c|}
\hline $\begin{array}{l}\text { - MFG. } \\
\text { - DATA SOURCE }\end{array}$ & $\begin{array}{l}\text { D-B } \\
\text { Visit }\end{array}$ & $\frac{\text { GHH }}{\text { Survey }}$ & $\begin{array}{l}\text { Hounden } \\
\text { Survey }\end{array}$ & $\begin{array}{l}\text { Howden } \\
\text { Survey }\end{array}$ & $\frac{\text { IR }}{\text { Survey }}$ & $\frac{\text { Sullair }}{\text { Tel. Conver. }}$ \\
\hline 1. Type & $\begin{array}{l}\text { Screw } \\
\text { 0il }\end{array}$ & $\begin{array}{l}\text { Screw } \\
\text { Oil }\end{array}$ & $\begin{array}{l}\text { Screw } \\
011\end{array}$ & $\begin{array}{l}\text { Screw } \\
\text { 011 }\end{array}$ & $\begin{array}{l}\text { Screw } \\
\text { Dry }\end{array}$ & $\begin{array}{l}\text { Screw } \\
\text { oil }\end{array}$ \\
\hline 2. Std. Flow-SCFM & $\begin{array}{l}2,500 \\
4,000\end{array}$ & $\begin{array}{l}2,300 \\
3,660\end{array}$ & $\begin{array}{l}2,900 \\
4,300\end{array}$ & $\begin{array}{r}8,700 \\
17,000\end{array}$ & $\begin{array}{r}200 \\
50,000\end{array}$ & $\begin{array}{l}2,100 \\
4,100\end{array}$ \\
\hline 3. Flow - SCFM & 3,000 & 3,660 & 3,800 & 8,700 & 6,000 & 4,100 \\
\hline 4. Stages, Casings. & 1,1 & 1,1 & 1,1 & 1,1 & 2,2 & 1,7 \\
\hline 5. $\mathrm{Pr} /$ Stage & 5 & 5 & 5 & 5 & 2.24 & 5 \\
\hline $\begin{array}{l}\text { 6. Vr } \\
\text { - Drive } \\
\text { - Seal }\end{array}$ & $\begin{array}{l}3.6 \\
\text { Direct } \\
\text { Hermetic }\end{array}$ & $\begin{array}{l}4.4 \\
\text { Gear } \\
\text { Shaft }\end{array}$ & $\begin{array}{l}3.6 \\
\text { Direct } \\
\text { Shaft }\end{array}$ & 3.6 & $\begin{array}{l}\text { Gear } \\
\text { Shaft }\end{array}$ & $\begin{array}{l}3.7 \\
\text { Direct } \\
\text { Shaft }\end{array}$ \\
\hline 7. Power - KH & $490^{\star}$ & 580 & 590 & 1,270 & $1,012 \star$ & \\
\hline 8. Eff. ${ }^{1}-q$ & & (71) & (78) & (74) & (58) & \\
\hline 9. Cost - \$ & 35,000 & 9,200 & 41,000 & 47,000 & 400,000 & \\
\hline 10. Lube 011 - \$ & Not incl. & Not incl. & Incl. & Incl. & Incl. & \\
\hline 11. Lube 011 - $\mathrm{KH}$ & $5 *$ & $6 *$ & 5.2 & 10 & & \\
\hline 12. Base $L, H, H$ ft. & & & None & None & & \\
\hline 13. Unit $L, W, H$ ft. & & & $13 \times 4 \times 9$ & $15 \times 5 \times 9$ & & \\
\hline 14. Cap. Cpgntrol? & $\begin{array}{l}\text { Yes } \\
\text { Stide Valve }\end{array}$ & No & $\begin{array}{l}\text { Yes } \\
\text { Slide Valve }\end{array}$ & $\begin{array}{l}\text { Yes } \\
\text { slide Valve }\end{array}$ & No & $\begin{array}{l}\text { Yes } \\
\text { Slide Valve }\end{array}$ \\
\hline 15. MT8M - Hrs. & · & 5,000 & 50.000 & 50,000 & 16,000 & \\
\hline 16. MTTR - & & 2 & 20 & 20 & 40 & \\
\hline 17. MTBF - & & 50,000 & & & 50,000 & \\
\hline 18. Mode 71 & Bearings & Oper. Error & Slide Valve & Seal & Seal & \\
\hline 19. Mode 12 & & Maint. Error & Thrust & Bearings & Instr. & \\
\hline $\begin{array}{r}6,000 \text { Hrs. } \\
15,000 \text { Hrs. } \\
50,000 \text { Hrs. } \\
80,000 \text { Hrs. }\end{array}$ & Present & $\begin{array}{l}\text { Present } \\
\text { Major }\end{array}$ & $\begin{array}{l}\text { Present } \\
\text { Major }\end{array}$ & $\begin{array}{l}\text { Present } \\
\text { Major }\end{array}$ & Present & \\
\hline \multicolumn{7}{|l|}{ ADD'L COSTS*. $\$$} \\
\hline Motor & Incl. & 15,900 & 15,900 & 26,400 & Incl. & \\
\hline O11 Pump & 2,500 & 2,500 & Incl. & Incl. & Incl. & \\
\hline Coolers & Incl. & .11,500 & Incl. & Incl. & Incl. & \\
\hline Separators & 9,600 & 11,500 & Incl. & Incl. & Incl. & \\
\hline Controls & 10,000 & 10,000 & 10,000 & 16,000 & Incl. & \\
\hline Admin. & 17,100 & 18,200 & 20,100 & 26,800 & 120,000 & . \\
\hline TOTAL \$ & 74,200 & 78,800 & 87,000 & 116,200 & 520,000 & \\
\hline \multicolumn{7}{|l|}{ Power" } \\
\hline Isothermal - KW & 248.8 & 303.5 & 315.1 & 721.5 & 497.6 & \\
\hline Actual $3-K M$ & 527.0 & 624.0 & 633.0 & $1,362.0$ & $1,076.0$ & \\
\hline Eff. $.^{*}-q$ & 47 & 49 & 50 & 53 & 46 & \\
\hline
\end{tabular}


TABLE 4.2

COMPRESSOR SURVEY

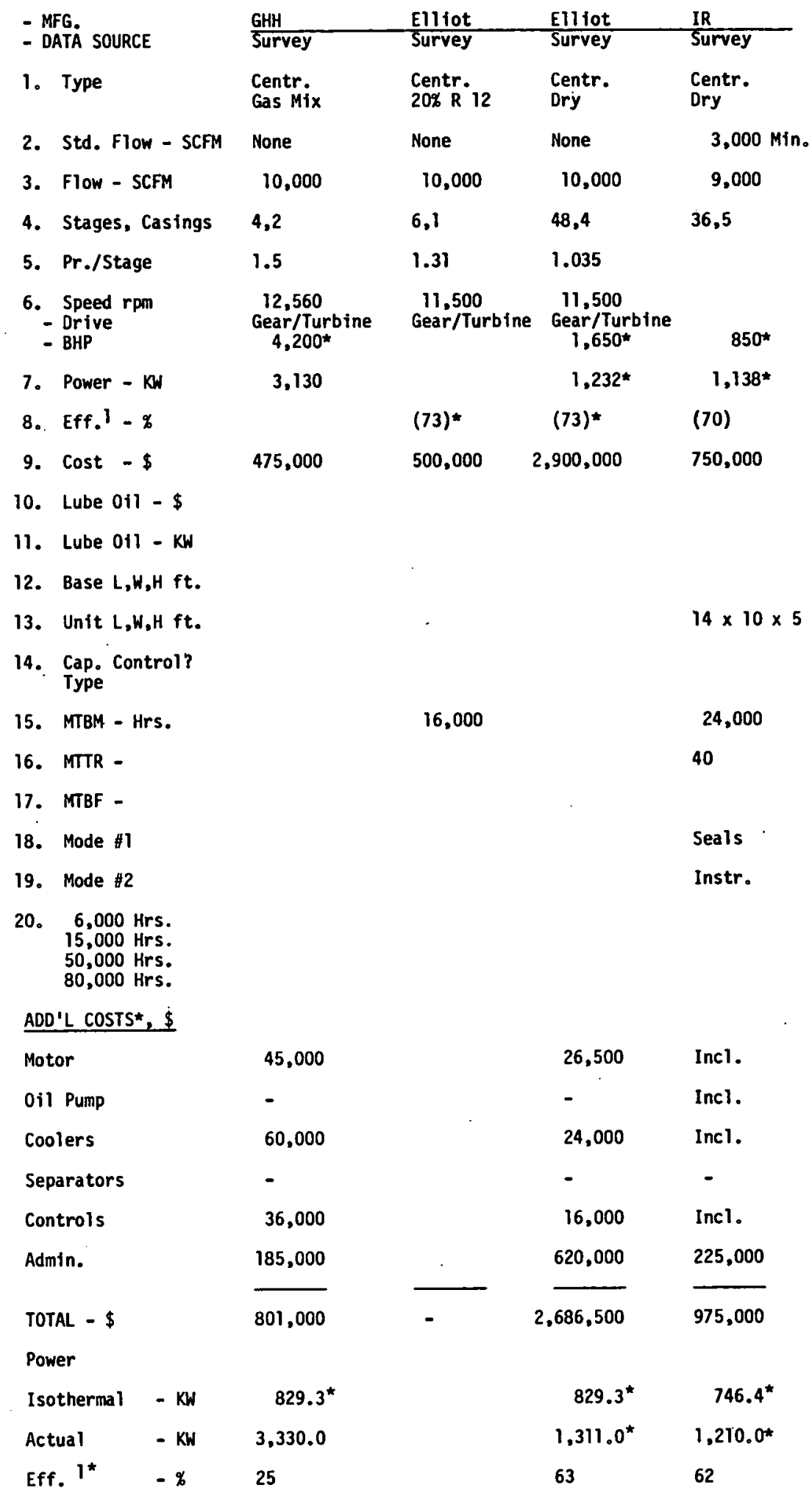




\subsubsection{Reciprocating Compressors}

Cooper Penjax, Ingersoll-Rand, and Worthington were solicited for information on dry lubricated reciprocating compressors which are characteristic of those which are also manufactured by several other companies. This kind of compressor is widely used in present large helium refrigerators and is known to have a relatively high failure rate and to require frequent maintenance. Another disadvantage which is not reflected in the results of the survey is the loss of helium in the packings which typically amount to about $1 / 4 \%$ of the throughput.

The main asset of this kind of compressor is its high efficiency which combined with its moderate cost and widespread availability have made them so popular. Valve failure is the most common cause of random failure while ring and packing wear are the primary cause of frequent scheduled maintenance. Repair and maintenance times are relatively long because of the large size of the components involved.

Manufacturers expressed the opinion that additional development work in improving valves, piston rings, and packings could extend the failure and maintenance intervals but it would be difficult to exceed 15,000 hours for either. It is also possible with special packing glands to trap the gas that leaks in the present units so it can be recovered. A new piston design has recently been announced which is similar to the labyrinth seal concept and is claimed to achieve a longer life [0.14].

The second most commonly used compressor in present large helium refrigerators is the Sulzer labyrinth seal unit [D.5]. It shares with the dry lubricated compressors the problems of valve failures, packing wear and leaking but has essentially eliminated ring wear and failure as sources of problems. The better reliability and slightly lower cost are somewhat offset by the lower efficiency.

\subsubsection{Screw Compressors}

The use of oil flooded screw compressors for helium service is receiving widespread interest because of their high reliability and relatively low cost. This has come about because oil removal systems on smaller reciprocating compressors have proven to be effective and reliable, $[0.6,7,8,9]$. Since screw compressors were considered to be prime candidates for the next generation of large helium refrigerators, they were studied in more detail than the other compressor types. The following paragraphs summarize the results of this effort. 
The first screw compressor is credited as having been built by Heinrich Krigar of Germany in 1880. The concept lay dormant until the late 1930's when Lysholm of Sweden developed a screw compressor that truly represents those built today. In recent years SRM (Svenska Rotor Maskiner), a Swedish based technology firm has acquired and developed screw compressor design and manufacturing technologies. All of the companies presently manufacturing screw compressors operate as licensees of SRM. As a result, all of the rotor configurations are standardized and the performance of all screw compressor rotors is similar. Differences between screw compressors made by different companies include such things as dry vs. oil injection, sleeve vs. anti-friction bearings, gear drive vs. direct drive, and open vs. hermetic motor.

Dry screw compressors operate at tip speeds about 3 to 4 times faster than oil flooded machines. Pressure ratios in the dry machine are generally limited to less than $3: 1$ because of gas leakage at the rotor tips and because a high gas temperature rise can destroy the rotor. All of the oil flooded machines inject oil at the inlet to keep the discharge gas below $200^{\circ} \mathrm{F}$. $0 i 1$ injection permits higher pressure ratios, thus there is no problem in compressing from 3 to 15 atm absolute in one stage.

The type of bearing used by most manufacturers depends on the trade-offs between bearing life, cost, and efficiency. In general the dry compressors operating at lower pressure loading use the anti-friction roller bearings while most of the oil flooded machines use sleeve bearings.

Dry screw compressors usually have the rotor driven through gears that permit it to be run faster than the motor. This also permits the manufacturer to offer a range of displacements with a single rotor merely by changing gears. It also permits multi-staging with a single motor. Many of the oil flooded screw compressors are direct driven and operate at 3,000 to $3,450 \mathrm{rpm}$. These cover the range of 100 to $6,000 \mathrm{CFM}$ displacement and 10 to $32 \mathrm{~mm}$ rotor diameter. In most cases screw compressors are driven by electric motors, however, turbine driven compressors are not uncommon.

The development of oil flooded screw compressors has taken place for the most part within the past fifteen years. The major application today is for use as air compressors. Within the past ten years they have been applied to compressing refrigerants in commercial air-conditioning systems in the 150 to $700 \mathrm{HP}$ range and most recently have competed with reciprocating compressors in the 50 to $150 \mathrm{HP}$ range for the same application. Dunham-Bush (D-B) has recently developed a hermetic screw compressor in which the motor is directly connected to the rotor and they are both contained in a common housing. The hermetic compressor eliminates the shaft seal, thus permitting a gas tight system to be built. The D-B unit is designed so that the compressed gas/oil mixture passes through the motor 
to provide cooling.

Screw compressor manufacturers and their compressor characteristics are summarized in table 4.3. This table was compiled from information contained in catalogs and papers in addition to the direct responses to the survey questionnaire as listed in table 4.2. At present there are many large screw compressors being used in industrial applications. Most of these are dry because the gases being handled cannot have contaminants introduced. 0il lubricated screw compressors in the middle size range, 100 to $700 \mathrm{HP}$, are being used primarily in refrigeration systems in which some oil circulates through the entire system with the refrigerant. Small oil lubricated screw compressors are being mass produced almost exclusively as air compressors. These are single stage units with delivery pressures in the range of 75 to 125 psig.

The first application of a screw compressor in a helium refrigeration system was by Linde A. G. around 1965 using a dry machine. This unit suffered from poor efficiency and mechanical problems and was subsequently replaced with a reciprocating unit.

A Howden oil flooded screw machine was installed on a system at IRD around 1970 with acceptable performance from the compressor, but problems in the oil clean-up system were not resolved. A similar unit recently installed at Westinghouse is reported to be operating satisfactorily now. These are both direct drive units of about $300 \mathrm{HP}$ operating from 15 to 125 psia in a single stage, [B.3].

Mycom (Mayekawa Mfg. Co.) of Japan reported last summer [0.7] the successful testing of a two-stage hermetic oil flooded screw compressor with helium.

Brookhaven National Laboratory is currently testing a $150 \mathrm{HP}$ D-B oil flooded hermetic compressor at suction pressures from 6 to $45 \mathrm{psia}$ and discharge pressures to $260 \mathrm{psia}$. They report efficiencies relative to isothermal work in the range of 40 to $50 \%$ and volumetric efficiencies of 79 to $98 \%$ depending on 0 il injection rates. Their compressor has a built in volume ratio of $4.1: 1$ which is optimum for a pressure ratio of about c $10: 1$. They have been able to operate the $150 \mathrm{HP}$ motor at $200 \mathrm{HP}$ power input by adding oil injection ports on the motor which improved the motor cooling.

Other characteristics of the oil flooded screw compressors that make them attractive are their relatively low noise level and slide valve capacity control. The slide valve permits operation down to $25 \%$ of maximum throughput with only small loss of efficiency. This would permit a compressor to be adjusted to match the actual heat load without a significant penalty in efficiency. All screw compressors share in being well balanced and they 
TABLE 4.3

SCREW COMPRESSOR MANUFACTURERS AND CHARACTERISTICS

MANUFACTURER

Altas Copco - Belgium

Atlas Copco - Belgium

'Beloit Power Syst.- U.S.

Demag - Germany

Dunham-Bush - U.S.

Dunham-Bush - U.S.

Dunham-Bush - U.S.

Gardner Denver - U.S.

Howden - England

Ingersoll Rand - U.S.

Ingersoll Rand - U.S.

Mycom - Japan

Sterkrade (GHH) Germany

Sulair - U.S.
USE

Air ${ }^{\star 2}$

Ind:

Ind.

Ind.

Refrig. 150-750

Refrig. $\quad 50-750$

Air

Air

Ind.

Air

Ind.

Ind.

Ind.

Ind.

HP

$25-75$

$75-750$

$5-1,500$

$50-350$
$100-5,000$

$200-1,250$

Dry

0i) Direct Shaft

0il Direct Hermetic

0il Direct Shaft

0il Direct Shaft

0il Direct Shaft

0il Direct Staft $200-8,000$

$100-2,000$
Dry 'Gear Shaft

0il Direct Shaft

oil Direct Shaft

0il Direct Shaft

1 Formerly Fairbanks Morse.

*2 Air Compressor

*3 Industrial 
thus require small pads. It is conceivable that a spare screw compressor could be truck mounted and connected into a station where needed faster than a unit can be repaired.

From table 4.2 it is seen that the manufacturers of oil flooded screw compressors who responded to the questionnaire anticipate the isothermal efficiency for a single stage unit to be about $50 \%$. This is low compared with reciprocating units and yet in air-conditioning applications where these compressors are replacing reciprocating units they claim that the efficiency is better. Mycom reported efficiencies in compressing helium from 1 to 10 or 15 atm or about $55 \%$ on an isothermal basis including allowance for motor efficiency of $94 \%$. It would seem to be reasonable to expect that if oil flooded screw compressors were to be optimized for helium that the efficiency could be improved to at least the high $50 \%$ range.

\subsubsection{Centrifugal Compressors}

Centrifugal compressors have never been used in large helium refrigerators, probably because of the relatively high cost that is anticipated. There is a general consensus among the manufacturers contacted and the APCI machinery engineers that isothermal efficiencies of about $62 \%$ are possible in current designs at the upper end of the specified flows and that if the flow is increased to very high values then the efficiency can be as good or better than that achieveable in reciprocating compressors. Present units with steel blades are limited to about 12,000 feet of head per stage while if titanium blades are developed then about 20,000 feet of head per stage might be achieved. This would reduce the number of stages required and thus reduce the cost without sacrificing much in efficiency. Current designs would require 4 or 5 barrels or casings, [D.11], while with titanium wheels this could be reduced to 3 casings. Since each casing has its own shaft, bearings, shaft seal, and drive gear, the reliability of centrifugal units improves as the number of casings is reduced.

Table 4.2 includes one response for a mixture of helium and freon which includes a prediction of the power input. The efficiency of $25 \%$ reflects the fact that a large fraction of the input power is used to compress the freon and unless the compressed freon can be used effectively its presence detracts from the compressor efficiency, [D.13].

\subsubsection{Summary of Compressor Characteristics}


Table 4.4 summarizes the characteristics of different type compressors as they have been determined from the survey, conversations with manufacturers, and present refrigerator users, and air piant data. Estimated costs are taken from figure 4.1 which plots the data from table 4.2 .

The meantime between failure, MTBF, times for reciprocating compressors that are presented are derived from estimates based on the user survey. This is assumed to include compressor controls but not the cooling system. The screw compressors are likewise derated from an accepted MTBF of 60,000 hours for the compressor alone by considering that multiple units are required for dry screw compressors. Present day oil flooded screw compressors for air-conditioning applications have a record of control problems that necessitates derating the MTBF for these units. The centrifugal compressors are derated from the single unit MTBF of 60,000 hours to allow for the additional bearings, gears, and seals in the multi-casing units.

Meantime between maintenance, MTBM, and meantime to repair times for regular maintenance, MTTRM, are taken from responses to the compressor survey. The meantime to repair after a random failure, MTBMF, is taken as being about $60 \%$ of the MTTRM. This ratio is a conservative projection of the ratio derived from air plant data.

The maximum flow rates that are listed are based on vendor replies to inquiries and catalogs for existing equipment.

The data summarized in table 4.4 serves as the basis for the reliabilitycost study presented later in this report.

\subsection{TURBINE EXPANDERS}

\subsubsection{Introduction}

Since some version of the Brayton cycle using turbo-expanders is proposed for refrigerating most proposed superconducting transmission lines, the optimum design and reliable operation of this type of equipment are paramount.

The theory and practice of turbo-expansion machinery is well developed in the hydrocarbon processing and air separation industries. Within the last decade it has been applied to helium liquefaction and helium refrigeration technology. The principle difference is their relative absolute temperature levels. For refrigeration down to $100^{\circ} \mathrm{K}$, the power extracted is relatively large compared to the compression power, its recovery 
TABLE 4.4

SUMMARY OF COMPRESSOR CHARACTERISTICS

\begin{tabular}{|c|c|c|c|c|c|c|c|c|c|c|}
\hline $\begin{array}{l}\text { Compressor } \\
\text { Type }\end{array}$ & $\begin{array}{l}\text { Injected } \\
\text { Fluid }\end{array}$ & $\begin{array}{l}\text { Est. Cost } \\
010,000 \\
\text { SCFM - K\$ }\end{array}$ & $\begin{array}{l}\text { Isothermal } \\
\text { Efficiency }\end{array}$ & $\begin{array}{l}\text { MTBF } \\
\text { Hrs }\end{array}$ & $\begin{array}{l}\text { MTTR } \\
\text { F-Hrs }\end{array}$ & $\begin{array}{l}\text { MTBM } \\
\text { Hrs }\end{array}$ & $\begin{array}{l}\text { MTTR } \\
\text { M-Hrs }\end{array}$ & $\begin{array}{l}\text { Max Flow } \\
\text { SCFM }\end{array}$ & $\begin{array}{l}\text { No. Stages } \\
\text { or Casings }\end{array}$ & Remarks \\
\hline \multirow{4}{*}{ Reciprocating } & & & & & & & & & & \multirow{3}{*}{$\begin{array}{l}\text { Teflon Piston } \\
\text { Rings } \\
\text { Labyrinth Seal }\end{array}$} \\
\hline & Dry & 416 & 67 & 5,000 & 16.2 & 7,000 & 27 & 96,000 & 2,3 & \\
\hline & Dry & 375 & .57 & 17,000 & 19.2 & 7,000 & 32 & 17,000 & 2 & \\
\hline & - & & & & & & & & & \\
\hline \multirow[t]{3}{*}{ Screw } & Dry & 730 & 46 & $.25,000$ & 24.0 & 16,000 & 40 & 50,000 & 2,3 & \multirow{3}{*}{$\begin{array}{l}\text { Eff. improves } \\
\text { with size to } 55 \% \\
\text { Includes oil } \\
\text { Separator }\end{array}$} \\
\hline & $0 i 1$ & 156 & 50 & 30,000 & 12.0 & 50,000 & 20 & 17,000 & 1 & \\
\hline & & & '. & & & & & & & \\
\hline \multirow[t]{2}{*}{ Centrifugal } & Dry & 1,050 & 62 & 25,000 & 24.0 & 25,000 & 40 & 100,000 & 4,5 & \multirow{2}{*}{$\begin{array}{l}\text { Eff. improves } \\
\text { with size to } 67 \% \\
\text { Assumes new } \\
\text { titanium blades }\end{array}$} \\
\hline & Dry & 925 & 60 & 30,000 & 24.0 & 20,000 & 40 & 100,000 & 3 & \\
\hline
\end{tabular}




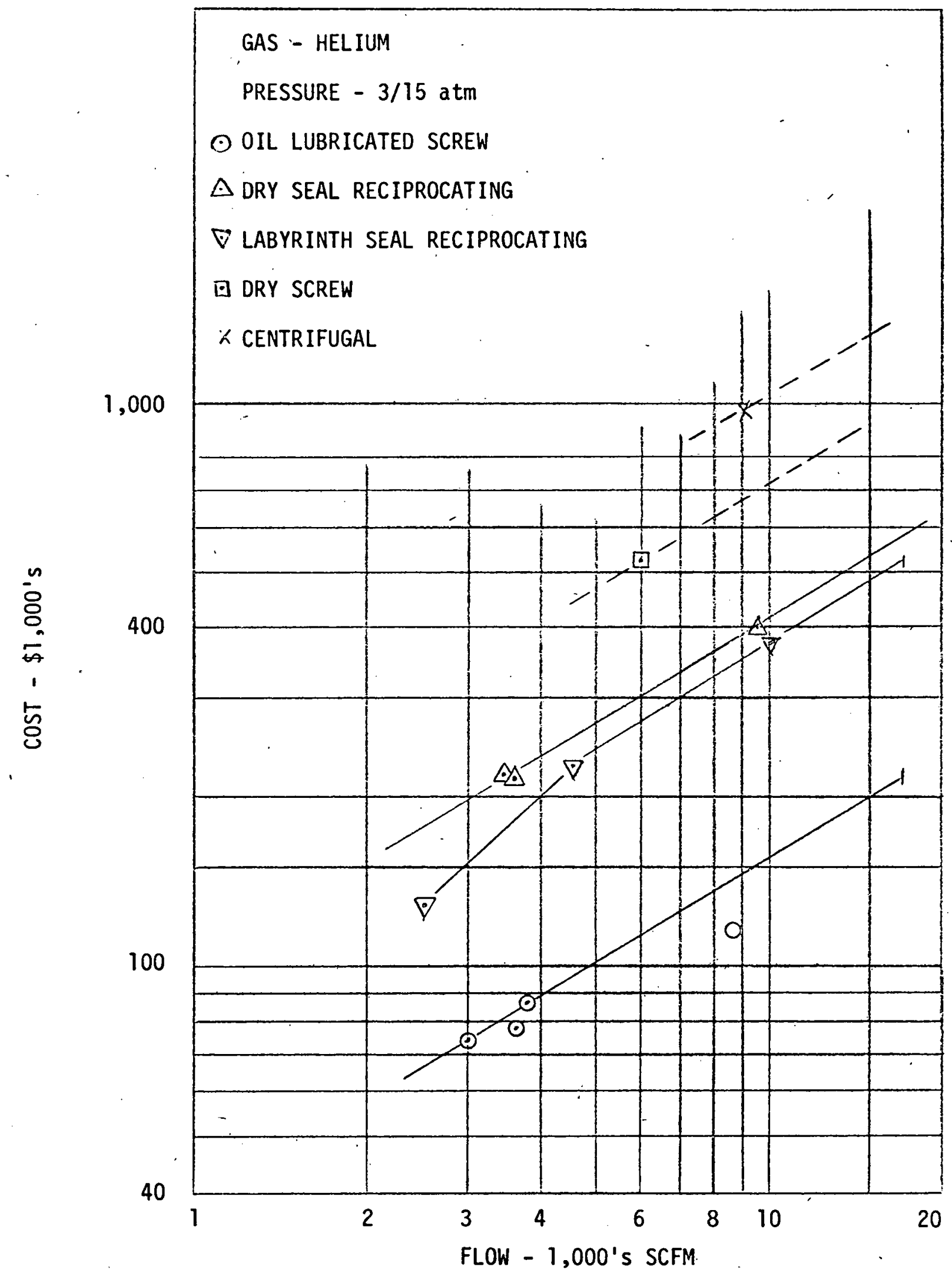

FIGURE 4.1 COMPRESSOR COST VS. FLOW 
is both economical and convenient. For example, some air plant cycles use combined expanders and compressors where two stages of expansion are mechanically coupled to power the final stages of compression. On the other hand, the recovery of expansion work as useful power becomes both economically and technically unattractive at the low temperatures of hel ium cycles.

As the temperature level decreases, the reduced specific volume and enthalpy requires machines of smaller dimensions operating at higher speeds. Heat leak, critical internal dimensions effecting helium bypassing, loading devices, and bearings play a larger role in the design.

\subsubsection{Turbine Expander Performance and Design Range}

0. E. Balje, [E.10] in his landmark survey articles on turbo-machinery has shown on figure 16, page 96 of Part A of his articles, reproduced here as figure 4.2, how limited an area of operating conditions within which the designer of a radial in-flow expander (or any other type) has to confine his efforts. He wants to operate in that region of machine dimensions and flow conditions, characterized as specific diameter, specific speed, and speed ratio, that give maximum efficiency. He often must compromise this choice to match a loader which must operate at the same speed, to live within limits of materials and geometrics when he must consider such troubles as maximum tip speed, critical shaft speed, heat leak, journal and thrust bearing design, etc.

The choice of gas compressor loading versus oil pump loading, gas bearings versus oil bearings, and if the former, the choice of static versus dynamic gas bearings, all must be considered. Figure 4.3 is an attempt to show the approximate range of design for various turbo-expanders as function of flowrate (grams per second) and adiabatic head (joules per gram). In general small, high speed machines use static gas bearings and large lower speed machines use oil bearings, with dynamic bearings in between. The number of operating turbines using dynamic bearings is 1 imited as there are few existing systems of this type. In general, the higher the flow and lower the head, the higher the efficiency. Most expanders for the present BNL, UC, and LASL processes will operate in the region where both static and dynamic gas bearing machines, oil bearing machines with either oil pump or gas compressor loading devices, or hybrids using gas and oil bearing are practical.

The cycle designer unconsciously imposes constraints on the turbine designer including pressure levels, to match compressor levels, operating temperatures, type of loader, type of bearing (gas or oil), and the bane 


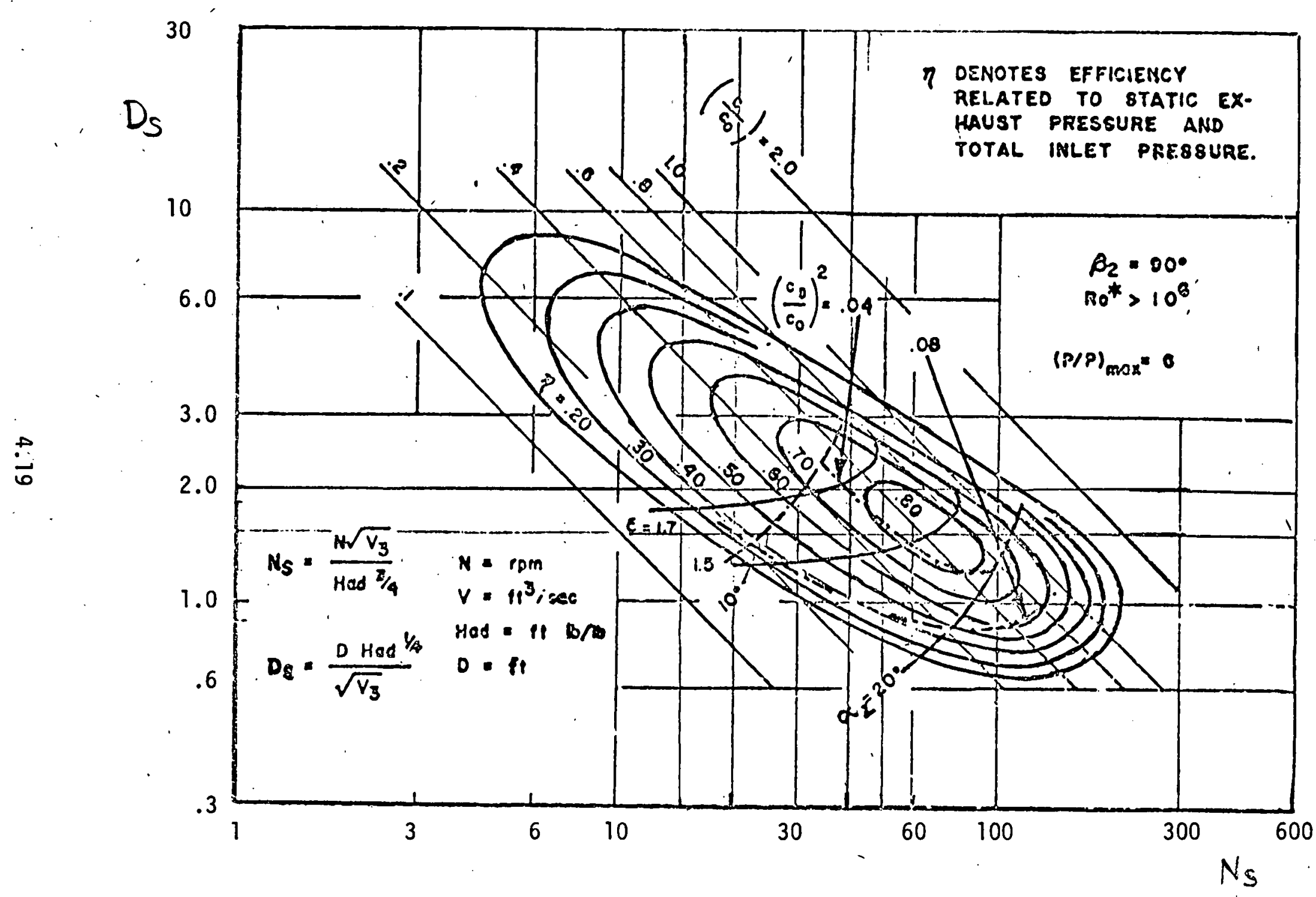

'FIGURE 4.2 BALJE DIAGRAM FOR SINGLE STAGE RADIAL TURBINE 


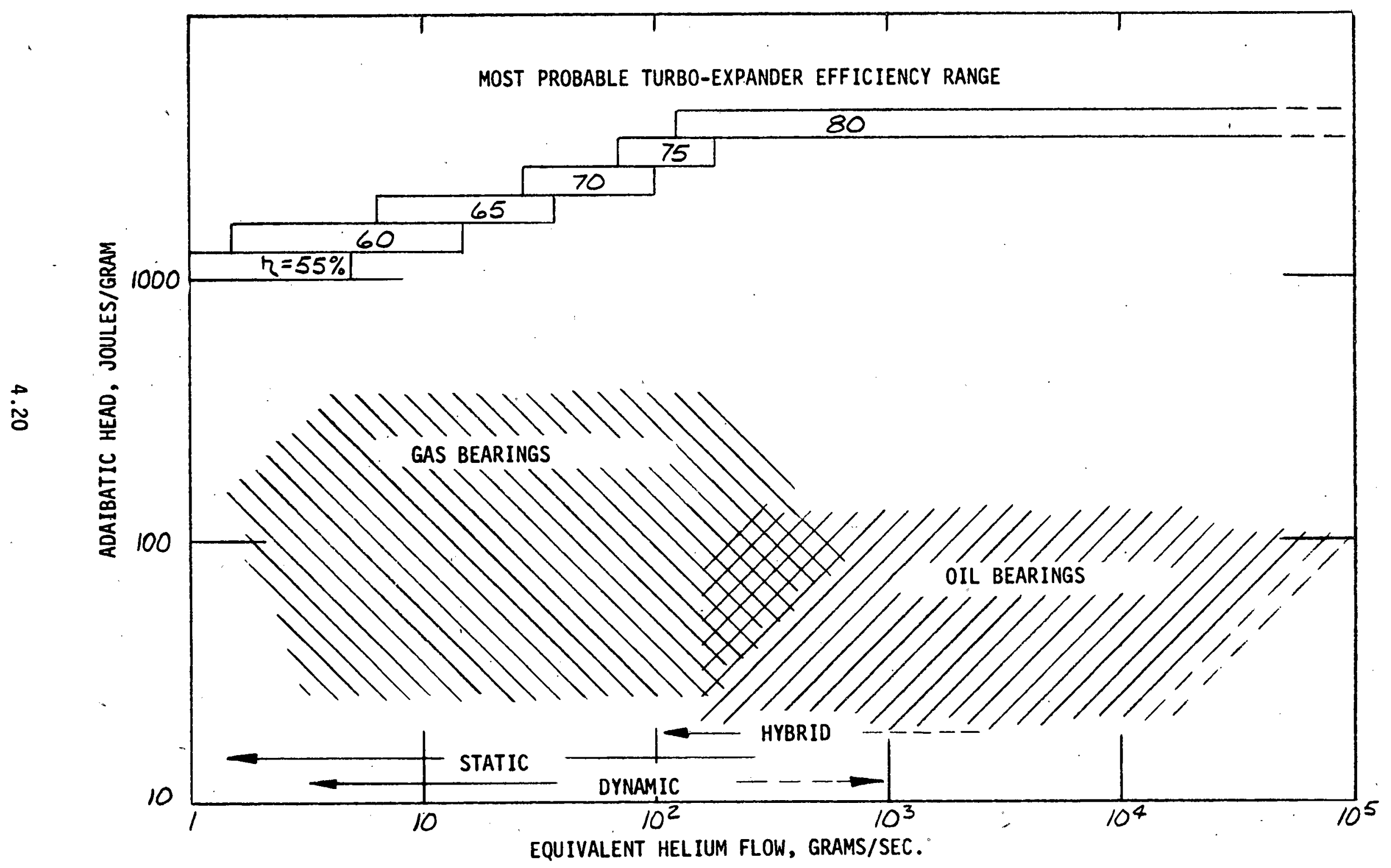

FIGURE 4.3 APPROXIMATE DESIGN RANGE FOR CURRENT HELIUM EXPANSION TURBINES 
of the expander designer - a plethora of unsteady and/or off-design conditions such as part loads, varying loads, bumpless switching to parallel units, initial cooldown, (including the line) and subsequent rapid warm-up and cooldown for inspection.

It is in this area of off-design conditions where more definition of the equipment limitations is needed and how best to integrate controls and operating procedures to maximize reliability.

The range of use for oil bearings, at high power outputs is obviously several orders of magnitude larger than for gas bearings, if one considers the bearing systems for massive industrial equipment such as $1000 \mathrm{MW}$ electric steam turbine generators, etc. For helium systems with refrigeration capacities of $2.0 \mathrm{KW}$ or larger, present state-of-the-art bearing technology favors oil. Conversely, at capacities equivalent to $1.0 \mathrm{KW}$ at $4.2^{\circ} \mathrm{K}$ or less the turbo-expanders must operate at high speeds for moderate to high expansion rates. 0 il bearings at these speeds usually require more power than available, precluding their use. As might be expected, contemplated systems tend to fall in the head-fiow region where gas and oil bearings overlap.

The prospect of a pristine system of helium uncontaminated by oil is an alluring one for the system designer in choosing between oil and gas bearing expanders, other things being equal. However, he must consider the type of compressor used. If oil lube reciprocating or screw compressors are used, the return of seal gas contaminated with trace turbine oil is not a problem, providing that the two types of machinery use similar hydrocarbon lubricants, which is usually the case. The bulk of oil is easily removed from the turbine seal gas in coalescing filters. The unremoved trace particulate and vaporized oil can be added to that of the compressor without difficulty. The principle advantage of gas bearings over oil bearings is that of precluding the possibility of getting oil into the cold end of the refrigeration system by seal gas reversal. This can be minimized by controls sensing wheel tip pressure versus seal gas pressure. The case favoring either type or their hybrid, where each could be used, appears not yet resolved.

\subsubsection{Refrigeration and/or Liquefaction Capacity of Commercially Available Systems}

Information relating to the capacity size range available in present stateof-the-art helium turbine expanders in terms of the ultimate cycle refrigeration or liquefaction capacity is shown in table 4.5. This information was gathered during personal visits to two major turbine manu- 
TABLE 4.5

TURBO-EXPANDER SIZE RANGE SUMMARY FOR PRESENT STATE-OF-THE-ART EQUIPMENT

TYPE OF EXPANDER AND MANUFACTURER

LOWER PRACTICAL LIMIT CAPACITY ISENTROPIC EFFICIENCY

Externally pressurized gas bearing turboexpander

$(B O C)$

(1)

Self-actuated gas bearing turbine

(Sulzer Bros. Ltd.)

(w/LIN precool)

$8 \mathrm{LL} / \mathrm{hr}$

$60 \%$
UPPER PRACTICAL LIMIT CAPACITY

EFFICIENCY

(w/LIN precool)

$1000 \mathrm{LL} / \mathrm{hr}$ or

$2.5 \mathrm{KW} \odot 4.2^{\circ} \mathrm{K}$

$5 \mathrm{Kw}$ ? $4.2^{\circ} \mathrm{K}$ with

2 turbines in parallel

(w/o LIN precool)

2000 watts $04.2^{\circ} \mathrm{K}$

(two turbines)

(w/LIN precool) 4000 watts $04.2^{\circ} \mathrm{K}$

Double above capacities with 4 turbines (two each in parallel)

$150 \mathrm{Kw} \odot 4.2^{\circ} \mathrm{K}$

$80 \%$

(this is economic

limit for turbine loading device) 
facturers and is probably fairly representative of the size range covered by other manufacturers since the same scaling laws apply in all cases.

Table 4.5 is broken up into three major bearing types; externally pressurized gas bearings, self actuating gas bearings, and oil lubricated bearings.

\subsubsection{Cost Estimates of Turbines in Size Range of Interest in BNL PIan 3A Study}

In order to carry out an effective cost/reliability analys is of the BNL Plan $3 A$ Study, it is important to establish realistic costs for the turbines which might be used in the proposed cold box. Figure 4.4 is a plot of turbine expander costs versus the turbine discharge volumetric flow rate; the volumetric flow rate being a good indicator of turbine frame size. The costs were assembled from quotations APCI has received from other turbine manufacturers over the past few years with a $30 \%$ increase included to cover overhead costs of specifying and purchasing equipment. Three of the gas bearing data points represent quotes from two different manufacturers and the two oil bearing turbine data points represent two other manufacturers. All costs include necessary turbine controls and the oil bearing quotes include the complete oil lube system.

\subsection{HEAT EXCHANGERS}

\subsubsection{General Discussion -}

Heat exchangers for cryogenic service and especially for helium systems operating-below $10^{\circ} \mathrm{K}$ must have high effectiveness; where effectiveness is defined as the ratio of heat actually transferred to the maximum amount that could be transferred consistent with the second law of thermodynamics. The typical type of exchanger for this service would have an effectiveness range of 0.90 to 0.99 , usually in the range of 0.95 to 0.98 . Another way of stating this is the transfer unit concept (NTU); helium refrigerators require exchangers having 10 to 50 NTU.

The two types most useful in large cryogenic systems are the wound coil type (Hampson) and the aluminum brazed plate fin type (core). Each has advantages and limitations. Currently most air separation plants are using reversing cores; while the large base load LNG plants use wound coil exchangers with individual bundles as large as 13 feet in diameter by 50 feet in length with an area of half a million square feet. Table 4.6 gives a brief comparison of the two types. The choice in the size of 


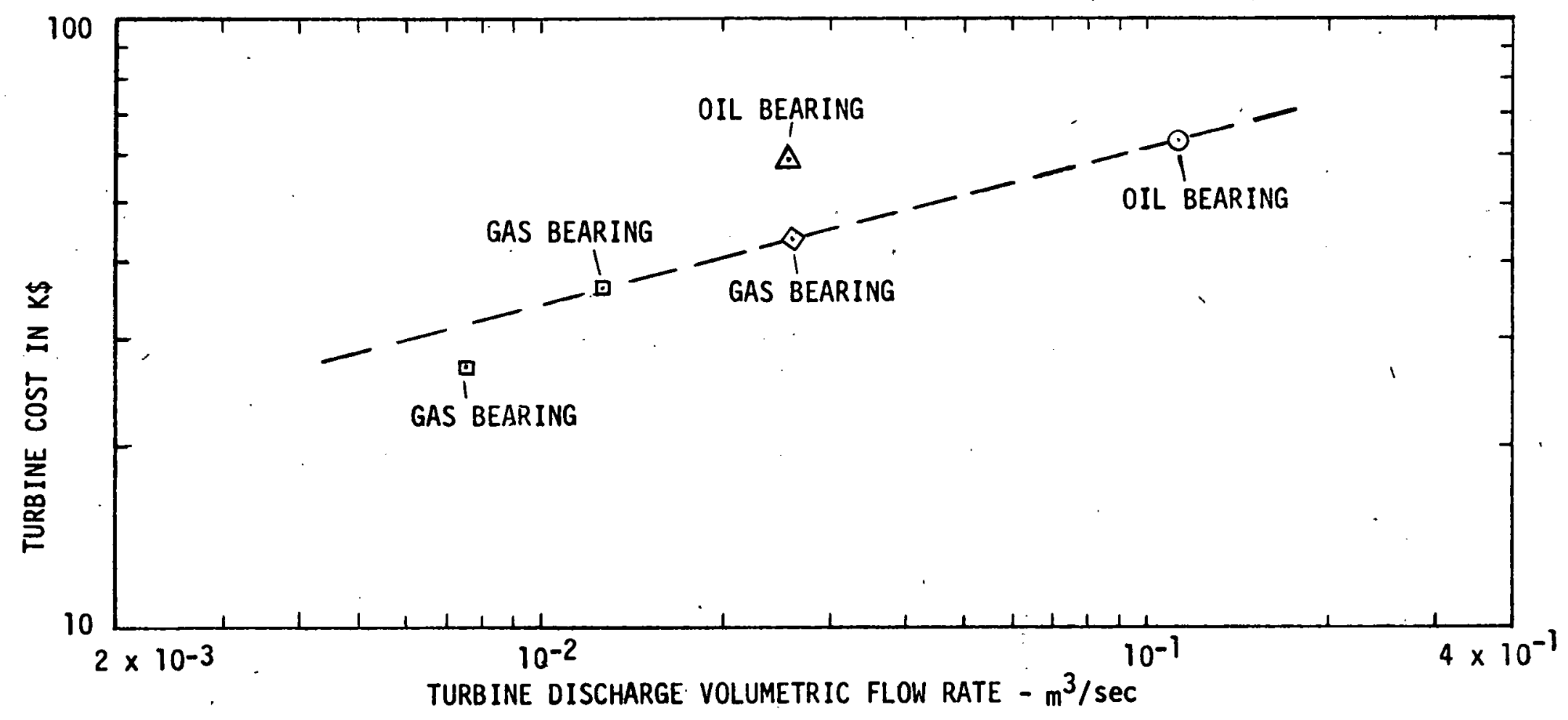

FIGURE 4.4 TURBINE EXPANDER COSTS 
TABLE 4.6

COMPARISON OF CORE AND COIL TYPE HEAT EXCHANGERS

FARAMETER

Material

Pressure

No. of streams

Symmetry

Relibaility

Cost
CORE

Aluminum

Vac to 700 psig

Six, either high or

low pressure

Theoretically uniform, however, unbalances can result from manifolding cores in parallel, passage arrangement, heat leaks, maldistribution in heads, and distributors.

High. Some problems in air plant service due to corrosion and fatigue in reversing service.

Probably cheaper for refrigerators with up to about $10 \mathrm{Kw}$ capacity of $5^{\circ} \mathrm{K}$
COIL

Aluminum copper

Vac to 2000 psig

(limited by tube)

One shell side at low pressure number of tube side stream not limited but usually less than 3. Low pressure tube side stream can be a problem.

Inherently unbalanced because of variations in number of turns or from one layer to another. Practically can be made to get as much or more NTU's in same volume as core: Shell side bypassing must be avoided.

Very high. Some in service for 30 years or more.

Probably cheaper in large systems where more than one core is needed. 
helium systems represented in table 2.1 is probably for cores, in that the process designer has more flexibility in arrangement and economics.

\subsubsection{Fast Cool Down}

One possible problem area in high reliability helium systems is the objective of having rapid cooldown capability. This is most readily achieved by having a supply of liquid cryogen (helium and/or nitrogen) available and providing exchanger by-passing. Most operating experience in commercial cryogenic systems (air plants, $L N G$, etc.) is based on longer cooldown periods. The supply of liquid is either not available or not economical to use. Also in the case of reversing service too rapid cooldown may result in undesirable longitudinal temperature gradients causing exchanger freeze-up. The problem of rapid cooldown of a helium system is not freezeup but thermal stresses. There has been some evidence of stress cracking in some reversing air plant cores in some types of environments. On the other hand cores have been inadvertently cooled from ambient to $80^{\circ} \mathrm{K}$ in less than 30 minutes without evidence of problems.

Optimization of cooldown, both from a thermal and from a mechanical point of view is an area of investigation where more data and study is indicated. These studies should include the stainless steel type heat exchangers recommended by two manufacturers as listed in table 4.1.

\subsubsection{Aluminum Prate Fin Exchanger Core Costs}

An estimate of aluminum plate fin core costs are required for the reliability/cost analys is to be presented in section 8.0 , in order that the cost of the stand-by helium storage dewar subsystem ( $\mathrm{D} / \mathrm{HX}$ ) may be established. Figure 4.5 shows the core cost for a 27.2 atm pressure rated core versus heat transfer surface area.

\subsection{INSTRUMENTATION AND CONTROLS}

The basic sensing of pressure, temperature, flow, rotational speed, vibration and liquid level even for cold helium systems is fairly well advanced. With the exception of temperature, helium level, and possibly flow in cold streams, the other variables can use instrumentation standard to the electric utility and process industries. Analytical instrumentation for trace impurities may pose some difficulties, as discussed in Section 4.6. 


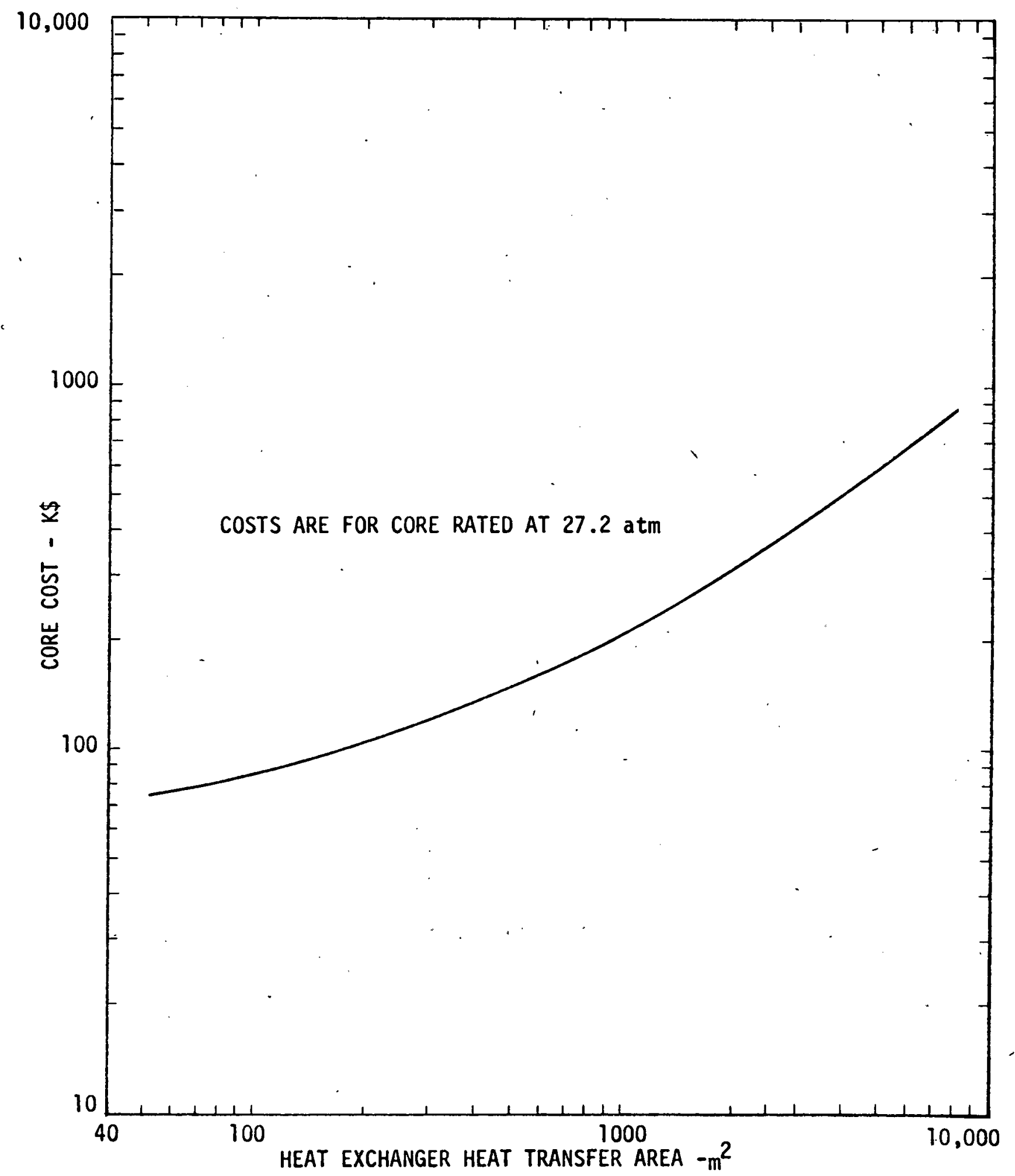

FIGURE 4.5 ALUMINUM PLATE FIN HEAT EXCHANGER CORE COSTS 
The type of control valve actuation is an area for investigation. Traditionally, the process industries and utilities have favored pneumatic actuation, using 3 to 15 psig signals, with some 60 psig piston operators, for reasons of cost, reliability, and speed of response. Electro-pneumatic, electrohydraulic, and electric motor valves are increasing in usage, actuated by millivolt or milliamp signals from an electronic analog instrument or a computer. These signal types are more compatible with the digital computer control as the latter tends to displace analog control.

Alternatively, pneumatic/electric and electric/pneumatic transducers can marry electronic instruments and pneumatic actuators. The relative reliability of all systems is an area for investigation. The experience on standard nitrogen plants indicate that electrical failures are a major source of plant outage.

Regardless of ultimate type of instrumentation used, the introduction of the concept of redundancy in equipment, whether as parallel compressors, expanders, or systems, raises a new problem not inherent in the simpler nitrogen generator with liquid nitrogen storage as back-up. The logic and accomplishment of switch-over must enhance, not dilute, the ultimate system reliability. First the valving isolating two compressors for instance must operate and must operate in the required sequence at the required speed. One compressor must be stopped safely while the other is brought up to speed and pressure with minimum disturbance of the process. The repetition of this chain of events, over and over again from $A$ to $B$ and $B$ to $A$, etc., without fault and a minimum of wear and tear of the equipment will be no mean accomplishment. Redundant lube oil pumps for a turbine is now done routinely as the time of switch is short and a hydraulic accumulator can provide transient flow during the switch. To apply this concept to switching turbo-expanders which operate at thousands of rpm at a few degrees above absolute zero increases the complexity of the problem several fold.

This general problem is discussed in more detail in Section 7 . It should be pointed out that there are to the author's knowledge no systems in operation which switch turbines for instance. The logic to accomplish this or to provide two hour cooldown of refrigerators which is a goal for some systems, or similar sequencing are not routine technology. We are in the initial phase of the learning curve.

\section{6 GAS PURIFICATION}

\subsubsection{General Problem}


It is quite appropriate to say that any other substance is potentially an impurity in helium in a system operating in the superconducting region $\left(20^{\circ} \mathrm{K}\right.$ or colder $)$. For example, assume grade $A$ helium containing one part per million by volume hydrogen. At a total pressure of one atmosphere, this hydrogen would start to precipitate from the gas to the solid phase at $5.8^{\circ} \mathrm{K}$. If the total pressure is increased to 10 atmospheres, one ppmv hydrogen would precipitate at $6.8^{\circ} \mathrm{K}$, a possible condition in the UC and BNL systems.

Obviously, all other gases having triple points at higher temperatures also are potential problems. What these problems might be are a function of the concentration and temperature. Generalizing, these contaminant problems include:

* plugging of filters

* plugging or fouling of heat exchangers

* plugging or seizure of expansion equipment

* plugging of piping and valving

* adverse effects on the dielectric strength of high voltage equipment

\subsubsection{Source of Contaminants}

There are several sources of contamination that a helium system is exposed to during the entire period from manufacturing to operation. Their chronological order is:

* use of materials that are contaminant sources

* contamination during manufacture, installation, and field assembly

* use of impure helium

* contamination in-leakage during operation

* lubricant migration

Cryogenic refrigeration and liquefaction equipment is almost entirely made of metallic materials with some use of inorganic materials, usually glass fibers as filler, and of organic materials. Examples of organic materials are TFE or Kel-F used in valve plugs and packing, and phenolic laminates used in some expansion equipment and thermal insulating supports. In addition superconducting transmission lines use relatively large masses (and areas) of inorganic and organic dielectric materials, possibly even using relatively hygroscopic materials such as paper. When such equipment is cold, the rate of contaminant diffusion into the helium would be extremely slow because of the temperature dependency of permeation. However, it is conceivable that the material could outgas into helium during periods when at ambient temperature. 
Contamination during manufacture can occur from water and solvent washing, cutting oil, or brazing fluxes. It is best controlled at the source by use of appropriate flushing, deriming, and degreasing procedures and stringent quality control. Contamination during installation includes many of the problems and their controls, as in manufacture, further complicated by the adverse field conditions. It is at this point that moisture, air, or purge nitrogen entrapped in the system becomes the largest source of contamination normally to be encountered. If the transmission line is flushed with $\mathrm{SF}_{6}$ to remove moisture then this may also become a helium contaminant.

Contamination by impure helium is best controlled by specification of the source helium confirmed by testing. Use of U.S. Bureau of Mines Grade A helium at 50 ppmv impurity requires a substantial impurity removal system to process the system inventory, especially for removal of neon which may exist in excess of $20 \mathrm{ppmv}$. The best source of helium appears to be liquid or previously liquefied helium, especially from those plants, which have neon removal adsorbers to protect their expanders and to minimize exchanger fouling. An appreciation of this problem is to consider 1,000,000 scf of helium with $20 \mathrm{ppmv}$ neon. The neon quantity is $5.3 \times 10^{-2} \mathrm{jb}-\mathrm{moles}$ or $1.0 \mathrm{lbs}$. For the BNL line this translates to about $0.2 \mathrm{lbs} / \mathrm{km}$ of neon contained in the helium. The inventory in a large system involves substantial quantities of neon for removal somewhere, and preferably before entering the transmission line complex.

Air in-leakage is most probable where there is sub-atmospheric suction pressure in the recycle compressor and inadequate seal purge and air detection. Another source of air is use of gas bags for low pressure bulk helium storage. Any elastomeric material is permeable to any gas to some extent. The best solution in this situation is to assume contamination and provide the appropriate purification equipment. More difficult to account for is air infiltration in counter-diffusion to leaking helium. This phenomenon is attributed to causing several cases of freeze-up from air where there was simultaneous loss of helium to ambient.

Contamination by lubricant migration can result from:

* teflon/filler dust from dry lube reciprocating compressors

* oil from oil lube reciprocating and screw compressors

* oil from oil bearing turbo-expanders and from reciprocator expander running gear

* water from water-injected positive displacement blowers and watersealed compressors. 


\subsubsection{Method of Removal}

The principle methods of impurity removal are summarized in table 4.7.

TABLE 4.7

IMPURITIES, REMOVAL METHODS

\begin{tabular}{|c|c|c|c|c|c|c|c|c|c|}
\hline \multirow{2}{*}{ METHOD } & \multirow{2}{*}{ 号 } & \multirow{2}{*}{ 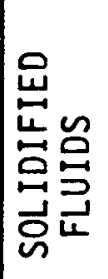 } & \multirow{2}{*}{ 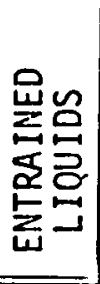 } & \multicolumn{3}{|c|}{ VAPORS } & \multirow[b]{2}{*}{ AIR } & \multirow[b]{2}{*}{$\mathrm{Ne}$} & \multirow[b]{2}{*}{$\mathrm{H}_{2}$} \\
\hline & & & & $\mathrm{HC}$ & $\mathrm{H}_{2} \mathrm{O}$ & $\mathrm{CO}_{2}$ & & & \\
\hline Filtration & $x$ & $x$ & & & & & & & \\
\hline $\begin{array}{l}\text { Coalescing Filters } \\
\text { (Ultrapor,Brink,etc.) }\end{array}$ & & - & $x$ & & & & & & \\
\hline $\begin{array}{l}\text { Entrainment Separator } \\
\text { (Impingement, cyclones, } \\
\text { demisters) }\end{array}$ & $x$ & & $x$ & & & & & & \\
\hline $\begin{array}{l}\text { Freeze-out Exchanger } \\
\text { (Switching exchangers) }\end{array}$ & & & & & $x$ & $x$ & & & \\
\hline $\begin{array}{l}\text { Adsorption } \\
300^{\circ} \mathrm{K} \\
\end{array}$ & & & & $x$ & $x$ & $x$ & & & \\
\hline $80^{\circ} \mathrm{K}$ & & & & & & & $x$ & $?$ & $?$ \\
\hline $30^{\circ} \mathrm{K}$ & & & & & & & & $x$ & $x$ \\
\hline
\end{tabular}


Solid filtration is required on the discharge of dry lube compressors for ring dust removal to prevent heat exchanger fouling and on the inlet of expanders to prevent wear and possible seizure. Liquid filtration is used to coalesce small liquid droplets (from oil to 50 microns diameter) to such a size that the liquid readily separates from the gas phase without re-entrainmant. Entrainment separators use inertia methods to impinge solid or liquid particles on collecting surfaces where they agglomerate and collect without re-entrainment. These are used as part of compressor intercoolers and aftercoolers and in phase separators as part of oil lubrication systems for turbo-expanders.

Freeze-out is the principle method of impurity removal in most air separation plants, including the APCI standard nitrogen plants described in detail in section 6 . Here the principal impurities are water and carbon dioxide, removed routinely to less than 1 ppmv. There are trace residual amounts which are entrained so they deposit on surfaces which are too cold to permit re-evaporation on exchanger flow stream switch. However, these are usually so small as to permit operation in excess of 10,000 hours before defrost is necessary for reason of exchanger fouling or excessive pressure drop. Freeze-out techniques which require the use of switching heat exchangers or frequent warm up are generally not used on present helium systems; it is a possibility, along with dessicant driers, when and if water-injected compressors become viable alternatives to the dry or oil lubricated compressors presently in use.

Adsorption is the most practical method for removal of gaseous components from helium. Adsorbers operate in the temperature range of $300^{\circ} \mathrm{K}$ to $27^{\circ} \mathrm{K}$ or lower. The trace hydrocarbon vapor in helium from oil-lubricated compressors can be removed using ambient temperature beds of alumina, molecular sieves, or activated carbon. Water vapor is removable by ambient beds of aluminia, molecular sieves, or silica gel. Carbon dioxide, if present, is removable by some types of molecular sieves.

The principle constituents of air, namely nitrogen, oxygen, and argon, and trace constituents such as xenon, krypton, and hydrocarbons, are removable by molecular sieves, silica gel, or activated carbon at or near liquid nitrogen temperature $\left(80^{\circ} \mathrm{K}\right)$. Activated carbon is not recommended if the oxygen quantity accumulating is more than one percent by weight of the carbon because of the possibility of ignition upon warm-up. Molecular sieves are usually the preferred adsorbent.

Trace neon and hydrogen can be adsorbed at $80^{\circ} \mathrm{K}$ using molecular sieves or carbon. Operation at $50^{\circ} \mathrm{K}$ permits high adsorbent loading.

Any adsorbent system must be regenerated periodically prior to break-through. Break-through occurs when the capacity of the bed is exceeded, resulting in an unacceptable impurity level in the effluent. Regeneration can be 
accomplished by heat or depressurization or both. Any generation scheme involves equipment, such as heaters, coolers, blowers, and controls. Depending on the scheme, there may be appreciable losses of helium which is contaminated in removal of the impurities. Ideally the impurity is rejected from the system with a minimum loss of helium. Where the quantity of impurity is not increasing in time, the approach may be to try to accumulate the impurity in a guard adsorber where it is trapped during startup. It is eventually necessary to valve off the adsorber from the system to prevent eluting the impurity through the adsorber and back into the system by passage of impurity-free helium through the adsorber.

Water vapor can be prevented from entering the cold box by using switching guard adsorbers with regeneration gas recycled to the compressor suction. Excess incoming moisture, say, from a leaking cylinder jacket or intercooler, will accumulate till it condenses out after compression and interstage cooling. Rejection of a liquid water phase will minimize the loss of helium.

Whether or not it is economical to recover regeneration helium from the air adsorbers will depend on the total quantity to be processed. It is probably not attractive for trace air or nitrogen rejection from individual helium refrigerators. A central purifier serving several refrigerators might provide a method to separate the combined regeneration flows, either by rejection of a liquid air phase with relatively little helium in solution or by re-adsorption taking advantage of a concentration effect so that the reject desorbed air will contain less helium than if rejected from single stage adsorption.

Guard adsorbers for hydrogen and neon probably should be operated to reject all regeneration helium to the environment. This quantity can be minimized by heating the adsorber without helium flow, either by heat leak or by resistance heaters. For example, a neon adsorber at $30^{\circ} \mathrm{K}$ can be effectively regenerated by warming to $80^{\circ} \mathrm{K}$ and venting. Provision must be made, of course, to cool the regenerated adsorber back to operation temperatures prior to putting it on stream.

Hydrogen conceivably can be removed catalytically by the addition of oxygen or air, with the excess residual being removed by the air adsorber. However, the probability is small that there will be more than trace amounts of hydrogen in helium from either the helium or metal outgassing.

In summary it can be said that the present state-of-the-art of purifying helium is probably adequate to meet the requirements of superconducting power transmission. 


\subsubsection{Contaminant Detection}

The determination of the existence of a problem is often more difficult than the solution of the problem; the diagnosis must precede the prescription. Testing for trace contaminants in helium is no exception. However, there has been considerable work done in analys is of noble gases, and on helium in particular, by various commercial producers, the Bureau of Mines, NASA, and groups working on the high temperature gas-cooled nuclear reactors (HTGR'S). For a comprehensive discussion the reader is referred to the survey article by G. E. Schmauch [F.8]. Methods discussed include gas chromatography, mass spectroscopy, infrared spectroscopy, emission spectroscopy, water vapor determination, total hydrocarbon determination, and some miscellaneous methods.

A gas chromotograph using one of several detectors is generally the most universal method to determine trace contaminants. However, it is a batch method taking several minutes or longer to effect the separation in the chromatographic column prior to detection. It is more useful as a laboratory tool than as a "continuous" process analyzer. This also applies generally to mass spectroscopy and related gas analyzers. Optical methods, such as infrared, are continuous and can be adapted to process monitoring, provided that the particular contaminant is detectable.

It should be remembered that the gas sample tap can be located at a midpoint in the adsorber so an appreciable time lapse can exist between taking a sample and having to regenerate the adsorbers.

The American Instrument Co., Silver Spring, Md. manufactures an oil-incompressed-gas detector developed originally to detect rupture of the diaphragm of a diaphragm compressor, an event which would result in oil contamination of the gas system. The principle used is ultra-violet fluorescence of napthalene quinoline, a compound present in all oils processed from continental shelf petroleums, but not usually found in synthetic lubricants. The manufacturer claims detectability to $2 \mathrm{ppm}$ oil in gas with napthalene guinoline concentrations as low as oil to 0.4 micrograms per milliliter.

Determination of water concentration in helium streams can be done using several commercial dewpoint detectors or electrolytic hygrometers. Both devices can measure dewpoints at one atmosphere to $-100^{\circ} \mathrm{F}$, or about 1.6 ppm water. The hygrometer is a continuous reading device which lends itself to process monitoring, including alarm and shutdown actuation.

In summarizing the status of the combined problems of helium purification and impurity detection it appears that purification techniques are adequately understood but more experience is needed to determine if present 
impurity detectors can be used in such a way that the requirements of less than $0.1 \mathrm{ppm}$ impurities are maintained.

\subsection{PIPING}

Cold box piping depends on the type of heat cxchangers used. If stainless or copper alloy wound coil exchangers are used, piping would probably be stainless steel, with possibility of copper low pressure circuits joined by high temperature brazing. If aluminum core exchangers are used, interexchanger piping would be aluminum and piping to valves, turbines, load, etc. would be stainless steel using commercial brazed transition joints between aluminum and stainless steel.

Warm piping around compressors and auxiliary equipment can be aluminum, stainless steel, or carbon steel. Carbon steel is less expensive but poses several problems.

* It must be internally cleaned and kept free of rust and scale during the construction phase when exposure to moist air occurs.

* It must be protected externally from environmental conditions by paint, coating, etc.

* It cannot be used for process lines that can become colder than $-20^{\circ} \mathrm{F}\left(-29^{\circ} \mathrm{C}\right)$, e.g. from upset or defrost flows.

There are several other aspects of piping design for consideration. First, cold boxes should have only welded or brazed joints, with no mechanical joints at all in the vacuum space. Warm piping should have the absolute minimum number of mechanical joints possible, basically around the compressor and at valves and safety relief valves for maintenance, in order to minimize helium losses.

Second, piping stress analyses are important in the cold box, accounting for both the cold steady-state conditions and transient conditions of cool-down and defrost.

Third, required flexibility is preferrably achieved by providing piping bends rather than by bellows. Where the latter cannot be avoided, they should be designed with restraints, etc. to provide only the required movement without kinking, buckling, etc. due to some otherwise permissable transient condition.

In general, it may be said that design and fabrication of piping that will meet the requirements of power transmission reliability are adequately 
understood at present.

\subsection{VACUUM SYSTEM}

\subsubsection{Insulation}

Excellent insulation is paramount for helium refrigeration. Since moderately high vacuum (10-3 to $10^{-6}$ Torr) is required to eliminate gaseous conduction as a mode of heat leak from ambient to the cold equipment, vacuum technology is involved in designing reliable helium refrigeration systems.

The principal mode of insulation for air separation plants, including the nitrogen generators described elsewhere, is the use of carbon steel cold boxes (rectangular or circular cross-section) packed with rock wool or perlite and purged with dry reject air or nitrogen at 2 to 6 inches water column pressure. This type of construction has also been applied to those portions of some helium refrigerators operating at $80^{\circ} \mathrm{K}$ or above.

For the colder exchangers, expanders, filters, and adsorbers operating from $80^{\circ} \mathrm{K}$ down to liquid helium temperature this method of insulation must be modified by 1) using helium as the purge gas, 2) careful placement of equipment to minimize temperature gradients, and 3) the use of an evacuated double-walled dewar, with or without a LIN-cooled shield, between ambient and the cold equipment. Double-wall construction requires that piping and other penetrations be through the single wall top or bottom of the dewar. Some liquid hydrogen plants have been built using a "bell-jar" concept. The double-wall can is removable by raising it off of the heat exchanger assembly; all penetrations, both ambient and cold are at the bottom. The resulting heat leaks caused by recirculation of purge hydrogen between warm and cold piping is low enough to be acceptable in large facilities. These losses are usually not acceptable for helium systems. Double-walled vessels for helium almost invariably have the penetrations through a top head, with cold lines using vacuum jacketing. This type of construction poses some difficulty in obtaining access to the cold equipment, requiring either an elevated dewar or use of a service pit to allow dropping the dewar can away from the exchangers. The al ternative design requires disconnection of the piping and lifting the exchanger assembly out of the dewar.

Evacuated double-wall dewar systems have been used in small hel ium liquefiers to minimize the internal helium leak problem. Internal nitrogen leaks are usually not a problem in that nitrogen circuits are in another rock wool insulated cold box. The only problem then might be external air 
leakage into the vacuum annulus, but this is unlikely.

A simpler method of assembly, equipment access, and piping evacuation is to use a single-wall evacuated vessel. By maintaining a pressure at less than $10^{-4}$ torr, gaseous thermal conduction is el iminated, leaving thermal conduction through piping and supports and radiation as the major heat leak contributors. Radiation can be significantly reduced by use of either a granular insulation, such as perlite or low density silica gel, or by applying multi-layer reflective insulations, such as foilfiber-glass laminates or metallized mylar, to all cold equipment, piping and supports.

The major drawback of the single-wall concept is the need of excellent leak integrity of both external envelopes and the entire internal exchanger piping assembly. This means, first, elimination of all mechanical joints (flanged, screwed, etc.); second, a well conducted helium mass spectrograph leak test campaign is required on all equipment and piping during manufacture; third, minimization of thermal and other strains on the assembly during cooldown and operation which may lead to cracks; fourth, use of a stand-by vacuum system of sufficient capacity to be put into service, if required, to maintain low enough pressure to continue operation or to effect an orderly shutdown.

Since the colder portions of a cold helium system are themselves cryopumps of high capacity for pump oil, water vapor, and air, the system normally is valved off to prevent the cryogenic system from pumping the vacuum system. The development of an internal hel ium leak would result in a rising vacuum space pressure and permit alarm and/or automatic application of pumping. The development of an external air leak through the shell probe would give a much slower response as most of the air constitutents would be pumped by the cold exchangers and piping, except for atmospheric helium (5 ppmv) and possibly atmospheric neon (13 ppmv). Eventually, this residual would actuate the high pressure alarm, if the existence of the leak were not already suspected by the determination of refrigerator performance, say, by a thermal short caused by accumulated frozen air.

Internal nitrogen leaks in refrigerators using liquid nitrogen as precoolant are similar to an air leak, assuming that the LIN has comparable amounts of the low boiling elements, neon, hydrogen, and helium, to permit detection by pressure rise, or residual gas analysis.

Single-wall vacuum vessels are widely used today for large helium refrigerators and transport dewars. These are evacuated then sealed. Getters such as charcoal thermally attached to the coldest point help maintain vacuum even in the presence of small helium leaks. Experience indicates that aluminum core type heat exchangers are the most likely source of leaks, thus they become the component which is most in need of development work to achieve leak free systems. 


\subsubsection{Vacuum Equipment}

There are several possible vacuum pumping arrangements. The most common being listed in table 4.8. The less practical for this service appears to be Ion pumps, sublimation pumps, sorption pumps, and cryogenic pumps.

The most common pumping systems on existing refrigerators have been diffusion pump mechanical pump combinations, probably because of their relative simplicity and cost. This combination is probably the best choice. Present vacuum pumps will be adequate for future superconducting power trans-

mission systems.

\subsection{STORAGE DEWARS}

Stand-by storage facilities for liquid helium to supplement refrigeration in case of outages are best based on the current commercial techniques of bulk storage and transport, namely vacuum insulated tanks with LIN or gas cooled shielding, multi-layer laminal - or super-insulation and low thermal conductivity supports for the inner tank. Anti-stratification baffling is also desirable.

Heat leaks equivalent to steady boil-off losses of $1 \%$ or less of the full tank contents are achievable. Vacuum insulation is usually static as the cryo-pumping (or cryosorption pumping using getter baskets) of the helium inner tank usually is sufficient to maintain pressures at or below 10-5 torr.

Costs for large vapor shielded helium storage dewars are approximately represented by the cost curve given in figure 4.6 . This cost information will be required in later sections. 
TABLE 4.8

VACUUM SYSTEM COMPARISON, INDOOR OPERATION

TYPE

Rotary

Mechanical

Roots blower $w-\quad 10^{1}$ to $10^{-5}$

mechanical

backup pump.

Turbo-molecular w-mechanical backup pump

Diffusion pump

torr

\section{PRESSURE RANGE}

atm / $10^{-2}$ torr

Sublimation pump

Ion pump

(sorption pump

backer)

Cryopump

Cryosorption

$10^{-2}$ to $10^{-7}$

$10^{-2}$ to $10^{-8}$

$10^{-3}$ to $10^{-8}$

$10^{-2}$ to $10^{-8}$

\section{ADVANTAGES}

Lowest cost. Adequate for initial pumpdown.

Moderate cost

High speed at $10^{-2}$ torr

0 il free

Good helium capacity

$0 i 1$ free

No baffles

Simple, reliable

Good helium capacity

Clean

Clean
LIMITATIONS

Cannot maintain a large helium leak.

Speed is maximum at $10^{-3}$ torr.

Some loss of speed for helium. Some cooling water required.

Requires water cooling on pump and baffles.

Requires LIN cooled baffle for ultimate cleanliness.

Requires 20 to $30 \mathrm{~min}$. heat-up time.

Poor helium capacity

Need packing system

Poor fine pressure tolerance

Low helium capacity

Requires liquid nitrogen and helium on refrigerator 


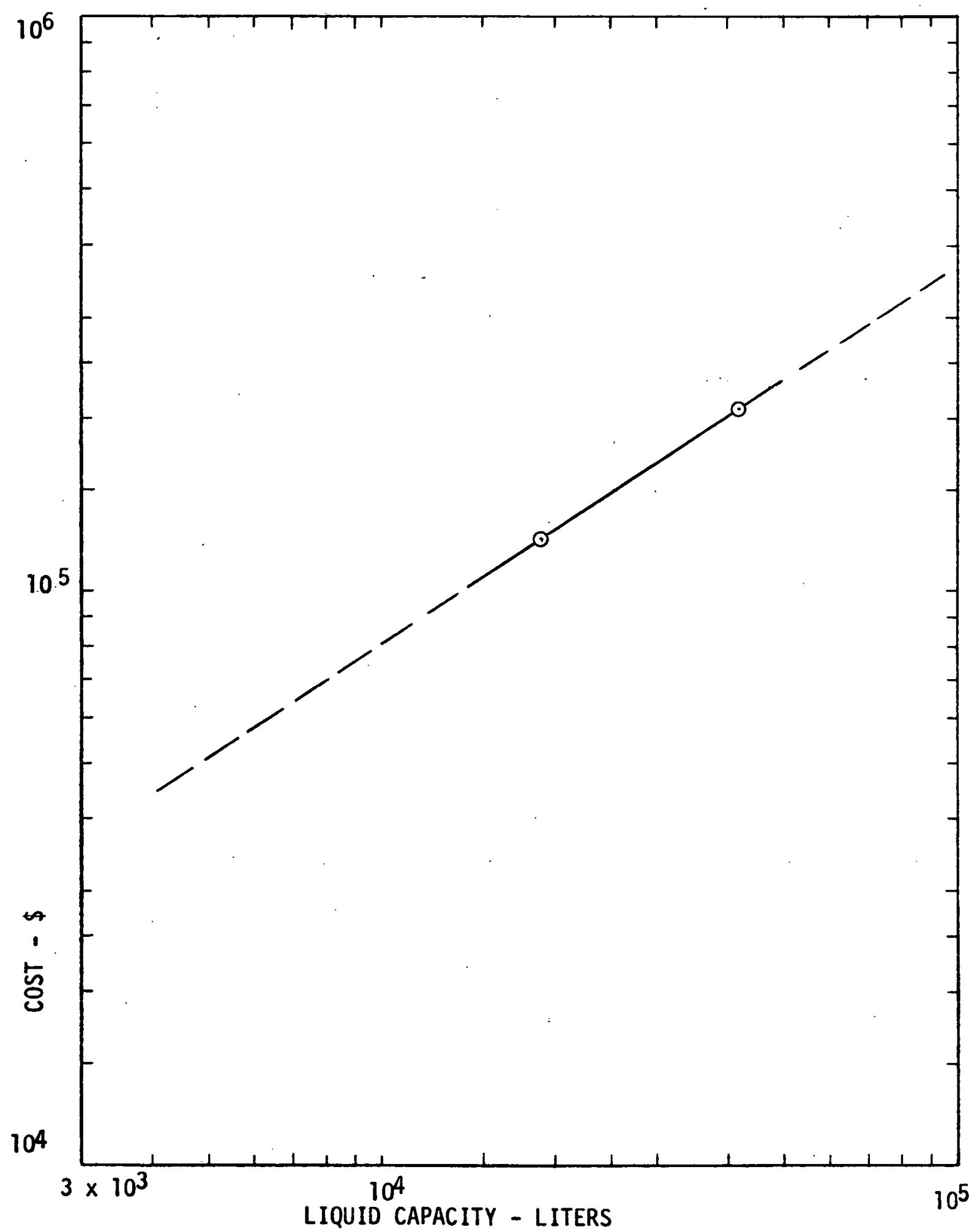

FIGURE 4.6 COST OF VAPOR SHIELDED HELIUM STORAGE DEWARS 


\subsection{REFRIGERATOR COLD BOX}

The refrigerator cold box is an assembly of the components described in paragraphs 4.3 through 4.8 namely turbine expanders, heat exchangers, controls, gas purification, piping, and the vacuum system. The purpose of this section is to define the operational requirements and design concepts as they are presently perceived which are deemed to provide the maximum reliability possible in the cold box. Costs of the cold box are also estimated for subsequent cost-reliability studies. This description which is based on the LASL flow sheet figure 2.3 can serve as the basis for a refrigerator specification.

Figure 5.1 is a flow sheet for a cold box which incorporates the recommended concepts and serves to illustrate the discussion that follows. Components are arranged in such a way in figure 5.1 as to suggest their physical location in the cold box.

\subsection{SYSTEM CLEANUP}

Heat exchangers and piping shall be arranged to permit ready draining and flushing of contaminants and cleaning solvents. System must be capable of being evacuated and purged in minimum practical time. Provision shall be made to prevent dead ended section of piping from trapping contaminants. Flushing of heat exchangers is facilitated by having the end that is exposed to contaminants down. This applies to the warm exchanger receiving gas from the compressor and the colder exchangers which receive gas from the expanders. Rapid evacuation of the dewar is facilitated by using vented laminar insulation rather than rock wool and having a large auxiliary pumpout port for connection to a large mobile vacuum pump.

\subsection{STARTUP}

The cold box shall be designed for rapid cooldown. It shall also be designed to minimize the cooldown time of the transmission line. Liquid nitrogen shall be used to help cool the cold box components and transmission line to $80^{\circ} \mathrm{K}$. It shall also be capable of effectively utilizing liquid helium to cool and fill the transmission line. Instrumentation and control should be such that an individual operator can start the plant. The heat exchangers shall be designed to tolerate the thermal stresses of rapid temperature changes and al so have the necessary auxiliary flow passages. 




FIGURE 5.1 FLOW SHEET OF RECOMMENDED LASL COLD BOX 
Figure 5.1 shows an auxiliary heat exchanger cooling a helium bypass stream to cool either the entire refrigerator or to cool each exchanger independently. For initial cooldown or when the entire refrigerator has been defrosted, cold gas passes through all low pressure circuits in the same direction as in normal operation. For conditions when an individual exchanger has been defrosted, provision is made to cool that exchanger by reverse flow through the high pressure circuit. This method is proposed to utilize the already required adsorber, turbine, and load insolation valves, without adding new larger isolation valves on the low pressure circuits. At this time concepts for cooling down the transmission line utilizing liquid nitrogen and helium have not yet been developed.

\subsection{STEADY STATE}

The efficiency of the cold box shall be such that the capital cost plus the present value of the associated power and maintenance are minimized.

\subsection{TRANSIENTS}

The cold box shall be designed to automatically adjust for transients in inlet gas pressure, supply and return cold gas pressure, return gas temperature, adsorber switch over, and turbine switch over.

\subsection{OFF DESIGN OPERATION}

Expanders shall be equipped with turn down control to permit operation during cooldown, at reduced load requirements, and under conditions when the cold box is being used to produce liquid helium.

\subsection{WARMUP}

Major components within the cold box shall be capable of being rapidly warmed individually. Components and the piping shall be designed to tolerate the thermal stresses imposed by rapid warmup.

Figure 5.1 shows gas coming from the compressor through external heaters into the cold box and distributed to the individual components. Hot gas 
flows through the high pressure side of the exchangers and flows through all components in the reverse direction from the operating flow.

\subsection{CONTROLS AND INSTRUMENTATION}

Controls shall permit unattended operation for the plant in steady state operation and in switch-over to redundant back-up systems. Instrumentation will permit problem anticipation in the areas of contaminant accumulation, machine wear, and leaks (oil, helium and vacuum). Essential instrumentation such as temperature sensors shall be redundant. Controls shall include protective devices for over pressure, high or low temperature leaks, adequate to protect the cold box from damage or contamination. Controls shall fail safe. The cold box will shutdown and warm automatically without damage to any components. Instrumentation shall permit rapid fault diagnosis. Time meters on active components shall give accumulated operating time and time since reset.

Figure 5.1 does not show the details of gas taps for monitoring pressure, gas purity, and oil purity (for wear particles). Temperature sensors are located at points to monitor heat exchanger and turbine efficiency, temperature of gas entering and leaving the cold box, adsorber status, etc. Pressure taps permit measuring increased pressure drop in the heat exchangers, adsorbers, and filters due to contaminant accumulation.

\subsection{GAS PURITY}

All warm gas lines entering the cold box shall have filters to trap solid particles. Each expander shall have particulate filters to prevent damage to the wheel. Adsorbers shall have filters on inlet and outlet. All lube oil and/or bearing gas lines shall have filters. All adsorbers shall be full flow and dual. Adsorber warmup, reactivation, and cooldown shall be as rapid as possible. Adsorbers shall be warmed by hot gas from a warmup/reactivation heater and shall be cooled by bleed gas from the process stream.

Three pairs of adsorbers shall be used, ambient adsorbers to remove water, $180^{\circ} \mathrm{K}$ adsorbers to remove $\mathrm{N}_{2}, 0_{2}, \mathrm{Ar}_{\text {and }} \mathrm{CH}_{4}$, and $30^{\circ} \mathrm{K}$ adsorbers to remove neon and hydrogen. Al1 adsorbers shall have gas sample taps no more than $2 / 3$ through the bed to monitor adsorber loading status. 
Figure 5.1 shows dual switching adsorbers located at the appropriate temperature levels. Hot gas warmup and reactivation lines are shown along with necessary valving. Cooldown of each adsorber during normal reactivation is shown as being accomplished with bypass process gas. During cooldown of the entire system the LIN cooled bypass gas flows through both the $180^{\circ} \mathrm{K}$ and $30^{\circ} \mathrm{K}$ adsorbers, now operating at $90^{\circ} \mathrm{K}$ to trap and reject impurities. The effluent from the $30^{\circ} \mathrm{K}$ adsorbers goes on to the high pressure circuit of exchanger E-4 to join the major cooldown from the $180^{\circ} \mathrm{K}$ adsorbers. Normal adsorber operating temperatures are reached in the latter stages of cooldown when flow is through the expanders. Filters accessible from outside of the cold box are shown ahead of each expander.

\subsection{CONSTRUCTION}

The cold box shall have two half size expanders in parallel at each expander level to permit maximum efficiency at half capacity. The "off" expander shall be kept cold to permit rapid startup. Expanders shall be capable of being valved off, warmed up, replaced, and recolled in minimum time. Expander seal gas shall prevent oil from getting into the cold box under all circumstances including stand-by warm, stand-by cold, normal running, off design running, transient upset, shutdown, and bearing failure. Turbine oil systems shall be parallel independent.

Seal gas and adsorber reactivation gas (except that with neon) shall be collected for recovery and purification.

Piping shall all be welded or brazed. Double block and bleed valves shall be included on all cold interconnecting lines. Dissimilar metal joints shall be capable of repeated temperature cycle between ambient and operating temperature. Piping shall allow for thermal stresses. Piping and instrument penetrations shall be in a fixed part of the vacuum shell and shall not have to be removed for access to internal components. A single wall vacuum shell shall be used which permits fast access to the internal components. Cold components shall be wrapped in laminar insulation.

Figure 5.1 shows parallel expanders with isolation valves in ready accessible pods. All piping penetrations are shown on the fixed hower section of the vacuum shell. The upper dome of the shell is shown as being readily removable for fast access to the internal components. 


\subsection{MAINTENANCE}

To the greatest extent possible maintenance items shall be serviceable from outside the cold box using a plug in concept. These shall include expanders, expander filters, valve plugs and seats, temperature sensors, pressure sensors. Components requiring maintenance shall be located where they can be easily worked on.

Figure 5.1 illustrates the concepts of having the valves, expander, and expander filters readily accessible on the fixed bottom part of the vacuum shell. These components can be located on the side skirt at an elevation where it is convenient to work.

\subsection{BACKUP REFRIGERATION}

It is quite probable that the cold box will utilize a liquid helium backup system to permit a continuous circulation of cold helium through the cable. This means that failures within the cold box should not prevent helium from being circulated during the time it takes to switch to an al ternate system. The liquid helium backup will be in a separate dewar. Cold gas flow to the line can pass through a heat exchanger which is fed with liquid helium when the gas temperature exceeds that required by the line.

In order to refill the liquid helium dewar the cold box must be designed to alternately produce liquid. Since refrigerator stations will probably have more than one cold box it is not necessary to have each cold box simultaneously produce both liquid and higher temperature refrigeration but rather the spare cold box can be used to produce liquid while the primary cold box is producing only refrigeration.

This entire concept and the associated controls needs further study and evaluation.

\subsection{COST}

Figure 5.2 shows the cold box cost exclusive of turbines and compressor versus compressor power input. This same plot also shows the cost of the cold box plus expander cost taken from section 4.3 and cold box plus expander and dry lube reciprocating compressor costs taken from 4.2. These 


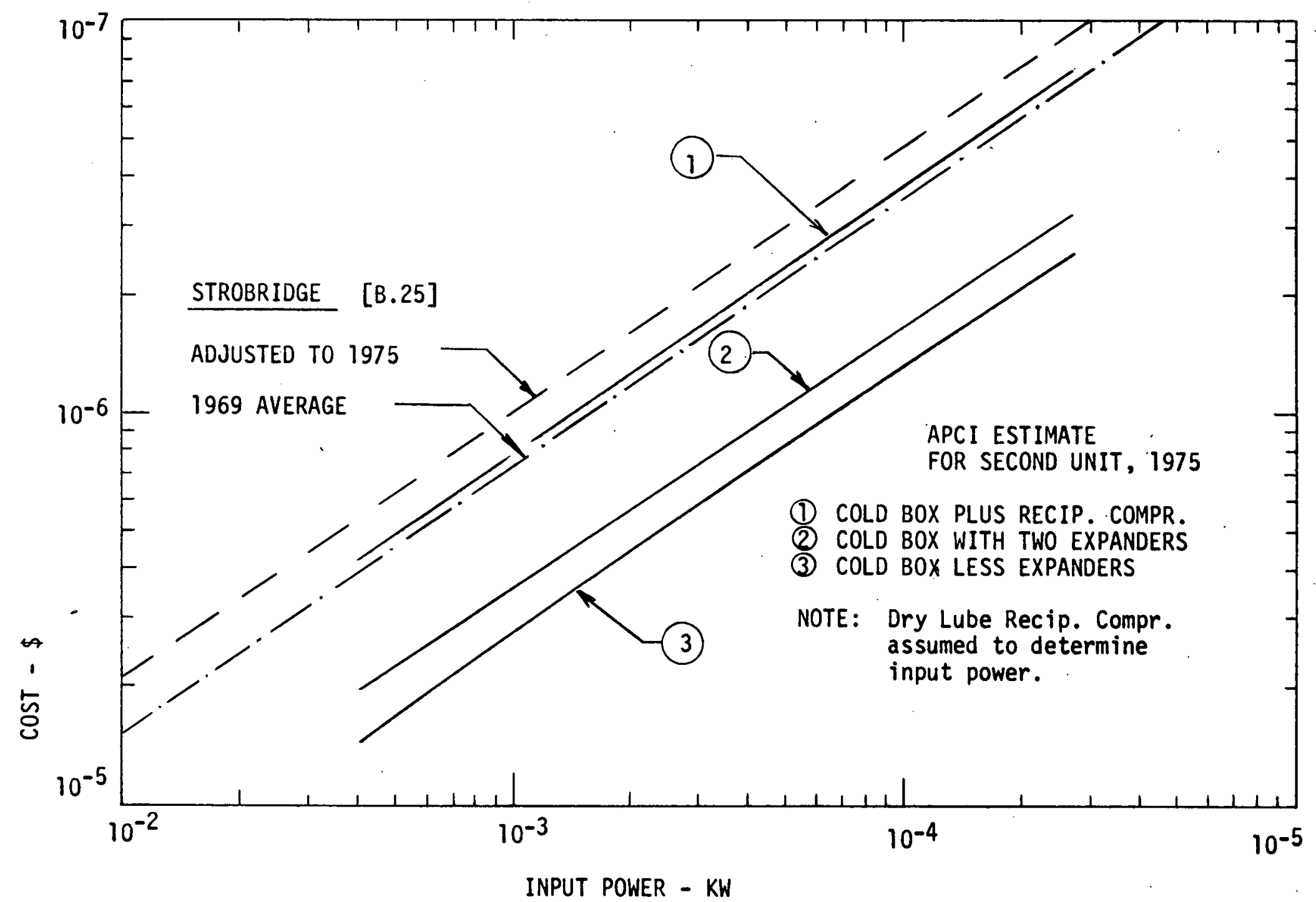

FIGURE 5.2 COLD BOX COST 
costs are based on a unit designed per current practice which would not contain redundant expanders or instrumentation or the fast cooldown and warmup circuits.

The Strobridge averages for cryogenic refrigerators [B.25] include many units from the late 60's which are "first" units. These costs are also shown projected to 1975 assuming $7 \%$ per year inflation. This curve lies about 35\% above the present APCI estimate of "second" unit cost. The difference reflects the design cost included in most first of a kind units.

The costs presented in figure 5.2 are used in section 8 where alternate station cost and reliability values are determined. 


\subsection{APCI EXPERIENCE WITH STANDARD NITROGEN PLANTS}

Air Products presently owns and operates on the order of thirty APCI built standard nitrogen plants which produce between 20 and 120 tons/day of product nitrogen. Some of the compressors used in these installations are about the same size as might be used in the superconducting power transmission line refrigeration plants. The cumulative running time on these plants represents about 200 years of operating experience. These plants are all unattended but are monitored and serviced by an operator who is usually within 100 miles of the plant.

Although one may argue against drawing too close a comparison between the operating characteristics of a standard nitrogen plant and a helium refrigeration plant of the type required for the superconducting power transmission line, there is enough similarity in the physical nature of the individual components (rotating compressors, turbo-expanders, platefin exchangers, and controls) to make it instructive to review the operating experiences on some of the plants to ascertain the major causes of plant shutdown. The failure modes experienced together with the techniques used in insuring high "on-stream factors" (percentage of available time a plant is actually generating nitrogen) can provide valuable insight into the design of helium plants for use on superconducting power transmission lines.

Both the nitrogen plants and the helium refrigeration plants should share the following design objectives:

Both systems strive for a high on-stream factor with virtually no interruption of service to the customer. During the past two year period, APCI standard nitrogen plants have established an overall on-stream factor of $98.5 \%$, that is, the production of nitrogen was interrupted during $1.5 \%$ of the contracted delivery period. Table 6.1 is a tally sheet showing the on-stream factors for APCI plants during the months of April, May, June, July, and August of 1975. APCI guarantees delivery of product 100\% of the contracted time period on all its standard plants; this is made possible by the on-site storage of LIN and in some cases, the delivery of LIN from nearby liquefaction plants. During 1974 there were only two instances in which product was not delivered to the customer; one case involved a failure of the automatic switching system used to switch over to backup liquid tank during a plant failure, and in another instance the automatic unit which notifies the district maintenance office that the plant had shut down failed to operate and the backup liquid supply was exhausted before it was realized that the plant had shut down. 
TABLE 6.1

PERCENT ON STREAM AVAILABILITY OF STANDARD NITROGEN PLANTS DURING THE MONTHS OF APRIL-AUGUST, 1975

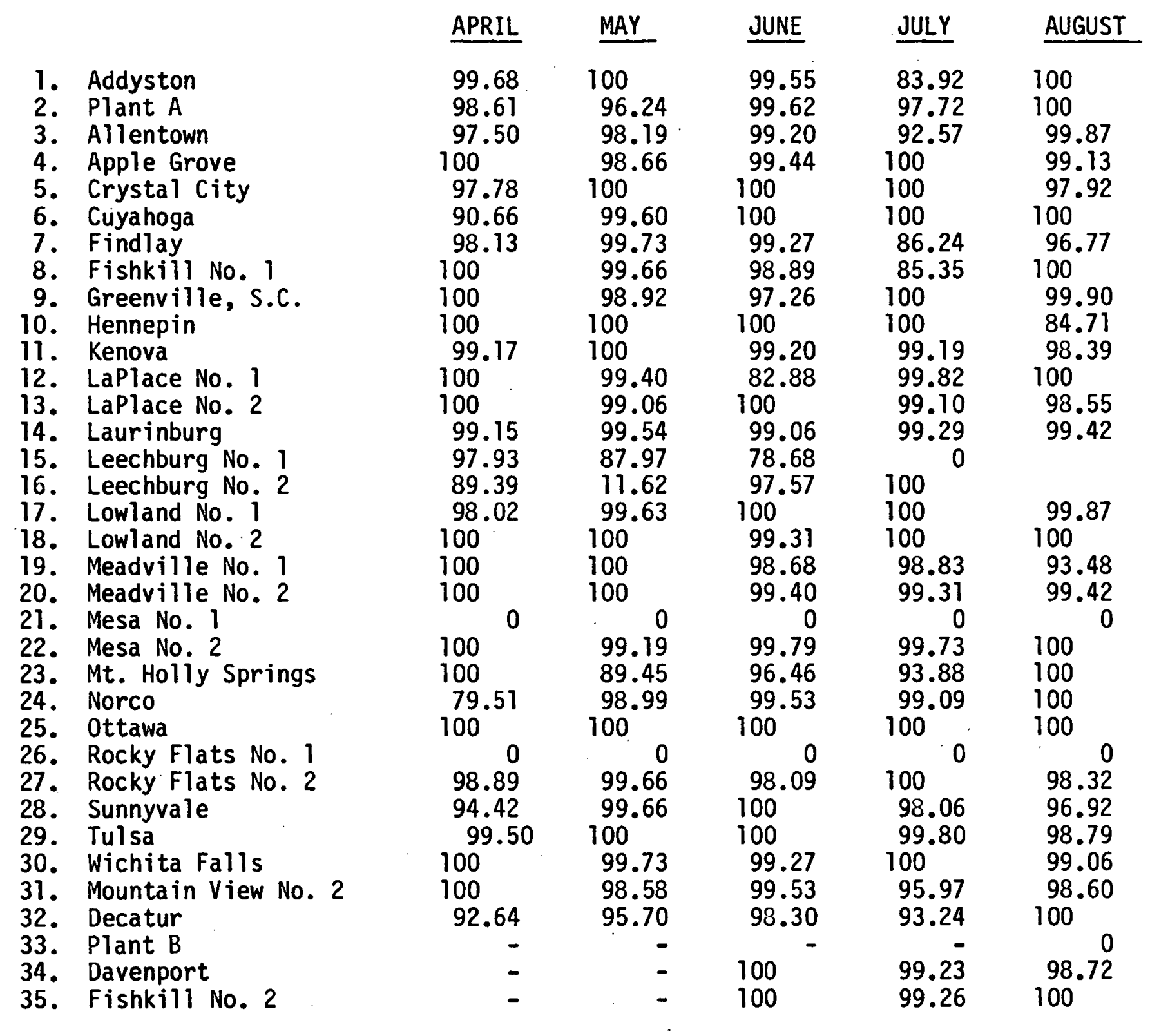


It would be economically advantageous if the helium refrigeration plants could be operated essentially unattended. All of the APCI standard nitrogen plants are designed to run unattended with the exception of a total of about 8 hours per week when an operator checks the plant. The unattended operation is made possible through the use of a "Telemergency" system (Eton Corp.) which automatically contacts the plant manager by phone if a failure occurs.

As will be the case for the design of the helium refrigeration stations, the nitrogen plant designer has had to confront the problem of increasing plant reliability through increased component reliability, preventive maintenance, fast change out of failed components, availability of spare parts, possible use of redundant components, or some alternate means. It may prove to be instructive to review the approach taken by the nitrogen plant designer which has led to the high percentages of "onstream" time illustrated in table 6.1.

In order to understand the approach taken in the design and operation of standard nitrogen plants, which insures product delivery $100 \%$ of the contract time period, it is important to look at a typical standard plant layout along with some representative sampling of the failure modes experienced together with the time interval during which the plant is not in operation during the outage. This information, together with an understanding of the preventative plant maintenance schedule followed in the operation of the nitrogen plants suggests an approach which can be taken in the design of the helium refrigeration plants for the superconductive power transmission lines.

\subsection{STANDARD PLANT DESIGIN AND OPERATIONS}

Figure 6.1 shows a typical, somewhat simplified APCI standard nitrogen plant flow sheet. For illustrative purposes this plant is assumed to produce high purity nitrogen at the rate of about 38,000 SCFM. This plant would require about a 650 BHP compressor to produce the stated product yield. The main air compressors (MAC) used are centrifugal, 3 or 4 stage (depending on plant design) compressors with a typical discharge pressure of about 110 psig. Cooling towers are used to reject waste heat. The air which enters the compressor passes first through the inlet air filter. Following the compressor aftercooler, the gas passes. through the aftercooler separator where much of the moisture is removed from the air. The gas then passes through a section of line which has provision for heating the gas during a plant defrost and proceeds from here to an automatic 


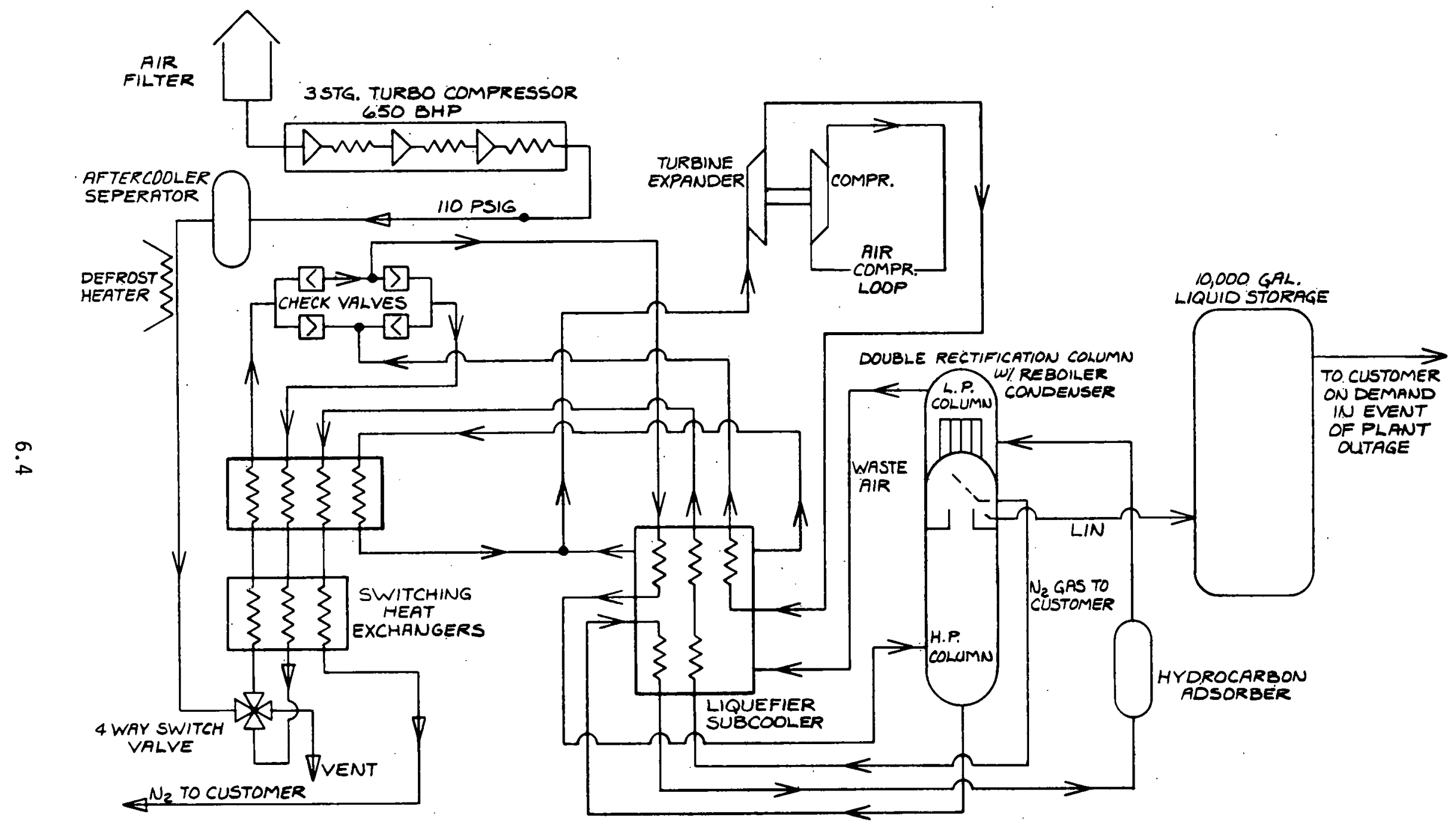

FIGURE 6.1 APCI STANDARD NITROGEN PLANT, SIMPLIFIED FLOW SHEET $(38,000$ SCFH) 
four way switch valve which regularly switches the high and low pressure flow circuits on the two ma in heat exchangers in order to flush out the ice and carbon dioxide on the low pressure exhaust phase of the cycle. The four way valve typically switches every five minutes.

The two main switching exchangers are fabricated from aluminum plate fin cores. After cooling down in the main switching heat exchangers, the gas enters the aluminum plate fin liquefier - subcooler and continues on to the high pressure section of the double rectification column where liquid air, which is higher in $\mathrm{O}_{2}$ concentration, is drained off the bottom of the column and is sent back to the liquefier-subcooler for further subcooling. From there, the air passes through a hydrocarbon absorber bed and is then sent into the low pressure half of the column where it boils as it provides refrigeration for condensing nitrogen in the LP column. The gaseous waste air is then removed from the top of the column. This gas makes another circuit through the liquefier-subcooler and then splits into two streams. One stream goes directly to the turbo-expander while the other stream goes to the expander after first making a pass through the colder of the two switching heat exchangers. The turbo-expanders used in these plants are APCI built radial inflow, oil lubricated turbo expanders which are loaded with an integral turbo compressor. The turbine wheel for this size plant is four inches in diameter and the journal rotates at about $30,000 \mathrm{rpm}$. The pressure ratio across the turbine is typically about 3.3 with an inlet temperature of about $125^{\circ} \mathrm{K}$. Typical isentropic efficiencies for these units are about $80 \%$. From the expander the cold gas, now at about $98^{\circ} \mathrm{K}$, is sent to the liquefier-subcooler once again, back through the switching exchangers, and is finally diverted by the four-way switching valve to a vent stack where it is returned to the atmosphere.

Cold product $\mathrm{N}_{2}$ gas is taken from the top of the high pressure section of the column and is channeled through both the liquefier-subcooler exchanger and the switching heat exchangers before it is sent on its way to the customer. Liquid nitrogen is also tapped off the high pressure column and is piped to a liquid storage tank which, for the case of a 38,000 SCFH plant, would typically be about 10,000 gallons. It is the inventory of liquid in this tank which is used in case of a plant shutdown to insure continuity of $\mathrm{N}_{2}$ supply to the customer. A simple calculation will show that the storage capacity of the storage tank, relative to the required customer demand of 38,000 SCFH, will allow the plant to be off-stream for about 25 hours. As will be shown later, this time interval is adequate to correct the source of the plant outage in a large percentage of the most common failure modes. This time interval is also adequate for most of the scheduled plant maintenance and plant defrosts. 
The principal controls and instrumentation on the compressor, expander and associated lube oil systems and cooling systems are typical of the controls and instrumentation found on other low temperature systems. These include temperature and pressure sensors, speed indicators, electrical power instrumentation, and vibration sensors on both the compressor and expander. Many of these sensors, such as the vibration sensors, provide the operator with an early warning of possible impending failure on either the compressor or expander, which could be prevented by taking corrective measures during scheduled plant shutdown.

Other instrumentation includes an Adelphi Al electrochemical cell analyzer used to measure the impurity level of $\mathrm{O}_{2}$ present in the $\mathrm{N}_{2}$ stream (typical impurity is on the order of 5-10 ppm $0_{2}$ or less). Gas samples may be taken from a number of locations in the plant flow circuit. Exceeding a preset impurity level in the product stream automaticaliy shuts down the plant and switches over to the LIN storage tanks. Also the rectification column liquid level is detected and controlled by two liquid level controllers used in conjunction with drain and vent valves. In the nitrogen plant outage case history which follows, LRC-2 refers to the high pressure column liquid level controller and LRC-3 refers to the low pressure column controller. Exceeding a preset value for any of the plant parameters mentioned above, automatically shuts down the plant, switches over to the reserve liquid supply, and notifies the plant manager of a shutdown via telephone.

\subsection{HISTORICAL EXPERIENCE}

Figure 6.2 is a bar graph showing the percent on stream time for standard nitrogen plants since the first one was put into operation in 1965. Plants which were shut down because of lack of demand, strikes, or lack of cooling water are not included in these averages. The on stream factor has improved from $96.6 \%$ in 1967 when there were four plants in operation, to $98.5 \%$ in 1975 when there were 39 in operation. Data on individual plants shows an overall improvement with time for most plants probably due to improvements in operating procedure and replacement of problem equipment.

\subsection{FAILURE AND MAINTENANCE EXPERIENCE FOR STANDARD NITROGEN PLANTS}

In order to gain insight into the operation of a standard nitrogen plant and the types of failures which cause interruption of service, a case 


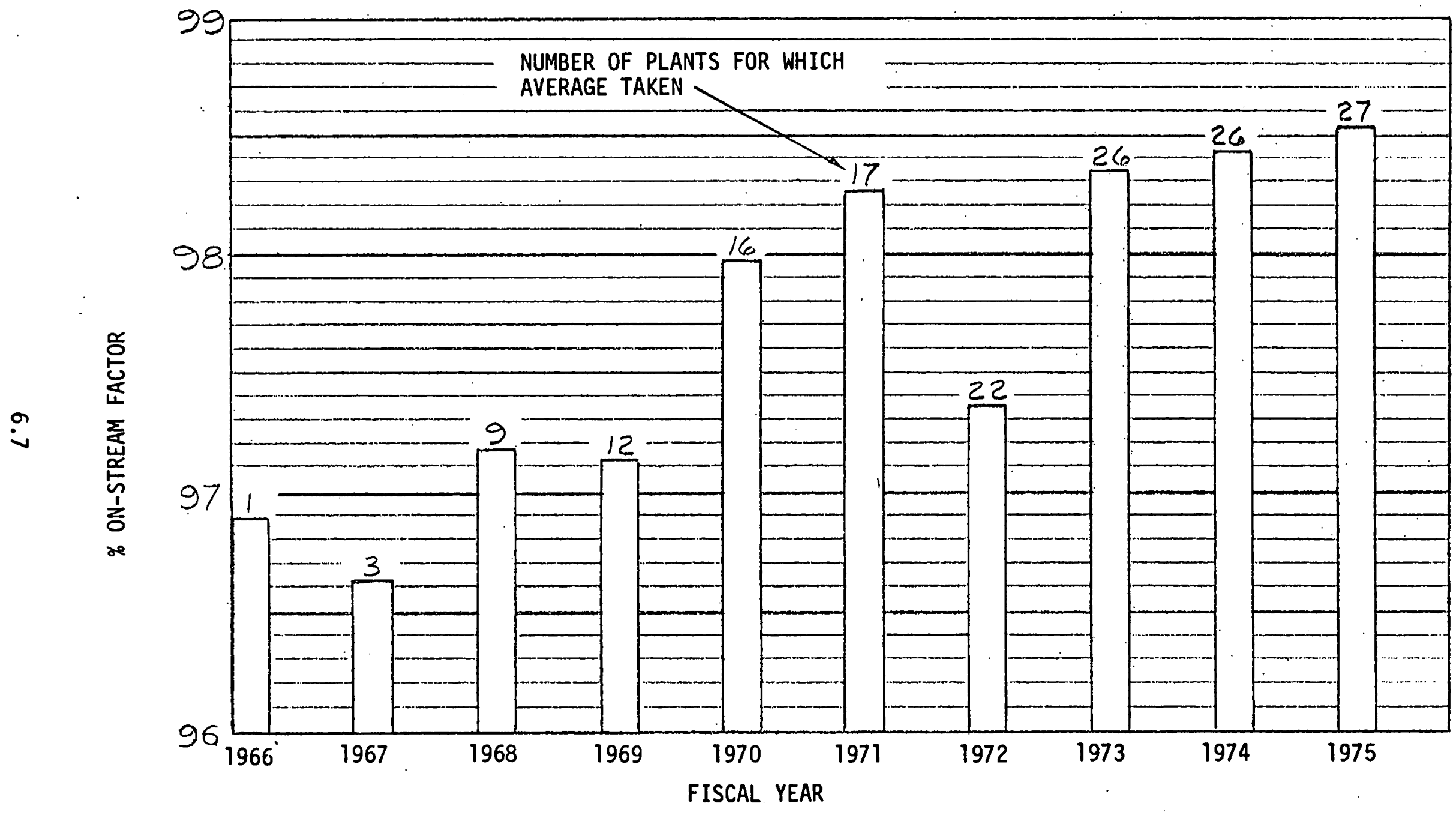

FIGURE 6.2 HISTORICAL ON-STREAM FACTORS FOR STANDARD NITROGEN PLANTS 
history of the outages occurring during the life of one specific plant is presented.

The plant which is to be examined is a 52,000 SCFH N2 plant in Tennessee, (Plant A). The plant outages which are listed in table 6.2 cover the period of operation from 14 July 1970 to 29 July 1975. The reasons for the outages were copied directly from the monthly outage reports submitted by the plant managers to the APCI Operations Department; in some cases, clarifying remarks have been added. A pie chart summarizing the causes of the outages in Plant A in terms of failure categories is given in figure 6.3. A word should be said at this point to clarify some of the categories which appear on the pie charts. Electrical problems refer to all outages of an electrical nature other than main power line interruptions and electrical malfunctions on instruments and process controls. This category would include such things as failures of power transformers, ma in motor controllers, and overloads in motors which cause plant shutdown. Miscellaneous maintenance refers to unscheduled maintenance outages which are of a general nature such as repairing leaks in piping, cleaning filters, etc. Cooling water interruptions include loss of cooling water, loss in cooling water pressure which would trigger an outage, or plugging of heat exchanger tubes because of mineral deposits or dirt. Scheduled maintenance refers to planned plant shutdown designed to perform scheduled preventative maintenance tasks or planned shutdown directed at correcting conditions which indicate deterioration of performance or potential failures in some of the components. The remaining categories are self-explanatory.

In order to obtain a more representative idea of the extent to which certain types of outages cause plant shutdown, an outage pie chart is generated which represents the cumulative experiences of six randomly chosen nitrogen plants (including Plant A). This chart is shown in figure 6.4. The total plant operating time represented by figure 6.4 amounts to about 259,000 hours ( 30 years). The overall on-stream record for these plants is $98.27 \%$.

The first observation one is forced to make in reviewing figure 6.4 is that it is the cumulative effects of mundane types of outages, such as scheduled maintenances, plant defrosts, power interruptions, electrical problems, cooling water problems, etc., which far outweigh the more "glamorous" types of failures such as catastrophic turbo-expander breakdowns and compressor failures, which contribute most to the down-time of the plant. It is interesting to note that the expander and compressor account for only $8.6 \%$ of the total down-time for the plants represented in figure 6.4 . 
Date of Outage

29 Jul 75

22 Jul 75

19 Jul 75

14 Jul 75

8 Jul 75

3 Jul 75

28 Jun 75

20 Jun 75

29 Hay 75

26 Ha6 75

25 Hay 75

24 Hay 75

14 May 75

14 May 75

11 May 75

7 Hay 75

5 May 75

30 Apr 75

$13 \operatorname{Mar} 75$
Duration of Outage (Hrs)

5.0

2.5

1.0

2.5

4.0

2.0

1.0

1.75

8.5

0.5

0.5

0.75

1.0

1.0

0.75

9.5

0.75

10.0

64.25
Reason for Outage

Repair LRC-3-RC (low pressure rectifaction column liquid level controller)

flooded reboiler

Flooded reboiler

Flooded reboiler

Flooded reboiler. $\mathrm{H}_{2} \mathrm{O}$ pump stopped

Low-high pressure column level

Low pressure column upper liquid level line plug

Low pressure column upper liquid level line plug

Low purity. Worked on FRC-6-VI and V2 (flow control valves)

Low purity, low pressure

Low purity, low pressure

Low purity, low pressure

Change switch valve actuator

Low pressure loss of purity

Low purity

Remove and repalr switch valve

Loss of purity

Low column and exchanger pressure

Scheduled plant defrost - 24 months 


\begin{tabular}{|c|c|c|}
\hline Date of Outage & Duration (IIrs) & Reason for Outage \\
\hline 14 Jan 75 & 5.50 & $\begin{array}{l}\text { Low flow to turbo-expander } \\
\text { (changed inlet filter) }\end{array}$ \\
\hline 18 Nov 74 & .1 .25 & Poiver failure \\
\hline 21 July 74 & 17.5 & Main breaker fallure \\
\hline 4 July 74 & 5.50 & $\begin{array}{l}\text { Changed switch vaive and work on } \\
\text { "A" cooling fan }\end{array}$ \\
\hline 30 Jun 74 & 1.0 & $\mathrm{O}_{2}$ Analyzer malfunction \\
\hline 26 Jun 74 & 9.0 & Scheduled defrost and minor raintenance \\
\hline 9 Jun 74 & 4.5 & Switch valve malfunction \\
\hline $26 \operatorname{Hov} 73$ & 3.0 & Earth quake \\
\hline 12 Ilov 73 & 1.50 & $\mathrm{O}_{2}$ analyzer malfunction \\
\hline 2 Nov 73 & 3.50 & Lo: level on H.P. column \\
\hline 29 oct 73 & 0.75 & Customer power failure \\
\hline 25 oct 73 & 4.50 & $\begin{array}{l}\text { Plant maintenance (replaced switch valve, } \\
\text { air inlet filters, etc.) }\end{array}$ \\
\hline 23 oct 73 & 1.75 & Customer power outage \\
\hline 22 oct 73 & 6.0 & Liquefier defrost \\
\hline 19 May 73 & 7.0 & $\begin{array}{l}\text { FRC- } 6-V 2 \text { venting low purity had } \\
\text { closed FRC-6-V1 }\end{array}$ \\
\hline $4 \mathrm{Apr} 73$ & 2.0 & Voltage dip - thunder storm \\
\hline 1 Apr 73 & 1.25 & $0_{2}$ analyzer malfunction \\
\hline 27 Mar 73 & 80.5 & Plant maintenance and defrost \\
\hline $10 \mathrm{Mar} 73$ & 1.0 & $\mathrm{O}_{2}$ analyzer problem \\
\hline 8 Mar 73 & 21.25 & Switch valve failure \\
\hline $2 \operatorname{Mar} 73$ & 2.25 & Harning light \\
\hline 19 Jan 73 & 3.0 & Warning ilght \\
\hline 18 Jan 73 & 3.50 & Marning light \\
\hline
\end{tabular}

Date of Outage Duration (Hrs) Reason for Outage

\begin{tabular}{|c|c|c|}
\hline 12 Jan 73 & 1.25 & Alarm (analyzer malfunction) \\
\hline 13 Jan 73 & 2.50 & Cooling water make-up valve malfunction \\
\hline 19 Dec 72 & 2.25 & High level in H.P. column \\
\hline 12 Nov 72 & 1.0 & Blip on $\mathrm{O}_{2}$ analyzer \\
\hline 16 oct 72 & $3.5]$ & Power interruption \\
\hline 30 Sep 72 & 3.75 & $?$ \\
\hline $4 \operatorname{Sep} 72$ & 2.5 & Cooling water tower problem \\
\hline 22 Jun 72 & 0.50 & $\begin{array}{l}\text { Install pilot vaive in compressor } \\
\text { control panel }\end{array}$ \\
\hline 13 Jun 72 & 9.0 & Electric and plant maintenance \\
\hline 18 May 72 & 2.5 & Change switch valve \\
\hline 8 May 72 & 9.0 & Low level in high pressure column \\
\hline 7 Hay 72 & 2.75 & Low level in H.P. column \\
\hline $8 \operatorname{Mar} 72$ & 2.5 & Low level in H.P. column \\
\hline 16 Jan 72 & 4.9 & $\begin{array}{l}\text { Float valve on cooling water make-up } \\
\text { valve frozen }\end{array}$ \\
\hline 4 Jan 72 & 69.25 & Plant defrost \\
\hline 17 Nov 71 & 8.5 & $\begin{array}{l}\text { Pressure drop across liquefier - H.P. } \\
\text { liquid level low }\end{array}$ \\
\hline 23 Aug 71 & 2.0 & $\begin{array}{l}\text { High oil temperature on air compressor } \\
\text { caused by automatic vaive failure in } \\
\text { water line from cooler }\end{array}$ \\
\hline 14 Jul 71 & 2.5 & Thunder storm \\
\hline 28 Jun 71 & 2.4 & Thunder storm (voltage drop) \\
\hline 27 May 71 & 5.4 & Liquefier defrost \\
\hline 8 May 71 & 4.25 & Electrical repair by customer \\
\hline
\end{tabular}

2 of 3 


\section{Date of Outage Duration (Hrs) Reason for Outage}

\begin{tabular}{|c|c|c|}
\hline $27 \mathrm{Feb} 71$ & 3.75 & $\begin{array}{l}\text { Restriction in H.P. coluan upper liqu } \\
\text { level line causing a low level shutdor }\end{array}$ \\
\hline 18 Jan 71 & Alarm & Low purity scam flashing \\
\hline 8. Dec 70 & 3.0 & $\begin{array}{l}\text { LRC2RC malfunctioned and held LRC2V } \\
\text { wide open causing low liquidd level } \\
\text { shutdown in H.P. column }\end{array}$ \\
\hline 7 Dec 70 & 2.0 & $\begin{array}{l}\text { LRC3V malfunctioned and lost } 1 \text { iquidd } \\
\text { level in reboiler causing lod product } \\
\text { purity }\end{array}$ \\
\hline
\end{tabular}

30 Hov 70

4.50

22 Nov 70

22 Nov 70

28 Nlov 70

27 oct 70

27 Oct 70

20 oct 70

11 oct 70

$28 \operatorname{Sep} 70$

$26 \operatorname{Sep} 70$

25 Sep 70

22 Sep 70

$12 \operatorname{sep} 70$
3.75

$$
4.75
$$$$
3.5
$$

7.75

6.0

5.5

Low cooling water pressure due to cooling water pressure switch frozen with ice

Electrical equipment malfunction

Electrical equipment malfunction

Liquefier defrost

$$
?
$$

Electrical power turned off by customer (did not notify plant)

Low water in cooling tower reservolr, ter pressure

$\mathbf{O}_{2}$ anaiyzer malfunction

High level in H.P. column - purity 9 ppm due to flooding column - caused by LRC-2 line restriction purity $76 \mathrm{pFi}$

High level in H.P. column - purity 9 ppm due to flooding column - caused by LRC-2 line restriction purity 87 ppm

To install larger 3rd stage impellor on Elllot compressor

Electrical equipment malfunction
Upper liquid level line restriction.

\section{Date of Outage Duration (Hrs) Reason for Outage}

$\begin{array}{lll}7 \text { Sep } 70 & 3.25 & \text { Low level }-H . P . ~ c o l u m n \\ 2 \text { Sep } 70 & 34.00 & \begin{array}{l}\text { llew transformer Installed. Hew 3rd } \\ \text { stage wheel installed. Checked 2nd } \\ \text { stage and 1st stage. }\end{array}\end{array}$

10 Aug 70

20 Aug 70

70.00

Expanaer warning flashing and series

\begin{tabular}{|c|c|}
\hline 1 Aug 70 & 3.25 \\
\hline 1 Aug 70 & 64.00 \\
\hline 25 Jul 70 & 2.0 \\
\hline 5 Aug 70 & 13.00 \\
\hline 14 Jul 70 & 4.0 \\
\hline 14 Jul 70 & 3.5 \\
\hline 14 Jul 70 & 3.9 \\
\hline TOTAL : & T9.96 hours \\
\hline AVAILABLE & 44,124 hours \\
\hline \& ON STREAM & 98.37 \\
\hline TOTAL OUTAGES & 89 \\
\hline OUTAGES/YR. & 17.5 \\
\hline
\end{tabular}
rectifier failure, also a transformer
replacement

Voltage dip due to thunder storm

Rectifier in motor control malfunction (installed new 800 amp breaker and rectiffer)

Alcoa power outage

Electrical malfuction (rectifier).

Had to reset (electrical device wires) to start plant

Had to reset (electrical device wires)

to start plant

Vibration switch malfunction 


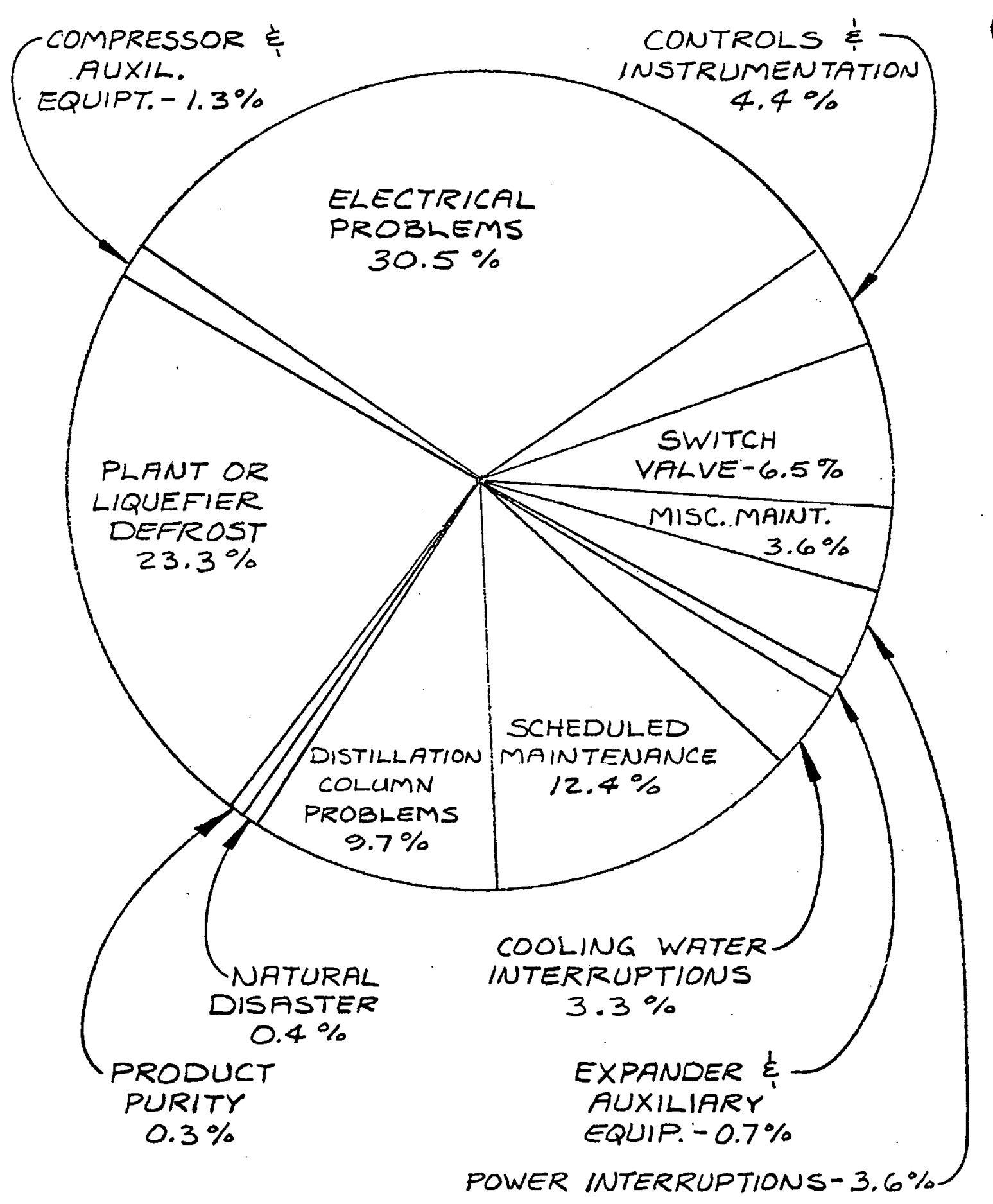

TOTAL PLANT ON STREAII TIME: 44,124 HRS.

TOTAL OUTAGE TIME: 719.9 HRS.

$\%$ OF AVAILABLE TIME ON STREAM: $98.37 \%$

FIGURE 6.3 PERCENTAGE BREAKDOWN OF SOURCES OF PLANT OUTAGE FOR A STANDARD NITROGEN PLANT 


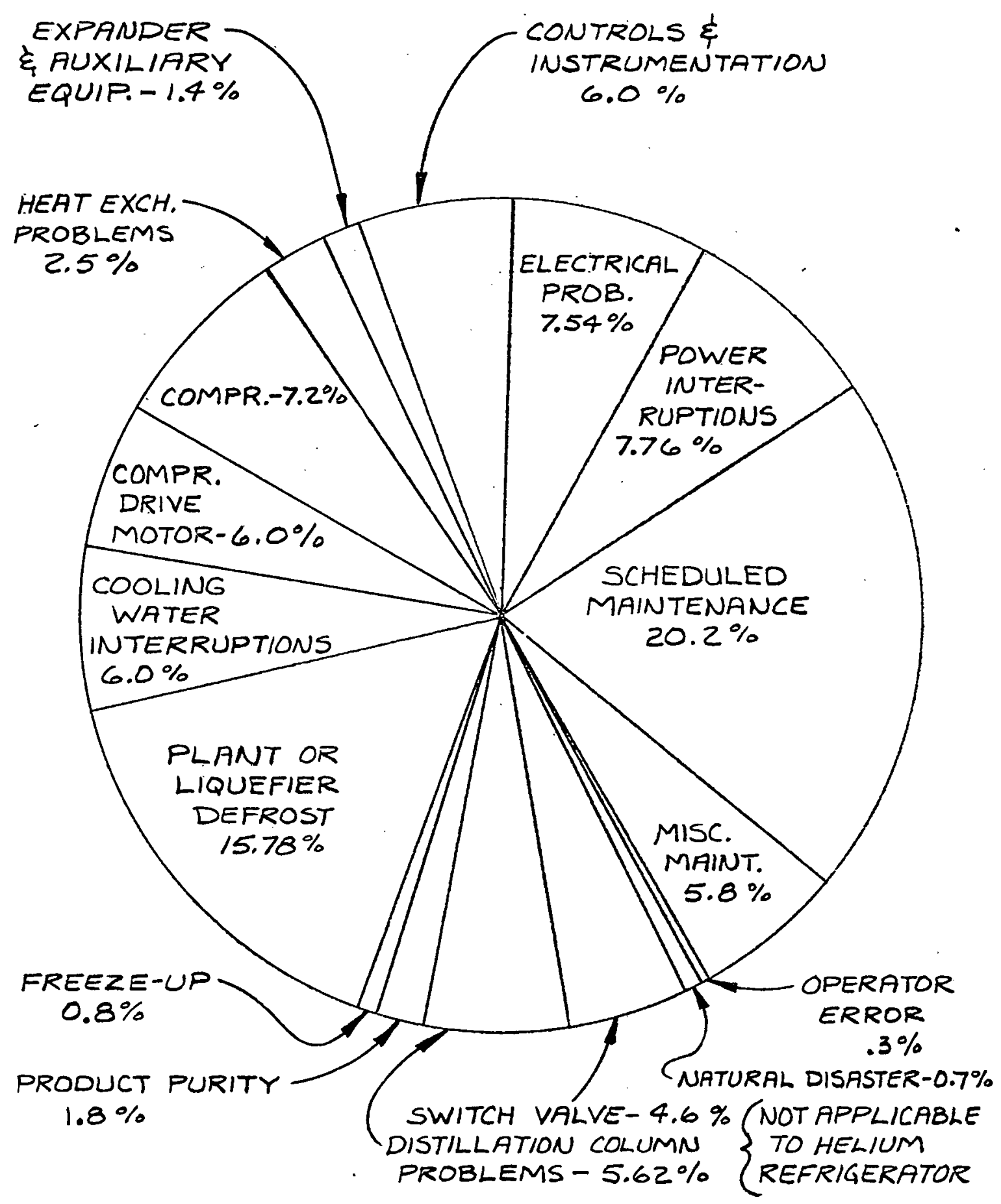

TOTAL PLANT ON STREAN TIME:

TOTAL OUTAGE TIME:

258,996 HRS.

4,465 HRS.

$\%$ OF AVAILABLE TIME ON STREAM: $\quad 98.27 \%$

FIGURE 6.4 AVERAGE PERCENTAGE BREAKDOWN OF SOURCES OF

PLANT OUTAGE FOR SIX STANDARD NITROGEN PLANTS 


\subsection{OUTAGE DURATION VS. FREQUENCY}

Another interesting bit of information which may be gleened from the $\mathrm{N}_{2}$ plant experiences is the time intervals during which the plant is not producing $\mathrm{N}_{2}$ during each outage. A survey was made of the outage time intervals for the six plants used in this investigation, and the findings were arranged in a manner which would show the percentage of outages which fell within ore of four outage time interval groups. These results are presented in table 6.3.

The significance of the results in table 6.3 is that $94.6 \%$ of all plant outages last less than 24 hours. Recall that the inventory of the liquid nitrogen tank shown in figure 6.1 was such that the tank could supply the customers with product for a period of 25 hours. Thus, a large majority of the plant outages can be taken care of without having to call on external sources of liquid nitrogen. A summary of the outages which took more than 24 hours is given in table 6.4. This table indicates that most of the outages in excess of 24 hours were due either to scheduled preventative maintenance or plant defrost. The remaining long outage times result from major breakdowns which require a considerable number of manhours to correct, or else result from the fact that some of the failed components are not usually kept in the plant site parts inventory. The preventative maintenance outage times could be reduced by breaking up the scheduled tasks into smaller groups, in which no group would require greater than a 24 hours outage, or by bringing in a larger maintenance crew to perform the maintenance. This is not done at the present time because there is no economic justification for increasing the maintenance crew size or trying to break a large group of maintenance tasks into a number of shorter tasks. A typical price for trucked in liquid $\mathrm{N}_{2}$ is about $14 \$ / 100 \mathrm{ft}^{3}$. This means that in order to supply a plant with 38,000 SCFH of nitrogen, the cost would amount to about $\$ 53 /$ hour. Thus any corrective measures taken to reduce a 38,000 SCFM plant ma intenance downtime must fall below $\$ 53 /$ hour to be considered - so far there has been no need to enlarge work crews or break the tasks into smaller groups. It can easily be seen that if the $\mathrm{N}_{2}$ which is produced were used in an installation as critical as a superconducting power transmission line there would be considerably more incentive to reduce these large outage periods.

\subsection{MAINTENANCE}

While the LIN storage tank does a great deal to insure that $\mathrm{N}_{2}$ is delivered $100 \%$ of the time, no realistic amount of storage capacity would 
TABLE 6.3

OUTAGE TIME INTERVAL BREAKDOWN

FOR SIX STANDARD NITROGEN PLANTS

DURATIONS OF OUTAGE (HRS.)

0-6

6-24

24-72

$>72$
PERCENTAGES OF OUTAGES

FALLING INTO THIS GROUP

$\%$

73.8

20.8

4.3

1.1 
TABLE 6.4

SUMMARY OF OUTAGES LONGER THAN 24 HOURS

SIX APCI STANDARD NITROGEN PLANTS, UNATTENDED

PLANT DATE HOURS

Addyston

$\begin{array}{llrrr}\prod 1,160 \mathrm{hrs} & 12 \text { Aug } 74 & 54.6 & \text { NCD } \\ 65 \mathrm{t} / \mathrm{d} & 12 \text { Jul } 75 & 112.5 & \text { NCD }\end{array}$

Plant A

$44,124 \mathrm{hrs}$ $45 \mathrm{t} / \mathrm{d}$

\begin{tabular}{|c|c|c|}
\hline 1 Aug 70 & 64 & Motor control rectifier failure \\
\hline Aug 70 & 70 tot. & $\begin{array}{l}\text { Series of expander alarms (no failures) } \\
\text { and several rectifier failures }\end{array}$ \\
\hline $\begin{array}{r}2 \text { Sep } 70 \\
4 \text { Jan } 72 \\
27 \text { Mar } 73 \\
13 \text { Mar } 75\end{array}$ & $\begin{array}{l}34 \\
69.25 \\
80.5 \\
64.25\end{array}$ & $\begin{array}{l}\text { Replace transformer and 3rd stage compressor wheel } \\
\text { PM } \\
\text { PM } \\
\text { PM }\end{array}$ \\
\hline
\end{tabular}

Allentown

$71,040 \mathrm{hrs}$

$10 \mathrm{Jan} 68$

$52 t / d$

16 Jul 68

28 Apr 71

11 Nov 71

3 Feb 72

5 Dec 72

24 Jul 73

15 Jul 74

23 Jul 74

21 Feb 75

32.5 Automatic shutdown, Unknown cause

58.75 PM

43.0 PM

67.33 Compressor motor failure

36.5 PM

42.33 Install experimental switch valve

40.75 PM

38.5 PM

55.25 PM

55.0 High acetylene, defrost

Apple Grove 64,920 hrs. $61 \mathrm{t} / \mathrm{d}$

23 Feb 68

10 Jun 68

10 0ct 69

29 Jun 70

9 Nov 70

10 Dec 72

2 Apr 74

\section{5}

47.5

79.0

57.5

62.5

34.0

27.5
Main air compressor motor failure Switch valve failure

PM

Plugged intercooler on main compressor

PM

Bearing failure on cooling system

PM

East Fishkill

\begin{tabular}{lrrrr}
\hline 49,056 hrs & May 73 & 43.0 & PM \\
$35 \mathrm{t} / \mathrm{d}$ & 25 Jul 75 & 109 & PM
\end{tabular}

Rocky Flats

$18,696 \mathrm{hrs} \quad 20$ Jun $73 \quad 42.5$ Problems with compressor motor and $61 \mathrm{t} / \mathrm{d}$ coupling clearance

NCD No customer demand

PM Preventive maintenance (scheduled)

Capacity is tons/day of gas

Power $\simeq 20 \mathrm{HP} /(\mathrm{t} / \mathrm{d})$ 
prevent the service from being interrupted if the failure rates of the plant components were too high. The outstanding plant outage records owe much to the judicious selection of plant components together with the well thought out and executed preventative plant maintenance program and spare parts inventory control. Both the preventative plant maintenance program and the spare parts inventory for each nitrogen plant are controlled by the APCI computer. The computer keeps track of plant operating time and past maintenance performed at each plant. Cards are then sent out by the computer to individual plants in order to notify plant managers of the need to replace components, perform maintenance checks on specific components, or perform routine plant defrosts. In addition, as spare parts are used up by a specific plant, cards are sent back to APCI which notify the computer of the removal from the parts inventory of a specific item. The computer then notifies suppliers who in turn replace the specific item. All plant managers are required to acknowledge completion of each task the computer has requested them to carry out. Each month the compliance record for each of the APCI plants are tabulated and distributed within the company. This type of "score keeping" insures a high level of compliance to the maintenance tasks requested by the computer; as an example, the overall compliance rate for the month of March 1975 was $98.8 \%$. It is these types of compliance rates which are required to insure on-stream factors on the order of $98.5 \%$.

\subsection{RELATION OF NITROGEN PLANT TO HELIUM PLANT}

The historical experience with standard nitrogen plants as shown in figure 6.2 is probably similar to that which can be expected for large helium plants. It should be kept in mind that this data is based on plants of different sizes which will undoubtedly be the case for the large helium refrigerators.

Table 6.5 compares the causes for outages in standard nitrogen plants with helium plants on a component basis. In general it can be said that there are more similarities than differences. Specific comparisons can be made as follows:

* Cooling Water - Cooling towers are currently common for both plants. The high failure rate in the cooling system plus some of the compressor failures due to heat exchanger corrosion indicate that this is an area that needs to be improved. 
TABLE 6.5

COMPARISON OF OUTAGE CAUSES FOR

STANDARD NITROGEN PLANTS WITH HELIUM PLANTS

COMPONENT

COMPRESSOR SYSTEM:

Cooling Water Interruptions Drive Motor

Compressor

TOTAL
$\% 1$

6.0

6.0

7.2

$\overline{19.2}$

\section{SIMILARITY TO PRESENT HELIUM PLANT}

\section{COLD BOX SYSTEM:}

Heat Exchangers

Expander

Controls and Instrumentation Electrical Problems

Power Interruptions

Operator Error

Natural Disaster

Switch Valve

Distillation Column

Product Purity

Freeze-up

Defrost

TOTAL

- Scheduled maintenance

Miscellaneous maintenance

Vacuum system
2.5 Similar equipment but air plants have cycling pressure and some corrosion

1.4 Similar but helium plants usually have more than one.

6.0 Some similarity

7.5 Typically similar

7.8 Typically similar

0.3 Air plant operators may be better trained at present

0.7 Typically similar

4.6 Not applicable

5.6 Not applicable

1.8 Different but equivalent problems

0.8 Probably more frequent for helium plants

15.9 Comparable but helium plants can be $\overline{54.8}$ defrosted faster

20.2 Helium plants probably have more

5.8 Typically similar

N/A No similarity

$1 \%$ outage time as taken from figure 6 . 
* Drive Motor - Single induction motors are common in both plants. Air Plants have 2-pole motors while most helium plants have multi-pole motors. Some helium plants have turbine drives which should be considered for transmission line helium plants in order to eliminate outages due to power interruptions.

* Compressor - Present helium plants have more outage time due to compressor maintenance because they use multi-stage reciprocating units rather than a single centrifugal unit.

* Heat Exchangers - Plate fin exchangers are common to both plants. Air plant heat exchangers experience pressure cycling and occasionally corrosion cracking that is not the case with helium plants. They are not cooled rapidly thus they provide no experiencial base for failure due to sudden thermal stress. Helium plants are more sensitive to leaks because of their vacuum insulation than are nitrogen filled rock wool insulated air plants.

* Expanders - These standard nitrogen plants all use single oil lubricated turbo-expanders versus one or two oil or gas bearing turboexpanders fould in helium plants. It is significant to note that no records were found of seal oil getting into the gas stream on any of the nitrogen plants that were studied. These expanders were all designed and fabricated by APCI. Turbines in present helium plants typically run at higher speeds but should experience comparable reliability after initial problems have been resolved.

* Controls and Instrumentation - Air plants have controls such as for liquid level and purity that are not found on most helium plants, but most of the temperature and pressure instrumentation is similar. Most controls and instrumentation are fairly standard for both.

* Electrical Problems - Problems with electrical equipment such as transformers, starters, etc., are experienced on both plants.

* Power Interruptions - These depend somewhat on the quality of service of the local power company. Problems should be similar for both plants. Helium refrigerators for superconducting power transmission will have to be designed to operate during periods of power interruptions.

* Operator Error - Operators of standard nitrogen plants receive a lot of trainirg in their operation and have a full time job of operating large cryogenic plants. This is frequently not the case with present helium refrigerators but would be for refrigerators which are part of a power line. 
* Natural Disaster - This problem is probably common to both present day plants. More consideration will have to be given to the location of power line refrigerator stations to avoid problems of floods, land slides, etc. Earth quakes present special problems that will have to be addressed in areas where they are known to occur.

* Switch Valve - Helium plants don't have switch valves and it seems unlikely that they will be considered along with reversing heat exchangers as a means of purifying the gas.

* Distillation Column - Hel ium plants don't have distillation columns.

* Product Purity - This is typically not monitored on present helium units but comparable problems can be expected on the refrigerators for the power line where purity is important and will be monitored.

* Freeze-Up - Present helium refrigerators probably experience more freeze ups than air plants because they are sensitive to air and neon in addition to water and carbon dioxide. They often freeze up because of contaminated gas returning from the dewar to which they are attached. The problems are thus different but similar in nature.

* Defrost - Present helium plants are typically defrosted more frequently than air plants. An air plant takes longer to defrost and return to operation because of the longer period required to cool the ma in heat exchanger and the time to accumulate a working liquid level in the distillation column.

* Scheduled and Miscellaneous Maintenance - Present helium plants probably are out more for regular maintenance because of use of reciprocating compressors and because there are few units that are required to run full time. The CENG hel ium refrigerator for which data is available shows the same outage rate of 18 per year found for the air plants. As system reliability is increased one would expect to see a relative increase of scheduled maintenance and a decrease in unscheduled maintenance.

* Vacuum Leaks - Vacuum insulation is essential for helium refrigerator operation and thus presents problems that are not experienced in air plants.

The standard nitrogen plant experience described in this section probably provides the best base of historical, component, and operating experience for determining what problems are most likely to be encountered in providing the reliable refrigeration required for superconducting power transmission. 
The following observations summarize some of the experience that is gained from review of the nitrogen plants.

* Standard Nitrogen Plants - Experience frequent outages (Ca. $18 /$ year) for a wide variety of reasons.

* High onstream \% is due to:

a) State-of-the-art component reliability.

b) Well planned and executed preventative maintenance program.

c) On-site availability of most needed spare parts and central supply of major spares.

d) Fast correction of problems.

* High onstream \% is not due to:

a) Redundant components.

b) On-site operator.

* Uninterrupted product delivery depends on:

a) Reliable switch over to backup.

b) Replenishment of backup in event of extended outage.

* Plant maintenance averages about 40 hours/month and does not justify on-site operating personnel. 


\subsection{EXTRACTION OF HELIUM PLANT RELIABILITY PARAMETERS FROM STANDARD NITROGEN PLANT DATA}

\subsubsection{APCI Nitrogen Plant Turbo-Expander MTBF}

Because the turbo-expanders used in the APCI plants are almost exclusively of APCI design, quite comprehensive records have been kept relative to turbine failures. Together with the total plant operating time this information allows one to make an estimate of the MTBF of the turboexpander. "Over a total accumulated operating time of a little over 200 years 20 "catastrophic" turbine failures have occurred. "Catastrophic" failure, as used here, refers to failures which occurred without prior warning and before any preventative maintenance could be performed to prevent total failure. If one assumes a $98 \%$ on-stream factor for the entire 200 year period, this translates to a MTBF of about 85,850 hours or a failure rate of

$$
\lambda=1.165 \times 10^{-5} \text { failures/hour }
$$

It should be noted, that when a failure does occur, the normal time which elapses from the time the plant shuts down to when it is back on-stream with the new plug-in expander replacements, is typically between four and seven hours.

\subsubsection{Hel ium Cold Box Reliability Parameters}

Table 6.6 shows the evolutionary thought process followed in deriving the reliability parameters $\lambda^{\prime}, t^{\prime}, \xi^{\prime}$ and $t^{\prime \prime}$ for the case of a helium cold box with three expansion turbines (simulates BNL Plan 3A cold box). The significance of the above parameters is discussed in detail in Section 8.0 dealing with reliability theory; however, for now, one may define the parameters as:

$$
\begin{aligned}
& \lambda^{\prime} \equiv \text { cold box failure rate (failures/year) } \\
& t^{\prime} \equiv \begin{array}{l}
\text { average time required for unscheduled } \\
\text { maintenance operations (hours) }
\end{array} \\
& \xi^{\prime} \equiv \begin{array}{l}
\text { frequency of scheduled maintenance operations } \\
\text { over a period of one year (schedule main./year) }
\end{array}
\end{aligned}
$$


TABLE 6.6

EVOLUTION OF HELIUM (THREE TURBINE) COLD BOX RELIABILITY

PARAMETERS FROM STANDARD NITROGEN PLANT DATA

\begin{tabular}{|c|c|c|c|c|}
\hline $\begin{array}{l}\text { Description of } \\
\text { Specific Plant } \\
\text { Under consider- } \\
\text { ation. }\end{array}$ & $\begin{array}{l}\text { Number of Cold } \\
\text { Box Random } \\
\text { Failures in } \\
\text { One Year } \\
\lambda^{\prime}\end{array}$ & $\begin{array}{l}\text { Average } \\
\text { Time for } \\
\text { Unscheduled } \\
\text { Maintenance } \\
\text { (Hrs.) } \\
t^{\prime}\end{array}$ & $\begin{array}{l}\text { Number of } \\
\text { Scheduled } \\
\text { Ma intenances } \\
\text { in One Year } \\
\xi^{\prime}\end{array}$ & $\begin{array}{l}\text { Average Time } \\
\text { for Scheduled } \\
\text { Maintenance } \\
\text { (Hrs.) } \\
t^{\prime \prime}\end{array}$ \\
\hline
\end{tabular}

Standard $\mathrm{N}_{2}$

Plant with

Water and

9.6

5.79

1.95

20.3

Distillation

Column Fàil-

ures Deducted

Above Plant

Data Corrected

for use of $3 \mathrm{~N}_{2}$

Plant Turbo-

$9.8^{(4)}$

$5.79^{(1)}$

$2.0^{(2)}$

$26.3^{(3)}$

Expanders in

Cold Box

(rather than

the usual single

expander)

Above Plant

Data Corrected

for Presence

of Vacuum

Problems in

Helium Plant

Cold Box

Above Plant

Data Corrected

for Hel ium

System Related

Impurities

Above Plant

Data Corrected

for 3 Helium

Turbines

$10.05^{(5)}$

$6.42^{(6)}$

$2.0^{(7)}$

$26.3^{(7)}$

$10.05^{(8)}$

$6.42^{(8)}$

$2.0^{(8)}$

$26.3^{(8)}$

10.78

(9)

6.42

2.0

26.3 


$$
t^{\prime \prime} \equiv \begin{aligned}
& \text { average time required for scheduled maintenance } \\
& \text { operations (hours) }
\end{aligned}
$$

The line of reasoning followed in evolving from the nitrogen plant cold box to the helium plant cold box is followed by the use of footnoted numbers assigned to some of the reliability parameters which have been modified during the transition from one step in the evolution to the next. The explanation of these footnotes is, found in Appendix $C$.

Table 6.7 presents the reliability parameters for the cold box case which misht use dual half size turbines at each turbine location. The reason for considering such a case is discussed in section 7.0. The procedure used to change $\lambda^{\prime}$ from the value in the previous case is also outlined in Appendix $\mathrm{C}$.

TABLE 6.7

EVOLUTION OF HELIUM (THREE DUAL TURBINE SETS)

\begin{tabular}{|c|c|c|c|c|}
\hline $\begin{array}{l}\text { Description of } \\
\text { Specific Plant } \\
\text { Under consider- } \\
\text { ation }\end{array}$ & $\begin{array}{l}\text { Number of Cold } \\
\text { Box Random } \\
\text { Failures in } \\
\text { One Year } \\
\lambda^{\prime}\end{array}$ & $\begin{array}{l}\text { Average } \\
\text { Time for } \\
\text { Unscheduled } \\
\text { Maintenance } \\
\text { (Hrs.) } \\
t^{\prime}\end{array}$ & $\begin{array}{c}\text { Number of } \\
\text { Scheduled } \\
\text { Maintenances } \\
\text { in One Year } \\
\xi^{\prime}\end{array}$ & $\begin{array}{l}\text { Average Time } \\
\text { for Scheduled } \\
\text { Maintenance } \\
\text { (Hrs.) } \\
t^{\prime \prime}\end{array}$ \\
\hline $\begin{array}{l}\text { Helium Cold } \\
\text { Box with } 3 \\
\text { Turbines }\end{array}$ & 10.78 & 6.42 & 2.0 & 26.3 \\
\hline $\begin{array}{l}\text { Hel ium Cold } \\
\text { Box with } 3 \\
\text { Dual Turbine } \\
\text { Sets }\end{array}$ & $10.25^{(10)}$ & $6.42^{(11)}$ & $2.0^{(11)}$ & $26.3^{(11)}$ \\
\hline
\end{tabular}

COLD BOX RELIABILITY PARAMETERS 


\subsection{OPTIMIZATION CRITERIA AND ALTERNATE REFRIGERATION SYSTEMS}

\subsection{CRITERIA USED FOR OPTIMIZATION}

Development of a valid component optimization criteria must take into account component reliability, efficiency, capital cost, maintenance costs and the cost of necessary utilities such as electric power and water. In order to be effective, the optimization criteria must provide a measure of how all of these component parameters influence the total system reliability and capital plus operating cost. The total system referred to here being the entire superconducting power transmission line refrigeration system, of which the component is a part. In the final analysis, the optimum component is that which permits the total system to reach the required level of system reliability at the lowest capital plus operating cost. The required level of system reliability must be set by the electric utilities. Evaluation of a component in this light requires that a reliability analysis of the entire network of components, which go to make up the complete superconducting power transmission iine, be performed. An analysis of this type would yield an overall system reliability for a specific assemblage of components. This computed reliability, together with the constituent component's associated efficiencies, capital cost, maintenance costs and the cost of utilities, would allow one to put a dollar value on the level of system reliability obtained. Should the computed level of system reliability not meet the level set by the electric utilities; this would then imply that the overall system reliability must be increased either through redundancy or through the use of more reliable individual components. Since the optimization analysis which follows assumes the use of present day commercially available components rather than components which could be made more reliable through development, the approach taken here will be to increase the level of reliability through redundancy.

Two types of redundancy are possible; redundancy of individual components within a sub-system or redundancy of sub-systems rather than components. For example, in the case of the cold box we may provide for an identical back-up cold box, or attempt to duplicate individual components such as turbo-expanders, heat exchangers, purifiers, etc. within a given cold box. Since situations will inevitably arise when a cold box must be warmed up to facilitate maintenance, duplication of cold boxes rather than components is the more feasible approach to take. Also, the requirement for sensing a malfunction within an individual component and the subsequent switch over to its back-up for a number of components within a cold box 
inherently reduces the overall system reliability much more than the sensing of the overall degradation in the output of a cold box and the subsequent switchover to the standby cold box. As will be shown in the section on reliability theory, each switch over has a reliability associated with it which, if less than $100 \%$, can very drastically degrade the reliability of entire system; for this reason it is wise to keep the individual sensing and switching circuits to a minimum, as in the case of the redundant cold box approach.

In the reliability/cost analysis which follows, the cold box and compressor are treated as independent subsystems; in this way the compressors and cold boxes can be optimized separately. Information relating degree of system redundancy, and associated reliability, to capital plus operating cost is generated for both subsystems. The actual cases studied are discussed in section 7.3 .

\subsection{APPLICATION OF OPTIMIZATION CRITERIA TO BNL AND LASL TRANSMISSION LINE CONCEPTS}

While one would like to carry out an optimization analysis for both the Brookhaven National Laboratory's line concept and that of Los Alamos

Scientific Laboratory's, it was decided that it would be more instructive to look in depth at one specific concept. Since a considerable amount of information was available related to BNL's work with the Long Island Lighting Company (A.6) concerning the possibility of running a two circuit superconducting transmission line from Shoreham to Ruland Road on Long Island (Plan $3 A$ ), it was decided to use this plan for the purposes of this study. Each circuit of Plan $3 A$ has a continuous contingency capability of 4800 MVA at $345 \mathrm{KV}$.

While the results of the optimization study of $P$ lan $3 A$ relating to the degree of redundancy required to achieve a specific overall system reliability will probably not be valid for the potentially longer LASL DC line, the procedure followed in the optimization is entirely analogous to that which could be followed to optimize the LASL line concept. The inability to generalize the results of a specific optimization results primarily because the number of stations may be different. As will be shown in section 8.0 , dealing with reliability, as the total number of refrigeration stations increase with the length of a superconducting power transmission line, in order to achieve a given level of total system reliability, the reliability of each of the separate refrigeration stations must increase. This increased reliability would probably manifest itself through increased redundancy. Thus, longer lines would require a greater degree of redundancy than shorter lines to achieve the same final system reliability. 
The requirements for the BNL Plan $3 A$ are given in table 2.1. and the flow schematic for the refrigerator is shown in figure $2 . i$.

It is well recognized that the efficiency of helium refrigeration systems increase with size [B.25] and that the reliability of a given system increases as the number of components decrease [G.1]. Both of the aforementioned facts point in the same direction relative to the design philosophy to be followed in constructing the refrigeration stations for Plan $3 A$; the cold boxes and compressors should be sized so that a single compressor and cold box have sufficient capacity to provide refrigeration for both 4800 MVA circuits (as opposed to one smaller refrigerator for each cable). The refrigeration requirements for a single cold box serving both lines is thus double the values of table 2.1 (see table 7.1).

\subsection{COMPRESSOR OPTIMIZATION}

Results of the compressor manufacturer survey (section 4.3) together with the findings of APCI helium refrigerator user visits (section 3.0) provide the reliability and cost input parameters required to apply the optimization criteria to the helium refrigeration station compressor subsystem. The degrees of compressor redundancy studied in this investigation, and for which cost versus reliability data are generated, are represented by cases CI, CII and CIII as illustrated in figure 7.1 . Case CI represents the use of one compressor per refrigeration station capable of delivering the required $1261 \mathrm{~g} / \mathrm{sec}$ of helium at $15 \mathrm{~atm} \mathrm{re-}$ quired to generate refrigeration for both superconducting transmission line circuits. Case CII represents one compressor identical to that in Case CI with another identical unit in stand-by reserve. Case CIII is the same as Case CII except that two compressors are in stand-by reserve. Cases CI through CIII are examined using the following alternate compressor types: (1) oil lubricated screw compressor, (2) dry lube screw compressor, (3) dry lube reciprocating compressor, (4) labyrinth seal reciprocating compressor, and (5) centrifugal compressor. Application of the optimization criteria selected the compressor type and redundancy option required to meet the level of reliability sought at the lowest capital plus operating cost.

\subsection{COLD BOX OPTIMIZATION}

Cold box design is investigated by looking at two basic design concepts, each with varying degrees of redundancy. In addition, some of these con- 
TABLE 7.1

REFRIGERATION REQUIREMENTS FOR BNL DUAL 4300 MVA, $345 \mathrm{KV}$ SUPERCONDUCTING POWER TRANSMISSION LINE (PLAN 3A)

Heat Load at Superconductor for two Circuits:

7200 watts

Temperature of Central Cable:

$6.75^{\circ} \mathrm{K}-8.75^{\circ} \mathrm{K}$

Load on Shield per Cable:

22,400 watts at $75^{\circ}-100^{\circ} \mathrm{K}$

Equivalent Refrigeration at $8^{\circ} \mathrm{K}$ Required to Cover Heat Shield Losses:

1400 watts

Total Loss at $8^{\circ} \mathrm{K}$ :

8600 watts

Mass Flow in Central Circuit for Two Cables:

$624 \mathrm{~g} / \mathrm{sec}$

Mass Flow of Helium in Shield Circuit:

$160 \mathrm{~g} / \mathrm{sec}$

Mass. Flow Required of Compressor

(from Figure 2.1):

$1261 \mathrm{~g} / \mathrm{sec}$

Compressor Discharge/Suction Pressure:

15 atma / 3 atma

Distance Between Refrigeration Stations:

$12 \mathrm{Km}$

Total Length of Line:

$68 \mathrm{Km}$

( 6 refrigeration stations) 


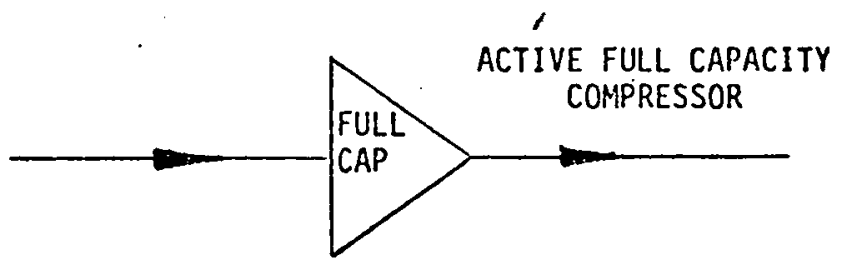

CASE CI

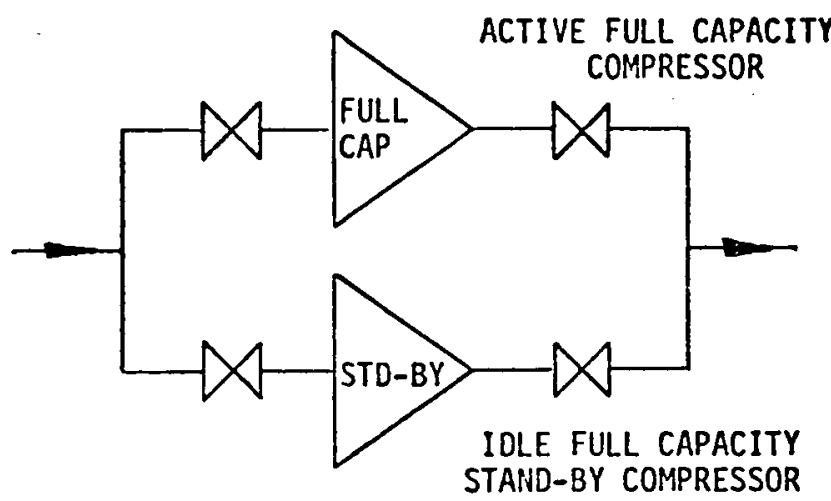

CASE CII

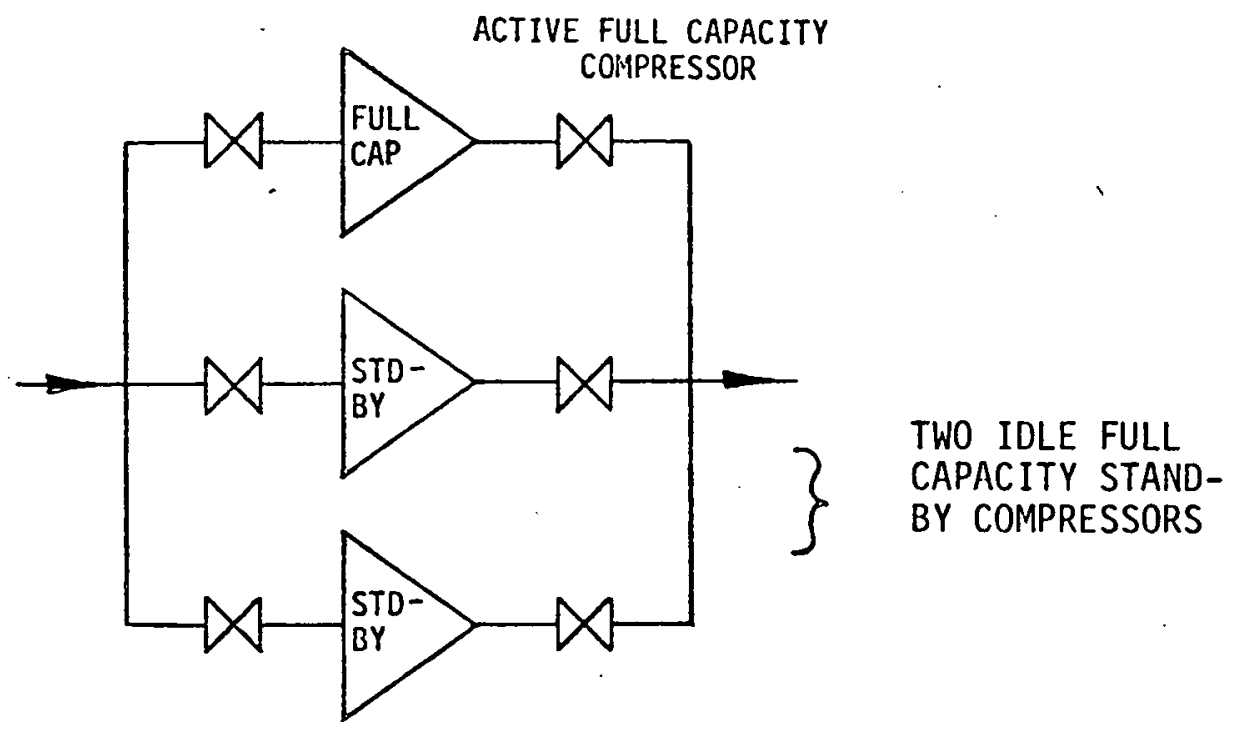

CASE CIII

FIGURE 7.1 COMPRESSOR CASE STUDIES 
cepts utilize a helium storage dewar to back-up the existing cold boxes in a manner analogous to the liquid nitrogen storage vessel used as a back up for APCI standard nitrogen plants. The details of how the liquid helium storage dewar could be utilized to provide refrigeration for the two superconducting transmission lines is discussed in the next section.

Figure 7.2 outlines one basic design concept considered for optimization together with the manner in which redundancy and back-up may be implemented. The basic design philosophy for this concept involves the use of full size cold boxes which, if the need arises, can individually supply sufficient refrigeration to operate both superconducting power transmission lines of Plan $3 \mathrm{~A}\left(8.6 \mathrm{Kw}\right.$ refrigeration at $\left.8^{\circ} \mathrm{K}\right)$; however, normal operation would involve running two of these full capacity sized cold boxes at half the full capacity. In other words, in the normal mode of operation each of two operating cold boxes would supply an equivalent of $4.3 \mathrm{Kw}$ of refrigeration at $8^{\circ} \mathrm{K}$. One possible way in which to implement this mode of operation would be to substitute two half capacity turboexpanders in parallel for each single full capacity turbine normally used in a cold box. Thus, in the normal half capacity operating mode only one turbine of each dual turbine set would be in operation.

The advantage of this type of dual turbine design becomes apparent when one considers the implications of the failure of one of the cold boxes. Since the removal of heat in the superconducting cable is dependent on the helium forced convective heat transfer coefficient as well as the helium temperature, the shut down of one of the cold boxes would, in effect, cut the flow rate of helium in half. This reduction in flow would also reduce the heat transfer coefficient. Because of the long flow lengths involved and the compressibility of the helium, estimation of the time during which one may stay at this reduced flow is a complex problem in transient, supercritical helium heat transfer. Although it is not presently known how long one can stay at this reduced flow, it is probably advisable to get back to full flow conditions as soon as possible - startup of the inactive turbo-expander of each dual turbine set would accomplish this very rapidly. The time involved in slightly altering the temperature profiles within the heat exchangers to correspond with doubling of the flow through the cold box would be much less than the time required to totally cool down another cold box.

In figure 7.2 , case $C B / H$ I refers to the use of two full capacity sized units running in parallei, each at one half their full rated capacity. Should either of these two cold boxes be shut down due to a chance failure or scheduled maintenance, the remaining cold box would immediately switch 
- S.C. Cable

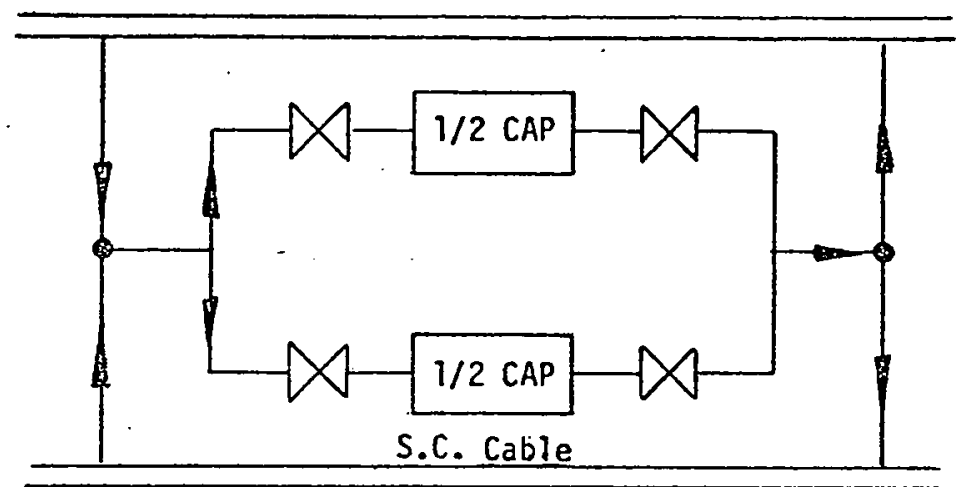

S.C. Cable

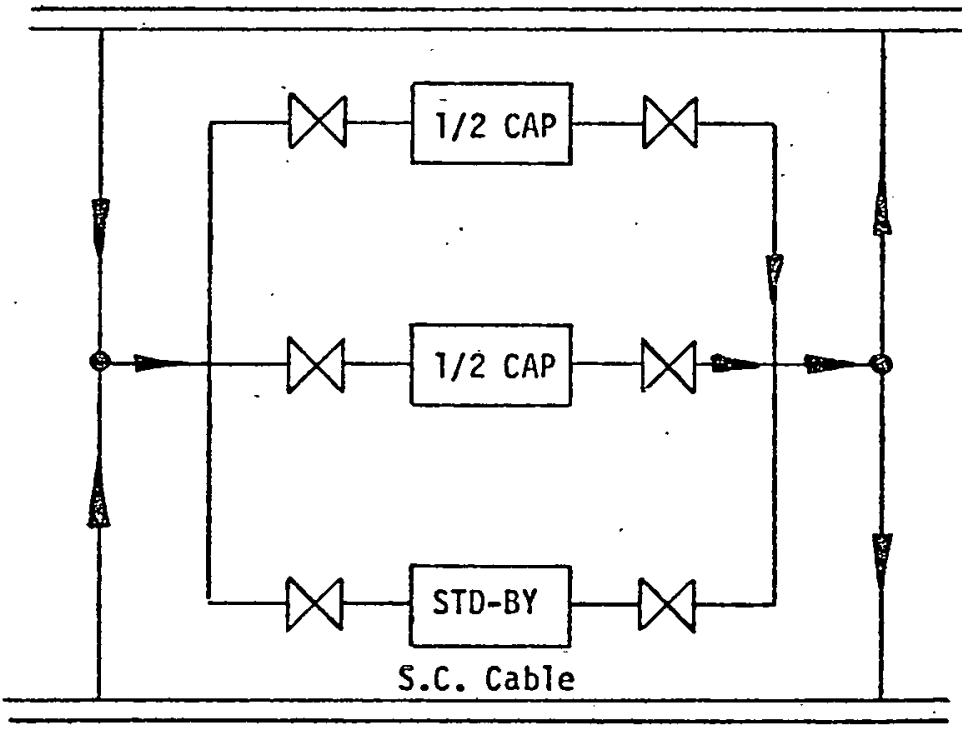

CASE CB/H I

TWO (2) FULL CAPACITY SIZED COLD BOXES RUWHING WORMALLY AT HALF CAPACITY
CASE CB/H II

TWO (2) FULL CAPACITY SIZED COLD BOXES RUNNINGG HORPALLY AT HALF CAPACITY

ONE (1) FULL CAPACITY SIZED COLO BOX CAPABLE OF HALF CAPACITY OPERATION IN STAIND-BY MODE

FIGURE 7.2 COLD BOX CASE STUDIES, FULL CAPACITY TWO HALF CAPACITY TURBINE SETS 
S.C. Cable

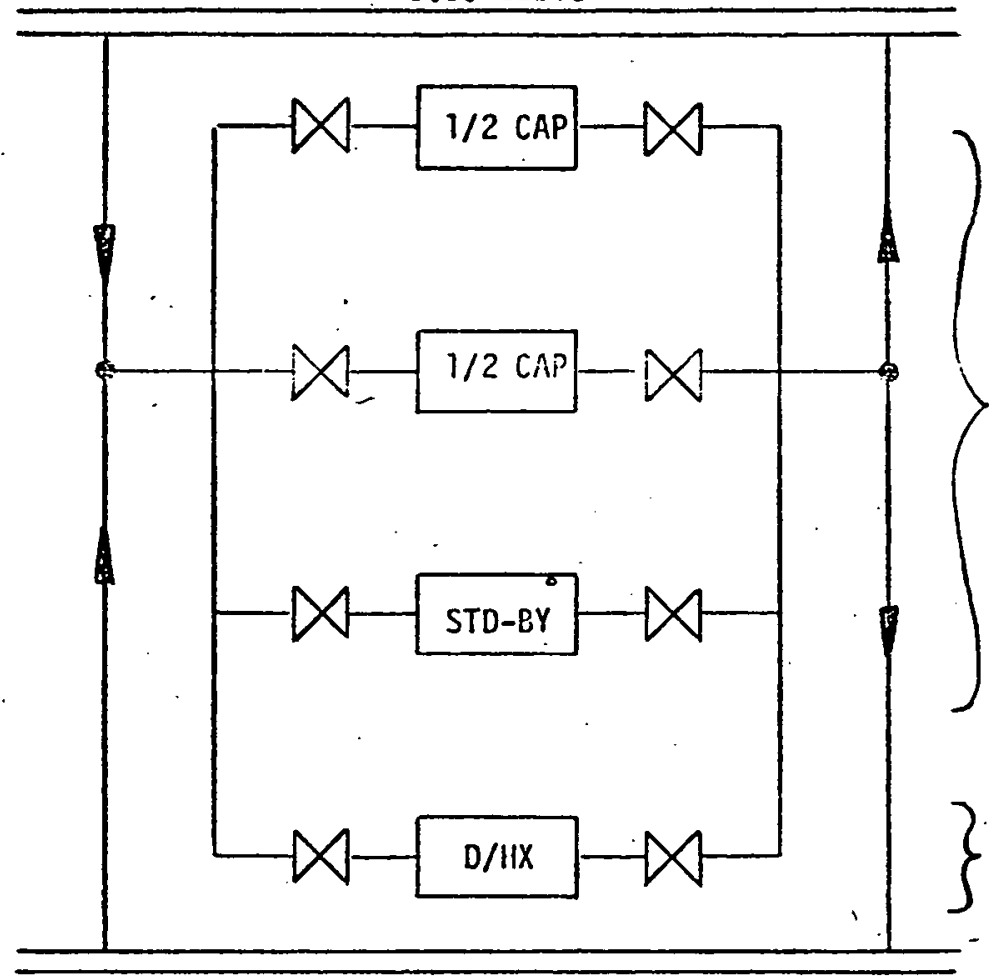

S.C. Cable

\section{S.C. Cable}

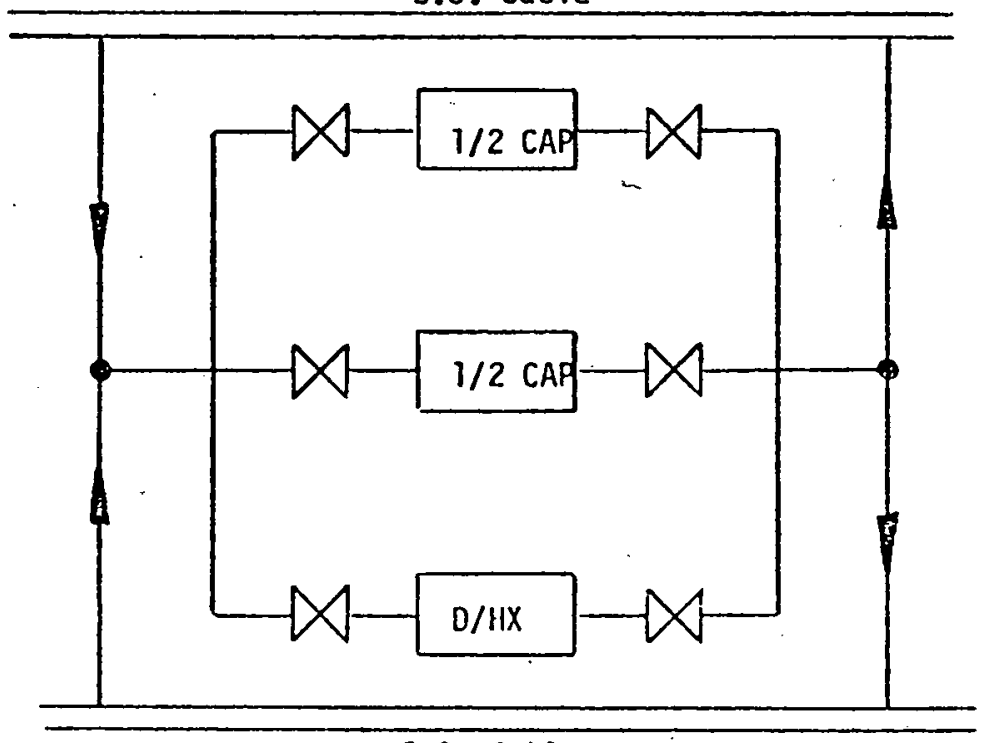

S.C. Cable
CASE CB/H II I

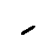

SAME AS CASE CB/H II

LIQUID HELIUM STORAGE DEWAR WITH HEAT EXCHANGER NORMALLY IN STAND-BY MODE - SIZED TO CARRY LOAD OF BOTH S.C. CABLES

CASE CB/H IV

SAME AS CASE CB/H I

LIQUID HELIUM STORAGE DEWAR WITH HEAT EXCHANGER NORMALLY IN STAND-BY MODE - SIZED TO CARRY LOAD OF BOTH S.C. CABLES

FIGURE 7.2 COLD BOX CASE STUDIES, FULL CAPÁCITY, (continued) TWO HALF CAPACITY TURBINE SETS 
to full capacity. Hopefully, this transition could be carried out without modifying the compressor output.

Case CB/H II is similar to case CB/H I except that a third identical unit has been added as a stand-by. In this configuration, should either of the two operating cold boxes shut down the following would take place: the half capacity unit would immediately switch to full capacity and at the same time another compressor would be turned on in order to begin the cooldown of the standby unit. Should the repair of the original cold box take longer than the cooldown time required for the third stand-by cold box, then both the stand-by and full capacity cold box would be switched back to half capacity and one of the two compressors would be shut down. In this configuration the last line of defense before failure of the entire refrigeration station would be to have two cold boxes down for repair and one running alone at full capacity.

Case CB/H III is similar to case CB/H II except for the addition of a helium storage dewar $(D / H X)$ as the last line of defense. Failure of the three cold boxes would necessitate switch over to this system. It is assumed here that the heat exchangers used in conjunction with the helium storage dewar can be kept cold, and ready to immediately take over full load, by utilizing the helium boil-off from the storage dewar.

Finally, case CB/H IV is the same as case CB/H II except for the substitution of the helium dewar/heat exchanger ( $D / H X$ ) for the stand-by cold box. This is the conceptual station shown in figure 1.1.

Figure 7.3 outlines another basic design concept considered for optimization together with its associated schemes for redundancy and back-up. The basic design philosophy for this design concept involves the use of a full size cold box which can handle the refrigeration requirements of both superconducting transmission lines. Unlike the cold box in the previous design concept, this cold box can only operate at full rated capacity. In this concept, failure of the cold box carrying the load of both cables requires immediate action to be taken since, in this case, rather than reducing the flow by 50 percent the flow rate in both cables goes to zero. In order to function properly, this design requires the . immediaie switch over to a helium dewar storage system of the type mentioned in relation to the first design concept. Again, it is assumed that the heat exchanger, which is an integral part of this storage system, be kept cold so as to minimize cooldown time and provide for rapid reestablishment of full load carrying capability.

In figure 7.3, case CB/F I refers to the use of one full capacity cold box and a stand-by helium dewar/heat exchanger system (D/HX). 


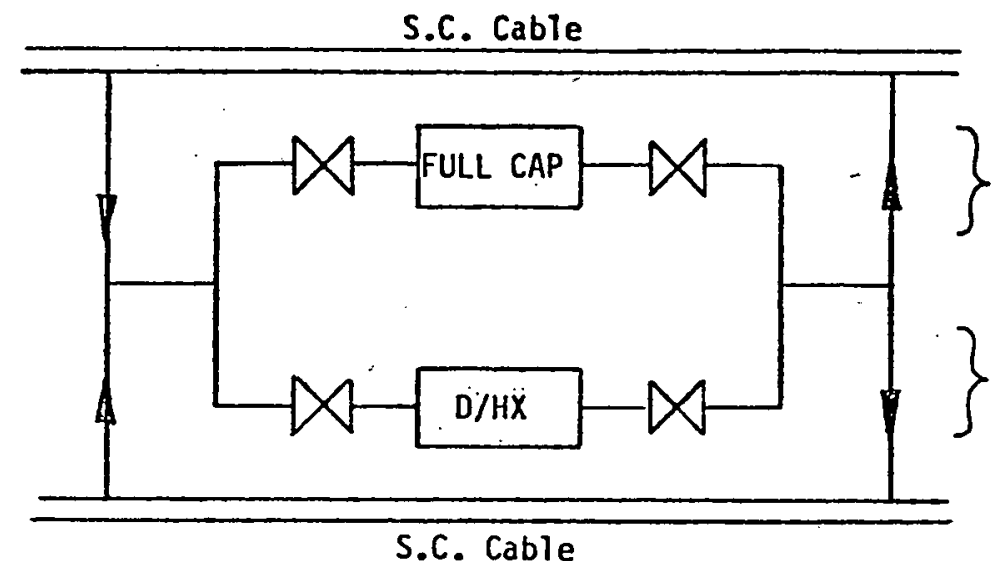

CASE CB/F I

ONE (1) FULL CAPACITY COLD

BOX CARRYING LOAD OF BOTH

S.C. CABLES

LIQUID HELIUM STORAGE DEWAR WITH HEAT EXCHANGER NORMALLY

IN STAND-BY MODE - SIZED TO

CARRY LOAD TO BOTH S.C. CABLES

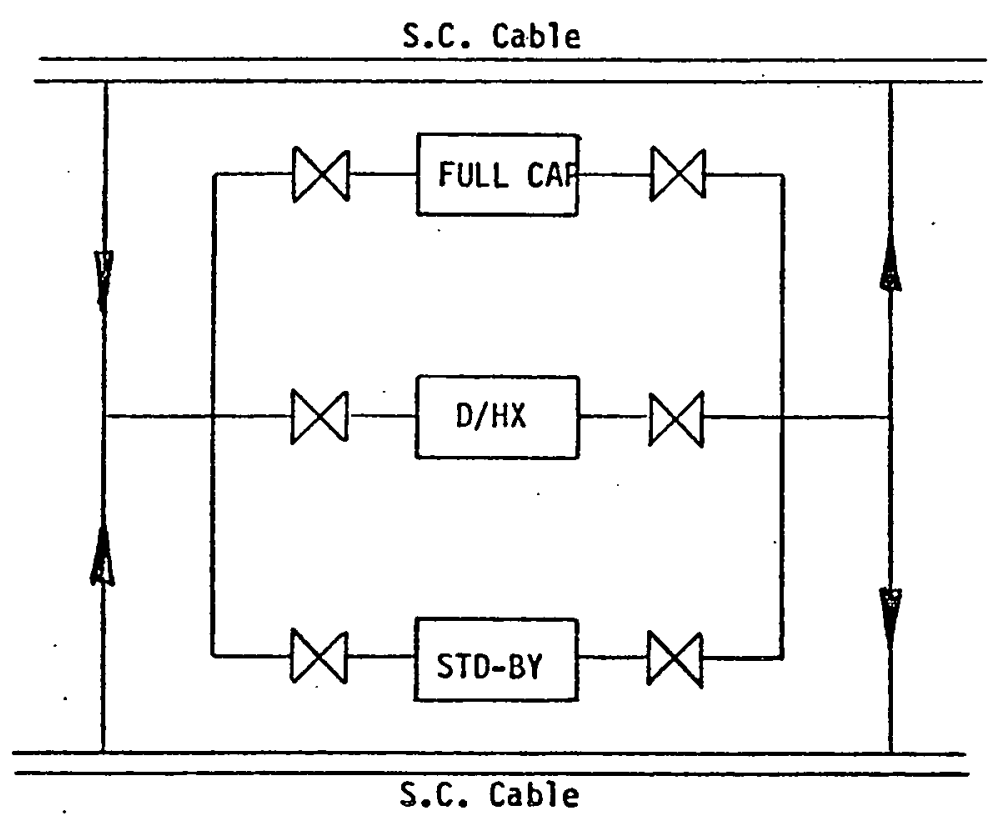

CASE CB/F II

SAME AS CASE CB/F I

ONE (1) FULL CAPACITY COLD

BOX IN STAND'-BY MODE

FIGURE 7.3 COLD BOX CASE STUDIES, FULL CAPACITY, ONE TURBINE SET 
Case CB/F II is similar to case CB/F I except for the addition of a second stand-by cold box. In this scheme, failure of the first full capacity cold box causes the load to be switched over to the dewar/heat exchanger system. At the same time a second compressor is turned on along with the stand-by cold box. If repair of the first cold box takes longer than the cooldown time of the stand-by cold box, then the dewar/exchanger system and one compressor is shut down and the load is now carried by the stand-by.

\subsection{BACK-UP LIQUID HELIUM STORAGE CONCEPT}

A review of APCI standard nitrogen plant experience as presented in section 6.0 clearly points to the need for a liquid nitrogen storage vessel to act as a buffer in the event of a plant shut down. It would be impossible for APCI to guarantee $100 \%$ product delivery if it were not for the presence of this liquid nitrogen storage vessel. In a similar fashion it is probably desirable to provide an analogous helium storage dewar back-up in the case of the superconducting power transmission line refrigeration stations. In the helium system, however, delivery of the "product" is somewhat more complex than in the case of the nitrogen plant, the reason for this being the requirement for a continuous flow of supercritical helium at $15 \mathrm{~atm}$ and a cable inlet temperature of $6.75^{\circ} \mathrm{K}$. This requirement necessitates the use of a back-up sub-system which utilizes a pumping device that circulates the cable helium and uses the helium in the storage dewar as a heat sink which receives the heat picked up from the transmission line.

\subsubsection{Cold Centrifugal Pump Loop System}

The first type of circulating device which comes to mind is a rotary or centrifugal type pump of the variety used by VanderArend [H.2]. A rotary type pump as opposed to a reciprocating pump is deemed to be more practical in the present case because of the high flow and low head requirements. Each $12 \mathrm{~km}$ cable section requires a flow of $312 \mathrm{~g} / \mathrm{sec}$ in the central superconducting cable section with a total pressure drop of about $1 \mathrm{~atm}$. One possible design for a combination pumped loop/dewar storage system is shown in figure 7.4. (Note that this figure shows the requirements for only one of the two cable circuits).

In order to get some idea of the boil-off rate induced in the helium storage dewar as a result of the operation of this loop, an approximate thermodynamic analysis was carried out. One of the parameters required to 


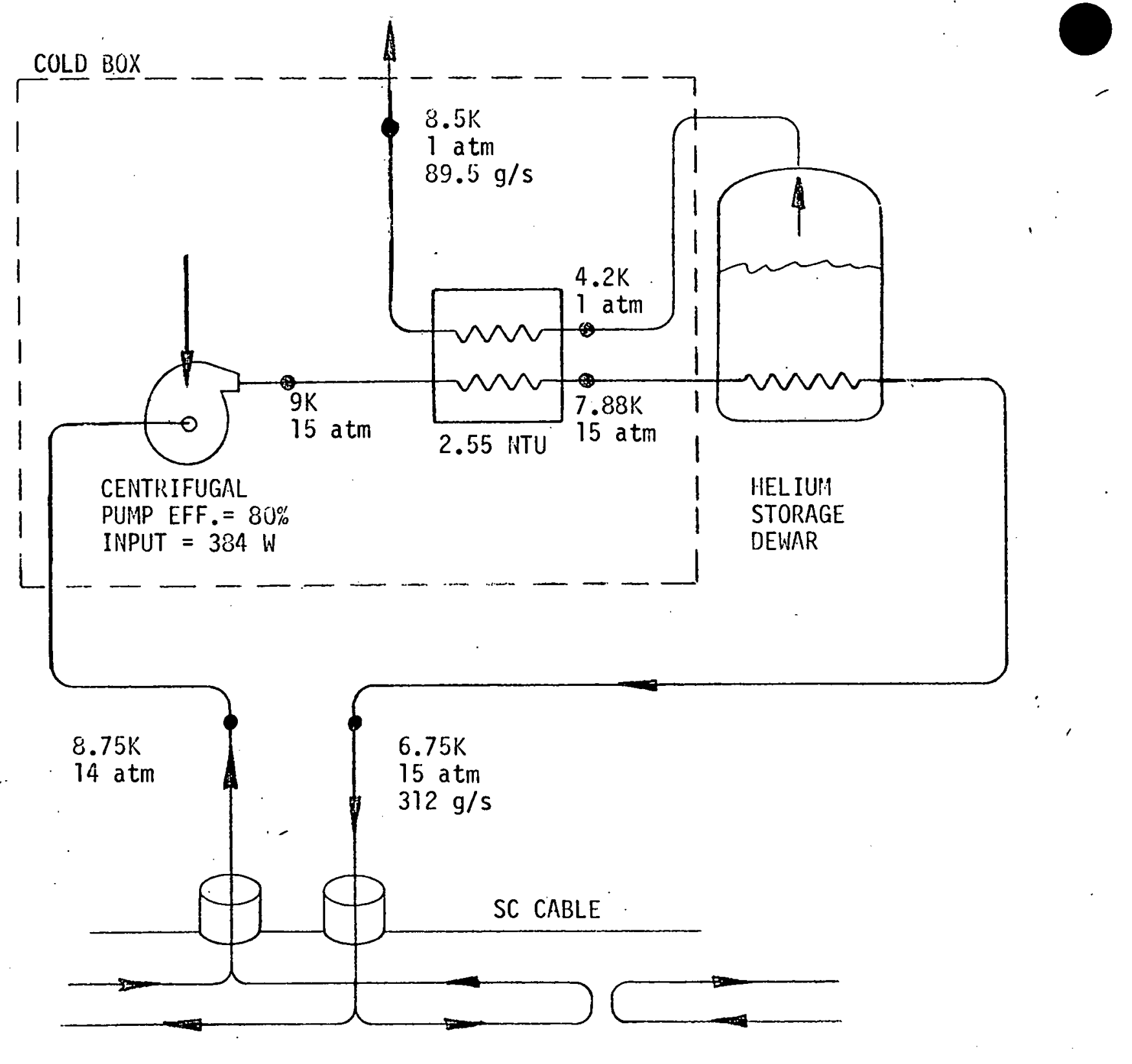

FIGURE 7.4 CONCEPTUAL DESIGN FOR A CENTRIFUGAL PUMP-LOOP/HELIUM STORAGE DEWAR BACK-UP SYSTEM FOR ONE CABLE OF BNL PLAN $3 A$ 
carry out this calculation is the circulating pump efficiency. In his work for EPRI, Strobridge (B.29) has assumed a maximum overall efficiency for submerged motor centrifugal pumps (including the losses in the impeller and motor) of 35\%. On the other hand, Bogner (A.7) cited the use of a Siemens helium pump capable of mass flow rates up to several thousand liters per hour which he reports to have an unusually high efficiency of greater than 90\%. It is not clear from this paper what is included in this efficiency. In order to give the pump the benefit of the doubt, the thermodynamic analysis is carried out with an assumed combined motor and pump efficiency of $80 \%$. The results of this analysis are displayed in figure 7.4. The analysis assumes a main exchanger warm end $\Delta T$ of $0.5^{\circ} \mathrm{K}$; this results in a heat exchanger NTU requirement of about 2.55 and a ratio between the ca ble helium mass flow rate and the helium dewar boil off of 0.287 . This analysis ignores heat leak to any of the cold components.

\subsubsection{Warm Compressor Circulating Loop System}

In order to have some basis of comparison, an alternate system is analyzed. The system chosen is illustrated in figure 7.5. This system uses a conventional warm compressor to circulate the helium in the superconducting cable. This concept would probably utilize one of the compressors used to supply gas to the cold box; this is especially true if the oil lube screw compressor were used since the flow control slide valve could be utilized in order to reduce the flow from the $1261 \mathrm{~g} / \mathrm{sec}$ required for the cold box down to the $624 \mathrm{~g} / \mathrm{sec}$ required if the circulating system supplied gas to both superconducting cable circuits.

The results of the thermodynamic analysis which was performed are displayed in figure 7.5. This analys is also ignores heat leak. Note that the ratio of the cable mass flow rate to the dewar boil off rate, is only slightly greater than the ratio obtained for the cold pump loop system. In this case the ratio is 0.30 .

As would be expected, the warm exchanger required for this application is quite large. Approximately 30 NTU's would be required and in terms of physical dimensions would need a plate fin aluminum core of about $0.91 \mathrm{~m}$ $\times 0.81 \mathrm{~m} \times 6.1$ (this would yield a heat transfer surface area of about $6225 \mathrm{~m}^{2}$.

The smaller cold exchanger would require a heat transfer area of about $130 \mathrm{~m}^{2}$. This surface could be obtained in a size of approximately 0.3 $\mathrm{m} \times 0.33 \mathrm{~m} \times 1.22 \mathrm{~m}$. 


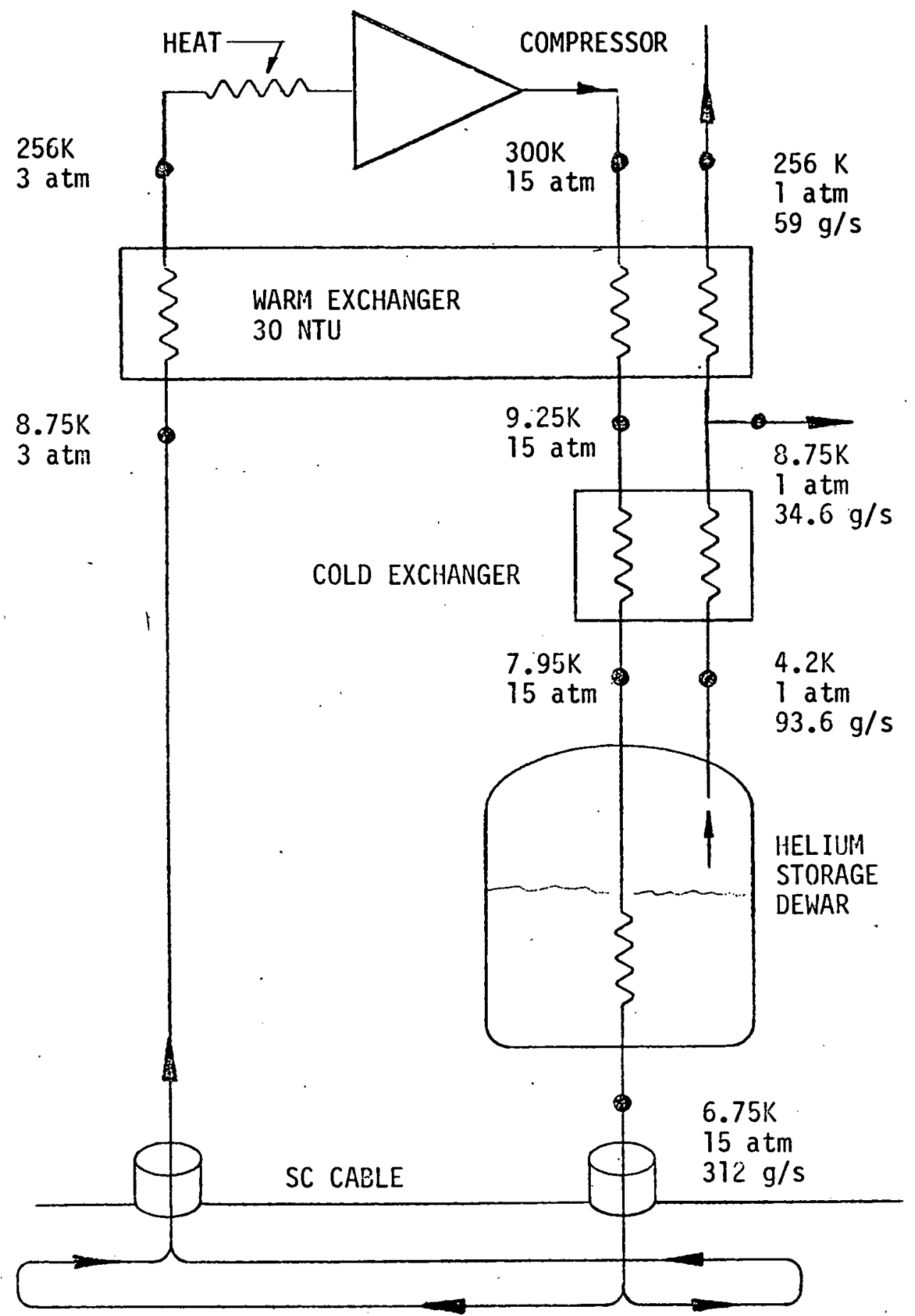

FIGURE 7.5 CONCEPTUAL DESIGN FOR A WARM COMPRESSOR CIRCULATING LOOP/HELIUIA STORAGE DEWAR BACK-UP SYSTEM FOR ONE (1) CABLE OF SNL PLAN $3 A$ 


\subsubsection{Circulation Option Chosen for Present Study}

The circulating device option selected for the helium storage vessel back-up system was the warm circulating pump concept. The reasons for choosing this concept over the cold centrifugal pump loop option are:

* The main compressor used to operate the cold box could be utilized to circulate the helium in the cable. This is particularly true in the case of the variable capacity oil lube screw compressor.

* Since the gas circulating device is at room temperature and readily accessible, it is easy to perform both scheduled and unexpected ma intenance operations.

* Probably the most compelling reason for selecting the warm circulating compressor is that it permits the development of much higher heads than is possible with a centrifugal type circulating pump. This is an important point particularly if BNL and LASL prove the feasibility of the far-end expander concept conceived by John Dean of LASL and discussed in section 2.5. Note that the diagram in figure 7.5 has already allowed for this possibility in that the helium gas pressure used at the inlet of the compressor is $3 \mathrm{~atm}$ rather than $14 \mathrm{~atm}$ as in the case of the cold circulating pump; however, this difference in pressure has no significant effect upon the heat exchanger size calculation.

A fortunate result of this selection is that both the reliability parameters and the cost information for the warm conventional type of compressor is fairly well defined whereas similar data for a centrifugal circulating pump of the proper size would be difficult to estimate.

While the warm compressor circulating system should work in principle, a number of potential problem areas, such as flow stability problems should be investigated.

\section{7:5.4 Storage Capacity Required for Helium Dewar}

The survey of six randomly selected APCI standard nitrogen plants presented in section 6.0 indicated that $94.6 \%$ of the outages experienced in these plants lasted less than 24 hours. If the outage intervals for the helium refrigeration plants also fall into, this range, the volume of 
stand-by helium required is easily computed. Actually, one would probably expect a higher percentage of outages to fall within the 24 hour time frame for the helium plant because of the much higher premium placed on short turn-around time in the superconducting transmission $l$ ine system.

On the basis of a 24 hour storage capacity the required liquid volume is about 130,000 liters or about 3.4 truck loads. This number is obtained by assuming a boil-off rate in the dewar of 5390 liquid liters per hour $(11 / h r)$. This corresponds to the heat load imposed by supplying refrigeration to both of the Plan $3 A$ cables.

Should the outage time exceed 24 hours it would be necessary to truck in liquid helium from the storage dewars of the two adjacent refrigeration stations. Using the value of the percentage of Carnot efficiency achieved by the full size refrigerators considered in the present investigation (about $16.6 \%$ based on the use of a dry lube reciprocating compressor) one can calculate the potential liquefaction rate of these refrigerators if they can be designed to al so act as liquefiers. This is done in a manner suggested by Strobridge (B.25). On this basis, each cold box has a potential of delivering about $1300 \mathrm{LL} / \mathrm{hr}$ of liquid helium. This tells us that after the helium supply of the two adjacent storage dewars. has been exhausted, it would take the liquefaction output of four cold boxes to enable the refrigeration station, with the inoperative cold boxes, to continue to carry the load of both superconducting cables.

\subsection{COST AND RELIABILITY PARAMETERS USED IN OPTIMIZATION STUDY}

The cost for the warm compressor dewar/heat exchanger system ( $D / H X)$ is calculated using the dollar value of heat exchanger cores taken from section 4.4 and the dollar value of helium storage dewars taken from section 4.9. The cost of the vacuum insulated cold box surrounding the warm and cold heat exchanger, in addition to the associated piping is computed on the basis of finding the cost of a helium dewar of the same volume as the heat exchanger cores. This should provide a conservative cost estimate. A tabulation of the cost for a system capable of handling both cable loads simultaneously follows: 
Warm Exchanger Core

$\left(0.91 \mathrm{~m} \times 0.81 \mathrm{~m} \times 6.1 \mathrm{~m} ; 6225 \mathrm{~m}^{2}\right.$ surface area)

$\$ 71,500$

Cold Exchanger Core

( $0.30 \mathrm{~m} \times 0.33 \mathrm{~m} \times 1.22 \mathrm{~m} ; 130 \mathrm{~m}^{2}$ surface area)

$\$ 9,100$

Cost of Helium Dewar of Same Volume as Heat

Exchanger Cores (4654 liters)

$\$ 48,390$

Cost for 130,000 Liter Vapor Shielded Helium

Storage Dewar

$\$ 440,050$

TOTAL COST

$\$ 569,040$.

From a reliability standpoint, the dewar/heat exchanger system (excluding the compressor) represents what can be termed a passive system; this infers the absence of any components with moving parts which are usually the components that appreciably reduce the overall reliability of the system. The only components other than the dewar, vacuum insulated cold box, purifier and heat exchanger cores which could contribute to the failure of the system would be controls which might be used to monitor impurity build-up in the heat exchangers. The sensing of these impurities could probably be handled by a differential pressure transducer. which would monitor the heat exchanger pressure drop.

With respect to the reliability of large helium storage dewars only; of four large storage dewars for which reliability data was available, no failures were experienced during a cumulative liquid hold time of 376,000 hours. Because of the nearly passive nature of the dewar/heat exchanger system (with the exception of some of the controls), it can conservatively be assumed that the mean time between failures for this system is about 30,000 hours. A value of 30,000 hours is used in the reliability analysis of section 8.0; and the effect on the overall system reliability of using dewar/heat exchanger systems with higher MTBF's is also discussed. 


\subsection{RELIABILITY AND COST OF ALTERNATE REFRIGERATOR SYSTEMS USING CURRENT TECHNOLOGIES}

\subsection{RELIABILITY THEORY}

In order to understand the concept of reliability, let us look at a simple example. Assume that one of the temperature sensors used in a refrigeration system is subject only to those failures which occur completely at random (chance failures). The reliability of this sensor during an interval of time, $t$, is given by the formula (G.I):

$$
R(t)=e^{-\lambda t}
$$

where $\lambda$ is a constant which expresses the chance failure rate (fa'ilure/unit of time) of the sensor. This failure rate is a statistically derived average value which is the reciprocal of what is known as the mean time between failure (MTBF) for the component in question. The reliability of the sensor, $R(t)$, expressed in equation (8.1) represents the probability that the device will not fail during the operating time interval, $t$.

As pointed out by Bazovsky (G.I), this formula is correct only for those components which have been adequately debugged and which have not as yet been subjected to appreciable wear. Note also that the time, $t$, used in the reliability formula must never exceed the useful life of the device.

Hel ium refrigerators are made up of many individual components; this makes the computation of a system reliability slightly more complex, but as will be shown below, the procedure to follow is fairly straightforward.

In order to illustrate how components are combined to obtain the reliability of a subsystem, reference is made to the component reliability block chart displayed in figure 8.1 .

This figure displays the BNL cold box with all the major components in a "series" configuration (1inked one to another). A "series" type block link implies that if any of the component blocks in the chain fails, then the entire subsystem itself will fail. If $R$ refers to the reliability of component 1 (heat exchangers), then the probability of no failure taking place during time $t$ is, 


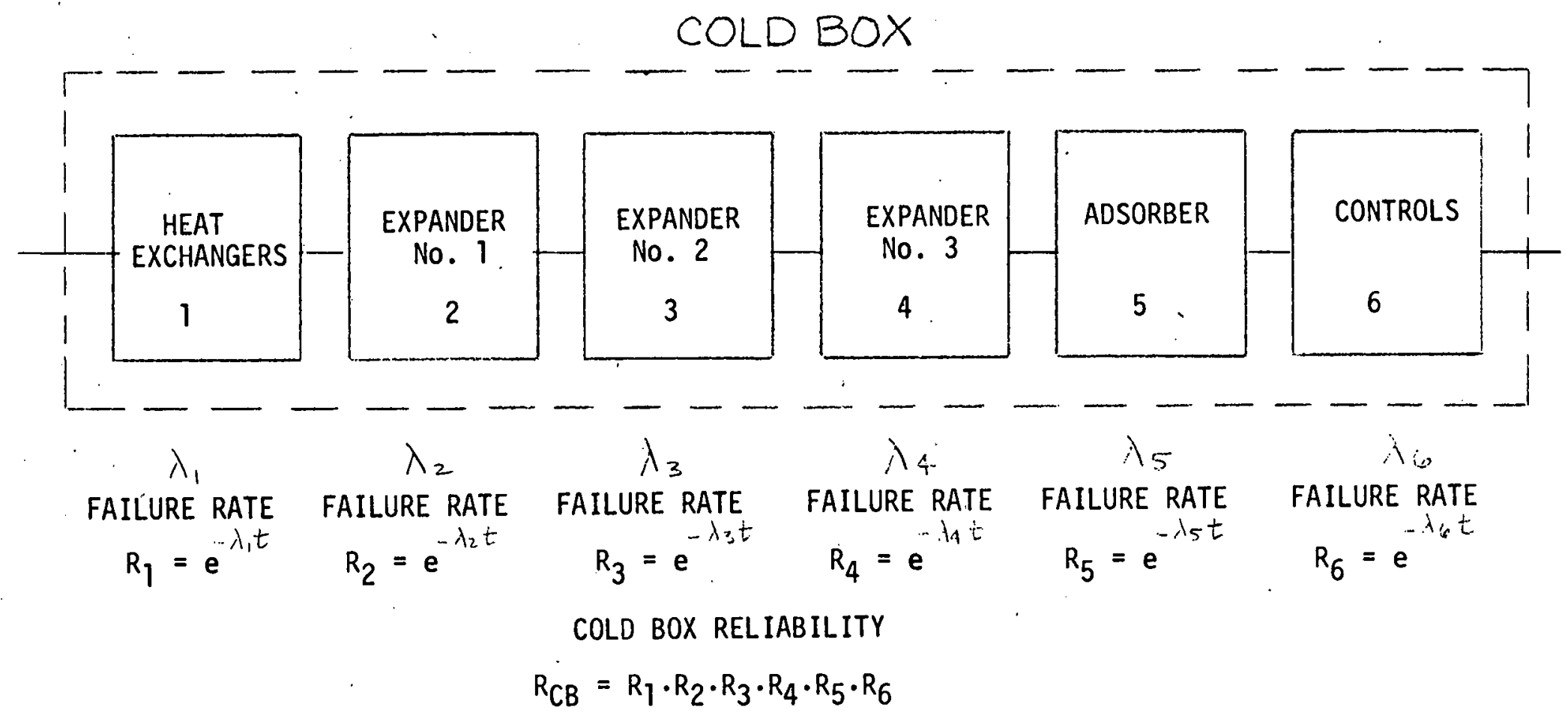

FIGURE 8.1 RELIABILITY BLOCK DIAGRAM FOR COLD BOX COMPONENTS 


$$
R_{1}=e^{-\lambda_{1} t}
$$

and if $R_{2}$ refers to the reliability of component 2 (expander no. 1) given by

$$
R_{2}=e^{-\lambda_{2} t}
$$

etc., then for the series network shown in figure 8.1, the overall subsystem reliability can be expressed as

$$
R_{C B}=R_{1} \cdot R_{2} \cdot R_{3} \cdot R_{4} \cdot R_{5}
$$

where $R_{C B}$ represents the probability that a single cold box, made up of series components 1 through 6 , will not fail during an interval of time, $t$. Examination of the probability of no failure in a single cold box for probable run time, $t$, soon makes it obvious that for realistically engineered components, one standard cold box at each refrigeration station is not sufficient to obta in any reasonable degree of overall system reliability. One is then faced with the alternative of providing either back-up components for each critical component within the cold box or, one must provide a duplicate back-up cold box. For this particular example we will consider the somewhat more practical approach of providing a duplicate cold box.

In order to illustrate how the reliability of a system which has a standby is computed, two simple cases will be derived in detail. One derivation will be for cold box case CB/H I described in section 7.3 and illustrated in figure 7.2 and the other derivation will be for compressor Case CII described in the same section and illustrated in figure 7.1.

Once the reliability of each minor subsystem is evaluated, such as the reliability of a single compressor or single cold box, we must then compute the combined reliability of the single unit and its back-up. It is at this point that we will depart from the conventional manner in which reliability analysis is applied to such systems as aircraft, missiles, etc., in which the operating time interval, $t$, is equal to the time required for a specific mission. Aircraft mission type reliability is usually computed on the basis that if the prime component fails and the back-up unit 
must take over, it is assumed that no maintenance is carried out on the failed unit during the remainder of the mission time. However, in the case of the superconducting power transmission line, this type of operation would be impractical. It is essential to the maintenance of a high level of total system reliability that as soon as a unit such as a cold box fails due to the failure of one of its series components, that measures be taken to repair or replace the malfunctioning unit as soon as possible. The need for this type of operation becomes evident when one examines the reliability equations and discovers that for the case of prompt repair or maintenance, the reliability of the prime component and its stand-by is no longer a function of the total system operating time, $t$, but is instead a function of the time, $t^{\prime}$, required to repair or replace the first unit in the event of a chance failure. More specifically, the reliability of the operating unit and its stand-by becomes the reliability of the stand-by unit operating for a period of time, $t^{\prime}$ herein lies the incentive for well planned and efficient unscheduled maintenance procedures. While $t^{\prime}$ is a very important time in the system reliability analysis it is not the only one. Besides the chance failure of the prime operating unit, another reason for the shutdown of this unit would be for scheduled preventative maintenance. The important time parameter for this case becomes the time required for scheduled maintenance, $t$ ". The reliability of the normally operating unit and its standby then becomes the reliability of the standby unit operating for a period of time, $t$ " - herein lies the incentive for well planned and efficient scheduled maintenance procedures. The manner in which the effects of $t^{\prime}$ and $t^{\prime \prime}$ are combined to arrive at an overall system reliability is illustrated via the example cases discussed below.

\subsubsection{Rel iability of Cold Box Case CB/H I}

Lets look at the reliability of the two cold boxes running in parallel at one half full capacity. One cold box is referred to as cold box $A$ and the other cold box $B$. It is assumed in this case that in the event one cold box fails that the other will pick up the entire load without any switch over failures. It is obvious that with two units operating simultaneously either $A$ or $B$ may fail. If $B$ fails first, the probability of failure of the remaining unit, $Q_{A \lambda}$, during the maintenance of unit $B$ in the interval $t^{\prime} B$ is given by

$$
Q_{A \lambda}=1-e^{-\lambda_{A} t_{B}^{\prime}}
$$


Note by definition, the probability of failure, $Q_{A \lambda}$, is equal to one minus the probability of no failure, that is -

$$
Q_{A \lambda}=1-R_{A \lambda}
$$

In equation (8.5), $t^{\prime} B$ is the time required to repair cold box $B$ after a chance or random failure and $\lambda_{A}$ is the failure rate of $A$.

If unit $A$ fails, then the probability of failure of the remaining unit during the time required to repair $A,\left(t^{\prime}{ }_{A}\right)$, is given by,

$$
Q_{B \lambda}=1-e^{-\lambda_{B} t_{A}^{\prime}}
$$

Since it is convenient to express the failure rates in terms of failures per year instead of the usual use of failures per hour, the following substitutions can be made:

$$
\begin{aligned}
& \lambda_{B}^{\prime}=8760 \lambda_{B} \\
& \lambda_{A}^{\prime}=8760 \lambda_{A} .
\end{aligned}
$$

As equations (8.5) and (8.7) now stand, they express the probability of failure of the second unit during one chance failure of the first. It would be more meaningful to compute the probability of failure of the parallel cold box combination during the course of one year - this would then involve the repeated chance failures of both units $A$ and $B$ during the course of one year; to be more specific, $\lambda_{B}^{\prime}$ failures of $B$ and $\lambda^{\prime} A$ failures of $A$ during the year. The manner in which to compute the overall probability of failure of repeated events is discussed on page 102 of reference [G.2] under the heading of repeated Bernoulli trials.

For the repeated failure of unit $B$ at the rate of $\lambda_{B}^{\prime}$ failure per year, the probability of failure of $A$ during one year becomes;

$$
Q_{A \lambda}^{\prime}=1-\left(e^{-\lambda_{A}^{\prime} t_{B}^{\prime} / 8760}\right)^{\lambda_{B}^{\prime}}
$$


For the repeated failure of unit $A$ at the rate of $\lambda_{A}^{\prime}$ failures per year, the probability of failure of $B$ during one year becomes,

$$
Q_{B \lambda}^{\prime}=1-\left(e^{-\lambda_{B}^{\prime} t_{A}^{\prime} / 8760}\right)^{\lambda_{A}^{\prime}}
$$

Over the course of one year, failure can therefore occur either through failure of unit $A$ or unit $B$. These two events are mutually exclusive, therefore, the probability of failure of the station through either failure of $A$ or $B$ during one year becomes the sum of equation (8.10) and $(8.11)$,

$$
Q_{\lambda}^{\prime}=2-e^{-\lambda_{A}^{\prime} \lambda_{B}^{\prime} t_{B}^{\prime} / 8760}-e^{-\lambda_{A}^{\prime} \lambda_{B}^{\prime} t_{A}^{\prime} / 8760}
$$

A similar analysis must now be carried out for failures which can occur during the scheduled maintenance of either $A$ or $B$. If $\xi^{\prime} A$ is the number of scheduled ma intenances per year done on unit $A$ and $\xi^{\prime} B$ is the number of scheduled maintenances performed on unit $B$ then the probability of failure of either $A$ or $B$ during the course of a year resulting from the scheduled maintenance of either $A$ or $B$ becomes

$$
Q_{F}^{\prime}=2-e^{-\lambda_{A}^{\prime} \xi_{B}^{\prime} t_{B}^{\prime \prime} / 8760}-e^{-\lambda_{B}^{\prime} \xi_{A}^{\prime} t_{A}^{\prime \prime} / 8760}
$$

Finally the probability of the cold box combination failure during the course of one year due to either chance failure of one of the components or scheduled maintenance becomes

$$
\begin{aligned}
Q_{C B}^{\prime}= & 4-e^{-\lambda_{A}^{\prime} \lambda_{B}^{\prime} t_{B}^{\prime} / 8760}-e^{-\lambda_{A}^{\prime} \lambda_{B}^{\prime} t_{A}^{\prime} / 8760} \\
& -e^{-\lambda_{A}^{\prime} \xi_{B}^{\prime} t_{B}^{\prime \prime} / 8760}-e^{-\lambda_{B}^{\prime} \xi_{A}^{\prime} t_{A}^{\prime \prime} / 8760}
\end{aligned}
$$


For identical units,

$$
\begin{aligned}
& \xi_{B}^{\prime}=\xi_{A}^{\prime}=\xi^{\prime} \\
& \lambda_{A}^{\prime}=\lambda_{B}^{\prime}=\lambda^{\prime} \\
& t_{A}^{\prime}=t_{B}^{\prime}=t^{\prime} \\
& t_{B}^{\prime \prime}=t_{A}^{\prime \prime}=t^{\prime \prime}
\end{aligned}
$$

equation $(8.14)$ reduces to

$$
\begin{aligned}
& Q_{C B}^{\prime}=2\left(1-e^{-\lambda^{\prime 2} t^{\prime} / 8760}\right)+2\left(1-e^{-\lambda^{\prime} \xi^{\prime} t^{\prime \prime} / 8760}\right) \\
& Q_{C B}^{\prime}=4-2\left(e^{-\lambda^{\prime 2} t^{\prime} / 8760}+e^{-\lambda^{\prime} \xi^{\prime} t^{\prime \prime} / 8760}\right)
\end{aligned}
$$

\subsubsection{Reliability of Compressor Case CII}

The probability of failure of a full capacity compressor running with an inactive stand-by can be derived in a manner analogous to the previous cold box case. Again it is assumed that switch over is $100 \%$ reliable. The result of this analysis can be expressed as;

$$
Q_{c}^{\prime}=3-e^{-\lambda^{\prime 2} t^{\prime} / 8760}-e^{-\lambda^{\prime} \xi^{\prime} t^{\prime \prime} / 8760}-e^{-\lambda^{\prime} \xi_{B}^{\prime} t^{\prime \prime} / 8760}
$$

Derivation of equation (8.17) has assumed compressor $A$ identical to standby compressor $B$ so that one can make the substitutions

$$
\begin{aligned}
& \lambda_{A}^{\prime}=\lambda_{B}^{\prime}=\lambda^{\prime} \\
& t_{A}^{\prime}=t_{B}^{\prime}=t^{\prime} \\
& t_{A}^{\prime \prime}=t_{B}^{\prime \prime}=t^{\prime \prime}
\end{aligned}
$$


Note, however, that the number of scheduled maintenances per calendar year for unit $B$ will not be the same as for unit $A\left(\xi_{A}^{\prime}=\xi^{\prime}\right)$ since $B$ operates for only a fraction of the calendar year and scheduled maintenances are usually planned on the basis of operating time, not calendar time. It can be shown that if one accounts for the fact that compressor $B$ runs only if $A$ is off for either scheduled or unscheduled maintenance, then the number of scheduled maintenances required on unit $B$ during $a$ cal endar year becomes:

$$
\xi_{B}^{\prime}=\xi^{\prime} \frac{\left(\lambda^{\prime} t^{\prime}+\xi^{\prime} t^{\prime \prime}\right)}{8760}
$$

\subsubsection{Tabulation of Failure Probabilities}

Table 8.1 lists all the expressions used to generate values for the probability of failure for the cold box and compressor subsystems discussed in section 7.3 .

\subsubsection{Failure Probability of BNL Plan 3A}

As illustrated in the block diagram of figure 8.2,- the cold box and compressor make up only part of the total subsystems which contribute to the overall reliability of a single refrigeration station. Recall that Plan $3 A$ calls for six such stations along the transmission line length. Some of the additional subsystems which must be considered include:

(a) the electrical power source for the refrigeration system with its associated reliability, $R_{e}^{\prime},(b)$ the cooling water supply system with reliability $R_{w}^{\prime},(c)$ the compressor system with reliability $R_{C}^{\prime}$, (d) the cold box system with reliability $R_{C B}$, (e) the superconducting cable with reliability $R_{s}^{\prime} c$, and ( $f$ ) the vacuum insulated cryogenic envelope with reliability $R_{C e}$.

APCI does not have a clear definition of what constitutes a failure on the Plan $3 A$ line, that is, if failure is defined as the loss of either of the two superconducting cables or failure of both superconducting cables. We have chosen to define line failure as the loss of both superconducting cables. With this assumption, the reliability of the refrigerator/cable combination along $12 \mathrm{~km}$ of line and for a period of one year. is given by: 
TABLE 8.1

EXPRESSIONS FOR. PROBABILITY OF FAILURE IN ONE YEAR FOR COMPRESSOR AND COLD BOX CASES LISTED

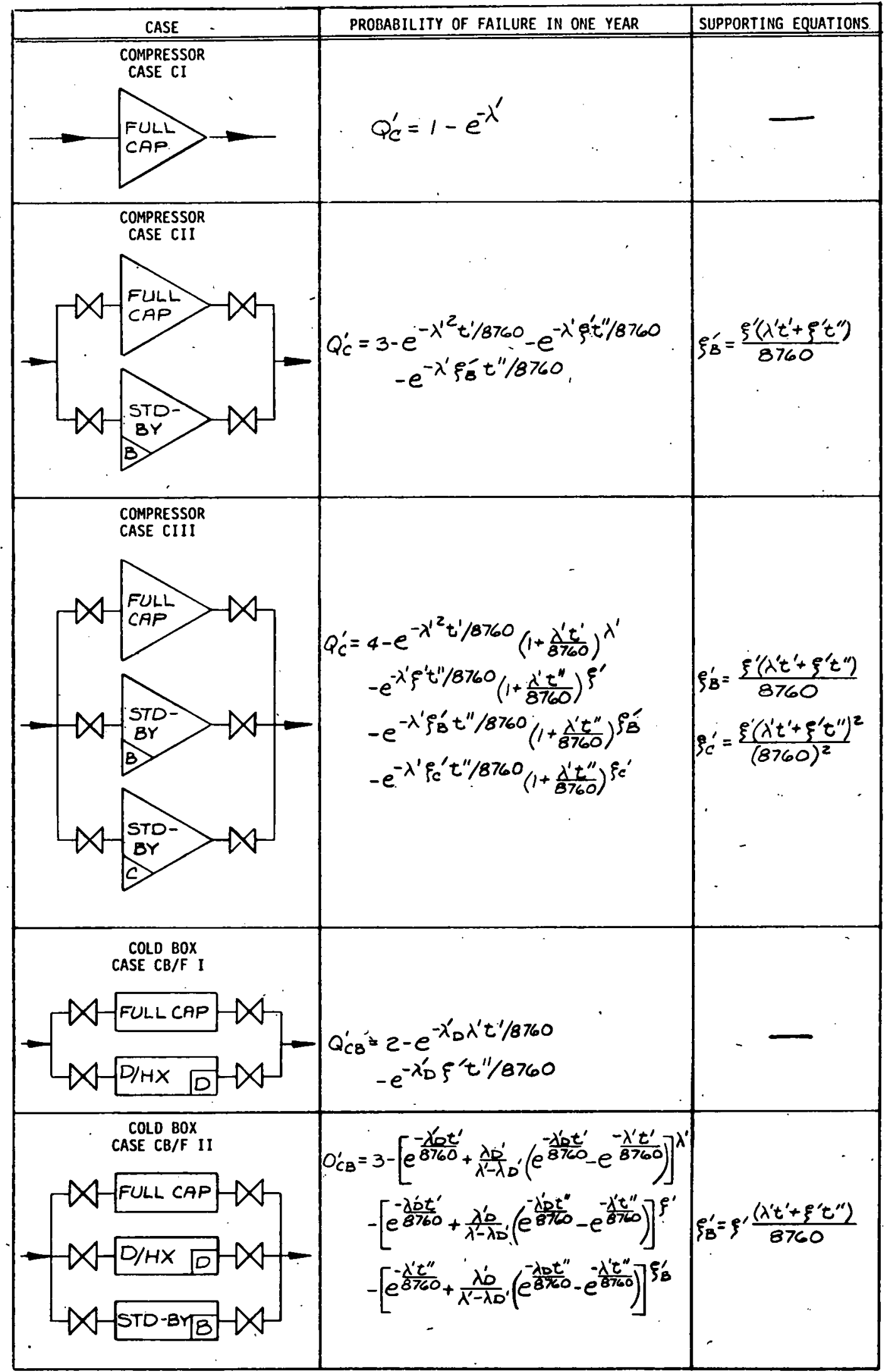


TABLE 8.1

EXPRESSIONS FOR PROBABILITY OF FAILURE IN ONE YEAR FOR COMPRESSOR AND COLD BOX CASES LISTED

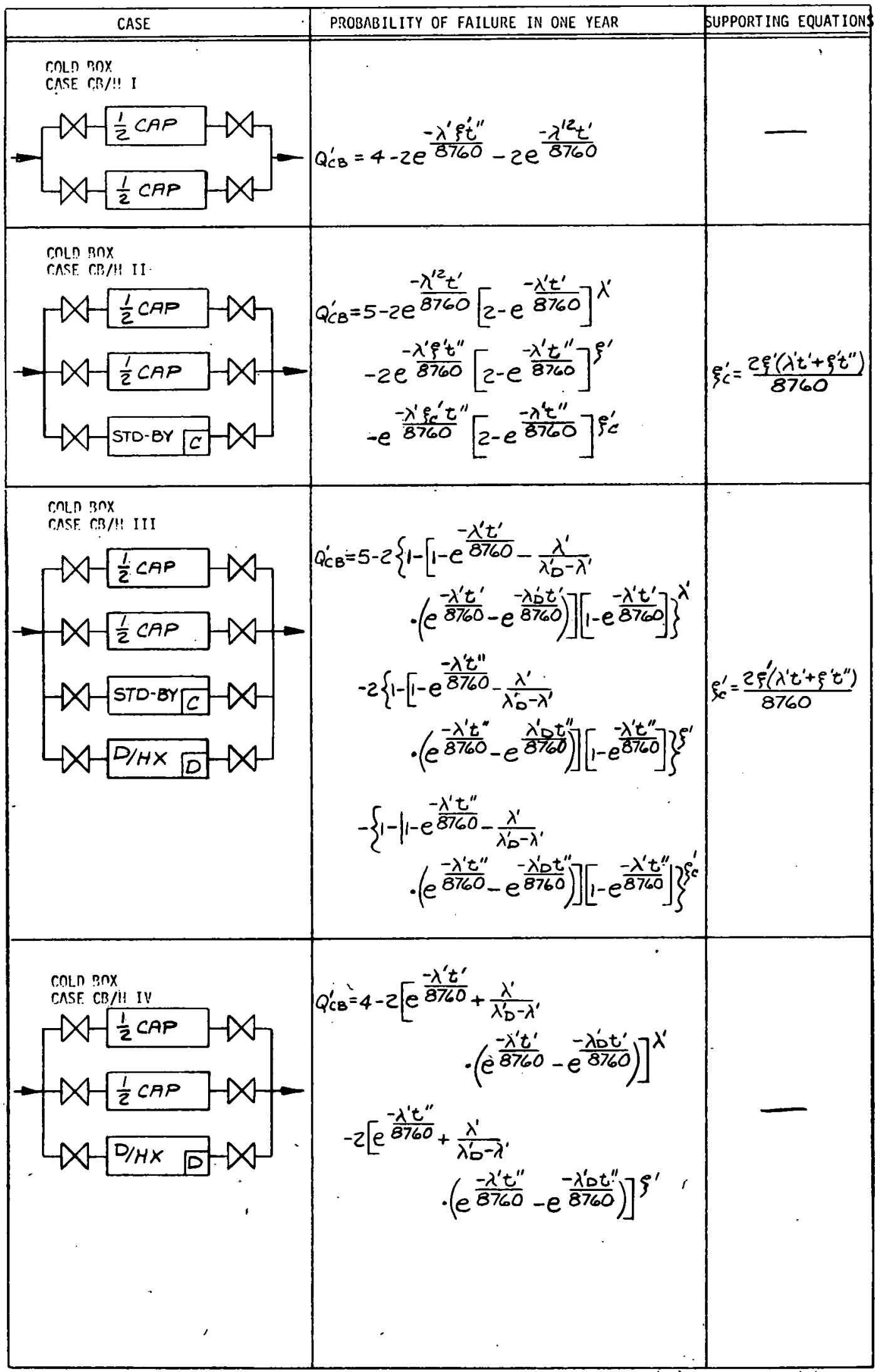




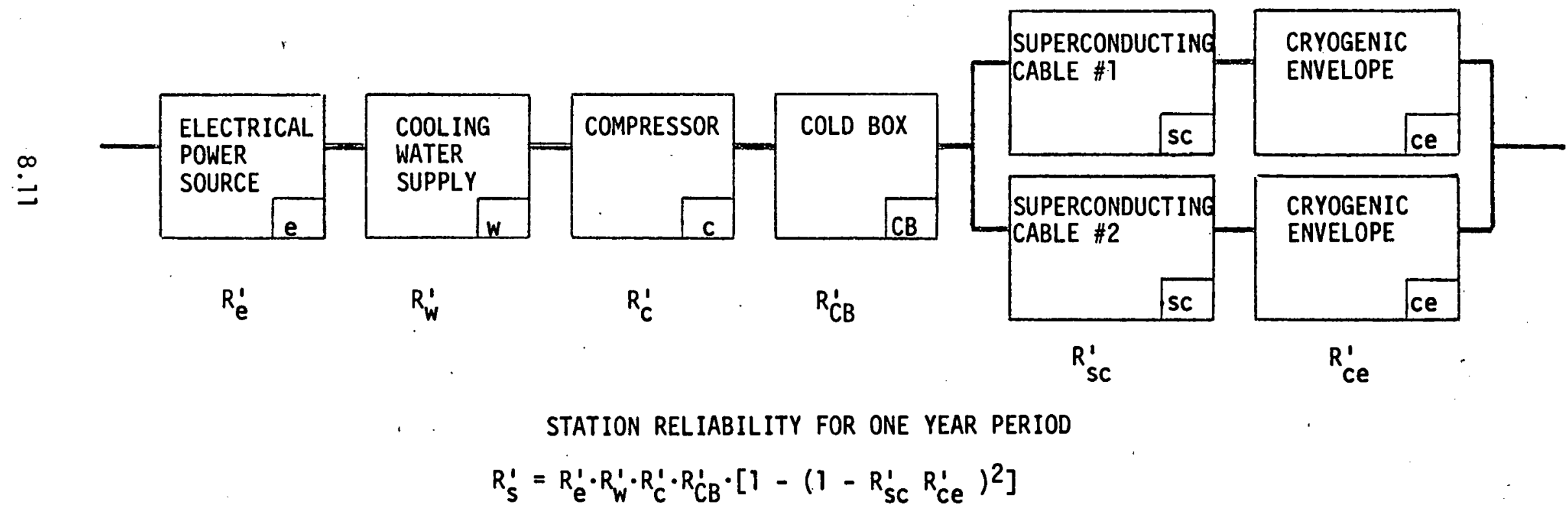

FIGURE 8.2. RELIABILITIES OF SUBSYSTEMS WHICH CONTRIBUTE TO THE TOTAL RELIABILITY OF A SINGLE REFRIGERATION STATION AND ITS ASSOCIATED $12 \mathrm{~km}$ CABLE LENGTH FOR BNL PLAN $3 A$ 


$$
R_{s}^{\prime}=R_{e}^{\prime} \cdot R_{w}^{\prime} \cdot R_{c}^{\prime} \cdot R_{C B}^{\prime} \cdot\left[1-\left(1-R_{s c}^{\prime} R_{c e}^{\prime}\right)^{2}\right]
$$

No information exists which would enable one to define $R_{s c}^{\prime}$ and $R_{c}^{\prime}$, and in addition, the systems supplying power and cooling at the refrigeration station must be defined before anything concrete can be asserted concerning $R_{e}^{\prime}$ and $R_{w}^{\prime}$. In the analysis of the present report no effort has been made to guess at the value of $R_{e}^{\prime}$ for the case of a real transmission line system; however, if the power outages on the APCI standard nitrogen plants are any indication of what can be expected, it will be absolutely essential to provide back-up in the way of diesel or turbine powered compressors and diesel driven generators or other types of power supplies which would provide auxiliary power for controls, oil pumps, etc. The power interruptions experienced by the nitrogen plants chosen for investigation in section 6.0 experienced an average of 2.83 failures per year and accounted for $7.76 \%$ of the total outage time. In arriving at estimates of helium cold box failure rates (see section 6.7.2) by using the APCI $\mathrm{N}_{2}$ plant data, the electrical failures are included on the assumption that the power sources for each compressor and cold box are independent of one another.

The nitrogen plant data also showed that cooling water failures accounted for $6.0 \%$ of the total outages. Most of the nitrogen plants reject heat to cooling towers which on an average experience about 1.46 failures per year. While this number could have been used in the present analysis to estimate a value for $R_{w}^{\prime}$, lack of any definitive information relative to the type of cooling system which might be used prompted us to neglect the effect of $R_{W}^{i}$ in the present analysis.

Figure 8.3 illustrates the influence of the utilization of the far-end expander concept. The overall station reliability for one year takes the form.

$$
R_{S}^{\prime}=R_{e}^{\prime} \cdot R_{w}^{\prime} R_{c}^{\prime} \cdot R_{c B}^{\prime}\left[1-\left(1-R_{F E}^{\prime} \cdot R_{S \dot{C}}^{\prime} R_{c e}^{\prime}\right)^{2}\right]
$$




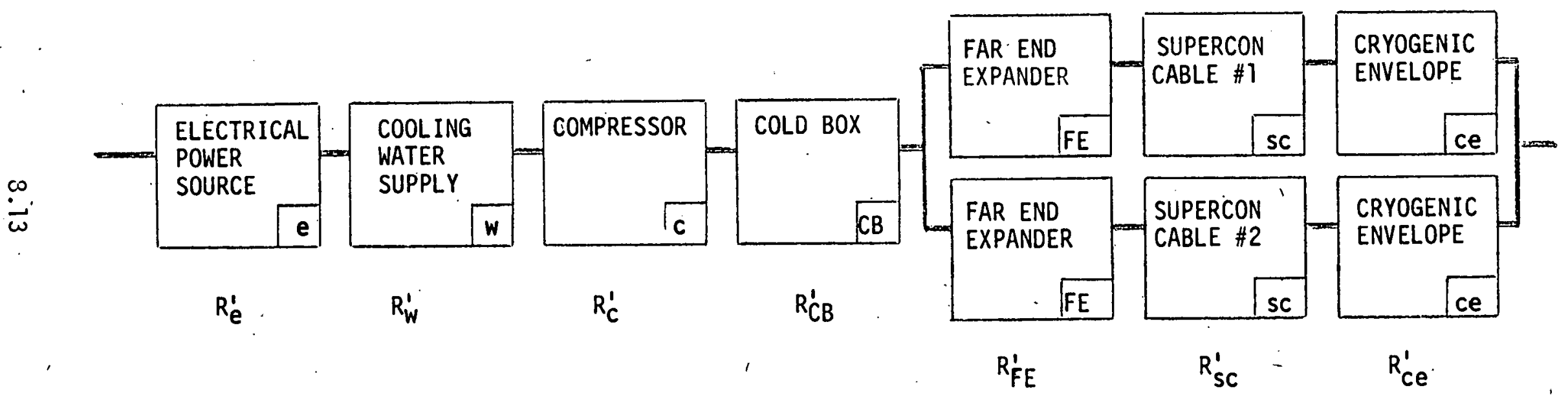

STATION RELIABILITY FOR ONE YEAR PERIOD $R_{S}^{\prime}=R_{e}^{\prime} \cdot R_{W}^{\prime} \cdot R_{C}^{\prime} \cdot R_{C B}^{\prime} \cdot\left[1-\left(1-R_{F E}^{\prime} \cdot R_{S C}^{\prime} \cdot R_{C e}^{\prime}\right)^{2}\right]$

FIGURE 8.3 RELIABILITIES OF SUBSYSTEMS WHICH CONTRIBUTE TO THE TOTAL RELIABILITY OF A SINGLE REFRIGERATION STATION AND ITS ASSOCIATED $12 \mathrm{~km}$ CABLE LENGTH FOR BNL PLAN $3 A$ WITH FAR END EXPANDER 
where $R_{F}^{\prime}$ refers to the reliability of the far-end expander subsystem over a period of one year.

Once the reliability of a single station is known, the reliability of the entire cable system, consisting of $N$ station locations, can be computed from equation (8.20) as:

$$
R_{\text {TOT }}^{\prime}=\left\{R_{e}^{\prime} \cdot R_{W}^{\prime} \cdot R_{C}^{\prime} \cdot R_{C B}^{\prime} \cdot\left[1-\left(1-R_{F E}^{\prime} \cdot R_{S C}^{\prime} \cdot R_{C e}^{\prime}\right)^{2}\right]\right\}^{N}
$$

Within the bounds of the present study it will be assumed that $R_{w}^{1}=1.0$, $R_{S C}=1.0$ and $R_{C e}=1.0$. In doing this, it is important to realize that one or a combination of these reliabilities may turn out in the future to be more of a controlling factor than $R_{C}^{\prime}$ and $R_{C B}$. Making these simplifictions, equation ( 8.21 ) becomes,

$$
R_{\text {TOT }}^{\prime}=\left\{R_{C}^{\prime} \cdot R_{C B}^{\prime}\left[1-\left(1-R_{F E}^{\prime}\right)^{2}\right]\right\}^{N}
$$

or, in the absence of the far end expander

$$
R_{\text {TOT }}^{\prime}=\left[R_{C}^{\prime} \cdot R_{C B}^{\prime}\right]^{N}
$$

In terms of probabilities of failure in one year, equations (8.22) and (8.23) can be respectively written as:

$$
\begin{aligned}
& Q_{\text {TOT }}^{\prime}=1-\left[\left(1-Q_{C}^{\prime}\right)\left(1-Q_{C B}^{\prime}\right)\left(1-Q_{F E}^{\prime}{ }^{2}\right)\right]^{N} \\
& Q_{T O T}^{\prime}=1-\left[\left(1-Q_{C}^{\prime}\right)\left(1-Q_{C B}^{\prime}\right)\left(1-Q_{F E}^{\prime 2}\right)\right]^{N}
\end{aligned}
$$

8.14 


\subsubsection{Reliability of Transmission Line}

A very important parameter in design of a superconducting power transmission line is the upper limit set on the probability of failure of a transmission line during the course of one year. This limit must be set by the electric utility who is to own and operate the line and represents the maximum value which, $Q^{\prime}$ 'rot can take on in equations (8.24) and (8.25). Unfortunately no clear cut upper limit on system reliability seems to have been established. Estimates have ranged from one days outage every twenty years to 0.031 outages per year per cable mile with an average outage duration of 336 hours. In terms of Plan $3 A$, the latter outage failure rate works out to 1.3175 failures per year per cable. These figures obviously represent quite a wide latitude in system reliability. It is clearly very important that a serious effort be made to get the utilities to define a ressonably concrete level of system reliability.

If one were to assume that the failure rate most accurately describing the requirements of the utilities would be one days outage in twenty years and if only one outage occurred which lasted one day (as opposed to a number of outages in twenty years which add up to one day), then the equivalent reliability for a one year period would be:

where

$$
\begin{aligned}
& R_{s}^{\prime}=e^{-\lambda_{s} t} \\
& \lambda s=\frac{1}{(20 \mathrm{yr} .)(8760 \mathrm{hr} / \mathrm{yr} .)}=5.71 \times 10^{-6} \text { failures } / \mathrm{yr} \\
& R_{s}^{\prime}=e^{-\left(5.71 \times 10^{-6}\right)(8760)} \\
& R_{s}^{\prime}=0.9512
\end{aligned}
$$

or the probability of failure in one year becomes

$$
Q_{s}^{\prime}=0.0488
$$




\subsubsection{Influence of the Number of Refrigeration Stations}

If it is assumed for the case of BNL's Plan $3 A$ that the upper limit on the probability of failure is set by equation (8.26) and that no far-end expander is utilized, the overall system probability of failure as given by equation ( 8.25 ) becomes,

$$
0.0488=1-\left[\left(1-Q_{C}^{\prime}\right)\left(1-Q_{C B}^{\prime}\right)\right]^{6}
$$

where the number of stations, $N$, is 6 for plan $3 A$.

Solving for Q $\mathrm{C}_{B}$

$$
Q_{C B}^{\prime}=1-{\frac{[1-0.0488]^{1 / 6}}{\left[1-Q_{C}^{\prime}\right]}}^{1 / 2}
$$

Figure 8.4 includes a plot of equation (8.27) for six refrigeration stations. This graph illustrates a very important point; if there are to be a total of six refrigeration stations along the transmission line and if either the compressor subsystem or the cold box subsystem could be made virtually failure proof (zero probability of failure), then the remaining subsystem could sfill have to have a probability of failure in one year less than $8 \times 10^{-3}$ in order not to violate the upper limit set on total system probability of failure. Intermediate points on the graph corresponding to $N=6$ tell us what the maximum permissible value of $Q_{C B}^{\prime}$ should be given the value of $Q_{c}^{\prime}$ or vice versa.

It is interesting to note, in figure 8.4 , the decrease in allowable subsystem probability of failure as the number of refrigeration stations along the line increase to tweive and then to eighteen. This points to the probable requirement for higher degrees of redundancy for the inherently longer DC power transmission lines.

\subsubsection{Influence of Far-End Expander}

It is of interest to investigate the influence, on overall system, $\overline{r e l i-}$ ability, of the implementation of the far-end expander concept being 


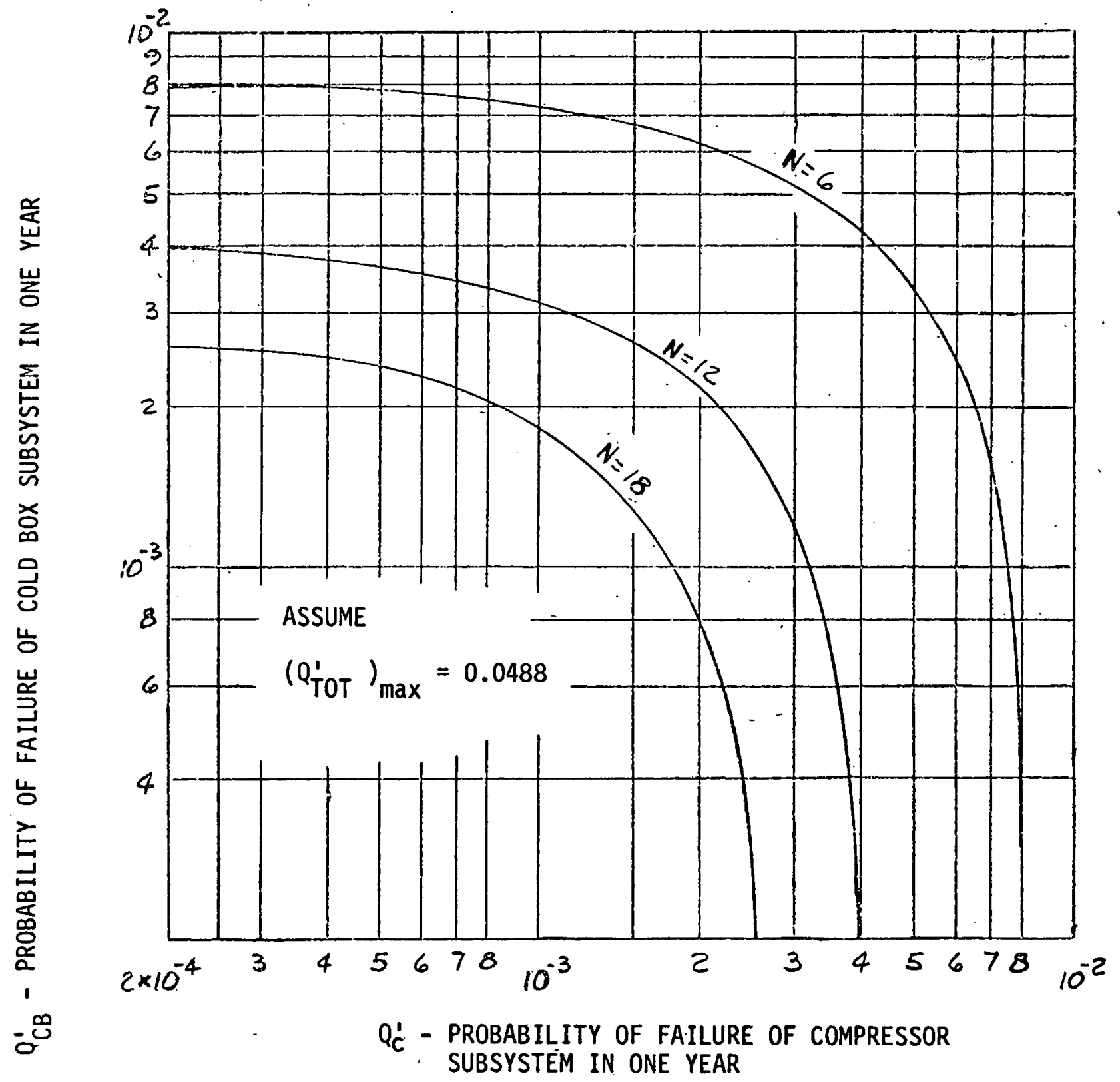

FIGURE 8.4 INFLUENCE OF THE NUMBER OF REFRIGERATION STATIONS, N, ALONG TRANSMISSION LINE ON THE ALLOWABLE LIMITS OF $Q_{c}^{\prime}$ and $Q_{c b}^{\prime}$ 
studied at BNL and LASL. In order to do this we must have an estimate of the probability of failure of the far-end expander subsystem. Using the data of Section 3.2, we can conservatively assume a turbo-expander MTBF of about 25,000 hours. This translates to a failure rate of 0.35 failures per year $\left(\lambda_{T}^{\prime}=0.35\right)$.

If only one expander is used at each far-end location, then the probability of failure of this expander over a period of one year becomes

$$
\begin{aligned}
& Q_{F E}^{\prime}=1-e^{-\lambda_{T}^{\prime}} \\
& Q_{F E}^{\prime}=0.296
\end{aligned}
$$

Alternatively, if each far-end expander location contains one active turboexpander and one in stand-by, the probability of failure in one year can be computed in the following manner:

For this case the far-end expander subsystem can fail only during the time involved in the replacement of a defective turbine. Assuming a plug-in unit is inserted whenever a turbine fails and the time required to do this is $t$ ' hours, the probability of the stand-by turbine failing during this time is,

$$
Q_{F E}=1-e^{-\lambda_{T}^{\prime} t^{\prime} / 8760}
$$

However, if the first turbine experiences $\lambda_{T}^{\prime}$ failures per year, the probability of failure of the total subsystem during a period of one year becomes,

$$
Q_{F E}^{\prime}=1-e^{-\lambda_{T}^{\prime 2} t^{\prime} / 8760}
$$


If, based on the standard nitrogen plant data, it is assumed that the average plug-in turbine change takes four hours, then the probability of failure becomes:

$$
\begin{aligned}
& Q_{F E}^{\prime}=1-e^{-(0.35)^{2} \cdot 4 / 8760} \\
& Q_{F E}^{\prime}=5.6 \times 10^{-6}
\end{aligned}
$$

Substitution of the values of $Q F E$ given by equations (8.28 and (8.30) into equation (8.24) with $Q^{\prime}$ TOT $=0.0488$ gives, for one turbine far-end expander and six refrigeration stations,

$$
Q_{C B}^{\prime}=1-\frac{1.087}{\left[1-Q_{C}^{\prime}\right]}
$$

and for a two-turbine far-end expander option,

$$
Q_{C B}^{\prime}=1-\frac{0.9917}{\left[1-Q_{C}^{\prime}\right]}
$$

Examination of equation (8.31) shows that no finite positive value of $Q \dot{C}$ will give a positive value for $Q_{C B}^{\prime}$; this implies that one expander in the far-end expander subsystem is presently unable to meet the requirements for the upper limit on probability of failure set for the entire superconducting power transmission line system.

Equation (8.32) turns out to be nearly identical to the case in which the far-end expander is not used and as such is closely plotted by the graph corresponding to $\mathrm{N}=6$ in figure (8.4). This result was to be expected since the addition of a stand-by turbine reduces the probability of failure to a negligible value in comparison with probability limit set for the entire superconducting transmission line system. 


\subsubsection{Effect of Switch-0ver Reliability}

All of the reliability analysis carried out in the present investigation assumes a $100 \%$ reliable switch over to stand-by components. This implies that the sensing of the failure of the component and the subsequent switch over of control to the stand-by unit must be accomplished without any failure. As will be shown by a simple example, the use of switch over devices with reliabilities only slightly less than $100 \%$ can quite appreciably affect the probability of failure of the subsystem.

Figure 8.5 shows the change in probability of failure of a system consisting of one active unit and one stand-by as a function of the switch over reliability. The governing equation for this system is

$$
Q=1-e^{-\lambda t}\left(1+R_{s s} \lambda t\right)
$$

where Rss represents the switch over reliability.

Figure 8.5 illustrates, for the case of the reliability parameters and times noted, an increase in the probability of system failure by a factor of 5.3 for a decrease in switch over reliability from 100\% to $99 \%$. This is quite a substantial drop for so small a decrease in switch reliability. This simple example illustrates the importance of highly reliable sensing and switching devices. Redundancy of major components is useless if the switch-overs cannot be executed with a high level of reliability. This point may be stressed even further by recalling the two instances during 1974 (cited in Section 6.0) when an APCI standard nitrogen plant failed to deliver product to the customer: One case involved a failure of the automatic switching system used to switchover to the back-up liquid tank during plant failure, and in another instance the automatic unit which notifies the district maintenance office that the plant shut down failed to operate and the back-up liquid supply was exhausted before it was realized that the plant had shut down.

\subsubsection{Tabulation of Reliability Input Parameters}

Table 8.2 contains a summary of the reliability input parameters used in the present reliability versus cost study. These parameters have been taken from the sections in this report related to compressors; cold boxes, turbines, helium dewar storage systems, etc. As pointed out in the 


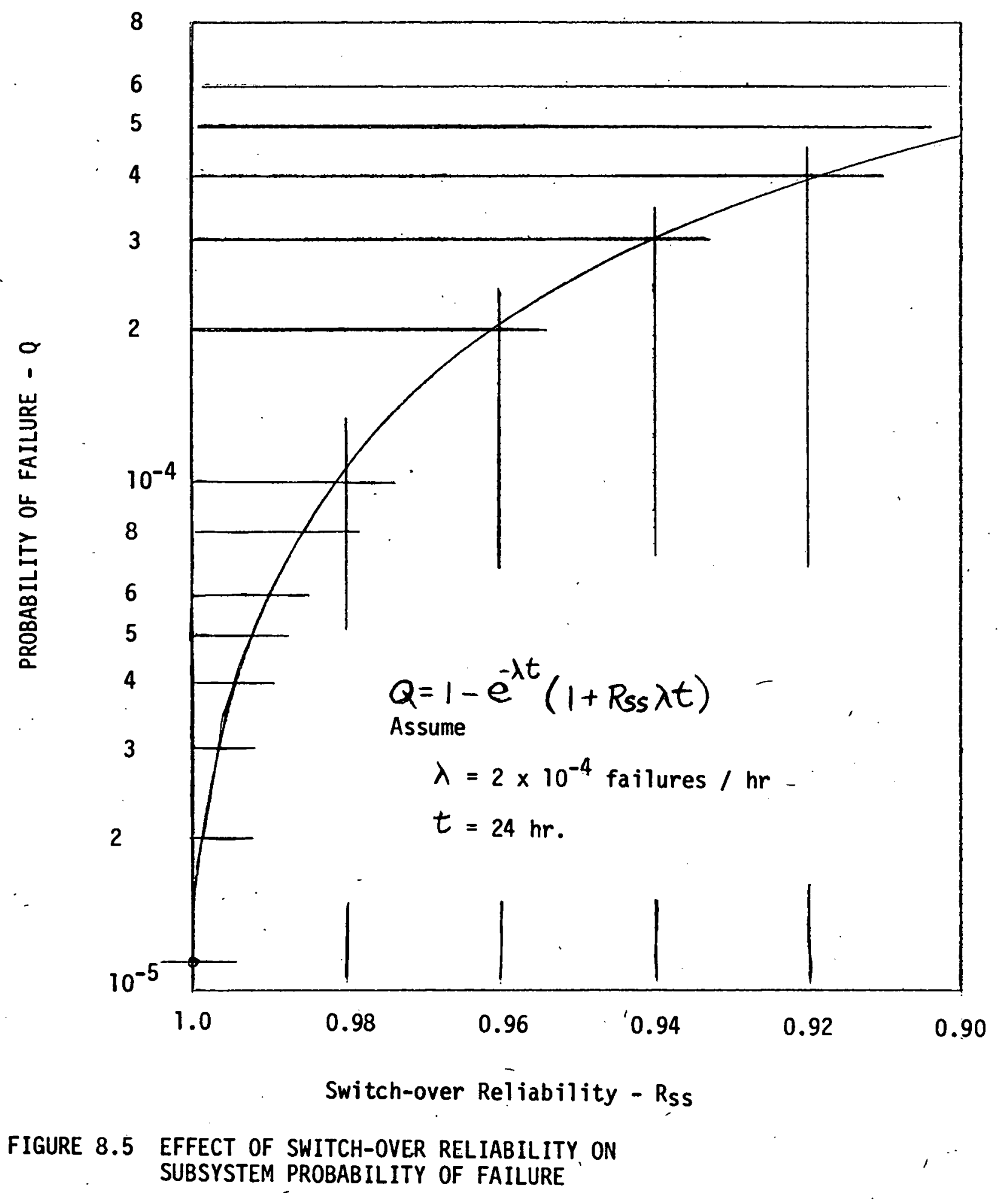


respective sections, the origin of these parameters have been mainiy manufacturer's responses to our questionnaires, helium refrigerator user visits and information gleened from APCI in-house experience with standard nitrogen plants.

\subsection{ECONOMIC EVALUATION OF ALTERNATE REFRIGERATION STATION SUBSYSTEMS}

One of the most common forms of analysis, used to compare the economic merits of two or more competing systems, is to apply what is termed the present value criteria. In this type of analysis, one computes the sum of the initial capital costs plus the total present worth of all system related operating costs. The present worth of all operating expenses can be thought of to represent the sum of money which would have to be in:vested at a return interest, $i$, over the economic life of the system ( $n$ years) in order that the annuities cover the total operating costs each year for a period of $n$ years and that at the end of this period no money should remain in the fund. The total operating expenses would include maintenance costs (parts and labor), power costs and the cost of other related utilities. An allowance is often also made for taxes, however, this will be neglected in the present analysis. The optimum system is the one which meets all requirements of performance at the lowest present worth.

An analogous economic analysis is carried out in the present analysis with the following modification: the present worth of the system under consideration is normalized with respect to what is termed the pay-off period. The present value factor of annuities,

$$
P V_{a}=\frac{(i+1)^{n}-1}{i(i+1)^{n}}
$$

is used to compute the present worth of the operating costs according to the equation,

$$
\text { PRESENT WORTH }=(\text { ANNUAL OPERATING COSTS }) \text { (PVa) }
$$


This is also numerically equal to the pay-off period required to cover the value of the initial capital expenditures.

$$
\text { PAY-OFF PERIOD }=P V_{a}=\frac{(i+1)^{n}-1}{i(i+1)^{n}}
$$

The remaining years of the economic life, $\left(n-P V_{a}\right)$, covers the interest on the initial capital.

As an example, the present worth' of a refrigeration station (excluding installation costs) is given by;

$$
\begin{aligned}
\text { PRESENT WORTH }= & (\text { CAPITAL COSTS })+(\text { DEMAND COSTS })+ \\
& \text { POWER COSTS }(\text { PVa })+(\text { TOTAL YEARLY LABOR COSTS }) \cdot \text { PVa } \\
& +(\text { COST OF PARTS }) \cdot(\text { PVa })
\end{aligned}
$$

However, we may also look at the yearly costs normalized over the pay-off period in which case,

$$
\begin{aligned}
\text { YEARLY COST } & =\frac{(\text { CAPITAL COST) }}{\text { PVa }}+\frac{(\text { DEMAND COST })}{\text { PVa }}+(\text { POWER COSTS }) \\
& + \text { (ANNUAL TOTAL LABOR COSTS })+(\text { COST OF PARTS })
\end{aligned}
$$

An equation of the above form is used in the economic evaluation of the present investigation.

The demand cost cited in equations (8.37) and (8.38) is the initial capital cost charged for power lines, transformers and other special. power equipment.

\subsubsection{Compressor Capital Plus Operating Costs}


The capital plus operating cost equations used for the compressor analysis are of the form:

$$
Y R L Y \$=\frac{(C A P T \$+D E M A N D \$)}{P V a}+P \$ Y R+L A B \$ Y R+P A R T \$ .
$$

where,

$$
\begin{array}{ll}
\text { YRLY\$ } & =\text { yearly capital plus operating costs } \\
\text { CAPT\$ } & =\text { initial capital costs } \\
\text { DEMAND\$ } & =\text { initial charge for el ectric power equipment } \\
\text { P\$YR } & =\text { power costs per year for compressor } \\
\text { LAB\$YR } & =\text { total labor costs per year } \\
\text { PART\$ } & =\text { cost of materials and replacement parts per year } \\
\text { PVa } & =\text { pay-off period as defined by eq. }(8.36)
\end{array}
$$

\subsubsection{Cold Box and Dewar/Heat Exchanger Cost}

The capital plus operating cost equation used for the cold box (and dewar/ heat exchanger subsystem if considered) analysis is of the form:

$$
\text { YRLY\$ }=\frac{\text { CAPT } \$(\text { Cold BOX })+\text { CAPT\$ (D/HX) }}{P V a}+P \$ Y R+L A B \$ Y R+P A R T \$
$$

where each term, except for P\$YR, is as defined in section 8.2.1.1. The power cost for the case of the cold box includes the incremental cost of power used to cool down a stand-by cold box in the event of a cold box failure and also the cost of power required to reliquefy any helium which might be boiled off if the dewar/heat exchanger system is used as in the case of cold box redundancy options $C B / F$ I and $C B / F$ II. The power used to reliquefy any helium which is vaporized is computed on the basis of the equivalent $1300 \mathrm{LL} / \mathrm{hr}$ liquefaction capacity of the full size cold boxes as discussed in section 7.3.3.4.

\subsubsection{Labor Cost}


The dollar value assigned to the term LAB\$YR is made up of two parts; the cost of labor required for maintenance of random failure and scheduled repairs, and also, a fixed labor rate dependent on the number of cold boxes or compressors at each station. The fixed labor rate is intended to cover the time spent in routine check-out of the system components on a weekly basis. Table 8.2 tabulates the equations used to compute the scheduled and unscheduled maintenance costs for the compressor and cold box reducdancy options discussed in Section 7.3, as well as the fixed labor rates assigned to each. Also shown in table 8.3 is the labor rate of $\$ 25$ per hour used in this investigation.

\subsubsection{Demand Cost}

The installed cost of power lines, transformers and other equipment required to deliver power to the individual refrigeration stations is computed on the basis of $\$ 133$ per kilowatt of the maximum power consumed at any one station $(A .41)$.

$$
\text { Demand } \$=(133) \cdot(\text { MAX. POWER })
$$

\subsubsection{Power Cost}

Power costs are computed on the basis of $0.02 \$ / \mathrm{KW} . \mathrm{HR}(\mathrm{A.41})$.

\subsubsection{Maintenance Cost}

On the basis of APCI standard nitrogen plant experience and some assumptions on the part of the author, the cost of parts and materials required for maintenance each year is computed as shown in tabie 8.4 .

\subsubsection{Capital Cost of Equipment}

A summary of the capital cost assigned to various components used in a refrigeration system, as discussed in the sections related to the respective components, is tabulated in table 8.5. All components are of a size sufficient to simultaneously hand le the refrigeration requirements of 
TABLE 8.2

TABULATION OF RELIABILITY ANALYSIS INPUT PARAMETERS

COMPONENT DESCRIPTION

$\begin{array}{llll}\text { MEAN TIME } & \text { NUMBER OF } & \text { MEAN TIME } & \text { NUMBER OF } \\ \text { BETWEEN } & \text { RANDOM } & \text { BETWEEN } & \text { SCHEDULED } \\ \text { RANDOM } & \text { FAILURES } & \text { SCHEDULED } & \text { MAINTENANCES } \\ \text { FAILURES } & \text { PER YEAR } & \text { MAINTENANCE } & \text { PER YEAR } \\ \text { (HR) } & \lambda^{\prime}- & \text { (HRS) } & \text { (HRS) } \\ \text { MTBF } & \text { MTBM }^{\prime} & \begin{array}{c}\xi \\ \text { MTBS }\end{array}\end{array}$

MEAN TIME

$-$

MTBF MTBM

\section{COMPRESSORS}

0i] Lube Screw Compr.

30,000

$0.292 \quad 50,000$

0.1752

12

UNSCHEDULED MAINTENANCES (HRS)

(with oil separator)

Dry Screw Compr.

25,000

$0.35 \quad 16,000$

0.548

24

16.2

MEAN TIME

Dry Lube Recip. Compr.

5,000

1.752

7,000

1.25

19.2

Labyrinth Seal Recip. Compr.

17,000

0.5153

7,000

1.25

24

SCHEDULED

Centrifugal Muiti-Casing

25,000

$0.35 \quad 25,000$

0.35

MAINTENANCE

(HRS)

Compr.

COLD BOX

Cold Box with three (3)

He Turbines (Case CB/F)

Cold Box with three (3)

Dual He Turbines

(Case $\mathrm{CB} / \mathrm{H}$ )

HELIUM DEWAR/HEAT EXCHANGER

SYSTEM (warm.circulating

30,000

812

10.78

4,380

2

6.42

26.3

compr.)

10.25

4,380

2

6.42

26.3

20

40

27

32

40 


\begin{abstract}
TABLE 8.3
YEARLY LABOR COSTS

LAB\$YR = MAINTENANCE COST + FIXED YEARLY COSTS
\end{abstract}

CASE

MAINTENANCE COST

FIXED YRLY COSTS

COMPRESSOR

OPTIONS

C I

$(\$ / H R) \cdot\left(\lambda^{\prime} t^{\prime}+\xi^{\prime} t^{\prime \prime}\right)$

$1 \cdot(52) \cdot(\$ /$ HR $)$

C II

$(\$ / H R) \cdot\left(\lambda^{\prime} t^{\prime}+\xi^{\prime} t^{\prime \prime}\right) \cdot\left[1+\frac{\left(\lambda^{\prime} t^{\prime}+\xi^{\prime} t^{\prime \prime}\right)}{8760}\right]$

$2 \cdot(52) \cdot(\$ / H R)$

C III

$(\$ / H R) \cdot\left(\lambda^{\prime} t^{\prime}+\xi^{\prime} t^{\prime \prime}\right) \cdot\left[1+\frac{\left(\lambda^{\prime} t^{\prime}+\xi^{\prime} t^{\prime \prime}\right)}{8760}+\frac{\left(\lambda^{\prime} t^{\prime}+\xi^{\prime} t^{\prime \prime}\right)^{2}}{(8760)^{2}}\right] 3 \cdot(52) \cdot(\$ / H R)$

COLD BOX

OPTIONS
$\mathrm{CB} / \mathrm{F}$ I
$(\$ / H R) \cdot\left(\lambda^{\prime} t^{\prime}+\xi^{\prime} t^{\prime \prime}\right)$
$\mathrm{CB} / \mathrm{F}$ II
$(\$ / H R) \cdot\left(\lambda^{\prime} t^{\prime}+\xi^{\prime} t^{\prime \prime}\right)\left[1+\frac{\left(\lambda^{\prime} t^{\prime}+\xi^{\prime} t^{\prime \prime}\right)}{8760}\right]$
$1 \cdot(52) \cdot(\$ / H R)$
$\mathrm{CB} / \mathrm{H} \mathrm{I}$
$(\$ / H R) \cdot(2) \cdot\left(\lambda^{\prime} t^{\prime}+\xi^{\prime} t^{\prime \prime}\right)$
$2 \cdot(52) \cdot(\$ / H R)$
CB/H II $\quad(\$ / H R) \cdot\left(\lambda^{\prime} t^{\prime}+\xi^{\prime} t^{\prime \prime}\right) \cdot\left[2+\frac{\left(\lambda^{\prime} t^{\prime}+\xi^{\prime} t^{\prime \prime}\right)}{8760}\right]$
$2 \cdot(52) \cdot(\$ / H R)$
CB/H III $\quad(\$ / H R) \cdot\left(\lambda^{\prime} t^{\prime}+\xi^{\prime} t^{\prime \prime}\right) \cdot\left[2+\frac{\left(\lambda^{\prime} t^{\prime}+\xi^{\prime} t^{\prime \prime}\right)}{8760}\right]$
$3 \cdot(52) \cdot(\$ / H R)$
$3 \cdot(52) \cdot(\$ / H R)$
$\mathrm{CB} / \mathrm{H}$ IV
$(\$ / H R) \cdot(2)\left(\lambda^{\prime} t^{\prime}+\xi^{\prime} t^{\prime \prime}\right)$
$2 \cdot(52) \cdot(\$ / H R)$

LABOR RATE: $\$ / H R=25$ 
TABLE 8.4

COST OF MAINTENANCE RELATED PARTS AND MATERIALS

SUBSYSTEM DESCRIPTION

COST OF PARTS PER YEAR

COLD BOXES

PART $\$=(0.875 \%)(N)($ CAPT $\$)$

COMPRESSORS

Dry Lube Reciprocating Compressor

PART\$ $=(2 \%)(N)($ CAPT $\$)$

Labyrinth Seal Reciprocating Compressor

PART\$ $=(2 \%)(N)($ CAPT\$)

0i1 Lubricated Screw Compressor

PART $\$=(1 \%)(N)($ CAPT $\$)$

Dry Screw Compressor

PART $\$=(1 \%)(N)($ CAPT\$ $)$

Centrifugal Compressor

PART\$ $=(1 \%)(N)($ CAPT $\$)$

$\mathrm{N} \quad=$ Number of normally running compressors or cold boxes.

CAPT $\$$ = Capital cost of a compressor or a cold box.

TABLE 8.5

CAPITAL COST OF MAJOR COMPONENTS AND SUBSYSTEMS

SUBSYSTEM DESCRIPTION

COST CAPITAL COST (CAPT\$)

COMPRESSORS

0il Lubricated Screw Compressor

Dry Lube Screw Compressor

$\$ 211,900$

Dry Lube Reciprocating Compressor

988,000

Labyrinth Seál Reciprocating Compressor

572,000

Centrifugal. Compressor (multi-casings)

513,500

COLD BOXES

Cold Box with three (3)

576,900

turbo-expanders

Cold Box with three (3) sets of Dual turbo-expanders

DEWAR/HEAT EXCHANGER SUBSYSTEM

679,600

569,000 
both the superconducting power transmission lines of Plan 3A. Compressors are sized to deliver $1260 \mathrm{~g} / \mathrm{sec}$ of helium at $15 \mathrm{~atm}$ discharge pressure and each cold box is capable of producing an amount of refrigeration equivalent to $8.6 \mathrm{Kw}$ at $8^{\circ} \mathrm{K}$.

\subsubsection{Life of Equipment and Return on Investment}

From the standpoint of the electric utilities, an appropriate economic life and return on investment would be (A.41):

$$
\begin{aligned}
& n=30 \text { years } \\
& i=15 \%
\end{aligned}
$$

On this basis, the pay-off period is equal to,

PVa $=6.57$

\subsection{RESULTS OF RELIABILITY AND ECONOMIC STUDY}

\subsubsection{Compressor Optimization}

The results of the compressor optimization analysis are tabulated in. table 8.6 and show graphically in figure 8.6.

Table 8.6 presents a breakdown of the costs which contribute to the yearly

- capital plus operating expenses as discussed in Section 8.2. The most noteworthly feature of this table is the overwhelmingly large percentage of the total yearly costs (YRLY\$) which are due to compressor electrical power consumption. The percentage of the total cost varies from compressor to compressor due to differences in initial capital cost and thermodynamic efficiencies; however, the average percentage of yearly costs devoted to electrical power for all compressors considered in Case CII is about $55 \%$. This is based on a power cost of $0.02 \$ / \mathrm{KW} \mathrm{Hr}[\mathrm{A.41]}$. As power costs continue to increase a greater emphasis will be placed-on increasing compressor efficiencies.

Figure 8.7 is a graphical representation of compressor probability of failure in one year versus yearly capital plus operating costs. Points representing one specific type of compressor in varying degrees of redundancy, as represented by compressor cases CI, CII, and CII, are con- 
TABLE 8.6

COMPRESSOR RELIABILITY AND COST ANALYSIS

\begin{tabular}{|c|c|c|c|c|c|c|}
\hline $\begin{array}{l}\text { COMPRESSOR } \\
\text { DESCRIPTION }\end{array}$ & $\begin{array}{l}\text { PROBABILITY } \\
\text { OF FAILURE } \\
\text { IN ONE YEAR } \\
Q_{C}^{\prime}\end{array}$ & $\begin{array}{l}\text { ANNUAL } \\
\text { CAPITAL PLUS } \\
\text { OPERATING } \\
\text { COSTS YRLY\$ } \\
\end{array}$ & $\begin{array}{l}\text { ANNUAL } \\
\text { CAPITAL } \\
\text { COSTS } \\
\text { CAPT\$ } \\
\end{array}$ & $\begin{array}{l}\text { ANNUAL } \\
\text { TOTAL } \\
\text { LABOR COSTS } \\
\text { LAB\$YR }\end{array}$ & $\begin{array}{l}\text { ANNUAL } \\
\text { POWER COSTS } \\
\text { P\$YR }\end{array}$ & $\begin{array}{l}\text { ANNUAL COST } \\
\text { OF PARTS AND } \\
\text { MATERIALS } \\
\text { PART\$ }\end{array}$ \\
\hline \multicolumn{7}{|l|}{ CASE C I } \\
\hline 0il Lube Screw & .253 & 529,763 & 83,411 & 1,475 & 442,758 & 2,119 \\
\hline Dry Screw & 0.295 & 698,406 & 205,990 & 2,058 & 481,258 & 9,100 \\
\hline Centrifugal & 0.295 & 632,135 & 258,913 & 1,860 & 357,063 & 14,300 \\
\hline \multicolumn{7}{|l|}{ CASE C II } \\
\hline 0il Lube Screw & $2.337 \times 10^{-4}$ & 614,480 & 166,822 & 1,735 & 442,758 & 2,119 \\
\hline Dry Screw & $1.214 \times 10^{-3}$ & 905,700 & 411,980 & 3,358 & 481,258 & 9,100 \\
\hline \multicolumn{7}{|l|}{ CASE C III } \\
\hline 0 il Lube Screw & $6.23 \times 10^{-8}$ & 648,028 & 199,075 & 4,075 & 442,758 & 2,119 \\
\hline Dry Screw & $8.623 \times 10^{-7}$ & $1,057,760$ & 562,360 & 4,658 & 481,640 & 9,100 \\
\hline Dry Lube Recip. & $2.75 \times 10-5$ & 684,917 & 337,553 & 5,464 & 330,459 & 11,440 \\
\hline Labyrinth Seal Recip. & $2.553 \times 10^{-6}$ & 727,634 & 324,151 & 5,147 & 388,057 & 10,270 \\
\hline Centrifugal & $6.085 \times 10^{-7}$ & $1,111,304$ & 735,482 & 4,460 & 357,063 & 14,300 \\
\hline
\end{tabular}




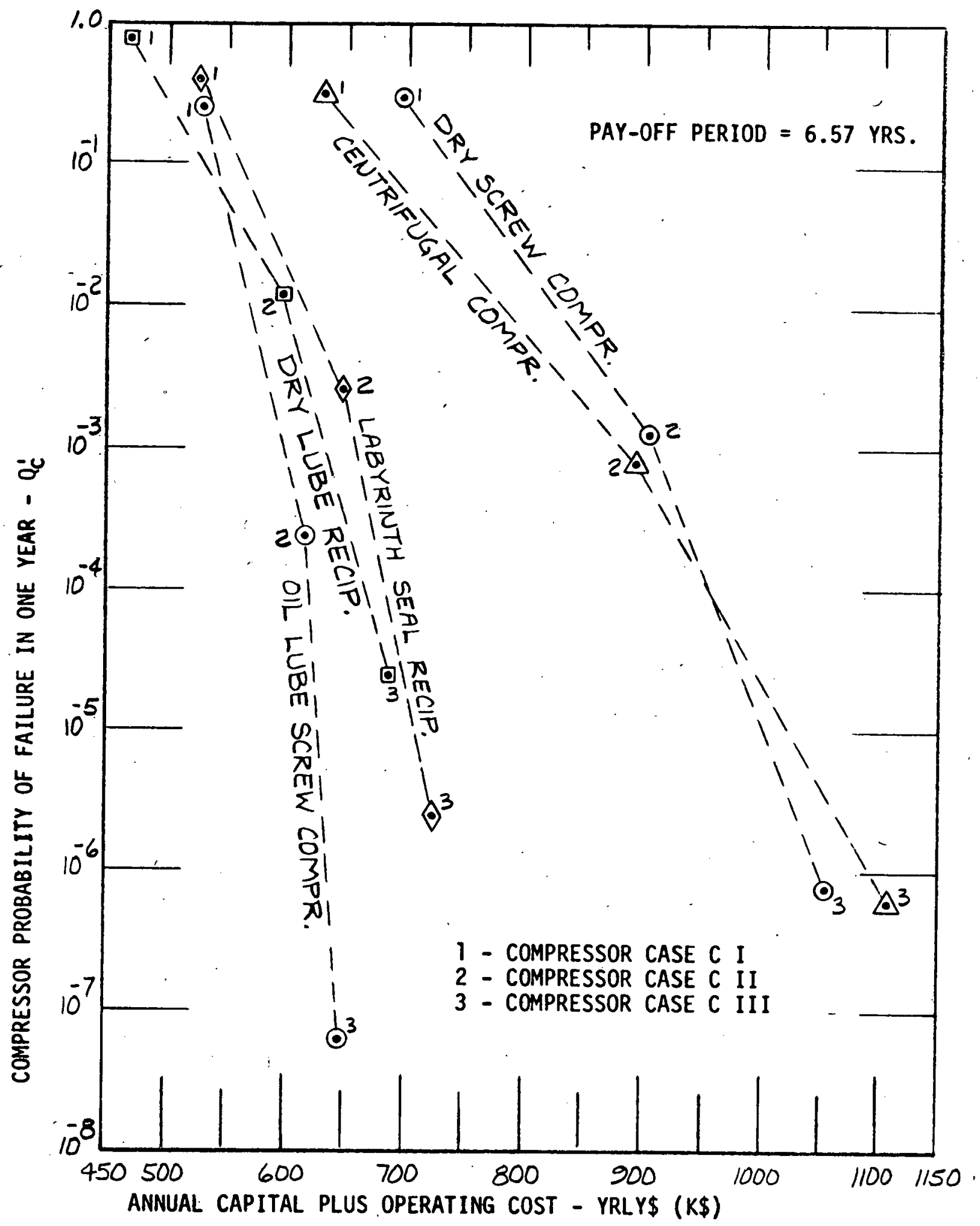

FIGURE 8.6 COMPRESSOR PROBABILITY OF FAILURE VERSUS

CAPITAL PLUS TOTAL OPERATING COST IN ONE YEAR 
nected by dotted lines for illu:trative purposes. It is evident from figure 8.6 that, for practical levels for probability of failure $\left(Q_{c}^{\prime}<10^{-3}\right)$, the oil lubricated screw compressor seems to be the most economical choice. It must be emphasized that, for constant compressor efficiency, as the cost of power increases, the dry lub reciprocating compressor and labyrinth seal compressor may begin to look more attractive. Because of the current high initial capital costs of the multi-casing centrifugal and dry lubricated screw compressors, these units are not competitive in the size units of interest in this investigation.

\subsubsection{Cold Box Optimization}

On the basis of the results of the compressor optimization study, the cold box analysis was carried out assuming the use of an oil lubricated screw compressor. Table 8.7 presents a break down of the costs which contribute to the yearly capital plus operating expenses as discussed in section 8.2 . Figure 8.7 gives a graphical representation of the results of the cold box analysis.

Referring to figure 8.7 , cold box option $C B / F$ I seems to offer a moderately low level for probability of failure in one year at a low annual cost; however, if figure 8.4 is reviewed for the case of six refrigeration stations along the transmission line, it is seen that the lowest possible value for the probability of failure that may be considered for the cold box is $8 \times 10^{-3}$.

Since figure 8.4 ignores the added effects of the unreliabilities associated with the refrigeration cooling system, the cryogenic transmission line envelope and the superconductor itself, the close proximity of $Q_{C B}^{\prime}$ (for case CB/F I) to $8 \times 10^{-3}$ prompts one to consider systems at the next higher level of reliability. The next logical cases to consider would be case $C B / F$ II and $C B / H$ IV. Cases CB/F II and CB/H IV appear to be very close to each other in reliability and cost with $C B / F$ II having a slight edge in both categories. Even though case CB/F II has a slight advantage in terms of cost and reliability, it is recommended to use $\mathrm{CB} / \mathrm{H}$ IV because of its inherent greater operating flexibility. The operating flexibility of case $C B / H$ IV is most noteworthy if one considers the implications of having to shut down a section of one of the two superconducting transmission lines for repair of the cryogenic envelope or cable. Under these circumstances case CB/F II provides no provision for reducing by one half the output of the operating cold box; this would necessitate devising a way to use up the extra refrigeration which would 
TABLE 8.7

COLD BOX RELIABILITY AND COST ANALYSIS

(ASSUMES GAS SUPPLIED BY OIL LUBRICATED SCREW COMPRESSOR)

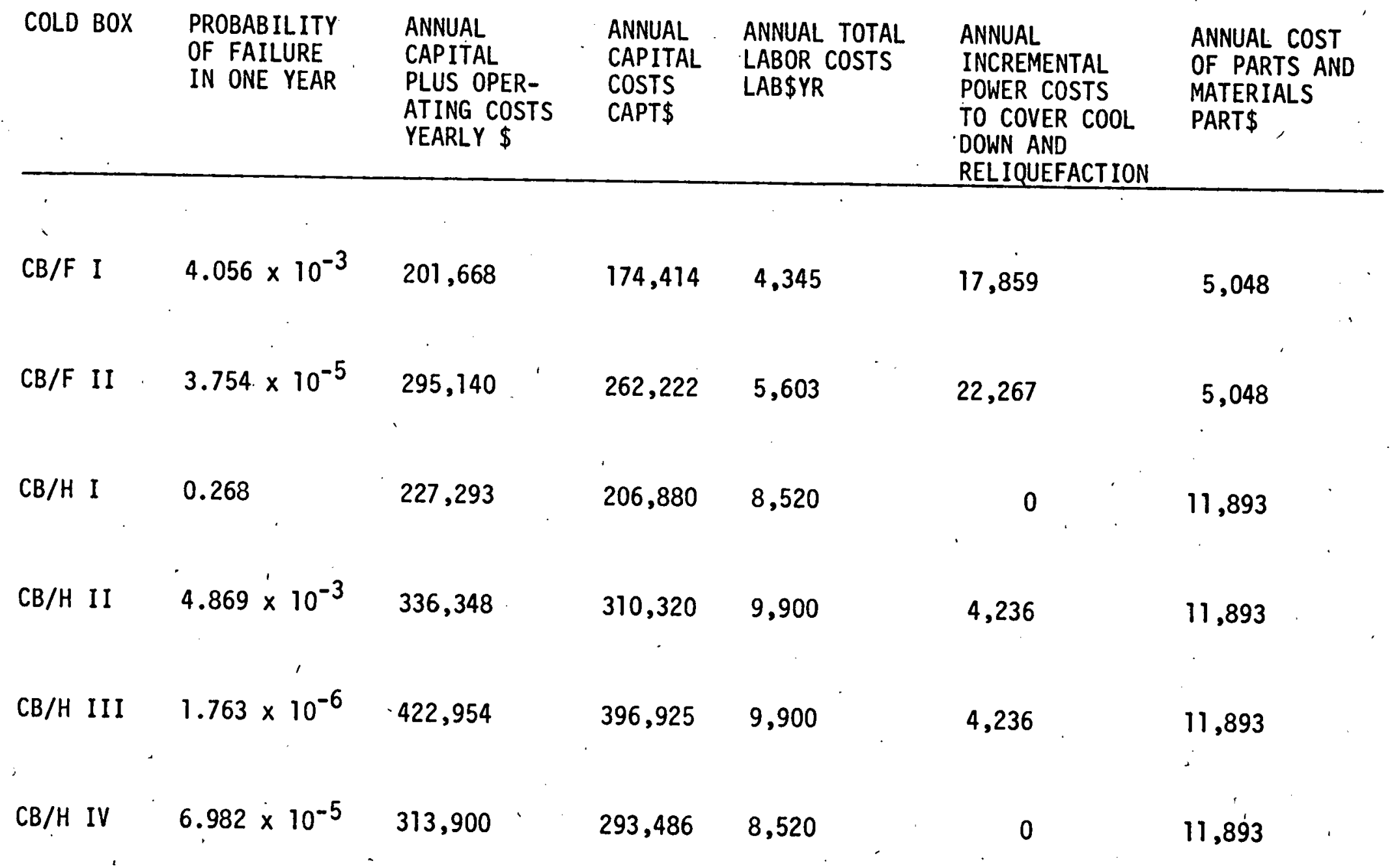




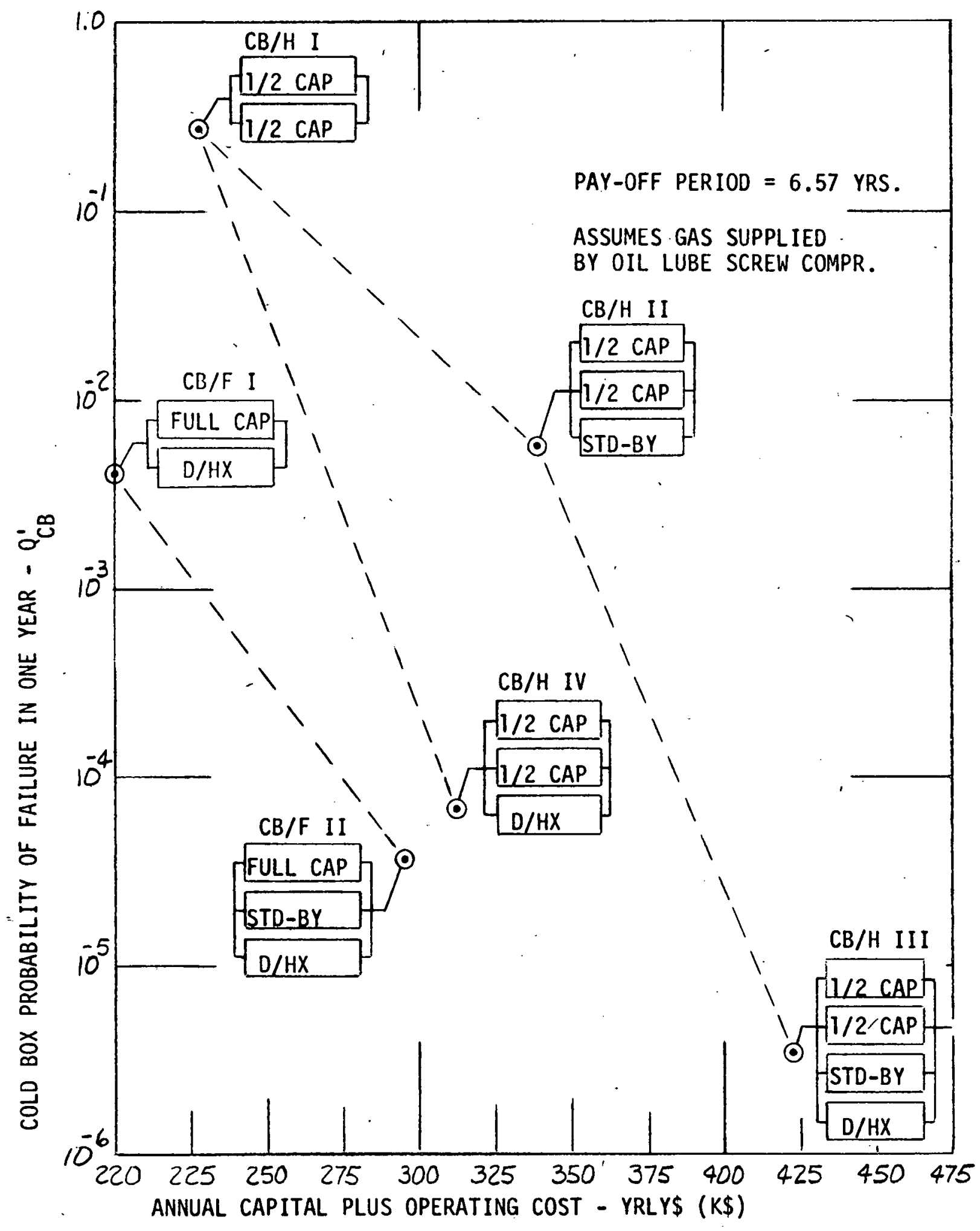

FIGURE 8.7 COLD BOX PROBABILITY OF FAILURE VERSUS CAPITAL PLUS TOTAL OPERATING COST IN ONE YEAR 
normally be used by the cable requiring repair. Case CB/H IV, on the other hand, could be made to carry the load of one cable by simply shutting down one of the two normally running half capacity cold boxes. This operation is made even easier by the use of an oil lubricated screw compressor whose capacity can be reduced by $50 \%$ without seriously affecting its efficiency.

\subsubsection{Refrigeration Station Optimization}

On the basis of the assumptions made in this analysis, the best compressor option to chose is the oil lubricated screw compressor version of compressor case C II; this option uses one full size screw compressor and one in stand-by reserve. Option CII would give a probability of failure in one year of $2.34 \times 10^{-4}$ at an annual cost of $\$ 614,480$ per station.

The best cold box option for Plan $3 A$ is case CB/H IV; this case uses two normally half capacity cold boxes with dual sets of turbine expanders and a back-up helium storage dewar/heat exchanger subsystem which would use one of the cold box screw compressors as a warm gas circulator. Case $\mathrm{CB} / \mathrm{H}$ IV has a probability of failure in one year of $6.98 \times 10^{-5}$ at an annual cost of $\$ 313,900$ per station.

The probability of failure for the transmission line refrigeration system as a whole can be computed using equation (8.25) The overall probability of failure of the transmjssion line system over a period of one year becomes $Q_{\text {TOT }}^{\prime}=1.82 \times 10^{-3}$.

This should give enough of a safety margin relative to the required probability of failure limit of 0.0488 to offset the added effects of unreliability in reasonably engineered refrigeration station heat rejection cooling systems, cryogenic envelopes and cable designs. The total annual capital plus operating cost for the six refrigeration station line of Plan $3 A$ is,

$$
6(\$ 313,900+\$ 614,480)=\$ 5,570,280 \text {. }
$$

A conceptual view of the BNL Plan $3 A$ transmission line (with far-end expanders), for the optimized system discussed in this section, is shown in figure 1,1 . 
For the purpose of comparing the present cost estimate with the BNL plan $3 A$ cost estimate shown in table 2.2, the annual costs are multiplied by the payout period of 6.57 years. This gives the capital cost of the equipment (uninstalled) from tables 8.6 and 8.7 as being $18.1 \mathrm{MM} \$$ and the capitalized power and maintenance as $18.5 \mathrm{MM} \$$. The capital costs (allowing for land and foundations) are about $44 \%$ greater and the capitalized operating costs are $42 \%$ greater. The capital cost difference is due to the use of two full size cold boxes rather than half size units and the backup helium dewar. The operating cost difference is due mostly to the assumed power cost of $.02 \$ / \mathrm{KW} \mathrm{Hr}$. of this study versus $.013 \$ / \mathrm{KW} \mathrm{Hr}$. previously, and a payout period of 6.57 years versus 5.27 years. 


\subsection{SENSITIVITY OF COST AND RELIABILITY TO IMPROVEMENTS IN KEY AREAS}

The computer program used in the cost/reliability analysis of the present investigation was utilized to study the sensitivity of the total system reliability and component operating costs to changes in magnitude of some primary reliability parameters such as $t^{\prime}, t^{\prime \prime}, \lambda^{\prime}$ and $\lambda_{D}^{\prime}$.

\subsection{EFFECT OF. REDUCTIONS IN $t^{\prime}$ and $t^{\prime \prime}$}

The effect on system reliability of reducing both the downtime due to random failures, $t$, and the downtime during scheduled repairs, $t$ ", is shown in figure 9.1. Figure 9.1 assumes that $t^{\prime}$ and $t^{\prime \prime}$ are both reduced by the same percentage for both the compressor option case C II and cold box option case $C \dot{C} / H$ IV. The graph shows the individual effects on both the compressor and the cold box as well as the effects upon one refrigeration station and the entire transmission line system consisting of six stations. Note that for the case of the entire transmission line system, a given percentage decrease in $t^{\prime}$ and $t$ " will yield about 1.15 times that percentage decrease in the probability of failure of the entire transmission line system. Maintenance costs and costs associated with the use of liquid reserves decrease in relation to the times $t$ ' and $t$ "; however, these represent a small reduction in total operating costs per year compared with the high capital and power costs.

Section 4 and 5 of this report include discussions of many aspects of the design and operation of the cold box that will enable maintenance to be performed faster. A reduction by 50\% from the values used in section 8 would be difficult but is probably possible.

\subsection{EFFECT OF REDUCING COMPRESSOR AND COLD BOX FAILURE RATES}

The effect of reducing either the compressor or cold box failure rate is shown in figure 9.2. Also displayed is the reduction in probability of failure of the entire transmission line system assuming equal percentage decreases in $\lambda^{\prime}$ for both the compressor and cold box. A given percentage decrease in $\lambda^{\prime}$ results in about 1.3 times that percentage decrease in probability of failure of the entire system in one year. Reductions in labor costs due to decreased $\lambda^{\prime}$ are insignificant relative to the annual capital and power costs. In order to determine what the reduction would be if a given component is improved, its separate impact on 


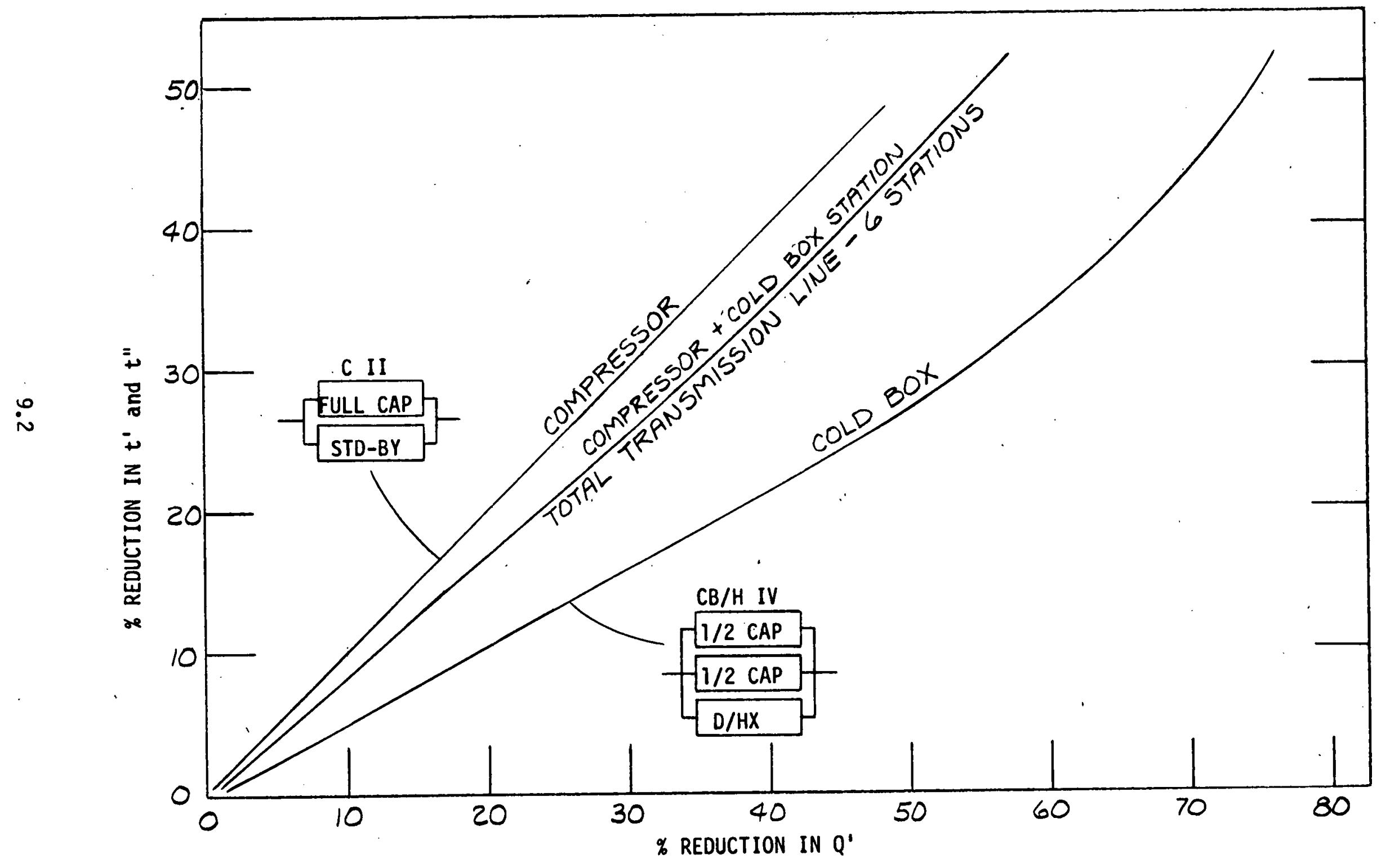

FIGURE 9.1 SENSITIVITY OF FAILURE PROBABILITY TO REDUCTIONS IN DOWNTIME 


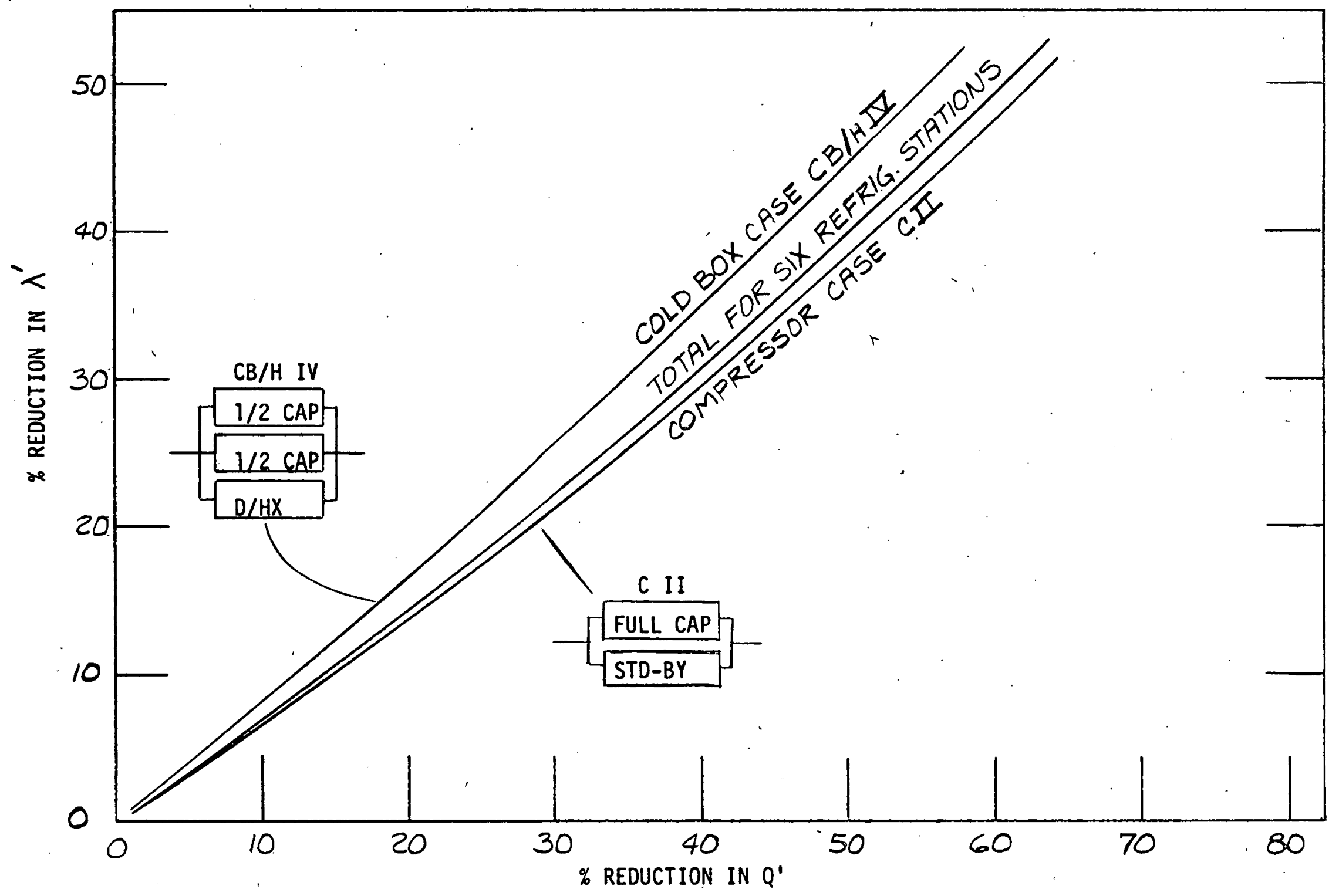

FIGURE 9.2 SENSITIVITY OF FAILURE PROBABILITY TO REDUCTIONS IN FAILURE RATE 
the overall reliability has to be calculated. The D/HX unit, turbine, and compressor are considered separately in the next paragraphs.

\subsubsection{Effect of Reducing Helium Storage Dewar/Heat Exchanger Backup System Failure Rate}

As discussed in section 7.2, the failure rate assigned to the helium dewar backup system corresponds to a MTBF of 30,000 hours $\left(\lambda_{D}^{\prime}=0.202\right)$. The effect of reducing $\lambda_{D}^{\prime}$ is shown in figure 9.3. There is a direct one to one correspondence between the percentage reduction in $\lambda_{0}^{\prime}$ and the percentage reduction in the probability of failure of the cold box subsystem. The effect of reductions in $\lambda_{D}^{\prime}$ upon changes in $Q^{\prime}{ }_{\text {TOT }}$ for constant compressor probability of failure is much less pronounced because the compressor has become the limiting reliability factor. Savings in yearly operating costs are negligible.

\subsubsection{Effect of Turbine Reliability and Efficiency}

In the later part of section 6.0 , the failure rate for a helium cold box with three helium turbo-expanders was derived based on APCI in-house operating experience in standard nitrogen plants. The cold box failure rate derived in this analysis was equal to 10.78 failures per year of which the three helium turbines (based on MTBF $=25,000$ hours) accounted for 1.0512 failures per year, or $9.75 \%$ of the total cold box failure rate. Suppose now that a major development effort was undertaken to increase the turbine MTBF by a factor of ten, that is, the new MTBF would be 250,000 hours. This order of magnitude increase in turbine MTBF would result in a cold box failure reduction of $8.8 \%$, and from figure 9.2 it appears that this reduction would yield about a $10.6 \%$ reduction in the case $\mathrm{CB} / \mathrm{H}$ IV cold box failure rate. A simple calculation based upon a compressor case C II failure rate of $2.34 \times 10^{-4}$ failures/hour and a baseline cold box failure rate of $6.98 \times 10^{-5}$ failures/hour shows that a $10.6 \%$ decrease in $Q^{\prime} \mathrm{CB}$ yields a reduction in the overall transmission line failure rate of $2.5 \%$. This reduction would hardly justify any turbine development. It seems that if any reduction in cold box failure rate is made it should be directed at the other elements in the cold box which contribute to failure; electrical failures, problems with impurity build-up, control failures, instrumentation problems, etc. The contribution of these failures to the total outages which normally appear in a standard nitrogen plant has already been discussed in section 6.0 . 


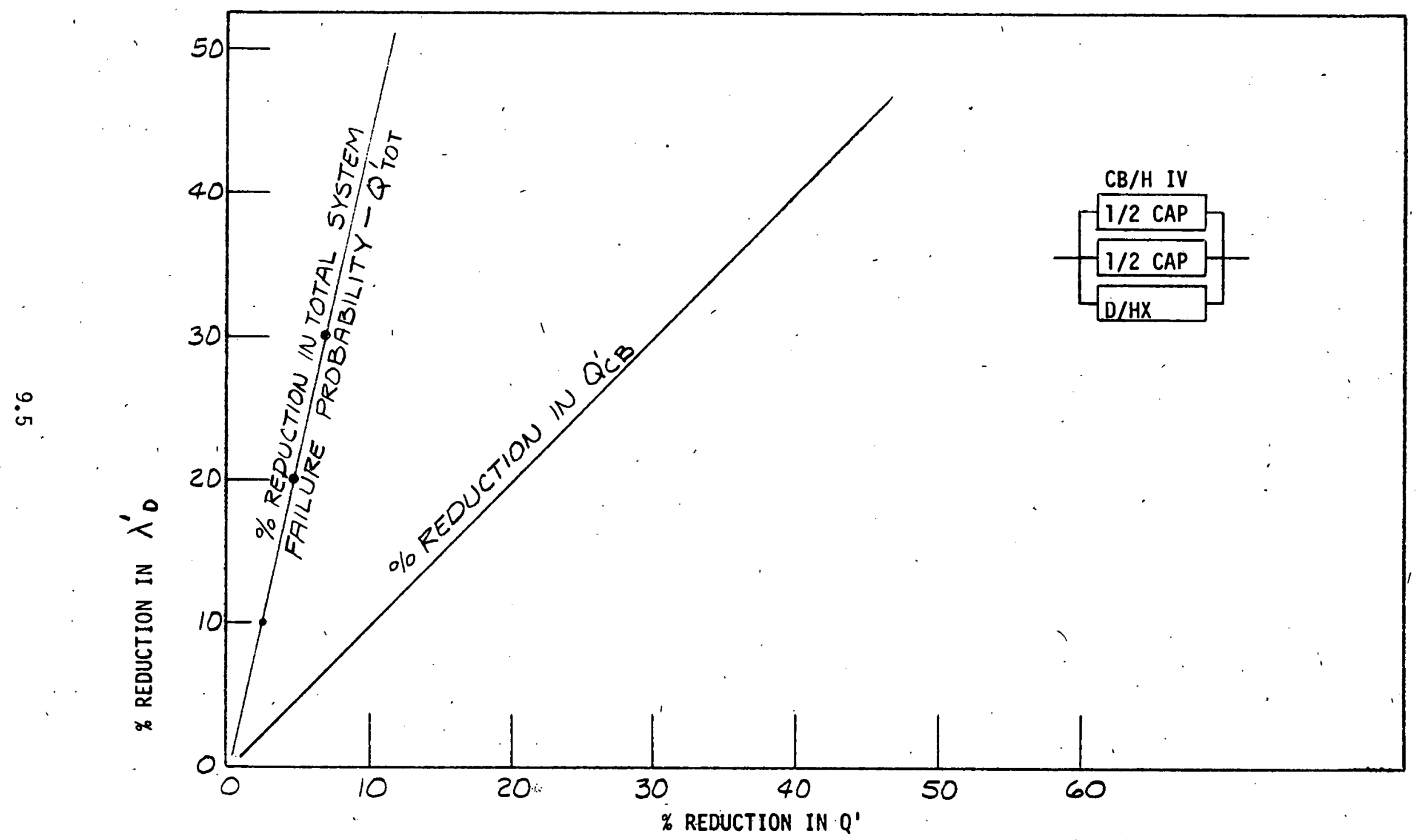

FIGURE 9.3 SENSITIVITY OF CASE CB/H IV AND TOTAL SYSTEM PROBABILITY OF FAILURE TO REDUCTIONS IN DEWAR/HEAT EXCHANGER FAILURE RATE, $\lambda_{D}^{\prime}$ 
In order to assess the sensitivity of annual operating costs to turbine efficiency it would be necessary to carry out a cycle analysis, in order to determine the influence of turbine efficiency on overall system efficiency. This analysis is beyond the scope of the present investigation; however, in light of the large percentage contribution energy costs make to the total annual operating expenses, it can be assumed that the effect of efficiency would be appreciable.

\subsubsection{Effect of Compressor Reliability and Efficiency}

The effect of decreasing the compressor reliability parameter has already been discussed in section 9.2. As can be computed with the aid of figure 9.2 and equation $(8.25)$, a $50 \%$ reduction in an individual compressor $\lambda^{\prime}$ will result in a case $C$ II reduction in $Q_{C}^{\prime}$ of $55.6 \%$ and an overall reduction in $Q$ HOT of $42.8 \%$ (assuming $Q C_{B}$ constant). As figure 8.6 indicates, the compressor system reliability can be increased several orders of magnitude by going from two to three compressors with an $8 \%$ cost increase.

The savings in energy cost with increase of compressor efficiency is also significant relative to other effects. Assuming the use of oil lube screw compressor case C II, a $7 \%$ increase in compressor isothermal efficiency will decrease the power costs in a single station by $1 \%$ or $\$ 4,427$ (based on $0.02 \$ / \mathrm{Kw} \mathrm{Hr}$ ).

\subsection{EFFECT OF SHITCH OVER RELIABILITY}

Switch over reliability has not been considered in the present report primarily because it is a new area of concern for hel ium refrigerators, and most of the required mechanisms have not yet been developed. Experience with standard nitrogen plants has been that failure of the switch over mechanism has been the principle cause of failing to deliver product; despite a switch over reliability of about $99.8 \%$.

The analysis of section 8 shows the use of stored liquid helium to be economically advantageous. This system is dependent on the compressors continuing to supply gas and the flow being switched through the helium heat exchanger. The probability of the system working is, of course, enhanced by decreasing the number of times it is called upon, i.e., by decreasing the cold box failure rate. For a given cold box reliability the reliability of the system becomes directly proportional to the reliability of compressor and liquid back-up switch over. 


\subsection{SUMMARY}

Reduction in maintenance time has a direct effect on improving reliability, however, the improvement possible in this area is about a factor of 2 .

Improvements in component reliabilities has comparable potential for improving system reliability. It is reasonable to expect to reduce the failure rate of a single unit from a current value of about 12 per year to about 6 , but it will be difficult to do much better.

From an economic stand point there is small advantage in reducing the maintenance time or failure rate until the improvements justify the elimination of one of the stand-by units. In the case of compressors it is inconveivable that fewer than two per station can ever be viable so improvements in reliab ility will have the effect of permitting more failures in the cold box and putting fewer demands on the switch over mechanism.

Cold box reliability improvements will come primarily from improvements in the multitude of components that presently cause problems, with expander improvements contributing a relatively small part. These improvements will contribute to reducing the demands on the backup system and switch over mechanism.

The component that has the greatest influence on system reliability (other than the switch over mechanisms) is the reserve helium dewar system. With reliable compressors and switch over the reliability of the line becomes dependent on the reliability of the helium dewar unit.

The switch over mechanism in the compressor system, and the switch over mechanism from the cold box to the dewar are in the long run the components that limit system reliability. No matter how many redundant components are used they will not compensate for failures in the switch over mechanism. This area seems to be the one that should be given primary attention. 


\subsection{BUSINESS FACTORS}

\subsection{EQUIPMENT SPECIFICATION, OWNERSHIP AND OPERATION}

The utility companies in planning the overall power transmission systems will of necessity have to specify the amount of refrigeration, the location of the refrigerators, all the details of interfacing with the line, and the refrigerator reliability. It is straight forward to install the refrigeration equipment and test it to demonstrate conformance to physical and performance specifications. But, what assurance does a utility have that the equipment is designed and will be operated in a manner consistent with the reliability specification? This question can best be considered in the context of the broader question of who should own and operate the refrigeration system.

At present it is the utilities practice to own and operate its equipment. By the same token it would be desirable from the standpoint of the major cryogenic companies, to own and operate the cryogenic plants that deliver product to the customer. Examples are the air separation plants that supply oxygen continuously to the steel mills, or nitrogen to glass producers. A third possibility of having the utility own the refrigeration equipment and have a cryogenic company operate it is another option to be considered. What are the advantages and disadvantages of each of these possibtlities in terms of cost and reliability?

If a failure of the refrigeration system causes the power transmission line to shut down there are economic losses to the power company and possibly to their customers. When the utility is able to continue supplying its customers through other lines then the loss to the utility is the difference in cost between supplying power from the alternate source versus the main source. If the utility can not deliver power to its customers then it loses the value of the power not sold less the savings in not producing it. Contracts with customers all disclaim liability for consequential damages.

It is probable that a cryogenic company that owned and operated the refrigeration system would accept liquidated damages due to failures within its control, assuming they could be set at a value consistent with the benefits the cryogenic company expects to receive. Since the losses incurred by a utility due to an outage are likely to be appreciably greater than the recoverable damages, it is fair to assume that the utility incurs most of the losses associated with a failure regardless of who owns and operates the equipment. The utility thus has an economic incentive to avoid a 
failure, but whether they can best do this by owning and operating their own equipment is problematical. There are many reasons why the lowest cost and highest reliability are achieved by having a cryogenic company own and operate the refrigerators. These reasons are:

* Experience - A helium refrigeration system is more complex in its construction and operation than most components in a utility system and can thus be operated most reliably by a company that has a great deal of experience with similar equipment.

* Commitment - Cryogenic companies in the past have guaranteed to deliver product in so far as it is within their control to do so. Their success in meeting this commitment is evidenced by the relatively few cases where they have paid damages resulting from a loss due to their negligence.

* Economy - A cryogenic company that designs, builds, owns, and operates the helium refrigerators will try to minimize the total iife cycle cost consistent with the performance and reliability objectives of the utility company. They will make the trade offs for example on the best compressor based on capital, power, and maintenance costs. Most utilities evaluate capital and operating costs on the same basis as cryogenic companies, e.g., payout times in the range of 5 to 7 years, thus given the same cost and reliability data on the equipment a utility would specify the same systems as the cryogenic company. The difference is that in reality the cryogenic company does have a better data base for making decisions than a utility.

* Learning Experience - A cryogenic company learns from its experience in operating refrigerators for one utility so that the system it builds for another utility can contain improvements. Experience gained in improving the operation of one plant is also transferred to another plant. Accurate operating and maintenance logs are kept not only to assure high reliability of the one system, but also to help identify problem areas that can then be improved.

* Centralized Maintenance Control - A company that is operating several refrigeration systems can maintain a larger controlled inventory of spare parts. They also have more control over the supply of manufactured parts. Most of the maintenance on refrigerator components is scheduled. It is proper scheduling and implementation of maintenance that assures a high system reliability. It is possible for a cryogenic company to draw from a larger pool of trained maintenance people to get a unit back in service. 
* Incentives - The cryogenic company has two basic incentives to minimize costs and provide adequate reliability. The first is that their profit is dependent on how well they manage the overall project and the second is that they have to do a good job if they want more business.

The possibility of having a utility own the refrigeration equipment and a cryogenic company operate it is an option that has some of the advantages listed above but also has some disadvantages. The major problem lies in the division of the responsibility between the owner and operator. The operating company would be reluctant to guarantee performance unless it had complete control over the equipment. It is questionable whether this point could be resolved to the mutual satisfaction of both parties.

Returning to the original question of what assurance does a utility have that the refrigeration system will be designed and operated to meet its reliability criteria, it is concluded that no matter who owns and operates the system there is no way of providing 100\% assurance that it will meet the reliability objective. On the other hand consideration of the alternate means of meeting the specified reliability at minimum cost seems to favor having a cryogenic company design and operate the refrigeration system.

\subsection{DEVELOPMENT INVESTMENTS -}

The present study indicates that refrigerators for superconducting power transmission can be built using existing technology. At this time, however, the 7 imited base of experience would probably result in units that were over designed and prices that include a large factor for contingency problems.

Development efforts thus seem to fall into the two categories of improving components, and integrating components into systems and operating them to demonstrate that they will meet the reliability requirements of power transmission.

To date there have been relatively few large helium refrigerators built. With the exception of a dozen or so units built for cooling space chambers the units have all been different. They have all been sold on a competitive bid basis where low cost is of prime importance. These factors have combined to result in systems that use a minimum amount of equipment designed specifically for the job, existing equipment has been adapted as much as possible, development costs have been minimized, and reliability 
and operating costs have not been improved if doing so was at the expense of capital investment.

It is estimated that most of the large helium refrigerators that have been built include design and development costs that represent about $35 \%$ of the project costs and only a small part of this represents the development of new components. Plate fin heat exchangers have been developed for other applications such as air plants, vacuum shell development has been done for large storage containers, controls and piping are the product of other cryogenic plants that have been developed, and compressors have been developed for the industrial gas and air conditioning industries. The two areas where there have been developments specifically for the large helium refrigerators is in expanders and compressor modification.

Historically it has been found that if an attractive well defined market exists for a product, in terms of the performance requirements and significant dollar sales, then private capital will make the investment justified by the market to meet the requirements. In doing this the private businesses also make the decisions as to what they feel is the best kind of equipment to build.

If on the other hand the market is small, fragmented, or long term and not attractive for private funding then it becomes necessary to seek federal funding if the equipment is to be developed. This also puts the funding agency in the position of having to make the decision as to what kind of equipment should be developed.

The present study provides some general guidelines in defining efficiency and reliability as being of primary importance, but the flow rates, pressures, and market are still poorly defined. Impressions gained from discussions and articles on the time table for installing the first large refrigeration system for power transmission, energy storage, fussion reactor, etc., indicate that the late 1980's is a probable date. At the present time one concludes, that because the equipment requirements are not well defined and the major applications are at least ten years in the future, there is little justification to invest private capital today for these projects.

In the near term it appears that component development work will continue as it has in the past focusing on improvements in expanders and improvements in modifying standard compressors on an as needed basis.

Development work in the area of integrating components into systems and operating them to demonstrate high reliability is not seen to be something that is going to happen in the near future in privately owned plants. 
Commercial helium extraction and liquefaction facilities do not have a requirement for the high level of reliability that will be required in future applications of superconductivity.

The approach to promoting development in these two areas must of necessity depend to a great extent on government incentives. Components, for example, can be developed in response to specifications, for new federally funded systems in which the equipment that is desired is specified and money budgeted to pay for the new equipment with bonuses and penalties used as incentives to meet the specification.

In the area of gaining operating experience and demonstrating reliability it would be desirable to have several of the large systems that will be built for federal projects to be owned and operated by cryogenic companies.

In summary, it appears that the long range objectives of minimum cost and high reliability can best be met by cryogenic companies owning and operating large.helium plants, with systems built for federal projects over the next 10 to 15 years serving as the mechanism for developing equipment and gaining operating experience. 


\subsection{RECOMMENDATIONS}

\subsection{FURTHER SYSTEM STUDIES}

The process of designing a complex system such as a superconducting power transmission line is an iterative one in which the system designer makes many assumptions in formulating a concept, uses the concept description to get more technical information from knowledgeable sources, then uses the information to refine the system concept.

One of the principal values of the present stidy is the accumulation and presentation of much of the basic information that the designer of the total power transmission system will need to advance the total system design. The detailed information contained herein on the cost, efficiency, and reliability of many of the critical components in the refrigeration system will help the designer of the total system to make better decisions wi th regard to such things as,

* spacing between stations

* use of heat shield in the cable envelope

* use of far end expanders

* effect of abnormal heat leak in the line

* effect of unequal station spacing

* use of improved cable insulation

* use of higher temperature superconductors

It is recommended that these and other factors relating to the refrigerator be studied further by the transmission line designers to provide a better "second generation" definition of the refrigerator requirements. The areas that require further definition include:

* refrigerator station capacity, temperature, pressures, and flow

* gas purity requirements

* refrigerator reliability design goal

* transient flow and temperature conditions generated in the line 
* tolerance of the cable to transients generated by switch over and upsets in the refrigerator

* tolerance of the line to flow stoppage

* necessity of cold surge volumes and/or restrictions to stabilize flow

* cooldown and filling requirements

\subsection{BEST CURRENT SYSTEM.}

The optimization studies of section 8 indicate that two full size oil flooded screw compressors manifolded to two cold boxes and a liquid helium dewar as shown in figure 1.1 provides the most economical refrigeration system for a transmission line that requires six stations and a failure rate of one outage in 20 years. It is pointed out that the ability to meet the specified failure rate is contingent upon $100 \%$ reliability in the compressor switch over and switch over to the backup liquid system.

The use of parallel half size expanders in each cold box is also recommended because of the greater flexibility it offers in adjusting to changes in load.

The costs and reliability advantage of all the systems considered that have liquid helium back up indicate that this will probably be included on all future systems regardless of improvements that might be achieved in the other components.

\subsection{DEVELOPMENT WORK}

Most of the areas that have been identified as benefiting from further development have been discussed in the body of this report. - They are summarized here as follows:

* Compressors - The oil flooded screw compressor is seen to have the best cost and reliability characteristics for the present requirements. There appears to be appreciable opportunity to increase its isothermal efficiency from about 50\% towards $60 \%$ with an appreciable reduction in power cost. Its reliability can be most readily increased by improvements in the controls. A spare compressor can probably be mounted on a truck thus providing a mobile back up unit. Confidence needs to be generated in the effectiveness and reliability of the oil cleanup system. 
It should be noted that if there is a trend towards larger refrigerators then parallel screw compressors may be needed because of the limited available size range. The cost curve would then increase linearly with size, and cross over one of the other compressor types. Further studies are thus needed in this area if station sizes increase appreciably.

* Compressor Cooling - The high failure rate of cooling towers, heat exchanger corrosion and fouling found in both air plants and present helium refrigerators indicates that improvements should be made.

* Instrumentation - Instruments for on line detection of low levels of impurities have to be developed or techniques of using existing instruments in combination with a final guard adsorber need to be worked out.

* Power Interruptions - It is ironic that the system responsible for keeping the main power line operating is itself subject to frequent failure of the local power supply. It will be imperative to have backup power for the control system and compressors. Many of the control actuators can be pneumatic, however, the control logic will undoubtably be electric. The backup compressor may be driven by a diesel or a gas turbine engine. Since many compressors are presently being driven by different kinds of engines this should not require an appreciable development effort.

* Controls - It is envisioned that there will be increasing activity in the area of process control by computers and that much of the technology that will be used on future helium plants will be developed for other applications.

Since the helium plant will be designed for unattended operation, computer control will be needed to monitor the system status; switch to backup systems in priority sequence; control components (such as expanders) during cooldown, transients, and warm up; switch adsorbers; call for maintenance; and diagnose faults.

* Heat Exchangers - Heat exchanger development will take the form of reducing the leak rate of present aluminum core units and perhaps developing stainless steel units. The ability of these large heat exchangers and Hampson type heat exchangers to withstand rapid temperature changes needs to be investigated.

* Liquid Helium Circuits - Studies of refrigeration process cycles need to include the circuits necessary to produce liquid.

* $^{-}$LIN Cooling - Refrigeration process cycle studies need to consider the way that LIN can be used to help cooldown the line. Consideration also 
needs to be given to the use of the refrigeration in the delivered liquid helium. Perhaps an entirely separate portable system should be developed to purge, cool down, and fill the line.

* Liquid Helium Backup - Studies are needed on the best way to use liquid helium as a backup. Either a warm circulation or a cold circulation system should be developed.

* Switch Over - The most important area of development is in the switch over mechanisms that are needed. The most essential switch overs are 1) from electrical to back up power (in the event of power interruption), 2) from one compressor to its backup and, 3) from cold box to liquid helium backup. Second order priority is switching from one expander to another and from one cold box to another.

* Maintenance - Designers of all equipment, related to the refrigeration system should be aware of the benefits of fast repair or replacement of individual components and design them for fast maintenance as well as high reliability.

\subsection{DEVELOPMENT PROGRAM}

Section 10 presents a discussion of carrying out needed development program from considerations of business factors. These are as follows:

* The long time between now and the late 1980's when refrigeration systems are needed means that most of the near term development work such as computer controlled processes will be done for other applications.

* Operating records should be kept at all large helium refrigerator plants to accumulate reliability data.

* Large federally funded systems can include specifications for new components and an economic incentive to develop them.

* In the long run it is probably best for cryogenic companies to own and operate large helium facilities. It would be desirable to have several of the large systems that will be built for federal projects be owned and operated by cryogenic companies in order to gain operating experience and encourage the development of new equipment. 


\section{ACKNOWLEDGEMENTS}

The authors wish to express their gratitude to the many people within Air Products who contributed to this report; in particular, we wish to thank A.R. Winters whose in-depth knowledge of large helium refrigeration sys tems proved invaluable:

The authors would also like to thank the many manufacturers and research institutions, both here and abroad, who supplied information and who, in many cases, permitted us to make personal visits:-

Finally we wish to thank our secretaries who contributed to this report and in particular Ruth Baker whose efforts enabled us to bring this project to a timely completion. 
OUESTIONNAIRE ENCOMPASSING HEL TUM REFRTGEPATION

SYSTEM STATE-OF-THE-ART AND FUTURE TRENDS IN REFRIGERATION EQUIPMENT

SOURCE OF INFORMATION:

NAME:

POSITION:

COMPANY:

DATE:

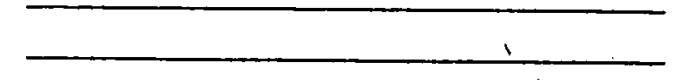

All topics covered in this questionnaire relate to either the current stateof-the-art of hel ium refrigeration equipment or probable directions of, future development.

In filling out this questionnaire, the manufacturer should keep in mind the primary design objectives sought in these refrigeration systems and their order

1. System reliability

2. Turn-around time during maintenance

3. System efficiency

4. System cost

System Specifications

All current cable designs under consideration rely on the use of supercritical hel ium to maintain the superconductors below their transition temperature. If the range in heat load in the cable due to electrical losses and heat leak varies from about $2.5 \mathrm{Kw}$ to over $4.3 \mathrm{KW}$ at the required temperature of the cable. The supercritical helium pressures vary from 5 to 15 atmospheres. The distances between refrigeration stations range from 8 to $12 \mathrm{kilometers.}$

For the purposes of this questionnaire, a spectfic set of system parameters are chosen; these parameters are:

- Allowable temperature variation in

$6.75^{\circ} \mathrm{K}-8.75^{\circ} \mathrm{K}$

$3.6 \mathrm{KW}+8^{\circ} \mathrm{K}$

- Load in cable due to electrical and dielectric 
- Equivalent refrigeration at $8^{\circ} \mathrm{K}$ required to cover heat shield losses

Total refrigeration required at $8^{\circ} \mathrm{K}$

$4.3 \mathrm{Kw}$

- Pressure of helium in cable

$15 \mathrm{~atm}$

- Distance between refrigerator stations

- Ambient conditions

- Cooling water available at

$80^{\circ} \mathrm{F}$

Currently, two possibilities exist for linking the refrigerator to the superconducting cable. In one scheme the cable forms a direct extension of the

refrigerator piping so that the same hel jum flows through the refrigerator and cable. In the other scheme, the helium in the cable is isolated from the helium in the refrigerator. The two streams are thermally linked through the use of a heat exchanger and the supercritical helium in the cable loop is circulated by

1. What type refrigeration system would you recommend?

$\square$ Integral refrigerator/cable flow circuit

L Separate pumped hel ium loop on cable

2. What type of compressor would you recommend?

$\square$ Reciprocating oil lubricated

$\square$ Reciprocating dry lube

$\square$ Labyrinth seal

$\square$ Helical-screw

Centrifugal

Other (specify)

3. For the category of compressor selected above, would any special modification to the cycle or equipment be utilized in order to factitate the compression of helium; this courd include such things as the use of a the cycle (e.g. mixture of helium and $R-12$ used to simulate the molecular weight furing the type of modification used.

4. What efficiency would be expected from the compressor (state type of efficiency cited, i.e., isothermal, isentropic, etc)?

5 What type of expander is recommended?

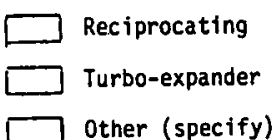

6. If a turbo-expander is specifted, what type of bearings would be used?
$\square$ 0il lubricated
$\square$ Static gas bearings
Dynamic gas bearings
Other (specify)

7. If a turbo-expander is used, what type of loading would be used?

Gas compressor or blower loading

D 0 il loading

$\square$ Alternator loading 
8. What type of heat exchangers would be used?

$\square$ Aluminum plate fin

$\square$ Hampson type tube and shell

Other (specify) 9. If a separate pumped loop is to be used what type of circulating pump
is recommended?

$\square$ Positive displacement

$\square$ Centrifugal

$\square$ Other (specify)

10. Which of the following types of controls would you recommend?

$\square$ Pneumatic actuated

$\square$ Electric actuated

i $\square$ Combination of elecric and pneumatic actuated

11. What type of helfum purifier would you recommend for this system?

12. Estimate the capital cost of one system assuming that ten units are purchased: $\$$

13. Estimate the amount of operator time required, (man-hours per day)?

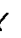

\section{RELIABILITY AND MAINTENANCE}

14. Estimate the total man-hours of scheduled maintenance required for the entire refrigeration system per year, (man-hours per year)

15. Which system component would require the most maintenance time per year?

$\square$ Compressor

$\square$ Expanders

$\square$ other (specify)

16. What would be the recomended maintenance interval for the compressors, (hours)?

17. What would be the recommended maintenance interval for the expanders, (hours)?

18. In your estimate, what would be the most frequent failure experienced by the system?

9. What would you estimate the mean time to faflure for the compressor (hours)?

20. What would you estimate the mean time to failure for the expanders (hours)?

21. From the standpoint of the compressor, how would you handle increasing the reliability of the existing system?

$\square$ Increased reliability through redundancy i.e., component back-up

$\square$ Increased reliability through development of more reliable component, thereby eliminating need for back-up components.

$\square$ other (specify) 
22. From the standpoint of the expanders, how could you handle increasing the reliability of the existing system?

$\square$ Increased reliability through reduncancy 1.e., component back-up.

$\square$ Increased reliability through development of more reliable component, thereby eliminating need for back-up components.

$\square$ Other (spectfy)

23. If you advocate increased rellability through redundancy, would you recommend providing a back up for any other system components?

Spectfy

24. In order to increase the overali rellability of the existing state-of-the-art system, what level of development effort would be required in each of the effort is reguired in order to achleve this end. Also, if a development the design of

\begin{tabular}{|l|l|l|l|l|}
\hline & $\begin{array}{l}\text { Present } \\
\text { state-of } \\
\text {-the-art } \\
\text { adequate }\end{array}$ & $\begin{array}{l}\text { Modest } \\
\text { develop- } \\
\text { ment } \\
\text { effort } \\
\text { required }\end{array}$ & $\begin{array}{l}\text { Major } \\
\text { develop- } \\
\text { ment } \\
\text { effort } \\
\text { required }\end{array}$ & $\begin{array}{l}\text { What area, or areas, } \\
\text { in component design } \\
\text { need to be concentrated } \\
\text { on } \\
-\end{array}$ \\
\hline Compressors & & & & \\
\hline $\begin{array}{l}\text { Expanders } \\
\text { Pumps (1f used) } \\
\text { on hel fum }\end{array}$ & & & & \\
\hline Controls & & & \\
\hline Relium purifier & & & & \\
\hline $\begin{array}{l}\text { pil clean-up package } \\
\text { (if oil lube comp- } \\
\text { ressor) used }\end{array}$ & & & & \\
\hline
\end{tabular}

25. Are there any other problem areas which have not been mentioned which could require some consideration?

26. Use remaining space for any other comments you would like to make. 
SOURCE OF IHFORMATION:

NAME:

POSITION:

COMPANY:

DATE:

All topics covered in this questionnaire relate to either the current state-of-the-art of helium compression equipment or probable directions of future development.

Because of the great number of options available in the design of a reliable helium refrigeration plant, information pertaining to two size ranges of compressors is being solicited. In order to cover both ranges, many of the questions are duplicated in two adjacent columns; one column pertains to the smaller size unit and the other column to the larger unit. Note

Due to the difficulty encountered in compressing helium gas as a result of its low molecular weight and high specific heat ratio, Air Products is trying to assess the merits of three (3) differenc modes of compression. These modes include:

a. Dry compression of helium gas; that is, the helium does not contact oil.

b. Compression of helium with oil injection (e.g., oil injection into helical screw or reciprocating compressors to reduce the helium temperature rise)

c. Compression of helium with another gas to simulate the
air (e.g., mixtures of refrigerant $\mathrm{R}-12$ with hel ium).

The possibility of selecting one of the above special options is covered by the sublist which follows the initial part of question "1. For example, if one wished to offer a conventional oil lubricated compresson with oll injer

for the purposes of the present study the following assumptions may be made:

- A total of ten (10) identical compressors will be required.

- Pressures required:

$3 \mathrm{~atm}$. abs. inlet pressure

$15 \mathrm{~atm}$. abs. outlet pressure

- Two flow ranges considered:

Flow range \#1: 5000-10000 SCFi

Flow range \#2: 2400-4500 SCFM

- Ambient conditions:

1 atm pressure

- Compressor cooling medium:

water at $85^{\circ} \mathrm{F}$

Because of the high reliability required on power transmission lines, reliability of the compression equipment must be assumed of utmost importance.

FLOW RANGE \#1
$5000-10000$ SCFM
GENERAL SPECIFICATIONS
1. What type of compressor would you off
A. $\square$ Reciprocating compressor
B. $\square$ Labyrinth seal reciprocating
C. $\square$ Hel ical-Screw
D. $\square$ Axial flow
E. $\square$ Centrifugal flow
F. $\square$ Other (specify)

FLOW RANGE \#2

Special Options

a. $\square$ Dry compression

b. $\square 011$ injection

c. $\square$ Gas mixture

d. None of the above
A. $\square$
B. $\square$
C. $\square$
D. $\square$
E. $\square$
F. $\square$

a.

b. $\square$

c. $\square$

d. $\square$ 
FLOW RANGE \#1
$5000-10000$ SCFM

$\int^{\prime}$ FLOW RANGE \#2 $2400-4500$ SCFM

2. What are the specific flow rates which are comercially avallable in these two flow ranges, (SCFM)? Include any units which exceed 10000 SCFil.

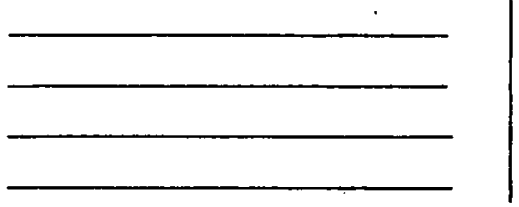

3. In order to answer questions 3 through 14 , select a specific size compressor for each of the two flow ranges cited above and indicate your flow rate

$$
\text { , }
$$

4. Based upon the size compressor selected in question \#3, what number of stages of compression are required?

w 5 . What is the pressure ratio per stage?

6. If the compressor offeres is of the helical-screw type, what is the volume ratio per stage?

7. What power input is required to drive the compressor (KW)?

What is the efficiency of the compressor (state efficiency quoted ite., 8. What is the efficiency of the compressor (state efficiency quoted; i.e.,
isothermal, isentropic, etc.).

9. What is the present capital cost of a single unit, $(\$)$ ? Do not include the cost of the driver or oil lube system unless they are an integral part of the compressor - if included please specify.
FLOW RANGE \#1
$5000-10000$ SCFM

FLOW RANGE \#2

$2400-4500$ SCFM 10. What is the capita cost of the ofl lube system if separate from the
compressor $(\$)$ ?

What is the power input required by the oil lube system (KW)?

2. What size foundaticn is required for the compressors specified? State recommended dimensions for concrete mounting pad ( $L X W X H),(f t$.$) .$

13. In order to get an idea of the volume occupled by the compressor, specify the dimensions of a box which would be required to completely enclose it (LxilXH), (ft.).

4. Any flow capacity control device available on the compressor?

$\square$ YES

If the answer to the above is yes, specify nature of this device.

What is the scheduled maintenance interva

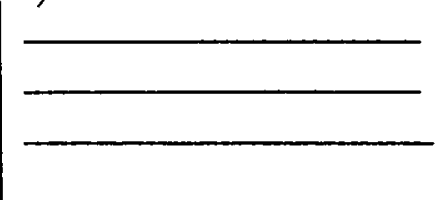

15. What is the scheduled maintenance interval (hours of operation)?

6. Approximate tíme required for a scheduled maintenance (man-hours). 


\begin{tabular}{l|l} 
FLOW RANGE \#1 & - \\
$5000-10000$ SCFM & $\begin{array}{l}\text { FLOW RANGE \#2 } \\
2400-4500 \text { SCFM }\end{array}$ \\
\hline RELIABILITY &
\end{tabular}

17. If the routine maintenance schedule is adhered to, what is the approximate mean time to failure of the compressor (hours)?

18. What is the most frequent mode of failure?

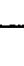

9. What is the second most frequent mode of fallure?

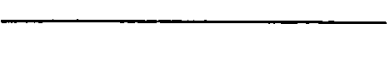

क. FUTURE TRENDS IN COMPRESSION EQUIPMENT

20. For the type of compressor offered for flow range \#1, please check the box which best describes the level of development required to achieve the expected mean time to failure specified in the left hand column below. Assume
that the scheduled maintenance has been adhered to (do not assume any major overhauls during this period).

\begin{tabular}{|l|l|l|l|l|}
\hline $\begin{array}{l}\text { Mean Time } \\
\text { to Fai lure } \\
\text { (hours) }\end{array}$ & $\begin{array}{l}\text { Existing Equipment } \\
\text { Meets Requirements }\end{array}$ & $\begin{array}{l}\text { Modest Development } \\
\text { Efort Required to } \\
\text { Meet Requiremeint }\end{array}$ & $\begin{array}{l}\text { Major OeveTopment } \\
\text { Effort Required to } \\
\text { Meet Requirement }\end{array}$ & $\begin{array}{l}\text { Goa not } \\
\text { Feasible with } \\
\text { this type of } \\
\text { Equipment }\end{array}$ \\
\hline 6,000 & & & & \\
\hline 15,000 & & & & \\
\hline 50,000 & & & & \\
\hline 80,000 & & & & \\
\hline
\end{tabular}

21. If funding were made available to impròve the state-of-the-art of helium che standpoint of reliability. in what specific areas of compressor design would money be spent?

. Please comment on any recent or proposed developmemt in hel lum compression equipment which you feel would be germane to our present investigation. dissemination, or use by anyone for any purpose. 


\section{APPENDIX C}

Explanation of Footnotes Found in Table 6.6 and Table 6.7

(1) As discussed in Section 6.7.1, turbine changes generally take from 4 to 7 hours. This is an average of 5.5 hours which is not significantly different from the value of 5.79 hours listed for $t^{\prime}$. Since the two times are nearly equal one would not expect the overall $t^{\prime}$ to change.

(2). Normally, one would schedule the maintenance of all three turbines in a cold box at one time. This would not affect the number of scheduled outages per year but it would increase the average time per schedule outage.

(3) It can be inferred from the preventative maintenance downtime tasks listed in the APCI preventative maintenance manual that the addition - of two more turbines would increase the total scheduled downtime maintenance hours in one year by about 10.6 hours. Since the single turbine cold box required a total of about 42 hours of downtime scheduled maintenance in one year and assuming two scheduled maintenance per year $\left(\xi^{\prime}=2.0\right)$ then the addition of the extra turbines would change $t^{\prime \prime}$ to:

$$
\begin{aligned}
& t^{\prime \prime}=\frac{(10.6+42)[\text { hours/yr.] }}{2.0 \frac{\text { scheduled maintenance }}{y r}} \\
& t^{\prime \prime}=26.3 \text { [hours/scheduled maintenance] }
\end{aligned}
$$

(4) The failure rate of an oil bearing APCI turbo-expander (as discussed in section 6.7 .1 ) is

$$
\lambda^{\prime}=1.165 \times 10^{-5} \text { failures } / \mathrm{hr}
$$

while the failure rate of a standard nitrogen cold box with one turbine is 


$$
\begin{aligned}
& \lambda^{\prime}=9.6 \text { failures } / \text { year } \\
& \lambda=1.096 \times 10^{-3} \text { failures } / \text { hour }
\end{aligned}
$$

Thus, for a series connected reliability system, the increased failure rate due to the addition of two turbines would be

$$
\begin{aligned}
& \lambda_{3 T}=\lambda+2 \lambda_{T} \\
& \lambda_{3 T}=1.1192 \times 10^{-3} \text { failures/hour } \\
& \lambda_{3 T}=9.8 \text { failures/year }
\end{aligned}
$$

(5) On the basis of information gathered for helium refrigeration system user visits, it can be assumed that vacuum related problems are not frequent but when they do occur they cause rather lengthy down times possibly on the order of 36 hours. These outages could result from internal cold box leaks such as leaks from the cold helium piping or heat exchanger transition joints, problems caused by the back-diffusion of vacuum pump oil, or the cryopumping of impurities in large quantities on the outside of components in the cold box. If one makes an assumption that one such 36 -hour unscheduled failure occurs once every 4 years than this gives a failure rate per year of.

$$
\lambda_{\text {vac }}^{\prime}=0.25 \text { failures/year }
$$

For series type component reliabilities, the modified cold box failure rate becomes

$$
\begin{aligned}
& \lambda^{\prime}=9.8+0.25 \\
& \lambda^{\prime}=10.05 \text { failures/year }
\end{aligned}
$$

(6) Based upon the standard nitrogen plant data, it can be shown thatthe addition of 9 hours per year downtime due to vacuum problems which occur at the rate of 0.25 failures/year, will cause the 
outage hours per unscheduled maintenance to increase by about $10.9 \%$.

(7) The cold box would normally never be opened unless a problem developed so that the $\xi^{\prime}$ and $t^{\prime \prime}$ should not change. As far as the vacuum pump itself is concerned; this can be worked on by closing the equipment off from the cold box and treating the repair as a no downtime (normal) scheduled maintenance.

(8) Schedule maintenance (both downtime and normal) associated with the switching adsorbers in the helium plant are assumed to be taken care of by the air clean-up equipment and switching exchangers of the standard nitrogen plant. This is probably a reasonable trade-off from a maintenance standpoint.

Chance shutdowns due to the build-up of impurities in the exchangers and other components are covered, in large part, by both the plant and liquefier defrosts on the nitrogen plant. The increased problems associated with the build-up of impurities on the turbine blades are allowed for through the use of actual helium turbine failure rates derived from helium refrigerator user visits (these failure rates include failures due to impurity build-up).

(9) If the failure rates associated with the standard nitrogen plant turbines (MTBF $=85,850$ hours) are subtracted from the overall cold box failure rate and the failure rates associated with three helium turbines (MTBF $=25,000$ hours from section 3.0) are then added to the remaining failure rate, then one obtains,

$$
\begin{aligned}
& \lambda=1.1102 \times 10^{-3} \text { failures/hour }+3\left(4 \times 10^{-5} \text { failures/hour }\right) \\
& \lambda=1.23 \times 10^{-3} \text { failures/hour } \\
& \lambda^{\prime}=10.78 \text { failures/year }
\end{aligned}
$$

The parameters $t^{\prime}, \xi^{\prime}$ and $t^{\prime \prime}$ would not be expected to change appreciably from the values used for the case of $3 \mathrm{~N}_{2}$ turbines.

(10) The failure rate of the helium plant cold box exclusive of the turbines is

$$
\lambda=1.1102 \times 10^{-3} \text { failures/hour }
$$


The failure rate of each dual turbine set is equal to the failure rate of an active turbine which has a single stand-by turbine.

The MTBF for the dual turbine set is

$$
\text { MTBF }=2(25,000)=50,000 \text { hours }
$$

or, the failure rate is,

$$
\lambda=2 \times 10^{-5} \text { failures/hour }
$$

The overall cold box failure rate with 3 dual turbine sets then becomes .

$$
\begin{aligned}
& \lambda=1.1102 \times 10-3+3\left(2 \times 10^{-5}\right) \\
& \lambda=1.1702 \times 10^{-3} \text { failures/hour }, \\
& \lambda^{\prime}=10.25 \text { failures/year }
\end{aligned}
$$

(11) Since only half the turbines will normally be running, one would not expect any appreciable increases in $\xi^{\prime}, t^{\prime}$ or $t^{\prime \prime}$. 
1. Belanger, B.C., "Superconducting Power Transmission Programme in the USA", Cryogenics, pp. 88-90, February 1975.

2. Forsyth, E.B., "Progress at Brookhaven in the Design of Helium-Cooled Power Transmission Systems", IEEE Transactions on Magnetics; Vol. MAG-11, No. 2, March 1975.

3. Forsyth, E.B., Garber, M., Jensen, J. E., Morgan, G. H., Britton, R. B., Powell, J. R., Blewett, J. P., Gurinsky, D. H., and Hendrie, J. M., "Factors Influencing the Choice of Superconductor in AC Power Transmission Applications", 1972 Applied Superconductivity Conf., pp. 202-210, 1972.

4. Forsyth, E. B., (ed). The Power Transmission Project - Progress in 1973, Part I - Cable Design, Power Transmission Project Technical Note \# PTP25, March 1974.

5. Forsyth, E. B. (ed), The Power Transmission Project - Progress in 1973, Part II - Cryogenic and Mechanical Engineering, Power Transmission Project Technical Note \# PTP 26, April 1974.

6. Forsyth, E. B. (ed), The Power Transmission Project - Progress in 1973, Part III - Systems Engineering Studies, Power Transmission Project Technical Note \# PTP27, May 1974.

7. Bogner, G., "Cryopower Transmission Studies in Europe", Cryogenics, pp. 79-87, February 1975.

8. Nicol, J., Underground Power Transmission, Study for the Electric Research Council by Arthur D. Little, Inc., Project RP78-8, ERC Pub. No. 1-72, October 1971.

9. Haid, D. A., "Future Application of Superconducting Cables to Electric Power Transmission", ASME paper 74-WA/P1D-18, November 1974.

10. Beall, W. T., "Development of a Niobium - Copper - Invar Composite Conductor for an A.C. Superconducting Power Transmission Cable", IEEE Transactions on Magnetics, Vol. MAG-11, No. 2, March 1975.

11. Dehaan, J. R., "Cryogenic Envelope for' a- Flexible Superconducting Power Transmission Line", ASEM paper 74-WA/P1D-11, November 1974.

12. Boesenberg, E. H., Zanona, A., "The Future of Superconductivity and Resistive Cryogenics for Power Transmission Systems", Proceedings of the American Power Conference, Vol. 33, pp. 980-988, 1971. 
13. Razevig, D. B., Blinkov, Y. L., Goldenberg, Y. S., "Research on a Laboratory Model of Superconducting Test Cable", Advances in Cryogenic Engr., Vol. 19, pp. 92-100, 1973.

14. Morihara, H., Webster, D. J., Kather, K. S., "Design and Construction of a Rigid Cryogenic Envelope with Low Heat Loss for a Superconducting Power Transmission Line", Paper J4, Cryogenic Engineering Conference, Atlanta, Ga., 1973.

15. Meyerhoff, R. W., "Development of a Rigid A.C. Syperconducting Power Transmission Line", Advances in Cryogenic Engr., Vol. 19, pp. 101-108, 1973.

16. Forsyth, E. B., Britton, R. B., Dean, J., Jensen, J. E., Minati, K., "A Supercritical Helium Facility for Measuring High-Volt tage Breakdown", Advances in Cryogenic Engr., Vol. 19, pp. 109-116, 1973.

17. Janocko, M. A., Dies, D. W., Carr, W. J., "Alternating Current Losses in Superconducting Conductors for Low-Field Applications", Advances in Cryogenic Engr., Vol. 19, pp. 171-180, 1973.

18. Long, H. M., Notaro, J., "Design Features of A.C. Superconducting Cables", Journal of Applied Physics, Vol. 42, No. 1, pp. 155-162, January 1971.

19. Meyerhoff, R. W., "Superconducting Power Transmission", Cryogenics, pp. 91-101, April 1971.

20. Nicol, J., "The Place of Cryogenic Systems in More Economical Power Transmission", 1972 Applied Superconductivity Conference, pp. 165-172, 1972.

21. Graeme-Barber, C., Maddock, B. J., "Large Composite Conductors for A.C. Superconductive Power Transmission", 1972 Applied Superconductivity Conference, pp. 211-212, 1972.

22. Schwall, R. E., Howard, R.E., Zubeck, "Evaluation of Layered $\mathrm{Nb}_{3} \mathrm{Sn}$ Conductor", IEEE Transactions on Magnetics, Vol. MAG-11, No. 2, 1975.

23. Beall, W. T., Meyerhoff, R. W., "Material Properties and Performance. II - A.C. Energy Losses Above and Below Hc, in Niobium and Niobium-25 At. \% Zirconium", Journal of Applied Physics, Vol. 40, No. 5, pp. 20522059, April 1969.

24. Hoffer, J. K., "Investigations on Potential Conductors for a D.C. Superconducting Power Transmission Line in a 20 Meter Test Bed", IEEE Transactions on Magnetics, Vol. MAG-11, No. 2, March 1975. 
25. Bochenek, E., Franke, H., Wimmershoff, R., "Manufacture and Initial Technical tests of a High-Power D.C. Cable with Superconductors", IEEE Transactions on Magnetics, Vol. MAG-11, No. 2, pp. 366-372, March 1975.

26. Bartlit, R. R., Edeskuty, F. J., and Hammel E. F., "Multiple Use of Cryogenic Fluid Transmission Lines", 4th International Cryogenic Engr. Conference, pp. 177-179, May 1972.

27, Schwab, M. A. M., Deschamps, L., "Electric Power Transmission by Cryocables", 4th International Cryogenic Engr. Conference, pp. 168-171, May 1972.

28. Meyerhoff, R. W., "A.C. Superconducting Power Transmission", 1972 Applied Superconductivity Conference, pp. 194-201, 1972.

29. Dubois, P., Eyraud, I., Carbonell, E., "Research and Development of Superconducting Cables for High Power Transmission", 1772 Applied Superconductivity Conference, pp. 173-181, 1972.

30. Bayl is, J. A., "Mechanical Design of Tubular Conductors for A.C. Superconducting Power Transmission", 1972 Applied Superconductivity Conference, pp. 182-193, 1972.

31. Forsyth, E. B., Mulligan, G. A., Beck, J. W., Williams, J. A., "The Technical and Economic Feasibility of Superconducting Power Transmission: A Case Study", paper T74 462-8 presented at IEEE PES Summer Meeting and Energy Resources Conference, Anaheim, Cal., JuTy 14-19, 1974.

32. Forsyth, E. B. (ed), Underground Power Trassmission by Superconducting Cable, Brookhaven National Laboratory Report BNL 50325, March 1972.

33. Superconducting Cable System Program (Phase II), Union Carbide Corporation Linde Division, Progress Report, Prepared for Electric Power Research Institute, Project RP7807-1, Twelfth Report, covering Third Quarter, 1974.

34. Superconducting Cable System Program (Phase II), Union Carbide Corporation Linde Division, Progress Report, Prepared for Electric Power Research Institute, Project RP78-7, Tenth Report, covering First Quarter, 1974.

35. Keller, W.E., and Taylor, R. D. (ed) USAEC-DAT-DC Superconducting Power Transmission Line Project at LASL, Progress Report, LA-5684-PR, 1 January through 31 March 1974. 
36. Keller, W. E., and Taylor, R. D. (ed), USAEC-DAT-DC Superconducting Power Transmission Line Project at LASL, Progress Report LA-5581-PR, TOctober through 31 December 1973.

37. Ibid., Progress Report LA5468-PR, 1 July through 30 September 1973.

38. Ibid., Progress Report LA5361-PR, I March through 30 June 1973.

39. Ibid., Progress Report LA5271-PR, 1 November 1972 th I.March 1973.

40. Dean, J. W., "Helium Refrigeration Systems Reliability for Large SuperConducting Systems", Brookhaven National Laboratory Report BNL 19405, 13 November 1974.

41. Seamans, R. C., "The Energy Related Applications of Helium", ERDA-13, a Report to the President and the Congress of the United State, April 1975.

42. Private Communications, Power Technology Inc., Schenectady, N.Y.

43. Private Communication, Los Alamos Scientific Laboratory. 


\section{BIBLIOGRAPHY B}

\section{HELIUM REFRIGERATION SYSTEMS}

1. Daney, D. E., Refrigeration for an $8 \mathrm{~K}$ to $14 \mathrm{~K}$ Superconducting Transmission Line, NBSIR 74-375, October 1974.

2. Snow, W. A., Winters, A. R., and Currie, R. B., "A Multi-Purpose High Capacity Helium Refrigerator Liquefier", 1.965 Proceedings/ Institute of Environmental Sciences.

3. Eatwel1, A. L., Clarke, M. E., Gardner, J. B., "U.K. Developments in High Reliability Helium Refrigerators for Cryoelectric Applications", ASME paper 74-WA/PID-12, November 1974.

4. Strobridge, T. R., and Cheiton, D. B., "Size and Power Requirements of $4.2^{\circ} \mathrm{K}$ Refrigerators", Advances in Cryogenic Engr.., Vol. 12, pp. 576-584, 1967 .

5. Strobridge, T. R., "Refrigeration for Superconducting and Cryogenic Systems", presented at the 1969 Particle Accelerator Conference, March 5-7, 1969.

6. Kneuer, R., Petersen, K., Stephen, A., "Hel ium Liquefier Operating Continuously with Large Impurities", 4 th International Cryogenic Engr. Conference, pp. 71-73, May 1972.

7. Arp, V. D., Refrigeration of Superconducting Rotating Machinery, NBSIR 73-331, June 1973.

8. Ratliff,.G., and St. Lorant S. J., "Large Scale Refrigeration Systems for the Temperature Range of 1.0 to $1.85^{\circ} \mathrm{K}$ ", Advances in Cryogenic. Engr., Vol. 16, pp. 154-172, 1970.

9. Hail, F. F., "Refriḡerators for Superconducting Accelerators and Auxiliary Experimental Equipment", Advances in Cryogenic Engr., Vol. 17, pp. 230-239, 1971.

10. Gessne, R. L., and Colyer, D. B., "Miniature Claude and Reverse Brayton Cycle Turbomachinery Refrigerators ${ }^{\circ}$, Advances in Cryogenic Engr., Vol. 13, pp. 474-484, 1967.

11. Maddocks, F. E., "Application of Turbomachinery to Small-Capacity Closed-Cycle Cryogenic Systems", Advances in Cryógenic Engr., Vol: 13, pp. 463-473, 1967.

12. Meier, R. N., and Currie, R. B., "A $4.0^{\circ} \mathrm{K}$ Single-Engine Cycle Hel ium Refrigerator", Advances in Cryogenic Engr., Vol. 13, pp. 441-449, 1967. 
13. Beasley, S. A., Halford, P., "Development of a High-Purity .Nitrogen Plant Using Expansion Turbines with Gas Bearings", Advances in Cryogenic Engr., Vol. 10, pp. 27-39, 1964.

14. Robinson, G. Y., "Large-Capacity Hel ium Liquefier", Advances in Cryogenic Engr., Voi. 10, pp. 22-26, 1964.

15. Baldus, W., and Sellmaier, A., "Large-Scale Helium Refrigerators with Turbines", Advances in Cryogenic Engr., Vol. 10, pp. 13-21, 1964.

16. Mann, D. B., Sixsmith, H., Wilson, W. A., Birmingham, B. W., "A Refrigeration System Incorporating a Low-Capacity, High-Speed, Gas Bearing-Supported Expansion Turbine", Advances in Cryogenic Engr., Vol. 8, pp. 221-227, 1962.

17. Trepp, C., "Refrigeratinn Systems for Temperatures Below $25^{\circ} \mathrm{K}$ with Turboexpanders", Advances in Cryogenic Engr., Vol. 7, pp. 251-261, 1961.

18. Jacobs, R. B., "The Efficiency of an Ideal Refrigeration", Advances in Cryogenic Engr. Vol. 7, pp. 567-571, 1961.

19." Fowler, W. B., Cryogenic Consultants, Inc. "Specification for 1500 Watt Hel ium Refrigerator", Exhibit B, Acceleration Division, Energy Doubler Project, Specification No. 0428.09-ES-53497, 28 June 1974 (Revised 24 March 1975).

20. Dean, J. W., Jensen, J. E., "Direct Cooling of the Cold Neutron Moderator by Hel ium", Brookhaven National Laboratory Informal Report BNL17504, 5 January 1973 (Revised 13 January 1973).

21. Strobridge, T. R.,-Sindt, C. F., "Operating Experience - Helium Extraction and Liquefaction Expansion Devices", Prepared for NAL, January 1974.

22. Cairns, D. N. H., Swift D. A., Edney, K., Steel, A. J., "Refrigeration and Circulation of Helium in Superconducting Power Cables", Low Temperature and Electric Power, II R Commission I, London (1969).

23. Tiepp, C., "Problems of Large-Scale Refrigeration", International Institute of Refrigeration - Low Temperatures and Electric Power, London, pp. 31-41,. 1969.

24. Jensen, J. E., "Large Helium Systems for Superconducting Power Applications and High Energy Physics", Brookhaven National Laboratory Report BNL 17228, 1972. 
25. Strobridge, T. R., "Cryogenic Refrigerators - an Updated Survey", NBS Technical Note 655, June 1974.

26. Dean, J. W., "The Thermal Efficiency of a Pumped Super-Critical Helium Refrigeration System Operating Below 6K", Cryogenics pp. 307-312, June 1975.

27. Carbone11, E., "Large Scale Refrigerators with Turbines", Proceedings of 5 th Intern. Cryogenic Engr. Conf., Kyoto, pp. 353-356, 1974.

28. Gigor, V., Quack, H., and Senn, A., "Combined Helium Refrigerator and Liquefier with Gas Bearing Turbines", Proceedings of 5 th Intern. Cryogen ic Engr. Conf., Kyoto, pp. 380-383.

29. Strobridge, T. R., " Feasibility Study of a Multipurpose Refrigerator for a Superconducting Cable Test Facility", EPRI Report No. 282, July - 1975.

30. Agerson, P., Astruc, J. M., Lacaze, A., and Verdier, J., "Cold and UItra Cold Neutrons, a Test Facility for Cryogenic Engineering", Proceedings of 5th International Cryogenic Engineering Conference, Kyoto, Japan. 


\section{BIBLIOGRAPHY C \\ FLUID FLOW AND HEAT TRANSFER}

1. Jones, M. D., Peterson, R. G., "A Study of Flow Stability in Helium Cool ing Systems", ASME paper 74-WA/HT-24, Winter Annual Meeting ASME, New York, N.Y., November 1974.

2. Keilin, V. E., Kl imenko, E. J., Kovalev, I. A., Samoilov, B. N., "Forced-Cooled Superconducting Systems", Cryogenics, pp. 224-232, June 1970.

3. Ogato, H., and Sato, S., "Measurements of Forced Convective Heat Transfer to Supercritical Hel ium:, 4th International Cryogenic Engr., Conference, pp. 291-293, May 1972.

4. Keilin, V. E., and $\mathrm{Kl}$ imenko, E. Y., "Cryogenic $\mathrm{P}$ oblems of Forced Cooled Superconducting Systems", Cryogenics, pp. 292-296, August 1972.

5. Mark, J. W., "Liquid Hydrogen Pumping for Hydrogen Targets", Advances in Cryogenic Engr., Vol. 19, pp. 248-252, 1973.

6. Carney, R. R.,"'Slush Hydrogen' Production and Handling as a Fuel for Space Projects", Advances in Cryogenic Engr., Vol. 9, pp. 529-536, 1963.

7. Hendricks, R. C., Simoneau, R. J., and Smith, R. V., "Survey of Heat Transfer, to Near-Critical Fluids", Advances in Cryogenic Engr., Vol. 15, pp. 197-237, 1969.

8. Arp, V., "Forced Flow, Single-Phase Hel ium Cool ing Systems", Advances in Cryogenic Engr., Vol. 17, pp. 342-351, 1971.

9. Bald, W. B., "Supercritical Helium Cooling of Holl ow Superconductors", Advances in Cryogenic Engr., Vol. 16, pp. 368-377, 1970. 
1. Yamamoto, Y., Suzuki, H., Ishu, J., Hamana, I., Hayashi, S., Mizutani, S., and Sanjo, S., "A New Hel ium Gas Recovery and Purification System", Proceedings of 5th Intern. Cryogenic Engr. Conf., Kyoto, pp.'387-289.

2. Kneuer, R., Peterson, K., Stephen, A., "Helium Liquefier Operating continuously with Large Imputities", 4th Intern. Cryogenic Engr. Conf., Eindhoven, pp. 71-73, 1972.

3. Purer, A., Stroud, L., Meyer, T. 0., "Simple Technique for the UItrapurification of Helium", Advanced In Cryogenic Engr., Vol. 10, pp. $398-401 ; 1965$.

4. Seitz, C. A., Bodine, W. M., and Klingman, C. L., "Apparatus and Procedure to Reduce Impurities in Helium to Less Than One Part per Billion", Journal of Chrom. Sco., Vol. 9, pp. 29-31, January 1971.

5. Harrison, W. E., "Instrumentation of Analysis of Hel ium for Trace Impurities", Brookhaven National Laboratory Report BNL 19570, January 1975.

6. Parrish, W. R., "An Analys is of Impurity Problems in Superconducting Transmission Lines", NBS - Institute for Basic Standards, Prel iminary Internal Report.

7. Dodge, B. F., "Removal of Impurities from Gases to be Processed at Low Temperatures", Adv. in Cryogenic Engr., Vol. 17, pp. 37-55, 1971 .

8. Schmauch, G. E., "Methods of Analysis för the Noble Gases", CRC Critical Reviews in Analytical Chemistry, October 1974, pp 107-139 (80 references). 
RELIABILITY THEORY

1. Bazovsky, Igor, Reliability Theory and Practice, Prentice-Hall Inc. 1961.

2. Parzen, Emanuel, Modern Probability Theory and Its Applications, John 


\section{LIQUID HELIUM CIRCULATING PUMPS}

1. Ludtke, P. R., "Performance Characteristics of a Liquid Hel ium Pump", NBSIR 75-816, Prepared for Air Force Aero Propulsion Laboratory, July - 1975.

2. VanderArend, P. C., and Richied D., "A Large Scale Pumped Subcooled Liquid Cooling System", Paper R-9, Presented at 1975 Cryogenic Engineering Conference, Kingston, Ontario.

3. Schuck, T. W., "Performacce Tests of a Reciprocating Liquid Helium Pump Used for Forced Convective Cooling", Paper R-10, Presented at 1975 Cryogenic Engineering Conference, Kingston, Ontario.

4. Sixsmith, H., and Giarratano, P., "A Miniature Centrifugal Pump:, Rev. Scientific Instrument 41, No. 11, 1570-1573 - 1970. 